\title{
Modelación numérica de los cambios hidrogeoquímicos en la zona no saturada del suelo sometida a distintos usos primarios en la región centro-sur bonaerense
}

\section{Tesis Doctoral}

DOCTORANDO: Ing. Agr. Claudio Ramón Mujica (IHLLA-CONICET)

DIRECTOR: Dr. Sergio Andrés Bea Jofré (IHLLA-CONICET)

CODIRECTOR: Dr. Javier Enrique Gyenge (CONICET)

ASESOR ACADÉMICO: Dr. Sebastián Besteiro (UNLP)

2019, Facultad de Cs. Agr. Y Ftales., UNLP. La Plata, Bs. As., Argentina. 


\section{ÍNDICE GENERAL}

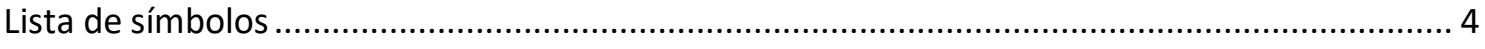

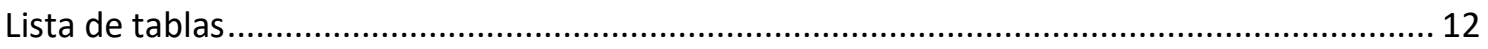

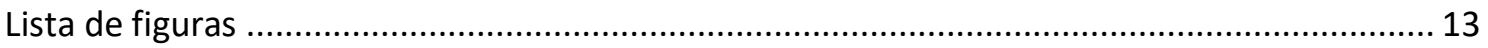

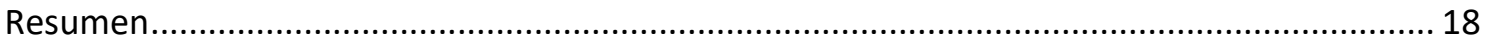

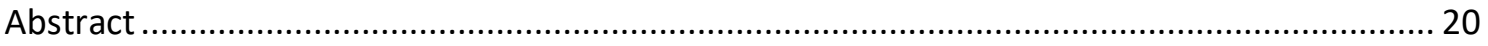

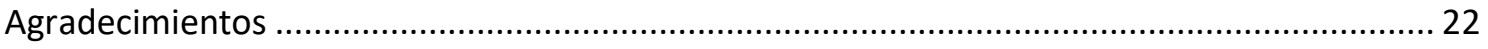

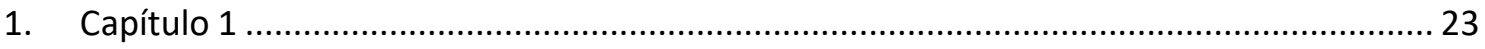

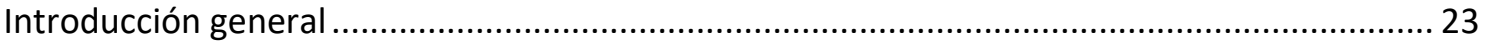

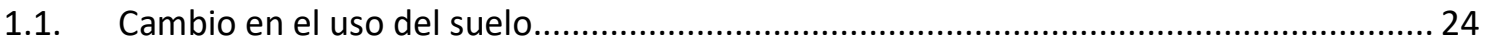

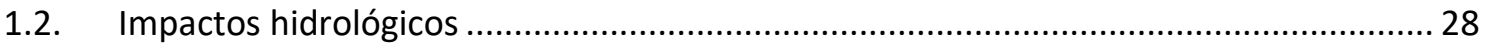

1.3. Salinización secundaria derivada de la forestación de pastizales ................................... 30

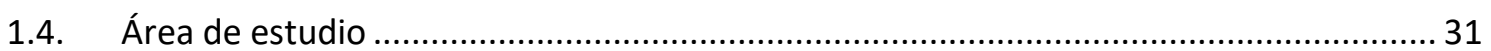

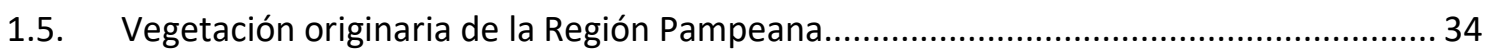

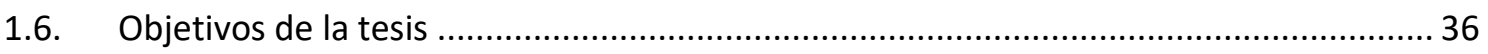

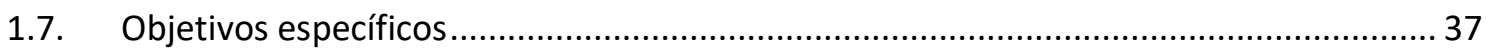

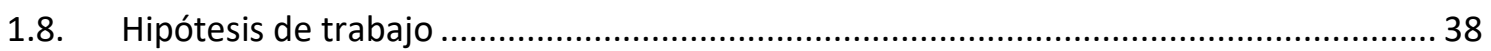

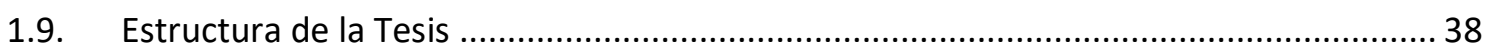

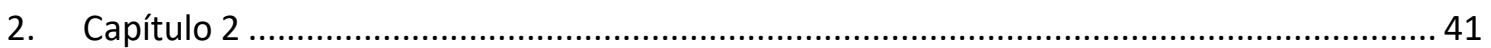

Impacto de la forestación de pastizales en la Llanura Pampeana. $\left({ }^{*}\right)$........................................... 41

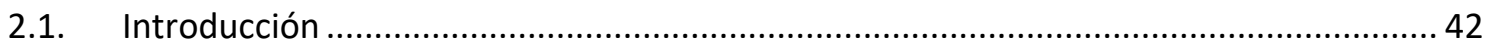

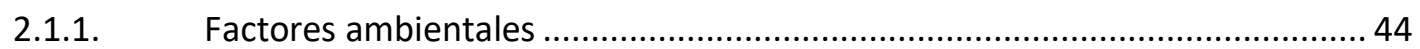

2.1.2. Factores ecofisiológicos de la forestación.......................................................... 46

2.1.3. Factores relacionados con el manejo de la plantación forestal....................... 48

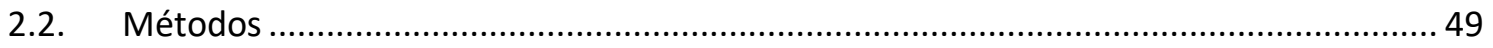

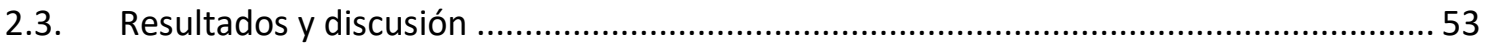

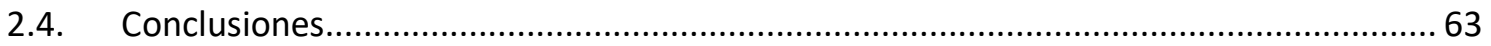

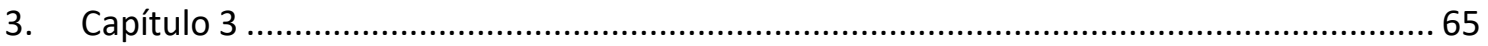

Control de las heterogeneidades del suelo sobre los procesos de salinización causados por la

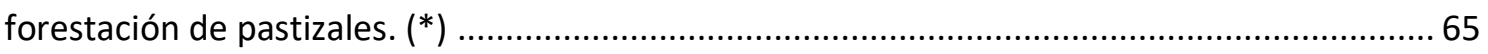

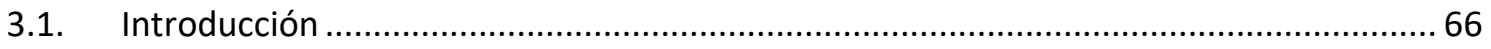

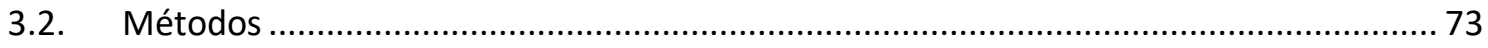

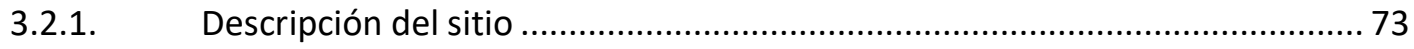

3.2.2. Características del pastizal y de la forestación................................................ 77

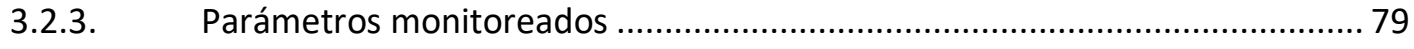

3.2.4. Cálculo de la conductividad eléctrica del agua de poro .................................... 80 


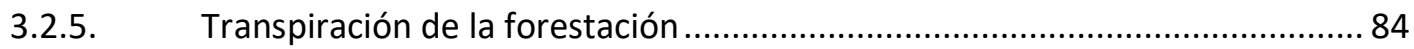

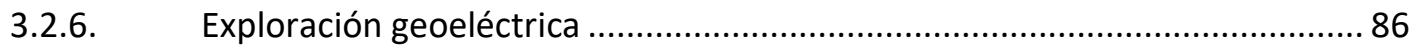

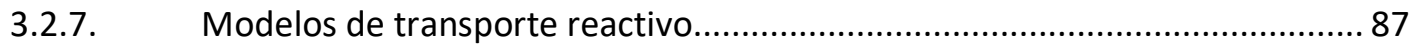

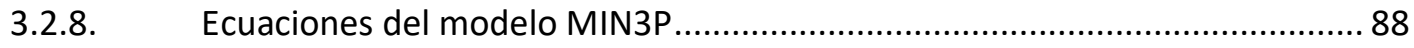

3.2.9. Dominio del modelo de flujo y condiciones de contorno ................................ 98

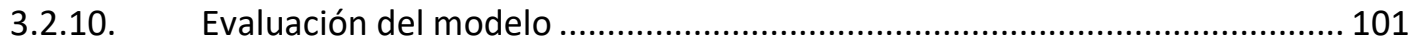

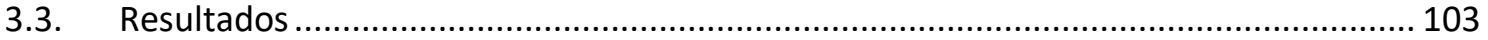

3.3.1. Evolución del contenido de agua del suelo (VWC) y la temperatura del suelo a

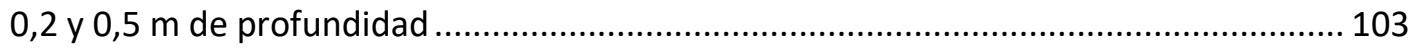

3.3.2. Evolución de la conductividad eléctrica ........................................................ 106

3.3.3. Evolución del nivel freático, temperatura y conductividad eléctrica............. 107

3.3.4. Evolución de la transpiración en la forestación .............................................. 108

3.3.5. Resultados de la exploración geoeléctrica..................................................... 109

3.3.6. Resultados de la modelación de flujo ............................................................. 111

3.3.7. Resultados del modelo de transporte ....................................................... 124

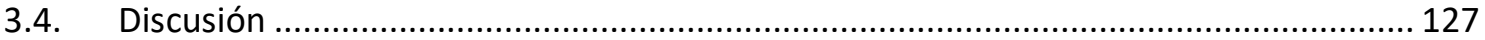

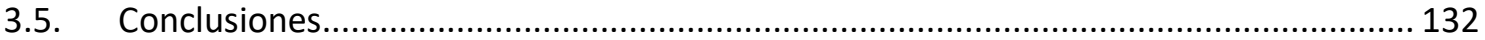

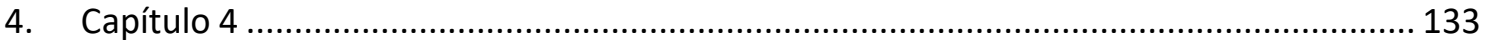

Control hidrogeoquímico del proceso de salinización causado por la forestación de pastizales.

$(*)$

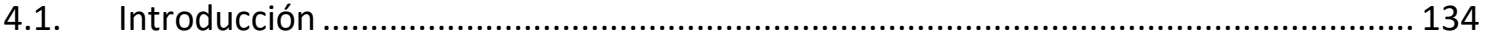

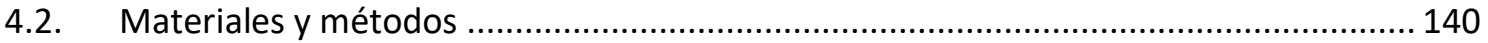

4.2.1. Descripción de la zona de estudio............................................................... 140

4.2.2. Dominio y características del modelo ..................................................... 147

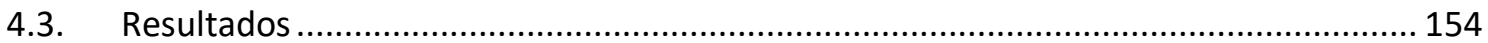

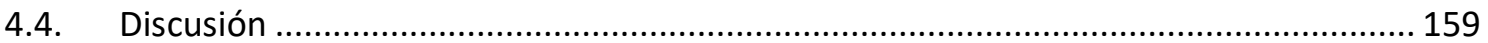

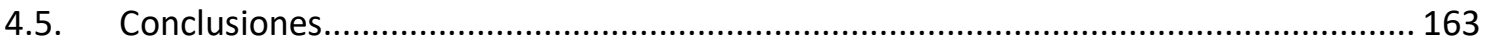

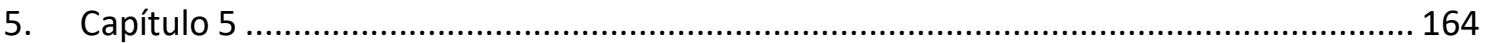

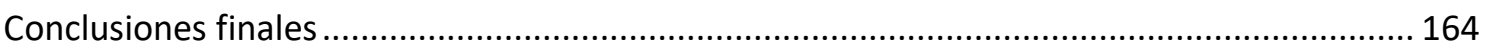

5.1. Cambio en el uso del suelo y sus implicancias ecohidrológicas..................................... 165

5.2. Control de las heterogeneidades del suelo sobre los procesos de salinización secundaria

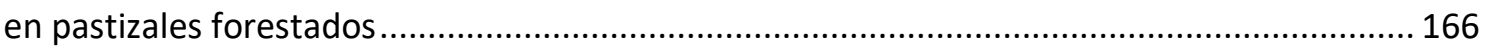

5.3. Control hidrogeoquímico del proceso de salinización secundaria en pastizales

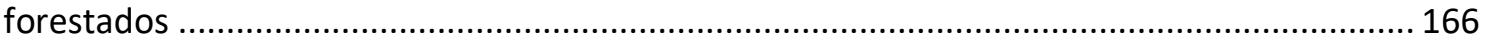

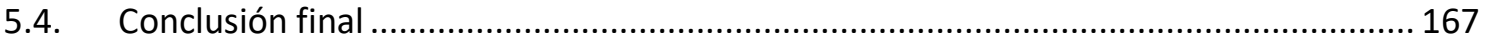

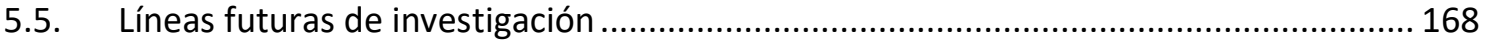

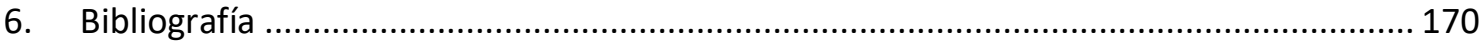




\section{Lista de símbolos}

BIAS error sistemático o sesgo;

$B_{A} \quad$ área basal o basimétrica $\left[\mathrm{m}^{2} \mathrm{ha}^{-1}\right]$;

$C^{c} \quad$ concentración en la fase acuosa $\left[\mathrm{M} \mathrm{L}^{-3}\right]$;

$C^{d} \quad$ concentración de especies químicas intercambiadas $\left[\mathrm{M} \mathrm{L}^{-3}\right]$;

$C^{g} \quad$ presión parcial en la fase gaseosa [M L $\left.\mathrm{L}^{-3}\right]$;

$D_{g} \quad$ dispersión mecánica en la fase gaseosa $\left[\mathrm{L}^{2} \mathrm{~T}^{-1}\right]$;

$D_{h} \quad$ tensor de dispersión térmica $\left[\mathrm{L}^{2} \mathrm{~T}^{-1}\right]$;

$D_{w} \quad$ dispersión mecánica en la fase acuosa $\left[\mathrm{L}^{2} \mathrm{~T}^{-1}\right]$;

E evaporación $\left[\mathrm{M} \mathrm{L}^{-2} \mathrm{~T}^{-1}\right]$;

EC conductividad eléctrica calculada en la solución del modelo $\left[\mathrm{dS} \mathrm{m} \mathrm{m}^{-1}\right]$

ECb conductividad eléctrica del suelo [dS $\left.\mathrm{m}^{-1}\right]$;

$E C b_{\text {ert }} \quad$ conductividad eléctrica del suelo medida con tomografía de resistividad eléctrica;

ECp conductividad eléctrica del agua de poro [dS $\mathrm{m}^{-1}$ ];

ECwt conductividad eléctrica del acuífero freático [dS m $\mathrm{m}^{-1}$;

$E T_{c} \quad$ evapotranspiración del cultivo bajo condiciones estándar $\left[\mathrm{L} \mathrm{T}^{-1}\right]$

$F_{i} \quad$ factor de evaporación del agua interceptada [-]; 


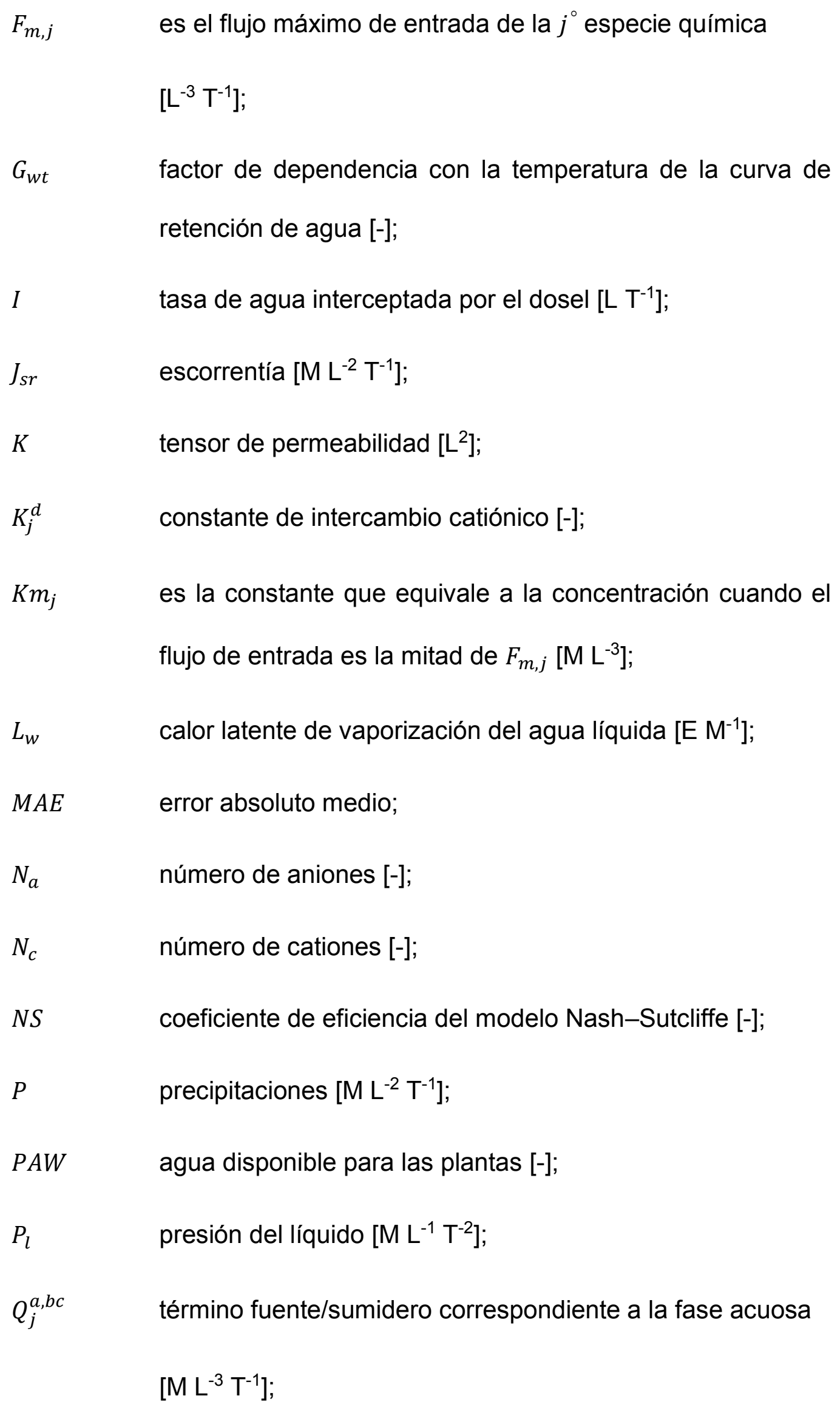




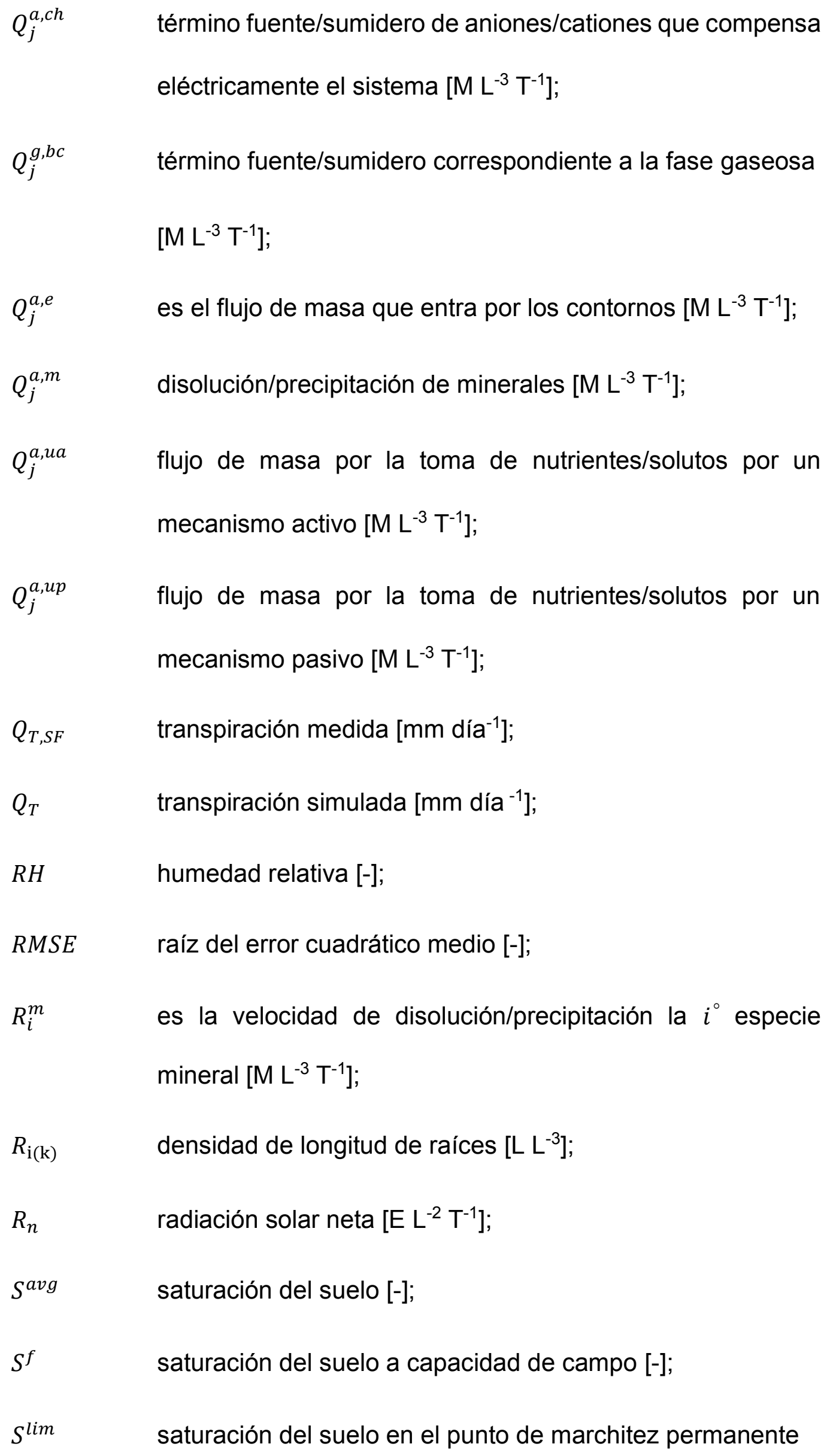


$[-]$

$S^{r l}$

saturación residual [-];

$S_{e a}$

saturación efectiva en fase acuosa [-];

$S_{l}$

saturación de líquido [-];

$S_{v}$

saturación de vapor [-];

$\operatorname{Sec}_{\text {cor }} \quad$ sección de la corteza $\left[\mathrm{L}^{2}\right]$;

$S e c_{\text {total }} \quad$ sección total de un árbol [ $\left.\mathrm{L}^{2}\right]$;

$S e c_{x a} \quad$ sección del xilema activo $\left[\mathrm{L}^{2}\right]$;

$T \quad$ temperatura del suelo $\left[{ }^{\circ} \mathrm{C}\right] ;$

$T_{j}^{a} \quad$ concentración total de la $j^{\circ}$ componente química en la fase acuosa $\left[\mathrm{M} \mathrm{L}^{-3}\right]$;

$T_{j}^{d} \quad$ concentración total de la $j^{\circ}$ componente química en la fase intercambiada $\left[\mathrm{M} \mathrm{L}^{-3}\right]$;

$T_{j}^{g} \quad$ concentración total de la $j^{\circ}$ componente química en la fase gaseosa $\left[\mathrm{M} \mathrm{L}^{-3}\right]$;

$T_{\text {atm }} \quad$ temperatura del aire $\left[{ }^{\circ} \mathrm{C}\right]$;

$T_{w t} \quad$ temperatura del acuífero freático $\left[{ }^{\circ} \mathrm{C}\right]$;

V volumen del suelo $\left[\mathrm{L}^{3}\right]$

$V_{f, i}^{m} \quad$ es la fracción volumétrica de la $i^{\circ}$ especie mineral [-];

$V_{i}^{m} \quad$ volumen molar de la $i^{\circ}$ especie mineral $\left[\mathrm{L}^{3} \mathrm{M}^{-1}\right]$, 


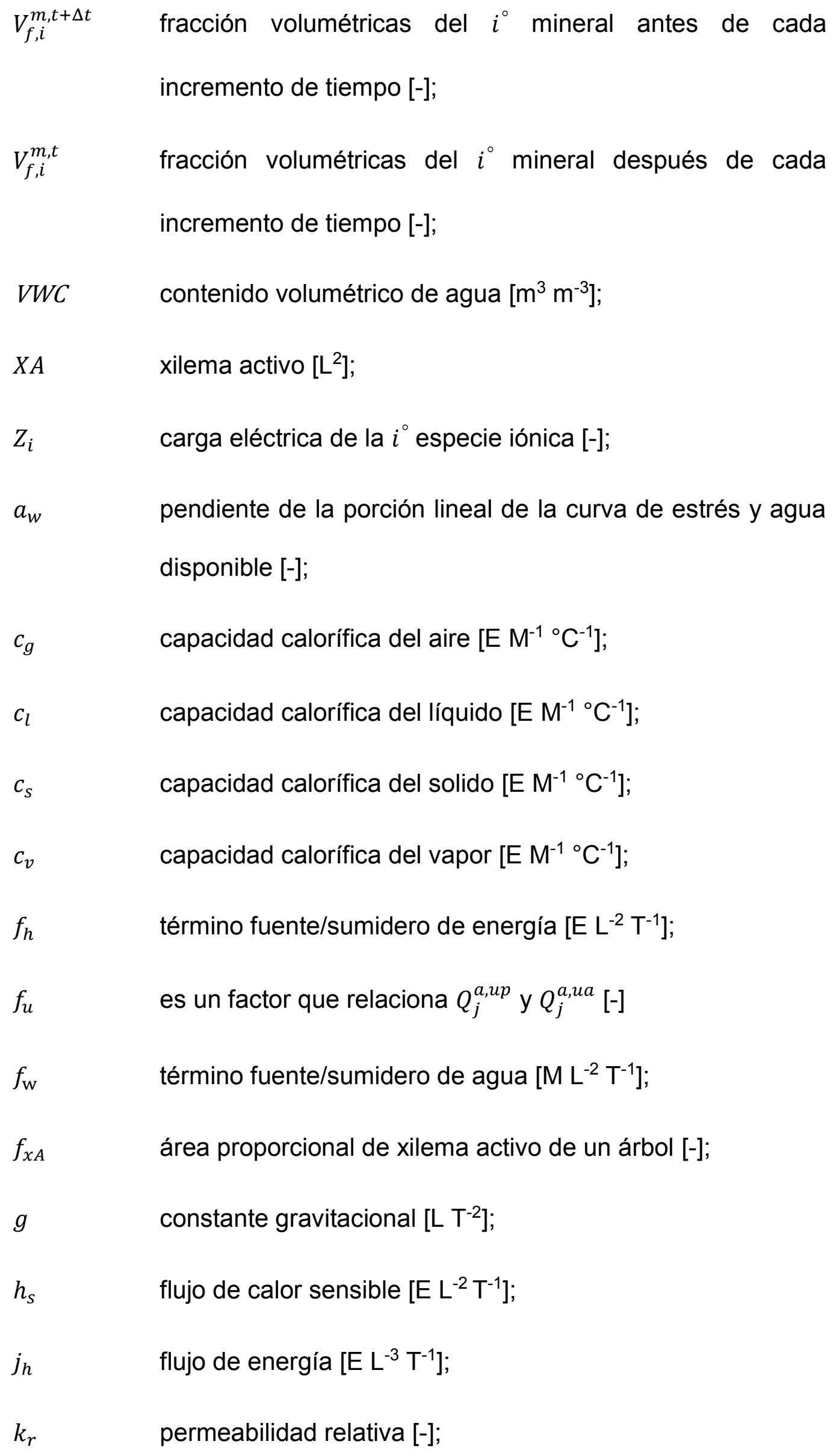


parámetro empírico de la ecuación de permeabilidad [-]; parámetro del modelo de van Genuchten (1980) derivado del parámetro $n[-]$; medida de la distribución del tamaño de poros [-]; flujo de líquido $\left[\mathrm{M} \mathrm{L}^{-2} \mathrm{~T}^{-1}\right]$;

$q_{v}$ flujo de vapor $\left[\mathrm{M} \mathrm{L}^{-2} \mathrm{~T}^{-1}\right]$;

$r_{h}$ resistencia de la capa límite atmosférica al flujo de vapor $\left[\mathrm{T} \mathrm{L}^{-1}\right]$

$r_{s}$ resistencia de la superficie del suelo al flujo de vapor $\left[\mathrm{T} \mathrm{L}^{-1}\right]$;

$t$ tiempo de simulación [T];

velocidad de flujo de sabia $\left[\mathrm{mm} \mathrm{s}^{-1}\right]$;

flujo Darcy modificado [L T-1]; coeficiente estequiométrico de reacciones en fase acuosa<smiles>[AlH2]</smiles>
coeficiente estequiométrico de especies intercambiables [-]; coeficiente estequiométrico de reacciones en fase gaseosa $[-]$ agua extractable [-];

$w_{0} \quad w$ para el cual $\alpha=1 / 2[-]$.

$\alpha$ relación entre la transpiración calculada y la evapotranspiración potencial [-]; 


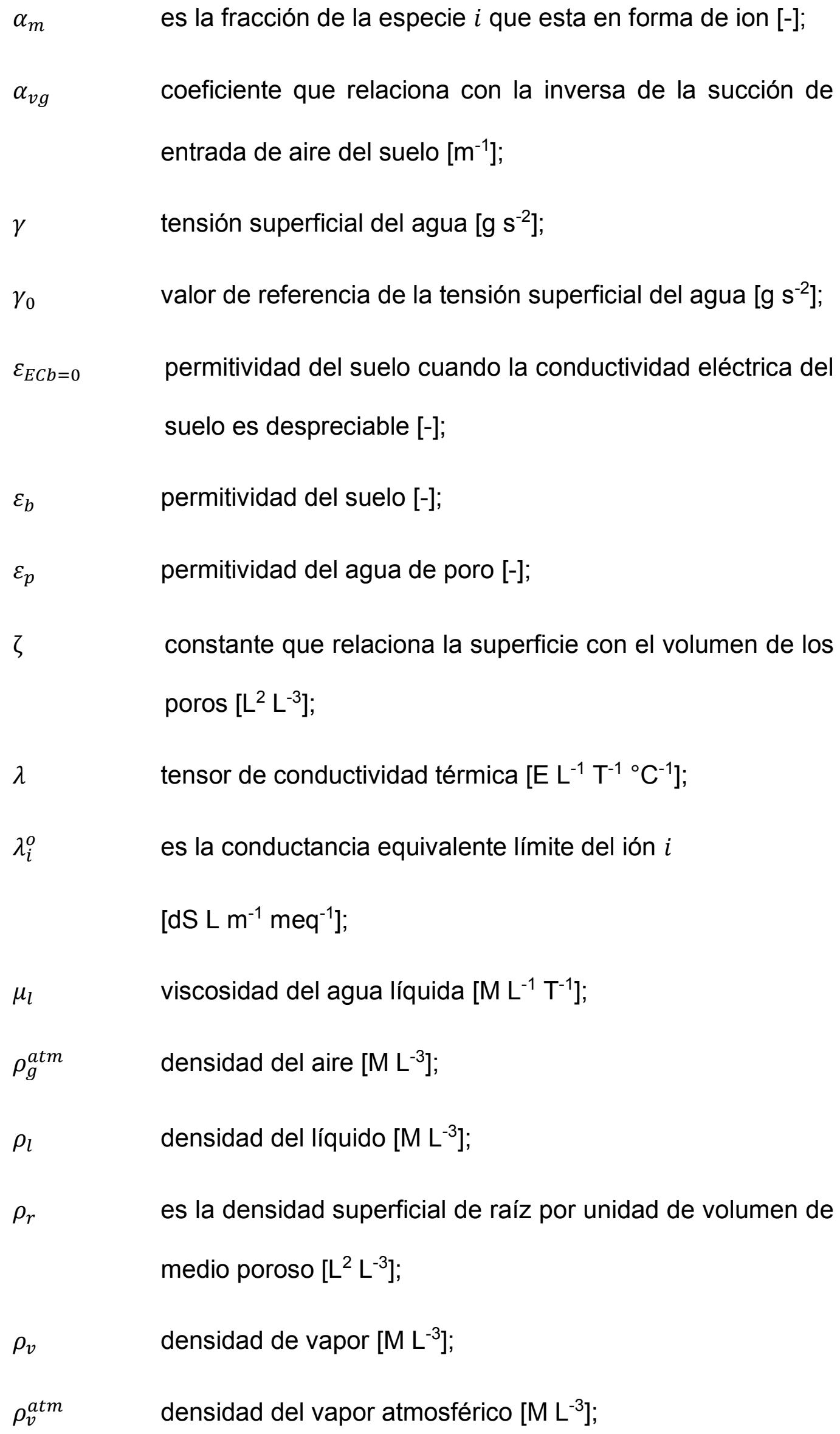


$\phi \quad$ porosidad [-];

$\Delta t \quad$ incremento de tiempo [T];

$\Delta T \quad$ diferencia de temperatura entre las termocuplas de Granier $\left[{ }^{\circ} \mathrm{C}\right]$

$\Delta T_{m} \quad$ máxima diferencia de temperatura entre las termocuplas tipo Granier $\left[{ }^{\circ} \mathrm{C}\right]$;

$\Omega_{\mathrm{i}} \quad$ estado de saturación de la $i^{\circ}$ especie mineral [-]. 


\section{Lista de tablas}

Tabla 2.1. Parcelas muestreadas, resumen de sus principales características.

Tabla 2.2. Análisis de varianza entre dos especies en el mismo sitio. Se comparan las EC1: 2.5

de dos especies forestales y de tres tipos de manejo ( $P$. radiata).

Tabla 3.1, Conductancias equivalentes limite extraído de (Selvaratnam y Spiro, 2004; Miller

et al., 1988)

Tabla 3.2. Parámetros físicos usados en el modelo

Tabla 3.3. Evaluación estadística de los resultados del modelo para casos base y escenarios

alternativos

Tabla 3.4. Balance hídrico para los escenarios de forestación

Tabla 3.5 Balance hídrico para los escenarios de pastizal.

Tabla 4.1. Parámetros físicos del modelo

Tabla 4.2. Reacciones del modelo de trasporte reactivo.

Tabla 4.3. Composición química de las aguas medidas y calculadas.

154

Tabla 4.4. Concentraciones de tritio en agua subterránea. Extraído de (Jobbágy y Jackson, 2007) 


\section{Lista de figuras}

Figura 1-1. Evolución del cambio en el uso del suelo a lo largo del tiempo. (a) extraída de Ramankutty et al. (2018). (b) modificada de Song et al. (2018), los números en círculo en la leyenda del color denotan direcciones de cambio dominantes: 1, ganancia de TC (cobertura arbórea) con pérdida de SV (vegetación corta); 2, ganancia de BG (suelo desnudo) con pérdida de SV; 3, TC ganancia con pérdida de BG; 4, ganancia de BG con pérdida de TC; 5, ganancia de SV con pérdida de BG; y 6, ganancia de SV con pérdida de TC. El conjunto de gráficas (c) representa la sumatoria de las áreas en (b).

Figura 1-2. Subregiones la región Pampeana ocupadas originalmente por pastizales y zona de estudio. Puntos rojos indican los sitios relevados en la presente tesis y círculos azules indican los puntos relevados en (Jobbágy y Jackson, 2007, 2004b, 2004a, 2003). La totalidad de los sitios serán utilizados en el análisis realizado en el Capítulo 2 y los puntos marcados como 'a' y 'b' se abordarán en los capítulos 3 y 4, respectivamente. . 32

Figura 2-1. Representación esquemática de los principales flujos y patrones de salinización en

(a) Pampa interior y ondulada (modificado de Nosetto et al., 2013), (b) Pampa austral y

(c) Pampa Deprimida. En sitios de cobertura herbácea, el balance hídrico es positivo ( $P$ $>E T_{c}$ ), lo que lleva a recargar los flujos que mantienen los suelos con baja salinidad. En las plantaciones de árboles y sitios conocidos como 'bajos', el balance hídrico es negativo $\left(E T_{c}>P\right)$, lo que genera una descarga. La captación de agua subterránea y la exclusión de la sal por las raíces de los árboles conducen a la salinización del ecosistema (zona sombreada en roja).

Figura 2-2. Ubicación de los sitios incluidos en el análisis de este capítulo. Los círculos azules corresponden con sitios muestreados por E. G. Jobbágy y sus colaboradores (Jobbágy y Jackson, 2003, 2004a, 2004b, 2007). Los sitios etiquetados en color rojo presentaron diferencias ( $\mathrm{p}<0.05)$ en $E C_{1: 2,5}$ a favor de la forestación. Las líneas negras corresponden con los balances hídricos anuales calculados por Nosetto et al. (2008) 
Figura 2-3. Conductividad eléctrica del suelo (EC1: 2.5) en sitios donde no se encontraron diferencias o donde la EC1: 2.5 fue mayor en la parcela herbácea. Los cuadrados blancos corresponden con la parcela herbácea y los negros con la forestal. las líneas horizontales indican el desvió estándar.

Figura 2-4. Conductividad eléctrica del suelo (EC1: 2.5$)$ en sitios donde se encontraron diferencias entre la parcela herbácea y forestal a favor de la forestación. Los cuadrados blancos corresponden con la parcela herbácea y los negros con la forestal y las líneas horizontales indican el desvió estándar. Nótese que la escala de $E C 1: 2.5$ varía entre los sitios.

Figura 2-5. Relación entre la conductividad eléctrica acumulada en el suelo de la parcela forestal y la posición en el terreno (la categoría loma incluye todas las posiciones altas, como loma, laderas de cerro y dunas). El coeficiente de correlación (R) entre estas dos variables es de 0.80

Figura 2-6. Relación entre la EC1: 2.5 de la forestación y cada una de las componentes texturales. Los coeficientes de correlación entre EC1: 2.5 y arena, limo y arcilla son de $0.37,0.04$ y 0.26 , respectivamente.

Figura 3-1. Distribución mundial probable de los horizontes cálcicos y petrocálcicos. El mapa fue generado interceptando los mapas de subórdenes de suelos que contienen horizontes cálcicos y petrocálcicos (global maps of soil taxonomy) y de carbono inorgánico del suelo (SIC). Extraído de (Duniway et al., 2010)

Figura 3-2. Distribución de la capa de tosca en los duelos de la Provincia de Buenos Aires bajo régimen de humedad del suelo údico, extraído de (Pazos y Mestelan, 2002).

Figura 3-3 (a) Localización del sitio de estudio y (b, c) principales variables medidas. ERT: tomografía de resistividad eléctrica ('electrical resistivity tomography'). 75

Figura 3-4. (a) Horizontes identificados en el perfil, (b) dominio del modelo y condiciones de contorno. 
Figura 3-5. Comparación entre los diferentes modelos de cálculo de la $E C p$. Valores medidos en el pastizal a $0.2 \mathrm{~m}$ de profundidad a modo de ejemplo.

Figura 3-6. Modelo conceptual contemplado por la modelación de transporte reactivo en la presente tesis.

Figura 3-7. Relación observada entre los parámetros $\alpha$ y $w$ (Ecuación 34 y Ecuación 35)

Modificadas de Battaglia \& Sands (1997) para E. globulus bajo secano y riego. 94

Figura 3-8. Evolución temporal de: (a) las precipitaciones y humedad relativa, contenido volumétrico de agua del suelo (VWC) en la parcela herbácea y forestal a (b) 0,2 y (c) 0,5 $\mathrm{m}$ de profundidad, y de (d) las precipitaciones acumuladas y nivel freático. 105

Figura 3-9. Evolución temporal de: (a) temperatura del aire y radiación solar, temperatura del suelo a (b) 0,2 y (c) 0,5 $\mathrm{m}$ de profundidad, y (d) temperatura del nivel freático en pastizal y forestación. 106

Figura 3-10. Evolución temporal de la conductividad eléctrica del agua de poro a (a) 0.2 y (b) $0.5 \mathrm{~m}$ de profundidad, y (c) del acuífero freático en pastizal y forestación. 108

Figura 3-11. Correlación entre déficit de presión de vapor y transpiración medida (QT, SF). 109

Figura 3-12. Conductividad eléctrica aparente del suelo (ECbgeo), en pastizal (a) y forestación (b), y $S l$ calculado con el modelo para el mismo momento (c).

Figura 3-13. Resultados del modelo base para la forestación. Evolución temporal de VWC observados y simulados (a) 0.2 y (b) $0.5 \mathrm{~m}$ de profundidad, (c) ETc, transpiraciones observadas y simuladas, y (d) balance hídrico mensual.

Figura 3-14. Temperatura observada y modelada a (a) 0,2 y (b) 0,5 m de profundidad bajo la forestación.

Figura 3-15. Distribución vertical de VWC y temperatura observada y simulada a (a) 60, (b) 200, y (c) 372 días de simulación.

Figura 3-16. Relación observada entre los parámetros $\alpha$ y $w$, Modificado de Battaglia \& Sands, (1997) para E. globulus en secano y bajo riego. Las líneas llena e interrumpida fueron 
calculadas con las Ecuación 34 y Ecuación 35, para la línea punteada w0 y aw fueron calibrados con el modelo PEST (Doherty, 2016) acoplado con MIN3P (Mayer et al., 2012).

Figura 3-17. Resultados de los modelos alternativos RSUP y RPROF. Evolución temporal de (a) VWC a 0,2 m de profundidad, (b) ETc, (c) y (d) balance hídrico mensual. Los resultados del modelo se comparan con el caso base y las observaciones.

Figura 3-18. Resultados del escenario alternativo REST. Evolución temporal de (a) VWC a 0,2 m de profundidad, (b) ETC y (c) balance hídrico mensual. Las áreas sombreadas indican los intervalos de tiempo en los que se aplicó menores tasas. Se muestran los resultados de estos modelos comparados con los del caso base y las observaciones.

Figura 3-19. Resultado del modelo base para le parcela herbácea. Evolución temporal de VWC observados y simulados (a) 0,2 m (b) 0,5 m de profundidad, (c) ETc, transpiraciones observadas y simuladas, y (d) balance hídrico mensual. 125

Figura 3-20. Resultados parcela herbácea (escenario SIN TOSCA). Evolución temporal de VWC observados y simulados (a) 0,2 y (b) 0,5 m de profundidad, y (c) ETc, transpiraciones observadas y simuladas.

Figura 3-21. Resultados del modelo de transporte de solutos y la correspondiente medición de ECp para forestación (a y b) y herbácea (c y d) a 0,2 m y 0,5 $\mathrm{m}$ de profundidad, respectivamente.

Figura 4-1. Esquema representativo de los mecanismos propuestos desencadenados por la forestación de pastizales sobre los flujos de solutos.

Figura 4-2. Ubicación y características transecta estudiada. *se refiere a las estaciones donde se monitoreó el nivel freático y la traspiración. Las líneas de flujo en (b) fueron extraídas y modificadas a partir de Jobbágy y Jackson 2007. 143

Figura 4-3. Características químicas de la transecta estudiada, extraído de Jobbágy y Jackson (2007). (a) La conductividad eléctrica (EC) corresponde con mediciones sobre una 
relación suelo:agua de 1:5, (b y c) para pH y cloruro se usó una relación 1:1. (d) el porcentaje de sodio intercambiable (PSI) indica el porcentaje del complejo de cambio que está saturado por ese elemento. La posición de pastizal se hizo a $100 \mathrm{~m}$ de la forestación, mientras que margen y centro se ubicaron a 50 y 150 m, respectivamente, hacia el interior de la misma. 144

Figura 4-4. Composición de la biomasa de Eucalyptus camaldulensis. Para detalles metodológicos sobre la obtención de estos datos ver Jobbágy y Jackson 2003.

Figura 4-5. Dominio del modelo (a), (b) modelo conceptual de flujo basado en Jobbágy y Jackson, 2007 y (c) modelos implementados

Figura 4-6. Series de niveles freáticos impuestos en el modelo de transporte reactivo........ 155

Figura 4-7. Resultados de campo y modelación para el margen de la forestación. En "a", "b", "c" y "d" resultados del modelo "Margen de Forestación Superficial" (MFS) comparados con las observaciones en el pastizal y en el margen de la forestación. De la misma manera, en "f", "g", " $h$ ", e "i" se comparan con los resultados del modelo "Margen de Forestación Profundo" (MFP). El aumento de la salinidad fue calculado como ECfinal/ECinicial (dS/m) para los datos medidos y modelados. *El volumen de calcita precipitada en MFS y MFP, respectivamente es calculado como: volumen de mineral/volumen de suelo

Figura 4-8. Resultados de campo y modelación para el centro de la forestación. En "a", "b", "c" y "d" resultados del modelo "Centro de Forestación Superficial" (CFS) comparados con las observaciones en el pastizal y en el centro de la forestación. De la misma manera, en "f", "g", "h", e "i" se comparan con los resultados del modelo "Centro de Forestación Profundo" (CFP). El aumento de la salinidad fue calculado como ECfinal/ECinicial (dS/m) para los datos medidos y modelados. 159 
Resumen

El cambio en el uso del suelo es un fenómeno que ocurre en todo el mundo y que se ha intensificado drásticamente en los últimos años generando una serie de impactos ambientales. Esta tesis se enfoca específicamente en las consecuencias del reemplazo de ecosistemas naturalmente herbáceos por plantaciones forestales en ambientes de la llanura pampeana.

Para evaluar este fenómeno se recabó información de campo de distintos ambientes a lo largo de toda la región. Con esto, sumado a los trabajos previos, se observó que existen una gran cantidad de factores ambientales que afectan el proceso, y por lo tanto que es de una gran complejidad. Se determinó que los principales elementos que desencadenan la salinización están relacionados con la posibilidad de la forestación de acceder a fuentes hídricas subterráneas.

Para profundizar en estos aspectos, por un lado, se realizó un monitoreo intensivo de las variables hidrológicas en una parcela para evaluar los flujos hídricos a través del horizonte petrocálcico, característica común en la región. Con esta información se elaboró un modelo de flujo y transporte. Así, se determinó que la presencia de estos horizontes constituye una barrera al crecimiento de las raíces de la forestación y a los flujos hídricos, alterando la disponibilidad de agua para la vegetación. Los horizontes petrocálcicos son una característica del ambiente que disminuye el riesgo de salinización causado por la forestación, ya que reduce la posibilidad de que esta acceda al acuífero freático.

Por otro lado, para identificar y caracterizar cuáles son los procesos hidroquímicos-biológicos que se desencadenan por la forestación de pastizales, se estudió un sitio con evidencias de salinización, característico de la Pampa 
Deprimida. En este caso, además de mediciones hidrológicas se contó con información hidroquímica del sitio. Se utilizó la herramienta de modelación de transporte reactivo para evaluar los mecanismos de intrusión, toma selectiva, exudación, reciclaje (cycling) y mayor tasa de respiración; que produjeron salinización, sodificación, acidificación, alcalinización en los distintos sectores de una forestación de eucaliptos. El modelo nos permitió desentrañar los mecanismos, las interacciones y la magnitud de todos estos procesos de la rizósfera. A partir de esto se determinó la gran importancia de considerar las características hidrogeoquímicas del sitio, a tal punto que pueden llevar a resultados muy diferentes partiendo de una situación aparentemente igual. Además, el impacto en el ambiente puede ser irreversible, inutilizando áreas de cultivo o ambientes naturales.

La salinización de pastizales forestados es un fenómeno complejo que difícilmente pueda ser abordado sin la herramienta de la modelación. En la región Pampeana esta es una problemática que sólo afecta a algunos ambientes y con prácticas de manejo adecuadas, que tengan en cuenta las características hidrogeoquímicas del sitio, se puede llevar a cabo un plan de manejo que permita la producción forestal evitando la salinización.

Palabras clave: Modelación numérica, forestación de pastizales, flujos de agua y solutos, cambios químicos. 


\begin{abstract}
The change in land use is a phenomenon that occurs throughout the world and has intensified dramatically in recent years, generating a series of environmental impacts. This thesis focuses specifically on the consequences of replacing naturally herbaceous ecosystems with forest plantations in environments of the Pampas plain.
\end{abstract}

To assess this phenomenon, field information was collected from different environments throughout the region. It was observed that there are a large number of environmental factors that affect the process, and therefore that it is of great complexity. It was determined that the main elements that trigger salinization are related to the possibility of afforestation to access groundwater sources.

To deepen these aspects, on the one hand, intensive monitoring of the hydrological variables was carried out on a plot to assess water flows across the petrocalcic horizon, a common characteristic in the region. With this information, a flow and transport model was developed. Thus, it was determined that the presence of these horizons constitutes a barrier to the growth of the roots of afforestation and water flows, altering the availability of water for vegetation. Petrocalcic horizons are a characteristic of the environment that decreases the risk of salinization caused by afforestation, since it reduces the possibility of access to the water table.

On the other hand, in order to identify and characterize which are the hydrochemical-biological processes that are triggered by grassland afforestation, a site with evidence of salinization, characteristic of the Pampa Deprimida, was studied. In this plot, in addition to hydrological measurements, there was available 
hydrochemical information. In this study case, the reactive transport modeling tool was used to evaluate the mechanisms of intrusion, selective root uptake, exudation, cycling and the higher respiration rate; that produced salinization, sodification, acidification, alkalization in the different sectors of a eucalyptus afforestation. The model allowed us to understand the mechanisms, interactions and magnitude of all these rhizosphere processes. From this, the great importance of considering the hydrogeochemical characteristics of the site was determined. According to their hydrogeochemical characteristics the systems could evolve in a very different ways. In addition, the impact on the environment can be irreversible, leaving areas of cultivation or natural environments, useless.

Salinization of afforested grasslands is a complex phenomenon that can't be addressed without the modeling tool. In the Pampean region, this is a problem that only affects certain environments and with appropriate management practices, taking into account the hydrochemical characteristics of the site, a management plan that allows forest production and avoid salinization could be carried out.

Keywords: Numerical modelling, grassland afforestation, water and solutes flows, chemical changes. 


\section{Agradecimientos}

Quisiera en agradecer primer lugar a mi director Sergio A. Bea por su apoyo y dedicación durante el desarrollo de esta tesis, y por transmitirme los conocimientos necesarios para abordar el entendimiento de sistemas naturales a través de la modelación numérica. También quisiera agradecer a los evaluadores Luis Alberto Lozano, Eduardo E. Mariño y María I. Delgado por sus comentarios positivos y constructivos. Por otro lado, agradezco a todos los integrantes del Instituto de Hidrología de Llanuras por su apoyo moral, académico y por su compañerismo y amistad.

Quisiera también agradecer a Germán Milione por su gran ayuda en las tareas de campo, laboratorio y escritorio. También a Luis Vives por el apoyo y los consejos durante el desarrollo de esta tesis. A Javier Gyenge por ser quien llevó adelante el proyecto que dio origen a este trabajo y su buena predisposición para brindar su ayuda en los temas relacionados a la ecofisiología forestal, mediciones y uso de equipos.

Quisiera agradecer especialmente a mis padres, Miguel y Gabriela y mis hermanos, Maxi y Julieta que me apoyaron y alentaron a seguir mi carrera. 
Capítulo 1

Introducción general 


\subsection{Cambio en el uso del suelo}

La humanidad depende de los bienes y servicios que obtiene de la tierra, y, así como todos los organismos vivientes, el Hombre modifica el ambiente que habita. El crecimiento de la población y del desarrollo tecnológico llevó esta transformación hasta al punto en que actualmente se estima que el $\sim 39-50 \%$ de los ambientes naturales terrestres han sido degradados o alterados por el hombre (Ramankutty et al., 2018; Vitousek et al., 1997). Tal es así que en los últimos 35 años se observan entre el $\sim 35 \%$ (Oceanía) y el $\sim 86 \%$ (Europa) de reemplazo de la cobertura del suelo (Song et al., 2018). Las principales transformaciones fueron la eliminación de selvas y bosques naturales, y su posterior reemplazo por cultivos agrícolas en zonas tropicales y viceversa (es decir, plantación forestal sobre un ecosistema herbáceo) en zonas sub tropicales, templadas y boreales.

Actualmente existe un consenso sobre la pérdida constante de superficie forestada (FAO, 2015), sostenido por la tendencia de los últimos 300 años (e.g. Ramankutty et al., 2018; Sunderland \& Rowland, 2019, Figura 1-1 a). Sin embargo, Song et al., 2018 determinó un incremento neto en la superficie forestada del 7,1\% en el periodo 1982-2016 (Figura 1-1 b y c).

El mercado de commodities agrícolas, la demanda de alimentos y productos primarios, y el aumento de la población, sumados al mercado de bonos de carbono, son las principales variables que controlan la dinámica de la cobertura del suelo y el impacto humano sobre los ecosistemas (Sunderland y Rowland, 2019; Wang et al., 2019; Leblois et al., 2017; López-Carr y Burgdorfer, 2013). 
En Argentina existen grandes áreas donde se dan estas dos tendencias en el cambio del uso del suelo. Por un lado, la deforestación del Chaco argentino, que se considera una de las más importantes que se han llevado a cabo en la región (e.g. Gasparri y Grau, 2009) y, por otro, el avance forestal en la región pampeana (p.e.j., Nosetto et al., 2012).

La deforestación del Chaco argentino se ha acentuado en las últimas dos décadas debido principalmente al avance de la frontera agrícola, y al proceso de sojización como consecuencia de la devaluación de la moneda nacional y la demanda internacional de commodities (Gasparri y Grau, 2009). La expansión de la soja ha mostrado tener un efecto no solo directo, con reemplazo de bosques nativos por el cultivo, sino también indirectamente por una competencia por el espacio con la ganadería, la cual se ha trasladado a nuevas áreas, incluidas las deforestadas en el Chaco (Fehlenberg et al., 2017; Sacchi y Gasparri, 2016; Zak et al., 2008). 

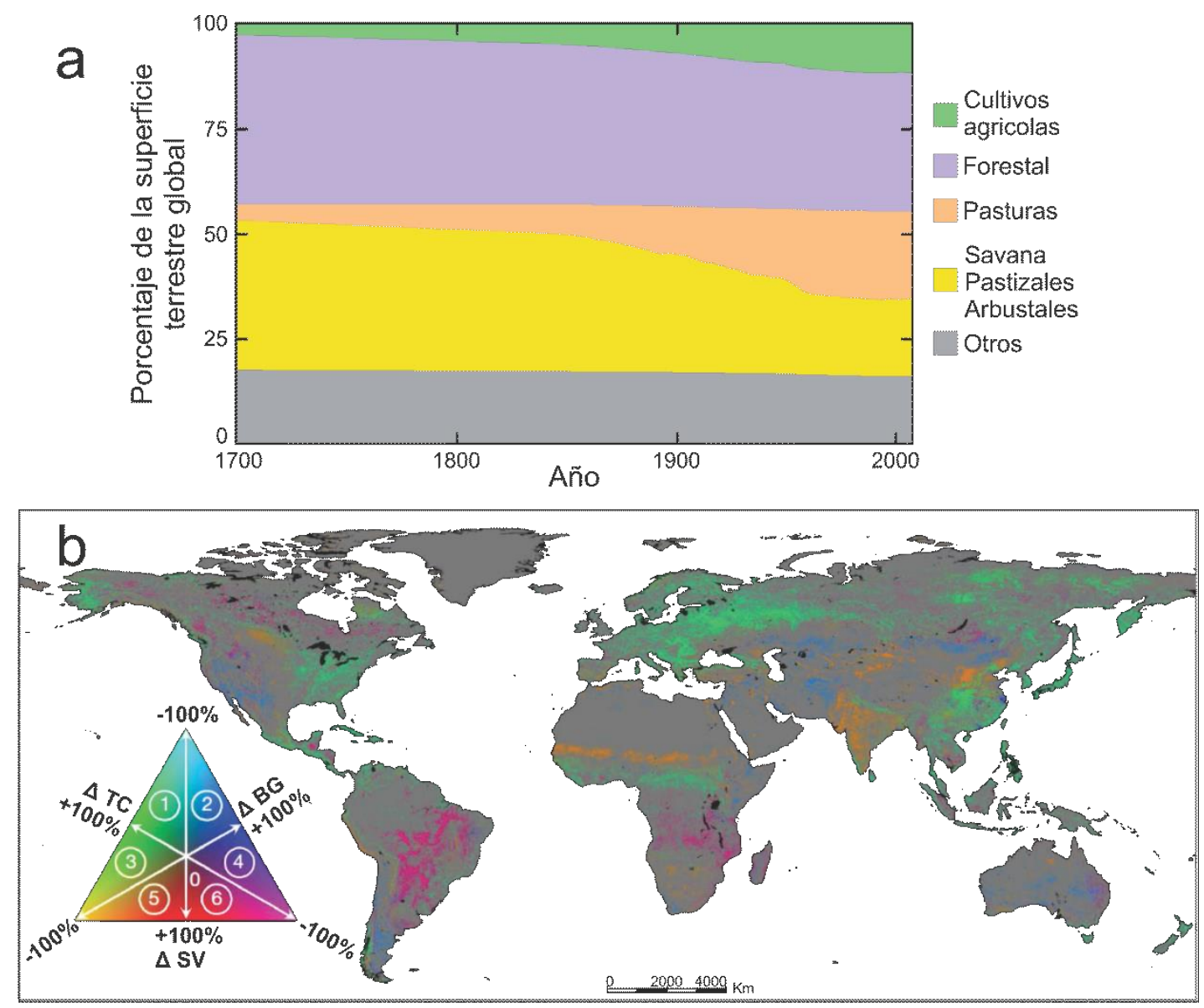

C

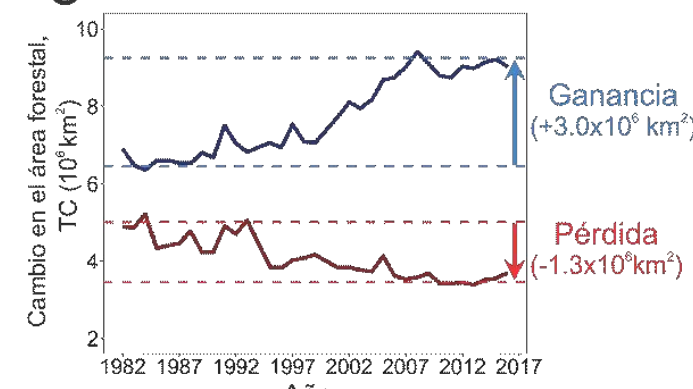

Año

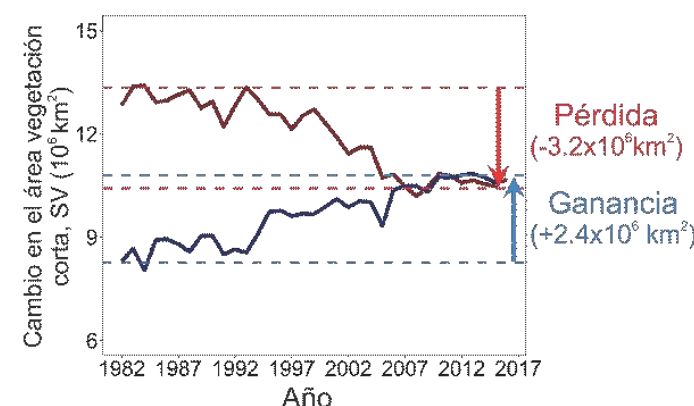

Figura 1-1. Evolución del cambio en el uso del suelo a lo largo del tiempo. (a) extraída de Ramankutty et al. (2018). (b) modificada de Song et al. (2018), los números en círculo en la leyenda del color denotan direcciones de cambio dominantes: 1, ganancia de TC (cobertura arbórea) con pérdida de SV (vegetación corta); 2, ganancia de BG (suelo desnudo) con pérdida de SV; 3, TC ganancia con pérdida de BG; 4, 
ganancia de BG con pérdida de TC; 5 , ganancia de SV con pérdida de BG; y 6 , ganancia de SV con pérdida de TC. El conjunto de gráficas (c) representa la sumatoria de las áreas en (b).

En la dirección contraria, la plantación de forestaciones sobre sitios naturalmente dominados por especies herbáceas (región pampeana), durante el período 1991-2001 alcanzó una tasa de 125000 ha plantadas anualmente (Nosetto et al., 2012; SAGPyA, 2002). Esta expansión se redujo en la actualidad ( 7000 ha $a n ̃ o^{-1}$, en las últimas décadas), debido a la ya mencionada competencia por el espacio con la agricultura (MAGyP, 2019). Sin embargo, el avance de las forestaciones sobre los pastizales se mantiene debido a la gran disponibilidad de tierras aptas para la actividad, la rentabilidad relativamente alta que generan y un conjunto de incentivos económicos estatales (Ley Nº 26.432, vigente actualmente). Además, es posible que en el futuro este avance pueda aumentar (Jobbágy et al., 2006b). Tal es así que durante el año 2019 el Estado argentino destinó fondos (apoyos económicos no reintegrables, MAGyP, 2019) para la forestación de 28399 ha en todo el País.

Otra causa del reemplazo de pastizales por forestaciones es la invasión por parte especies de árboles exóticas introducidas por el hombre, ya sea por sus capacidades de colonizar nuevos sitios o favorecidas por el ambiente agropecuario y ciertas prácticas de manejo (Jackson et al., 2002; Zalba y Villamil, 2002; Richardson, 1998). Esta invasión de especies arbóreas sobre pastizales nativos ha tenido más incidencia en el hemisferio sur, y en la Argentina en particular se documentó en diferentes ecorregiones como el Chaco seco (Ferreras et al., 2014), Bosques Subtropicales de Montaña (i.e., 'Las Yungas'; Fernández et al., 2016), los pastizales Pampeanos (Amodeo y Zalba, 2015; Zalba y Villamil, 2002), y el espinal (Ruiz Selmo, 2007). 


\subsection{Impactos hidrológicos}

Los cambios en el uso del suelo de vegetación herbácea por arbórea suelen desencadenar, en general, impactos en el medio ambiente. Una de las consecuencias suele estar ligada a la gran diferencia en el consumo de agua entre estos tipos de vegetación. La vegetación herbácea tiene una menor capacidad de transpirar agua debido a una menor rugosidad aerodinámica, un menor índice de área foliar, menor intercepción de agua por el dosel, menor desarrollo radicular, y mayor albedo (Nosetto et al., 2012; Gyenge et al., 2002; Jackson et al., 2001; Calder, 1998).

Como consecuencia de estas diferencias el reemplazo de forestaciones por pasturas o cultivos herbáceos podría generar excesos hídricos, ascenso de los niveles freáticos, aumento de la escorrentía, aumento del riesgo de inundaciones, movilización de sales hacia la superficie y contaminación de suelos y acuíferos (Koul y Taak, 2018; Nosetto et al., 2012; Viglizzo et al., 2009; Schofield, 1992). Además este cambio puede generar consecuencias en el clima a gran escala, tales como cambios en la nubosidad, en los flujos de calor, disminución en precipitaciones y aumentos en la temperatura (Lejeune et al., 2018; Laguë y Swann, 2016; Swann et al., 2015).

Por el contrario el reemplazo de vegetación herbácea por forestal puede desencadenar descensos en los niveles freáticos, salinización del ecosistema y aridificación (Hoyk et al., 2007; Jobbágy y Jackson, 2007; Engel et al., 2005; Timlin et al., 2001).

El uso de agua por parte de las forestaciones, si bien puede variar de acuerdo a si se trata de una especie de hoja caduca o perenne, en el caso de especies de crecimiento rápido o lento, o según sus características adaptativas, 
en general es mayor que el de las especies herbáceas (Nosetto et al., 2008, 2012; Farley et al., 2005). Por ejemplo, se estimó un consumo de alrededor de $3,15 \mathrm{~mm}$ día $^{-1}$ para bosques nativos y plantaciones, mientras que este valor es de 2,15 $\mathrm{mm}_{\text {día }}{ }^{-1}$ para el caso de cultivos trigo/soja y $1,15 \mathrm{~mm}$ día ${ }^{-1}$ para trigo (Nosetto et al., 2008).

Las características particulares de las forestaciones, como el hecho de tener un sistema radicular profundo y mayor superficie foliar, les permite acceder a fuentes de agua profundas. Esta capacidad de acceder a la zona saturada (ZS) les permite a las forestaciones mantener sus requerimientos hídricos sin depender del agua de lluvia almacenada en las primeras capas de suelo, como sí sucede comúnmente con las especies herbáceas.

Esta ventaja de las forestaciones les deja como única limitante (hídrica) para la transpiración, la demanda atmosférica (Nosetto et al., 2008; Jobbágy y Jackson, 2007; Engel et al., 2005; Salama et al., 1994). Tal es así que a menudo la transpiración de las forestaciones genera descensos observables de los niveles freáticos (Engel et al., 2005; Salama et al., 1994), incluso generalmente se asume que la transpiración tiene una dependencia directa con el déficit de presión de vapor del aire (De Kauwe et al., 2019; Oren et al., 1999; Granier et al., 1996).

Existen, sin embargo, situaciones en la cuales estas especies arbóreas no pueden acceder a estos recursos hídricos, ya sea porque este mantiene un nivel demasiado profundo, porque existe un sustrato con capas que mecánicamente impiden el crecimiento de las raíces, o porque su composición química es tóxica para la especie arbórea en cuestión (Jobbágy y Jackson, 2003; Bañuls et al., 1997). 


\subsection{Salinización secundaria derivada de la forestación de pastizales \\ El acceso al acuífero freático por parte de las forestaciones puede}

aumentar la productividad del sitio, sin embargo, también es posible que genere impactos negativos. Los ya mencionados efectos sobre los flujos hídricos generalmente también tienen impactos sobre la química del agua del suelo y del acuífero freático. Al volumen de agua transpirado por las forestaciones se suma con su capacidad de excluir ciertos solutos y de liberar exudados para mantener sus funciones biológicas (Mujica et al., 2019c; Hong et al., 2018; Dakora y Phillips, 2002). Así, se genera acumulación y cambios químicos que a su vez pueden desencadenar alcalinización, acidificación, precipitación de minerales, dispersión de suelos, pérdida de materia orgánica, entre otros.

Estos procesos generalmente disminuyen la fertilidad del suelo y son en muchos casos irreversibles (Berthrong et al., 2009; Nosetto et al., 2008; Jobbágy y Jackson, 2001, 2003, 2004a, 2007; Heuperman, 1999). Tal es así que en numerosas situaciones se han documentado cambios en la salinidad y $\mathrm{pH}$ del suelo y acuífero freático cuando los pastizales se reemplazan por plantaciones forestales (Nosetto et al., 2007; Jobbágy y Jackson, 2003; George et al., 1997).

En nuestro país este fenómeno se documentó en numerosos sitios de la región Pampeana donde el pastizal natural ha sido reemplazado por forestaciones. Por ejemplo, Jobbágy y Jackson (2004) y Mujica et al. (2019c) describen acumulación de sales en el acuífero freático de hasta $\sim 30$ veces respecto del pastizal sin forestar, en la región de la Pampa Ondulada, Pampa deprimida y Pampa Interior. 


\section{4. Área de estudio}

Los pastizales nativos pampeanos ocuparon originalmente una amplia región de $\sim 70$ millones de hectáreas, entre Argentina, Brasil y Uruguay (Nosetto, 2007; Paruelo y Piñeiro, 2004). En esta región se reconoce cierta heterogeneidad determinada por diferencias geomorfológicas, edáficas, climáticas y fitogeográficas, que permitieron delimitar subregiones (Figura 1-4; Oyarzabal et al., 2018; Paruelo \& Piñeiro, 2004). En la parte que abarca el territorio argentino el promedio anual de precipitaciones va de $\sim 600 \mathrm{~mm}$ a $\sim 1000 \mathrm{~mm}$, llegando a $1300 \mathrm{~mm}$ en sector brasileño, y las temperaturas medias anuales rondan aproximadamente los $\sim 14^{\circ} \mathrm{C}$ a $\sim 17^{\circ} \mathrm{C}$ (Podestá et al., 1999). 


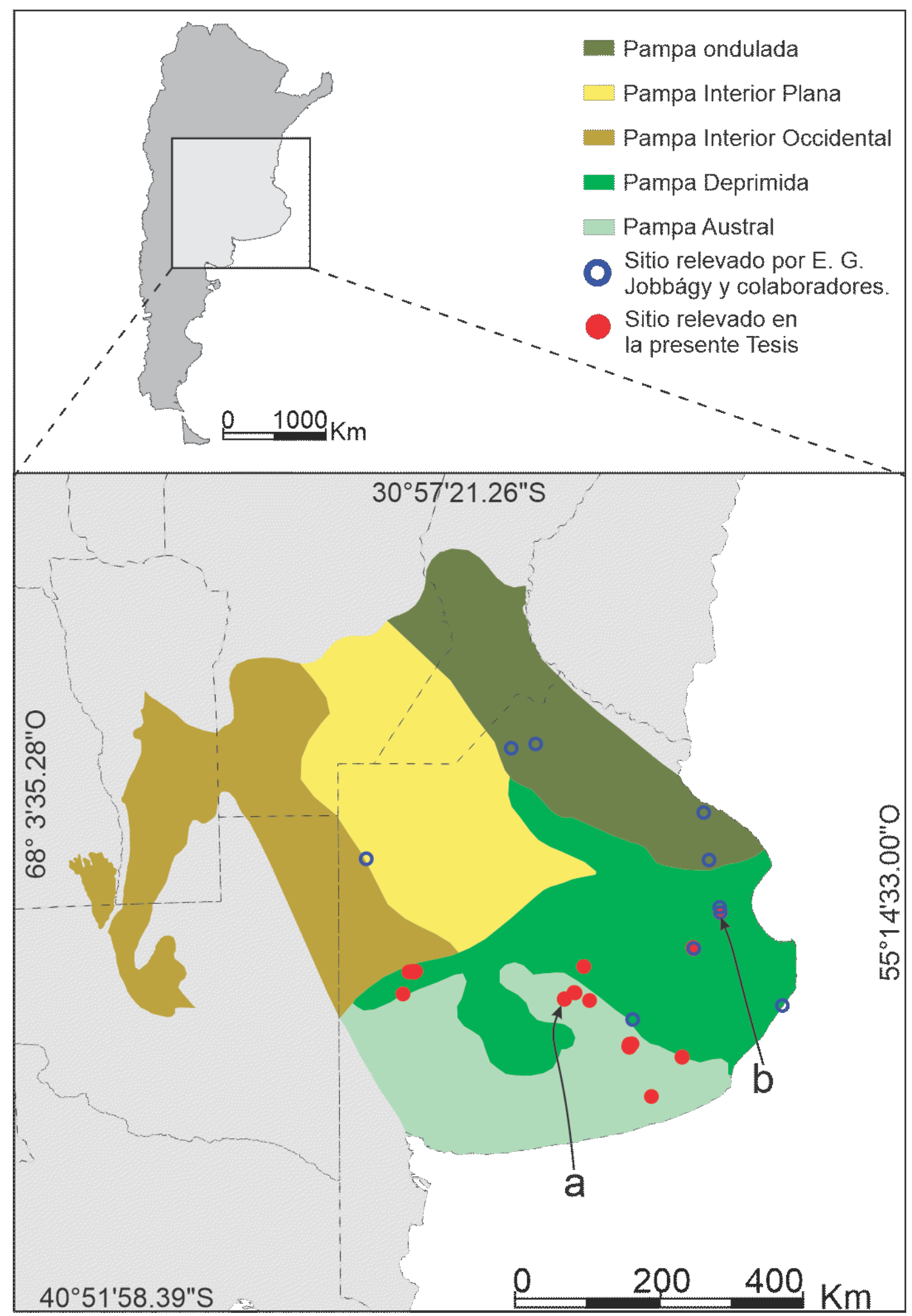

Figura 1-2. Subregiones la región Pampeana ocupadas originalmente por pastizales y zona de estudio. Puntos rojos indican los sitios relevados en la presente tesis y círculos azules indican los puntos relevados en (Jobbágy y Jackson, 2007, 2004b, 2004a, 2003). La totalidad de los sitios serán utilizados en el 
análisis realizado en el Capítulo 2 y los puntos marcados como 'a' y 'b' se abordarán en los capítulos 3 y 4 , respectivamente.

Los suelos dominantes de esta región son los Molisoles formados a partir de sedimentos depositados durante el Pleistoceno tardío-Holoceno (Zárate, 2003; Teruggi, 1957). El relieve en general presenta bajos gradientes topográficos con bajo escurrimiento por lo que predomina el almacenamiento local y el flujo vertical de agua, la escorrentía es escasa y los excesos hídricos se eliminan en un 90-100\% vía evapotranspiración (Taboada et al., 2009; Varni y Usunoff, 1999). Esta característica genera recurrentes inundaciones y un gradiente de aumento de salinidad y disminución profundidad de la napa freática (e.g., de 0.653 a $5.780 \mathrm{dS} \mathrm{m}^{-1}$ y >1 a $5 \mathrm{~m}$, respectivamente, Zabala et al., 2016a) desde las cabeceras hasta los cierres de las cuencas (Jobbágy et al., 2017; Zabala et al., 2016a; Barranquero et al., 2012; Pessolano et al., 2010).

En la subregión clasificada como Pampa Ondulada (Figura 1-2) el paisaje está formado por suaves ondulaciones, drenadas por varios cursos tributarios del río Paraná y el Río de la Plata. Sus suelos se formaron a partir de loess arcillosos con bajo contenido de arena (<5\%) y alto contenido de limos $(\sim 70 \%)$, regionalmente tiene un gradiente decreciente en tamaño de grano con dirección SO-NE (Zárate y Tripaldi, 2012; Zárate, 2003).

La Pampa Interior Plana tiene un relieve suave de dunas eólicas que controlan su pobremente integrado drenaje superficial, y suelos de texturas de grano grueso. En la Pampa Interior Occidental se desarrolla una planicie de relieve bajo, drenada por corrientes efímeras y el río Quinto y presenta un complejo patrón de dunas formadas por sedimentos de arenas finas y limos (Zárate y Tripaldi, 2012). 
La Pampa Deprimida consiste de un terreno muy plano que se desarrolló a partir de los mismos sedimentos loésicos, más arenosos hacia el sudoeste y además tienen aportes de sedimentos limosos. La deposición de estos sedimentos trazo formaciones longitudinales de varios kilómetros de largo, 1-1.5 $\mathrm{m}$ de alto y algunos cientos de metros de ancho, así como dunas parabólicas adyacentes a cuencas de deflación.

En la Pampa Austral (también conocida como Pampa Interserrana), los depósitos loésicos forman un manto continuo sobre los grandes y complejos sistemas de dunas arenosas del centro de Argentina. Los sedimentos que forman esta subregión son más gruesos, clasificados comúnmente como arenas, limosas arcillosas, aunque se pueden encontrar sitios con suelos de texturas más finas y presencia de horizonte petrocálcico, heterogéneo con distintos grados de cementación y espesor (Zárate y Tripaldi, 2012; Zárate, 2003).

\subsection{Vegetación originaria de la Región Pampeana}

La vegetación natural fue caracterizada en cada una de sus subregiones (Figura 1-2) haciendo evidentes sus particularidades ambientales y la calidad de cada sitio en términos agronómicos y forestales (Oyarzabal et al., 2018; Burkart et al., 1990, 2005; Lewis et al., 1985; Ragonese y Covas, 1947; Parodi, 1940).

En la Pampa Ondulada en posiciones positivas con suelos profundos y bien drenados predominan comunidades de Bothriochloa laguroides y Nassella charruana, mientras que en las posiciones negativas con drenaje limitado están dominadas por Paspalum quadrifarium, Paspalum dilatatum y Setaria parviflora, así como también se pueden hallar halófitas como Distichlis spp. y Sporobolus pyramidatus. 
La Pampa interior tiene suelos más arenosos-franco-arenosos y profundos con comunidades de Poa ligularis, Nassella tenuisima y Nassella trichotoma, también se pueden hallar halófitas. Continuando un gradiente hacia los menores regímenes hídricos en la Pampa Interior Occidental, la vegetación se compone de pseudoestepas de Sorghastrum pellitum y Elionurus muticus.

Descendiendo hacia la parte central de la provincia de Buenos Aires, en la Pampa Deprimida el régimen hídrico del suelo es mucho más húmedo, y se puede distinguir un gradiente con distintos tipos de pastizales característicos desde las posiciones más altas y drenadas hacia las más bajas y anegables. Entre estas comunidades vegetales podemos encontrar praderas de mesófitas (Piptochaetium stipoides, Nassella trichotoma, Paspalum dilatatum), pradera húmeda de mesófitas (Nassella neesiana, Piptochaetium montevidense, $P$. bicolor) y pradera húmeda de higófitas (Solanum glaucophyllum, Glyceria multiflora, Paspalidium paludivagum). Asimismo, este gradiente puede tener la presencia de acumulación natural de sales en las posiciones más bajas con lo cual quedan definidas comunidades de halófitas (Sporobolus pyramidatus, Hainardia cylindrica, Hordeum stenostachys y Spartina densiflora).

Finalmente, la Pampa Austral presenta una gran heterogeneidad determinada por la presencia y la profundidad de horizontes petrocálcicos con distintos grados de cementación y espesor o roca, asociada a los sistemas serranos de Tandilia y Ventania. Las comunidades vegetales de esta región están dominadas por especies de los géneros Nassella, Piptochaetium, Melica, Briza y Danthonia. Si bien los pastizales son la formación predominante de esta región, existen especies arbustivas y arbóreas. Estas últimas se pueden hallar 
en la Pampa Austral como arbustos de Baccharis tandilensis, B. articulata, Colletia paradoxa y Discaria longispina en cerros y laderas serranas.

Asimismo, en las márgenes orientales de Pampa ondulada y en la Pampa Deprimida se pueden encontrar especies arbóreas mayormente de Celtis ehrenbergiana (conforman los bosques en galería conocidos como "talar", Parodi, 1940), acompañada de Prosopis alba, Jodina rhombifolia, Aspidosperma quebracho-blanco y Phytolacca dioica sobre las barrancas de río Paraná, el estuario de Río de la Plata y paralelo a la costa atlántica (Oyarzabal et al., 2018). Como única especie arbórea que ingresa al interior de la llanura Pampeana, Salix humboldtiana se encuentra naturalmente en las márgenes de los cursos de agua, como arroyos y ríos.

Estos pastizales han sido reemplazados por cultivos agrícolas, verdeos y pasturas, sobre todo en Pampa ondulada, Interior e interserrana. En la Pampa Deprimida estos cultivos solamente ocupan los sitios más altos y drenados con mejores aptitudes, generalmente con geomorfología de dunas o lomas. En las zonas bajas o con limitaciones edáficas para los cultivos comúnmente permanecen los pastizales naturales alterados por diferentes intensidades pastoreo, intersiembras de pasturas y forestaciones (Montico y Leo, 2007; Nosetto, 2007; Paruelo et al., 2006; Paruelo y Piñeiro, 2004; Viglizzo et al., 2001).

\subsection{Objetivos de la tesis}

Siendo la provincia de Buenos Aires una de las más importantes de Argentina desde el punto de vista productivo y en cuanto a superficie de pastizales naturales remanentes (Carreño et al., 2012), la presente tesis se enfoca en la evaluación del impacto de su reemplazo por forestaciones. El área 
que abarcó este estudio es complementaria de trabajos previos (Jobbágy y Jackson, 2004a, 2007) recurrentes en el centro-Norte de la región, y comprende una transecta que abarca el centro-sur de la provincia de Buenos Aires (Figura $1-2)$.

Los objetivos principales de la presente tesis son comprender:

(1) Aquellos procesos que controlan los cambios hidrogeoquímicos en la zona no saturada de diferentes tipos de suelos sometidos a la actividad forestal en pastizales pampeanos;

(2) La sensibilidad de estos cambios a sus características edáficas, biológicas, climáticas, y a la composición química de las aguas subterráneas.

Para alcanzar estos objetivos se plantearon objetivos específicos:

\subsection{Objetivos específicos}

(1) Identificar y caracterizar los elementos del sistema que controlan el proceso de salinización secundaria de suelos sometidos a los distintos usos productivos identificados en la región (pastizales, cultivos agrícolas y forestación).

(2) Evaluar, mediante modelos numéricos, el impacto de forestación sobre los flujos de agua en el suelo, y su dependencia con las características edáficas e hidrológicas del sitio.

(3) Evaluar, mediante modelación numérica, potenciales escenarios de evolución hidroquímica de sistemas salinizados. 


\subsection{Hipótesis de trabajo}

A los efectos de establecer una guía se formularon hipótesis para cada uno de los objetivos específicos.

(1) La ocurrencia del proceso de salinización secundaria derivado de la forestación de pastizales de la región Pampeana Argentina es controlada por las características del ambiente, las especies forestales utilizadas y el manejo de la plantación.

(2) El efecto de la forestación de pastizales sobre los flujos hídricos depende de las características edáficas e hidrológicas del sitio.

(3) La evolución de los cambios químicos provocados por la forestación de pastizales depende de una serie de procesos hidroquímicos que actúan conjuntamente e interactúan entre sí.

\subsection{Estructura de la Tesis}

Sobre la base de estos objetivos, esta tesis se desarrolló partiendo de la conceptualización de la temática descrita en el Capítulo 1, donde se plantea la situación actual del reemplazo de los pastizales por forestaciones, y se enuncian los modelos conceptuales vigentes.

Dentro de este marco, en el Capítulo 2 se aborda el Objetivo específico (1) con un análisis regional donde se relevaron numerosas situaciones de pastizales forestados en la región (Figura 1-2). Sobre la base de estos, se buscaron relaciones entre la ocurrencia de los procesos de salinización en suelos con las características del sitio y de la forestación (i.e., balance hídrico, posición en el paisaje, textura del suelo/acuífero, profundidad del nivel freático, especie forestal y manejo, entre otras). 
Dentro de los principales procesos físicos e hidrogeoquímicos que controlan la salinización secundaria de suelos, en el Capítulo 3 se aborda el Objetivo específico (2), explorando el impacto sobre los procesos de salinización de la presencia de horizontes petrocálcicos (también conocido como "tosca"), una característica muy extendida en la región pampeana. Comúnmente los sitios con la presencia subsuperficial de estas capas, o la presencia de basamento cristalino (e.g., en la Pampa Interserrana), son consideradas como áreas marginales a la actividad agrícola. Por este motivo, estas áreas son propensas a ser utilizadas para la forestación.

Sumado a esto, su impacto sobre los flujos de agua no ha sido lo suficientemente estudiado con lo cual existe cierta incertidumbre sobre la potencial salinización secundaria de estos sistemas. Para esto se presenta una metodología basada en la instalación de sensores de medición del contenido de agua en suelo que se basan en el principio de la reflectometría de dominio temporal (TDR por su nombre en inglés), medición de flujo de savia (E. viminalis), medición de variables hidrológicas, exploración geoeléctrica, y modelación numérica de flujo de agua y energía.

En el Capítulo 4 se evalúa el impacto de la forestación (E. camaldulensis) sobre los flujos y la hidroquímica de los suelos por medio de la modelación del TR en un ambiente de llanura sin restricciones edáficas (e.g, sin la presencia de tosca). En este sentido, se evalúan las características químicas del suelo y del acuífero freático a lo largo de una transecta que incluye pastizal, margen y centro de la forestación. 
Finalmente se analizan en conjunto los diferentes aspectos discutidos en cada uno de los anteriores capítulos para elaborar las conclusiones finales de la tesis (Capítulo 5). 


\section{Capítulo 2}

Impacto de la forestación de pastizales en la Llanura Pampeana. (*)

* El presente capítulo se basa parcialmente en: Milione, G.M., Mujica, C.M., Bea, S.A., Domínguez Daguer, D., Gyenge, J.E., 2019. Forestación en pastizales: el rol de las especies y el manejo forestal sobre el proceso de salinización secundaria de suelos. RIA (en prensa), 1-13.

Además, parte de los datos de campo también fueron analizados en la tesis: Milione, G. M. (2019). Salinización y otros cambios hidrogeoquímicos asociados a distintos usos del suelo en la Región Centro-Sur bonaerense, Argentina. (Doctoral Dissertation, Universidad Nacional de La Plata). 


\subsection{Introducción}

La salinización secundaria de suelos desencadenada por la forestación de pastizales es compleja de caracterizar, principalmente por las interacciones entre los procesos involucrados. Este fenómeno ha sido ampliamente observado tanto en nuestro país como en el resto del mundo, y responde a una serie de modelos conceptuales que dependen de factores ambientales, antrópicos y ecofisiológicos de las especies vegetales involucradas (Nosetto et al., 2008; Jobbágy y Jackson, 2004a, 2007; George et al., 1999; Heuperman, 1999).

Gran parte de los pastizales Pampeanos tienen la presencia de un nivel freático somero que se origina por las características del relieve poco drenado y por un régimen hídrico que genera excedentes y que, en su mayoría, se eliminan por evapotranspiración (Varni y Usunoff, 1999; Lavado y Taboada, 1988). Las características hidrológicas de los sistemas de llanuras provocan recurrentes inundaciones, formación de cubetas y encharcamientos, lo cual genera una acumulación y redistribución de solutos. De acuerdo al grado de permanencia y el nivel dentro del perfil de suelo de estas acumulaciones de excedentes hídricos, se pueden generar desde la formación de rasgos hidro-halomórficos (comúnmente en los horizontes más superficiales), hasta salinización y alcalinización (normalmente en horizontes profundos o en zonas de larga permanencia de agua en superficie, i.e., "bajos/cubetas", ver Figura 2-1 ; Lavado y Taboada, 1988). 


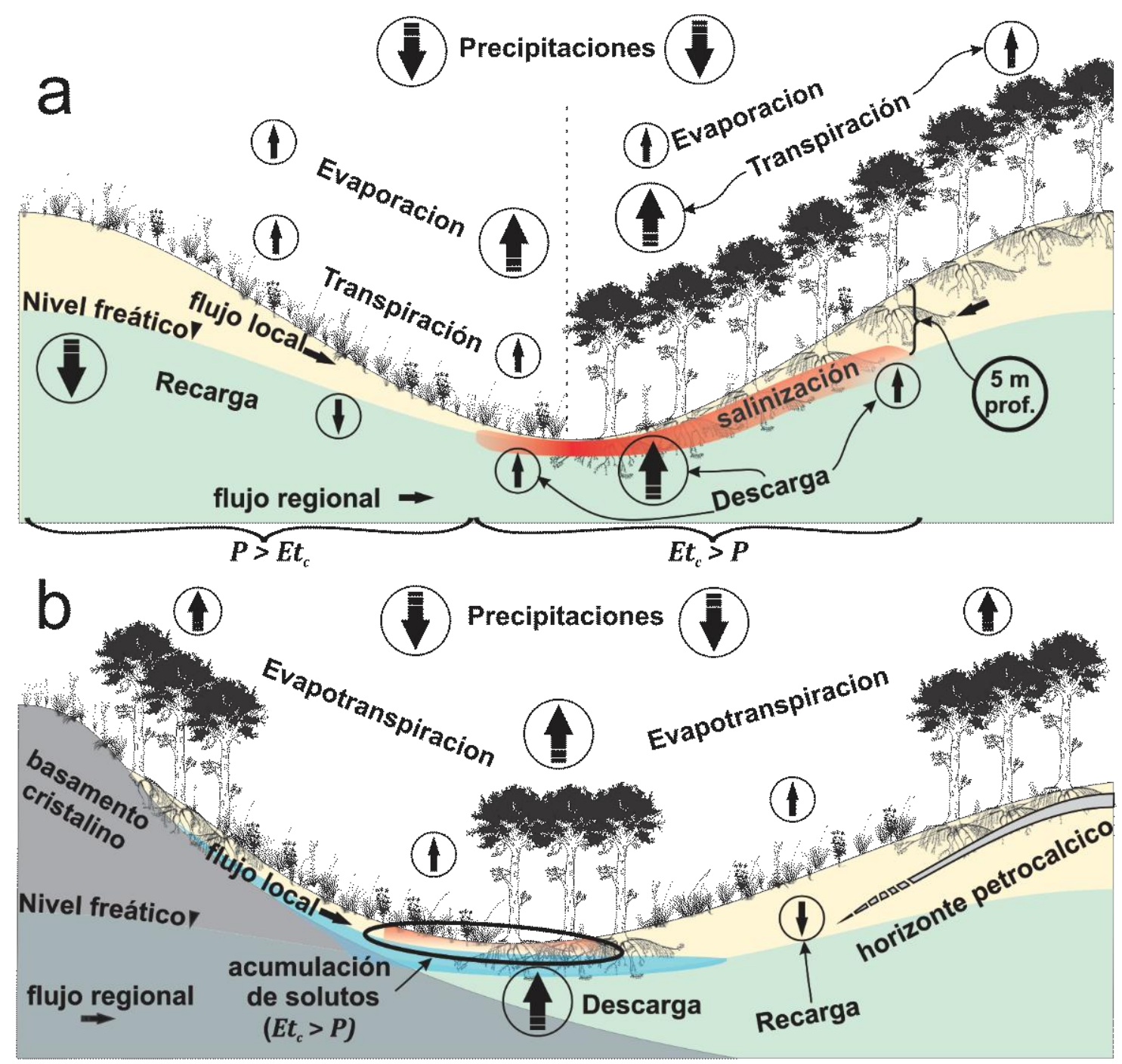

C

(1) Procipitaciones (\$)

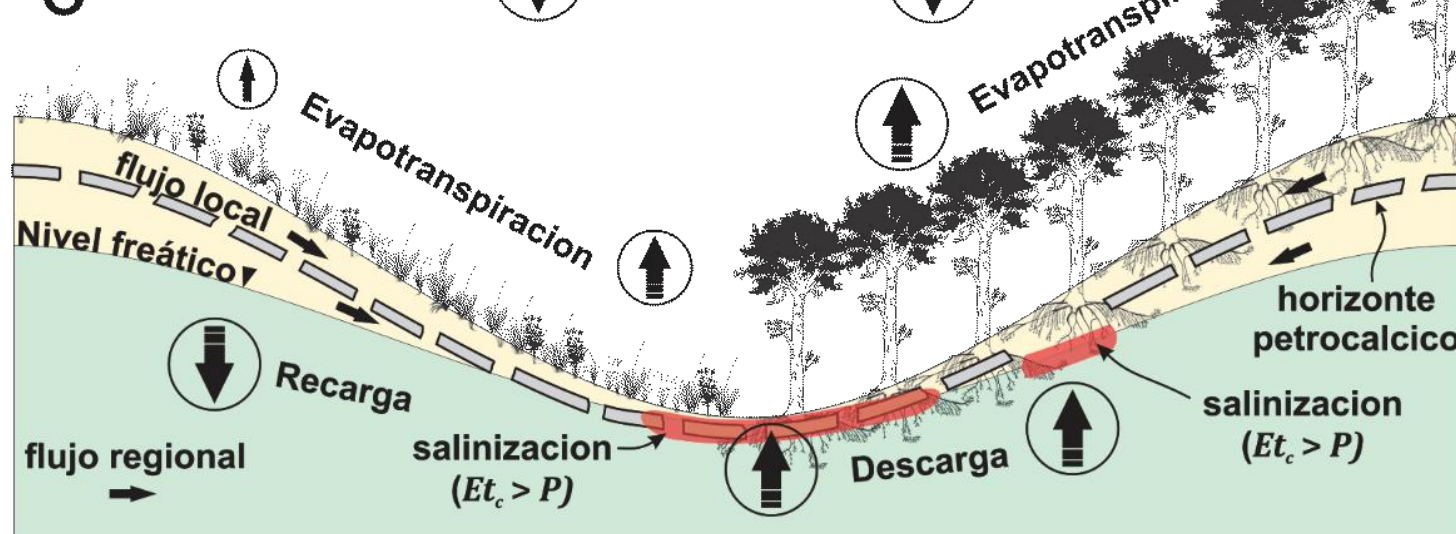

Figura 2-1. Representación esquemática de los principales flujos y patrones de salinización en (a) Pampa interior y ondulada (modificado de Nosetto et al., 2013), (b) Pampa austral y (c) Pampa Deprimida. En sitios de cobertura herbácea, el balance hídrico es positivo $\left(P>E T_{c}\right)$, lo que lleva a recargar los flujos que mantienen los suelos con baja salinidad. En las plantaciones de árboles y sitios conocidos como 'bajos', el balance hídrico es negativo $\left(E T_{c}>P\right)$, lo que genera una descarga. La captación de agua subterránea y la 
exclusión de la sal por las raíces de los árboles conducen a la salinización del ecosistema (zona sombreada en roja).

En este contexto, existe un consenso general de que el acceso de la forestación al acuífero freático sería uno de los principales factores ambientales para que se desencadene el proceso de salinización (Figura 2-1; Heuperman, 1999; Jobbágy y Jackson, 2003; Nosetto et al., 2013, 2008, 2007). Sin embargo, esto por sí mismo no es determinante, dado que para generar la acumulación de sales son necesarias otras condiciones.

\subsubsection{Factores ambientales}

El balance hídrico $(\mathrm{BH})$ que se establece con la plantación de la forestación (entradas-salidas de agua) determinará la proporción de agua subterránea que será consumida por esta, si tiene acceso a la misma (Figura 2-1). Los BH más negativos son aquellos que generarían un mayor consumo de agua del acuífero freático por parte de la forestación, y serían estos casos los más propensos a generar procesos de salinización. Nosetto et al., (2008) halló que el mayor riesgo de salinización en la región Pampeana se da cuando las forestaciones se establecieron en sitios donde el BH anual es de $\sim 100 \mathrm{~mm}$ año-

${ }^{1}$ y estas satisfacen entre el 40 y el $80 \%$ de sus demandas transpiratorias con agua del acuífero freático. Por debajo de este umbral, los suelos de las plantaciones duplicaron su conductividad eléctrica con respecto los suelos de los pastizales (e.g., 2,340 y $1,140 \mu \mathrm{S} \mathrm{cm}^{-1}$, para el caso de la forestación y pastizal respectivamente), mientras que no se observaron diferencias por encima de este umbral ( 340 y $390 \mu \mathrm{S} \mathrm{cm} \mathrm{cm}^{-1}$, respectivamente).

Otro factor que influye en la ocurrencia de los procesos de salinización secundaria de suelos, es su textura. Según las observaciones de Jobbágy y Jackson, (2004) y Nosetto et al. (2008), aquellos suelos que presentan texturas 
intermedias a gruesas (i.e., francos a franco-arenosos) al ser más transmisivos desde el punto de vista hidráulico, favorecen el consumo de agua por parte de las forestaciones y la ocurrencia de los procesos de salinización. En cambio, los sitios con sustratos de texturas finas (i.e., arcillosos) pueden restringir este consumo de agua freática por su menor capacidad de conducción, reduciendo así el riesgo de salinización (Nosetto et al., 2008).

Cuando se dan las condiciones propicias, debajo de las forestaciones se genera una zona de acumulación de sales muy similar a aquella que naturalmente ocurre en los sectores más bajos de la cuenca, como se ha mencionado anteriormente (Jobbágy et al., 2017; Lavado y Taboada, 1988). Sin embargo, los pastizales forestados han mostrado ser capaces de alcanzar niveles más altos de salinidad que los naturales de las zonas bajas y en áreas donde previamente no se había observado acumulación de sales (Jobbágy y Jackson, 2004a).

Comparando las profundidades del nivel freático en parcelas forestadas con su salinidad, Nosetto et al. (2013, Pampa Interior) hallaron una correlación entre estas dos variables y además influenciadas por la topografía. Es decir que, cuando el nivel freático estaba posicionado a menores profundidades (e.g., $\sim 2 \mathrm{~m}$ ), generalmente en las partes más bajas de la topografía, el proceso de salinización desencadenado por la forestación fue más intenso (Figura 2-1 a). Cuando el nivel se encontraba entre 3.5 y 5.5 m de profundidad se observó una acumulación de sales hasta 8 veces la observada en el pastizal, con un acuífero freático 7 veces más salino. De estos hallazgos se puede deducir la gran importancia de considerar la hidrología del sitio a escala de parcela y la geomorfología (Nosetto et al., 2013). 
En general, las cabeceras de las cuencas hidrológicas presentan un acuífero freático más profundo, menos salino y materiales con mayores conductividades hidráulicas (Zabala et al., 2016a, 2016b; Varni y Usunoff, 1999; Sala et al., 1987). En cambio, hacia las zonas de descarga de estas cuencas, el acuífero freático incrementa naturalmente su carga de solutos (i.e., su salinidad), a la vez que se vuelve más somero con materiales menos transmisivos. En este sentido, el riesgo de salinización causada por la forestación de pastizales (o de áreas de cultivos agrícola) incrementaría desde las cabeceras de estas cuencas hacia la los sectores de descarga de las mismas.

Por otro lado, también es relevante considerar la presencia de horizontes en el perfil del suelo que dificultan la infiltración de agua y la penetración de las raíces, como lo son horizontes argílicos y petrocálcicos (Mujica y Bea, 2020; Mujica et al., 2019a, 2019b; Pazos y Mestelan, 2002) o roca. La presencia de estos horizontes podrían dificultar el acceso de la forestación al acuífero freático o el flujo del agua hacia la rizósfera, limitando así la acumulación de sales en el sistema (Mujica et al., 2019a, 2019b; Dietrich et al., 2014; Jobbágy and Jackson, 2004a; Shreve and Mallery, 1933).

\subsubsection{Factores ecofisiológicos de la forestación}

Además de estos factores ambientales, ciertas características ecofisiológicas de las especies forestales utilizadas también han sido identificados como controladores del riesgo de salinización (más allá de sus grandes diferencias con la vegetación herbácea que reemplazan). La intensidad de la salinización es proporcional a la capacidad de transpirar agua de las forestaciones. Por lo tanto, todas aquellas características ecofisiológicas que diferencien a las especies forestales en este aspecto, afectarán también en la 
ocurrencia e intensidad del proceso. Una de estas características es la capacidad de crecimiento de la especie, siendo las de rápido crecimiento (y en general alta productividad) las que generarían mayor riesgo por tener la capacidad de consumir más agua (Nosetto et al. 2008, 2012). Por ejemplo, especies de rápido crecimiento como E. viminalis (35-40 $\mathrm{m}^{3} \mathrm{ha}^{-1} \mathrm{año}^{-1}$, Ferrere et al., 2008), tendría un mayor impacto que Pinus radiata $\left(15 \mathrm{~m}^{3} \mathrm{ha}^{-1} \mathrm{año}^{-1}\right.$, Ferrere et al., 2015).

Además de la capacidad productiva de la especie, la capacidad para interceptar el agua de lluvia es otro factor relacionado con las características de las especies que podría influir en el proceso. Esta característica afecta la cantidad de agua de lluvia que entra en el sistema, que se traduce en una salida de agua extra además de la consumida propiamente por las raíces. Por ejemplo, Besteiro (2014), midió el doble de volumen de agua interceptada por los pinos que en eucaliptos (20.3 y $9.5 \%$, respectivamente). Esto a su vez está relacionado con la proporción de escurrimiento a través del fuste del árbol y con la redistribución de la lluvia que se trascola a través del dosel, afectando la infiltración y el escurrimiento superficial de agua (Besteiro, 2014).

Otro aspecto a considerar, entre las especies forestales, es si se trata de una especie caduca o perenne. Si bien el consumo total de agua podría no necesariamente estar restringido a este aspecto, es importante tener en cuenta su efecto en la dinámica hídrica. Las especies caducas presentan un periodo sin consumo de agua lo que permitiría el lavado de las eventuales sales acumuladas (Jobbagy et al., 2008; Nosetto et al., 2008). Esto podría ser favorecido a su vez por el aumento en la porosidad del suelo y el control sobre el crecimiento de vegetación en el sotobosque (Nosetto et al., 2008; Alvarez, 2006). 
Por otro lado, la intensidad y el riesgo de salinización también estará determinada por la capacidad para tolerar distintos niveles de salinidad de las distintas especies forestales (e.g., E. camaldulensis tolera $\sim 40 \mathrm{dS} \mathrm{m}^{-1}$ y Cedrus deodara 2.8 dS m-1; Donaldson et al., 1983; Wu et al., 2001). Así, las especies tolerantes a la salinidad serán capaces de mantener ciertas tasas de transpiración aun con altas concentraciones de sales acumuladas (o preexistentes), lo cual desencadena una mayor salinización y degradación de suelos (Nosetto et al., 2008, 2013).

Además, se pueden mencionar otros factores relacionados con la ecofisiología de la especie forestal como: (1) sus requerimientos nutricionales, (2) las interacciones simbióticas con microorganismos del suelo, (3) sus estrategias particulares de exudación y toma de nutrientes del suelo, y (4) la composición de la hojarasca (Lambers et al., 2008b; Nosetto et al., 2008; Jobbágy y Jackson, 2007; Ae et al., 2001; Nye, 1981). Algunos de estos últimos aspectos serán abordados en los siguientes capítulos.

\subsubsection{Factores relacionados con el manejo de la plantación forestal}

Además de la especie de que se trate y de sus características ecofisiológicas, el manejo y las prácticas que se apliquen sobre la forestación tienen un gran impacto sobre el riesgo de salinización. Aquel conjunto de prácticas que maximicen el consumo de agua por parte de la forestación (e.g., fertilización, plantación en altas densidades, riego, etc.) conllevarán un mayor consumo de agua, y por lo tanto un mayor riesgo de salinización (Hubbard et al., 2004, 2010; Gyenge et al., 2008; Nosetto et al., 2008).

Dentro de la región de estudio, además de plantaciones con un aprovechamiento comercial de la producción, existen otras que, alcanzados los 
turnos de corta, permanecen así indefinidamente, sin aprovechamiento. Además, en muchos de estos casos no se les aplicó ninguna práctica de manejo (o solo se aplicó en los primeros años; Jobbágy y Jackson, 2007, 2004a). Este último caso sería el que eleva el riesgo de salinización del suelo ya que se alcanza una ocupación plena del sitio, y se mantiene así indefinidamente alcanzando los niveles máximos de salinización observada.

En cambio, en el caso de que tengan lugar prácticas de raleo y/o tala rasa se producirían ciclos de bajo consumo de agua, y por lo tanto de lavado de sales que revertirían en parte los procesos de salinización (Milione, 2019). Del mismo modo se esperaría que en los sistemas forestales con menor cobertura, como los silvopastoriles, el riesgo de salinización también sea menor. En este sentido, Heuperman (1999) propone un manejo en 'plantaciones ambulatorias' o 'walking plantations' para evitar el efecto negativo de la acumulación de sales sobre el suelo que dejaría el esquema de plantación permanente.

Teniendo en cuenta la gran cantidad de factores que influyen en el proceso de salinización secundaria causada por la forestación de pastizales, el objetivo de este capítulo es evaluar los más influyentes en un conjunto de ambientes de la región Pampeana.

\subsection{Métodos}

Para evaluar distintas situaciones de pastizales forestados, se analizaron (34) sitios en las subregiones de la Pampa deprimida, Pampa austral (o interserrana), y Pampa Interior Occidental (Tabla 2.1 y Figura 2-2). En cada uno de estos sitios se delimitaron una parcela forestal y una con vegetación herbácea (cultivos, pasturas y pastizales). En cada parcela se extrajeron muestras de suelo mediante barreno helicoidal, en intervalos de $20 \mathrm{~cm}$ hasta la profundidad máxima 
del perfil de suelo (en muchos casos interrumpido por un horizonte petrocálcico) o hasta los $200 \mathrm{~cm}(\mathrm{n}=5)$. Cada una de estas muestras de suelo se secó al aire durante 7 días, se pasó por un tamiz de $2 \mathrm{~mm}$ de abertura, se prepararon extractos con una relación 1:2.5 (suelo:agua destilada), se agitó a mano durante un minuto y se dejó reposar durante una hora. Finalmente, en el sobrenadante se midió la conductividad eléctrica $\left(E C_{1: 2.5}\right)$ y el $\mathrm{pH}$ usando un lector OAKTON PC700 con sonda de pH Cole-Palmer 05992-62 y sonda de CE-temperatura 35608-74, con corrección automática por temperatura. Además a cada muestra se determinó la textura aplicando el método de Bouyoucos (Bouyoucos, 1936, 1962).

En cada una de las parcelas forestales, a su vez, se delimitaron parcelas menores de 10 y 30 m de diámetro, cuando la distribución de árboles era irregular, o de 4 filas de 10 árboles, cuando la distribución era regular. En cada una de estas parcelas menores se midió el diámetro a la altura del pecho (DAP, $\mathrm{cm}$ ) con cinta diamétrica, de todos los árboles vivos y la altura de los árboles dominantes $(\mathrm{H}, \mathrm{m})$ mediante clinómetro Suunto PM-5/360PC (Suunto, Finlandia). Se consideró como pie individual a todos aquellos fustes mayores de $3 \mathrm{~cm}$ de diámetro. Con estos datos se estimó la densidad (árboles ha-1), y área basal $(A B$, $\left.\mathrm{m}^{2} \mathrm{ha}^{-1}\right)$. La cobertura forestal se estimó a partir del análisis de fotografías mediante el programa ImageJ v.1.48 (Wayne Rasband, National Institutes of Health, EEUU). La edad de las forestaciones se obtuvo vía comunicación personal con los propietarios/encargados de los establecimientos. En los casos donde esta era desconocida se estimó mediante la observación de series temporales de imágenes satelitales mediante Google Earth (Google Earth v.7.3.2.5776). 
Además de los sitios relevados en la presente tesis, se incluyeron en el análisis 6 sitios ( $\mathrm{CH}$, TA0, PM, CT, AM y GR, ver Tabla 2.1 y Figura 2-2) analizados en trabajos previos (Jobbágy y Jackson, 2003, 2004a, 2004b, 2007).

Se aplicó el análisis ANOVA para determinar diferencias estadísticas en la salinidad del suelo en cada par de parcelas y para cada intervalo de profundidades muestreadas (se utilizó el software SPSS versión 24). Además, se hizo un análisis de correlación entre la magnitud de la salinización (en los sitios donde se pudo constatar) y las otras variables medidas (e.g., edad de la forestación, grado de ocupación del sitio forestal, posición en el terreno, textura del suelo, manejo y especie forestal). 
Tabla 2.1. Parcelas muestreadas, resumen de sus principales características.

\begin{tabular}{|c|c|c|c|c|c|c|c|c|c|}
\hline Sitio & $\begin{array}{c}\text { Posición } \\
\text { en el } \\
\text { paisaje }\end{array}$ & Textura & $\begin{array}{l}\text { Cob. } \\
\text { Forestal }\end{array}$ & $\begin{array}{c}\% \\
\text { Cob. }\end{array}$ & $\begin{array}{l}\text { Edad } \\
\text { (años } \\
\text { ) }\end{array}$ & $\begin{array}{c}E C_{1: 2.5} \\
\text { forestal } \\
(\mu \mathrm{S} / \mathrm{cm})\end{array}$ & $\begin{array}{l}\text { Cob. } \\
\text { Herbá- } \\
\text { cea }\end{array}$ & $\begin{array}{c}E C_{1: 2.5} \\
\text { herbácea } \\
(\mu \mathrm{S} / \mathrm{cm})\end{array}$ & $\begin{array}{c}\text { Relación } \\
E C_{1: 2.5} \\
\mathrm{~F}: \mathrm{H}\end{array}$ \\
\hline $\mathrm{CH}$ & $\mathrm{L}$ & $\mathrm{CL}$ & EC & - & 46 & 108.54 & PAS & 246.21 & 0.44 \\
\hline AZ2 & L & FC & EV & 66.62 & 16 & 87.32 & PN & 158.24 & 0.55 \\
\hline BA2 & $\mathrm{L}$ & C & EG & 62.07 & 17 & 116.76 & $\mathrm{~s}$ & 164.64 & 0.71 \\
\hline GU2 & $\mathrm{L}$ & FAR & EV & 43.78 & 6 & 60.30 & G & 83.46 & 0.72 \\
\hline BA1 & $\mathrm{L}$ & $\mathrm{F}$ & EG & 50.01 & 19 & 104.08 & PN & 142.80 & 0.73 \\
\hline GU1 & $\mathrm{L}$ & FC & EV & 60.91 & 16 & 83.32 & $\mathrm{M}$ & 103.16 & 0.81 \\
\hline GU5 & L & $A R$ & EV & 34.31 & 8 & 54.26 & PN & 65.38 & 0.83 \\
\hline GU4 & $\mathrm{L}$ & FAR & EV & 31.01 & 6 & 52.52 & $\mathrm{PN}$ & 60.70 & 0.87 \\
\hline TA9 & C & FC & TR & 0.00 & 28 & 65.08 & PN & 71.80 & 0.91 \\
\hline TA7 & C & FC & PR & 19.90 & 28 & 143.04 & PN & 150.66 & 0.95 \\
\hline TA8 & C & FC & PR & 11.20 & 28 & 163.86 & A & 150.66 & 1.0 \\
\hline TA4 & C & FC & PR & 71.60 & 28 & 164.72 & A & 150.66 & 1.0 \\
\hline TAO & C & FC & EC & - & 50 & 40.36 & PN & 35.37 & 1.14 \\
\hline TA5 & C & FC & PR & 67.10 & 28 & 87.52 & PN & 71.80 & 1.22 \\
\hline TA1 & C & FC & ED & 60.80 & 28 & 188.16 & A & 150.66 & 1.25 \\
\hline TA2 & C & FC & EV & 49.20 & 28 & 104.42 & PN & 71.80 & 1.45 \\
\hline GU6 & B & FAR & EV & 49.71 & 17 & 89.85 & PN & 59.90 & 1.5 \\
\hline TA3 & C & FC & EV & 57.10 & 28 & 107.94 & PN & 71.80 & 1.5 \\
\hline AZ4 & $\mathrm{L}$ & FC & EV & 68.14 & 33 & 187.92 & $\mathrm{M}$ & 121.72 & 1.54 \\
\hline PM & D & $A R$ & EC & - & 30 & 279.59 & PN & 171.77 & 1.63 \\
\hline AZ3 & M & FC & EC & 61.00 & 33 & 267.84 & PN & 148.86 & 1.8 \\
\hline AZ1 & $M$ & FC & EV & 60.63 & 16 & 321.92 & PN & 158.24 & 2.03 \\
\hline AZ5 & $M$ & FC & EV & 55.35 & 33 & 256.86 & $\mathrm{~S}$ & 126.00 & 2.04 \\
\hline GU3 & $\mathrm{M}$ & $A R$ & EV & 53.28 & 54 & 145.24 & PN & 68.22 & 2.13 \\
\hline TA6 & C & FC & PR & 76.30 & 28 & 193.68 & PN & 71.80 & 2.7 \\
\hline AZ7 & L & $\mathrm{F}$ & EC & 57.07 & 33 & 358.40 & PC & 112.60 & 3.18 \\
\hline AZ6 & B & FC & EC & 51.97 & 94 & 1189.80 & PN & 333.00 & 3.57 \\
\hline $\mathrm{PI3}$ & B & $\mathrm{F}$ & EV & 44.50 & 44 & 755.00 & PN & 208.90 & 3.61 \\
\hline CT & $M$ & $\mathrm{FL}$ & EC & - & 52 & 918.35 & PN & 197.02 & 4.66 \\
\hline $\mathrm{Pl} 2$ & B & $\mathrm{F}$ & EC & 62.80 & 44 & 1234.60 & PN & 208.90 & 5.91 \\
\hline $\mathrm{PI} 4$ & B & $\mathrm{F}$ & EV & 44.60 & 44 & 1299.00 & PN & 208.90 & 6.22 \\
\hline PI1 & B & $\mathrm{F}$ & $\mathrm{EC}$ & 54.50 & 44 & 1552.20 & PN & 208.90 & 7.43 \\
\hline BA3 & B & FC & EG & 35.18 & 33 & 1692.67 & $\mathrm{~s}$ & 179.75 & 9.42 \\
\hline AM & $M$ & $\mathrm{FL}$ & EC & - & 42 & 810.37 & PAS & 56.16 & 14.43 \\
\hline $\mathrm{GR}$ & $M$ & $\mathrm{FL}$ & EC & - & 95 & 1208.16 & PN & 64.94 & 18.6 \\
\hline
\end{tabular}

Las primeras dos letras de cada sitio indican la localidad donde está emplazado: Azul (AZ); Balcarce (BA); Guaminí (GU); Tandil (TA); Pinamar (PM); Pila (PI); Chascomús (CH); Castelli (CT); América (AM) y Guerrero (GR). Coberturas arbóreas: Eucalyptus globulus (EG); $E$. viminalis (EV); E. camaldulensis (EC); E. dalrympeana (ED); Pinus radiata (PR); sitio talado (TR). Coberturas herbáceas: pastizal natural (PN); pastura de avena (A); cultivo de maíz (M); cultivo de girasol (G); pastura cortada (PC); cultivo de soja (S); pastura bajo pastoreo (PAS). Clases texturales: Arcillo-limoso (CL); Franco arcilloso (FC); Arcilloso (C); Franco-arenoso $(F A R)$; Franco $(F)$; Arenoso (AR); Franco- limoso (FL). Posición topográfica: Loma (L); Media loma (M); Bajo (B); Ladera de cerro (C); Ladera de duna (D).

$E C_{1: 2.5}$ representa la conductividad eléctrica $(\mu \mathrm{S} / \mathrm{cm})$ del suelo en la profundidad donde se hallaron mayores diferencias entre el pastizal y la forestación. 


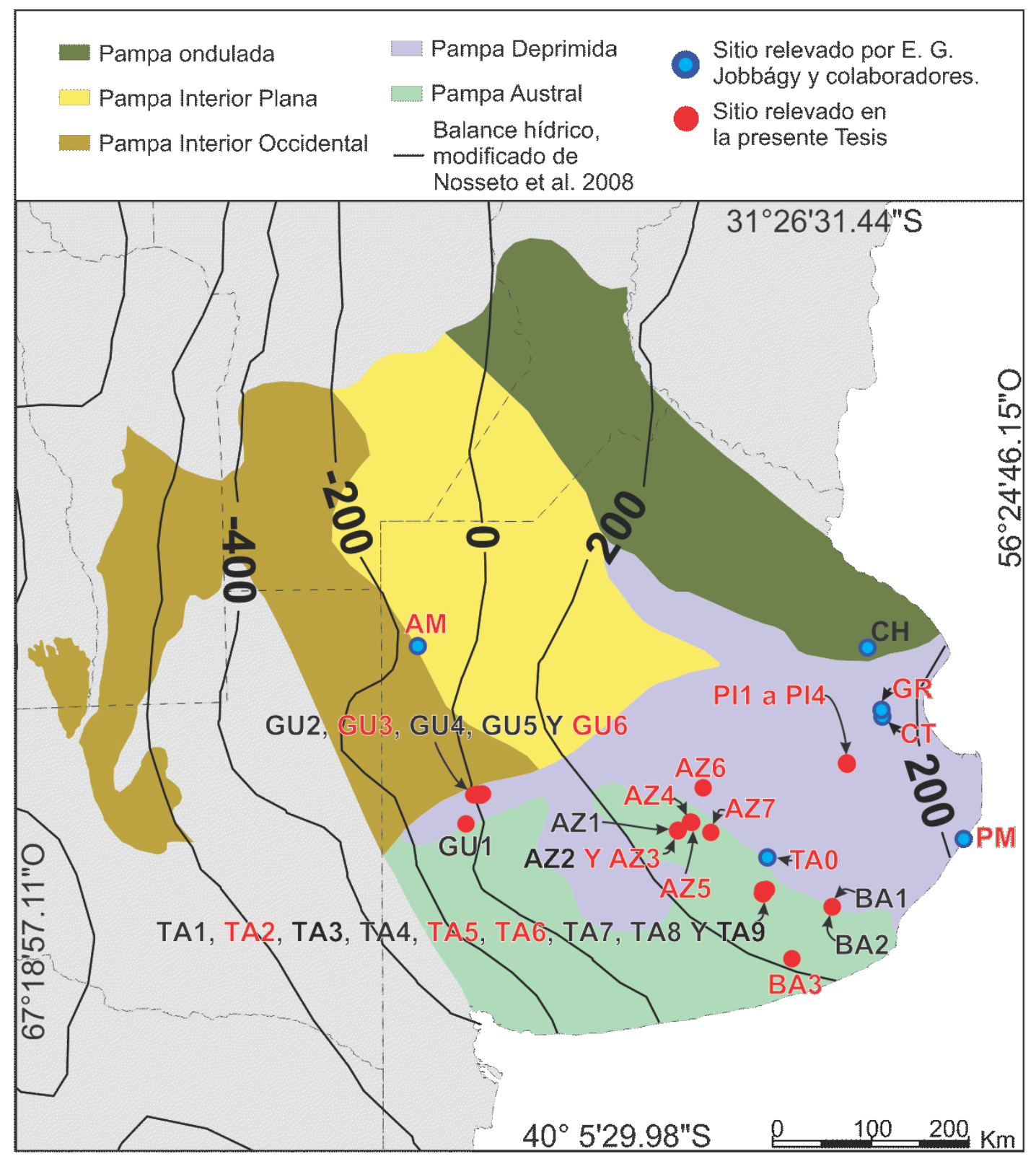

Figura 2-2. Ubicación de los sitios incluidos en el análisis de este capítulo. Los círculos azules corresponden con sitios muestreados por E. G. Jobbágy y sus colaboradores (Jobbágy y Jackson, 2003, 2004a, 2004b, 2007). Los sitios etiquetados en color rojo presentaron diferencias ( $<<0.05$ ) en $E C_{1: 2,5}$ a favor de la forestación. Las líneas negras corresponden con los balances hídricos anuales calculados por Nosetto et al. (2008).

\subsection{Resultados y discusión}

Tal como lo predice el modelo conceptual se pudieron hallar situaciones donde el reemplazo del pastizal por forestación generó acumulación de sales en el perfil del suelo. El rango de acumulación de sales va desde $\sim 18$ veces hasta sitios donde no hubo acumulación, o incluso donde la acumulación de sales fue menor que en la parcela herbácea adyacente (ver Tabla 2.1). 
La interacción entre los distintos factores característicos de cada sitio hace que sea imposible encontrar tendencias que engloben el total de los ambientes muestreados al observar una sola variable a la vez. Debido a esto, el análisis se llevó a cabo agrupando aquellos sitios que presentan ciertas características en común. En aquellas zonas donde alguno de estos factores no es favorable para que se dé el proceso de salinización, el mismo podría generar una interpretación incorrecta de los restantes.

En base a esto, una primera agrupación fue entre aquellos sitios que no presentaban acumulación de sales debajo de la forestación en ninguno de los intervalos de profundidad muestreados (ya sea porque no presentaban diferencias $(\mathrm{P}<0.05)$ en la variable $E C_{1: 2.5}$, o cuando esta diferencia era en favor de la parcela herbácea), y aquellos que sí la presentaban al menos en alguno. Dentro del primer grupo, se encontró que en su totalidad se localizaban en una posición topográfica relativa elevada respecto del terreno circundante (i.e., no estarían recibiendo agua por escurrimiento o subterránea de otras zonas), y/o sugerían la presencia de algún impedimento físico para que la forestación accediese al acuífero freático. Esto último ya sea porque el sitio se localizaba: (1) sobre la ladera de un cerro con suelos someros sobre basamento cristalino (ver TA4, TA7, TA8 y TA9 en Figura 2-2 y Figura 2-3), (2) en lomas con presencia de horizontes petrocálcicos (ver AZ2, BA1, BA2 y CH en Figura 2-2 y Figura 2-3), o (3) en la cresta de dunas con niveles freáticos muy profundos (ver GU1, GU2, GU4 y GU5 en Figura 2-2 y Figura 2-3).

El segundo grupo incluye a los sitios que sí presentaron salinización en al menos una profundidad del suelo. Si bien algunas de las características anteriormente favorables al proceso de salinización no estaban presentes, las 
forestaciones podían acceder a fuentes de agua provenientes desde fuera del propio rodal. Es decir, de origen freático y/o porque recibe agua del terreno circundante por estar en una posición topográfica más baja. De hecho, los sitios con mayor acumulación de sales respecto de la parcela herbácea ( $>3$ veces, ver AM, AZ6, BA3, CT, PI1, PI2, PI3, PI4, y GR en Tabla 2.1 y Figura 2-4), presentaron esta característica en común. Esto último sugiere el un predominio del control topográfico en la acumulación de sales debajo de la forestación (Figura 2-5), tal como lo observó Nosetto et al., (2013, Figura 2-1). 

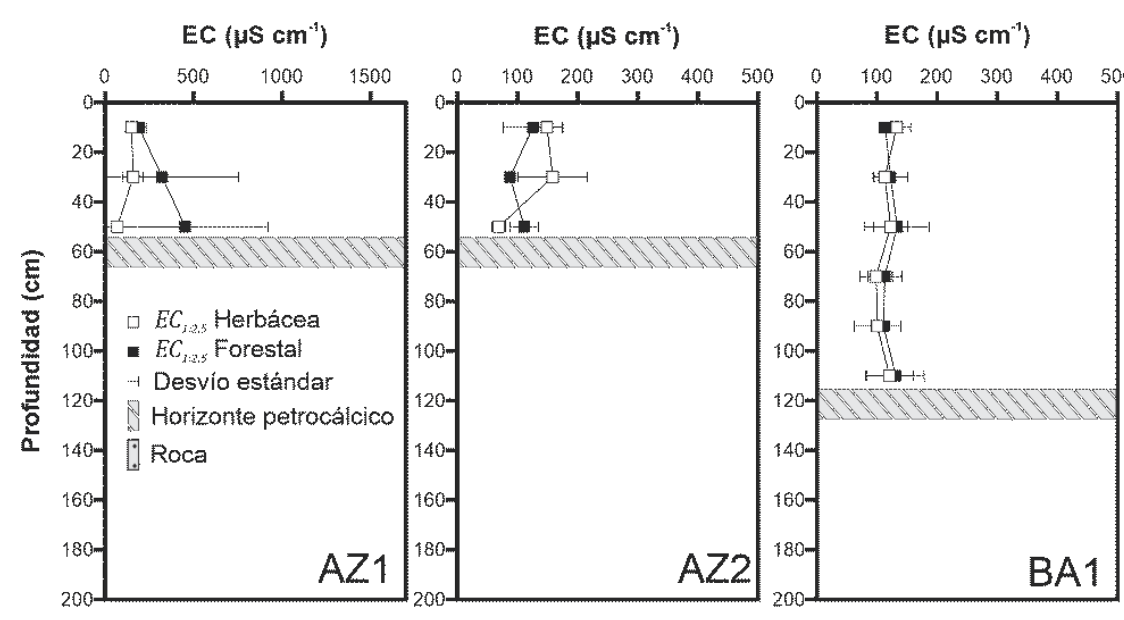

$E C\left(\mu S \mathrm{~cm}^{-1}\right)$
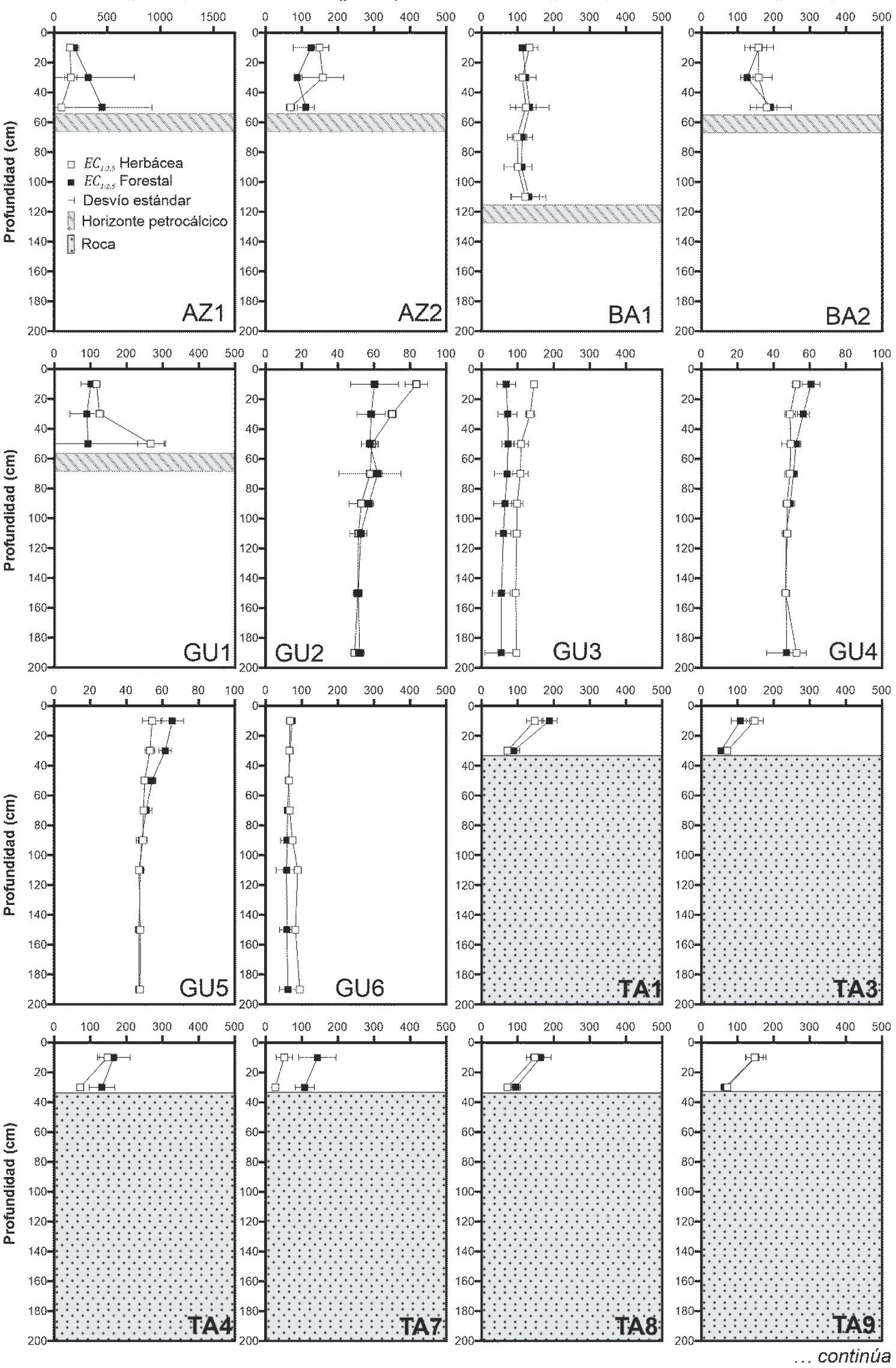


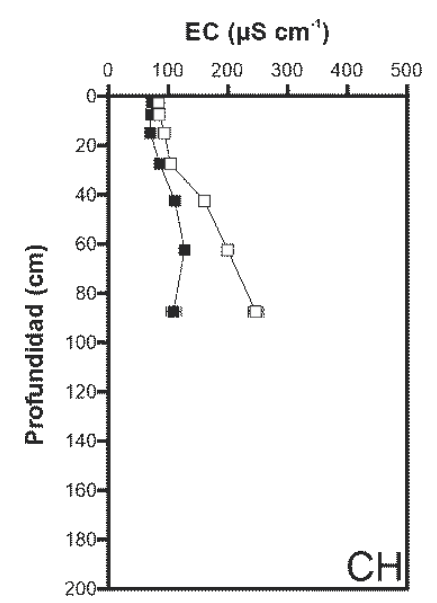

Figura 2-3. Conductividad eléctrica del suelo $\left(E C_{1: 2.5}\right)$ en sitios donde no se encontraron diferencias o donde la $E C_{1: 2.5}$ fue mayor en la parcela herbácea. Los cuadrados blancos corresponden con la parcela herbácea y los negros con la forestal. las líneas horizontales indican el desvió estándar. 

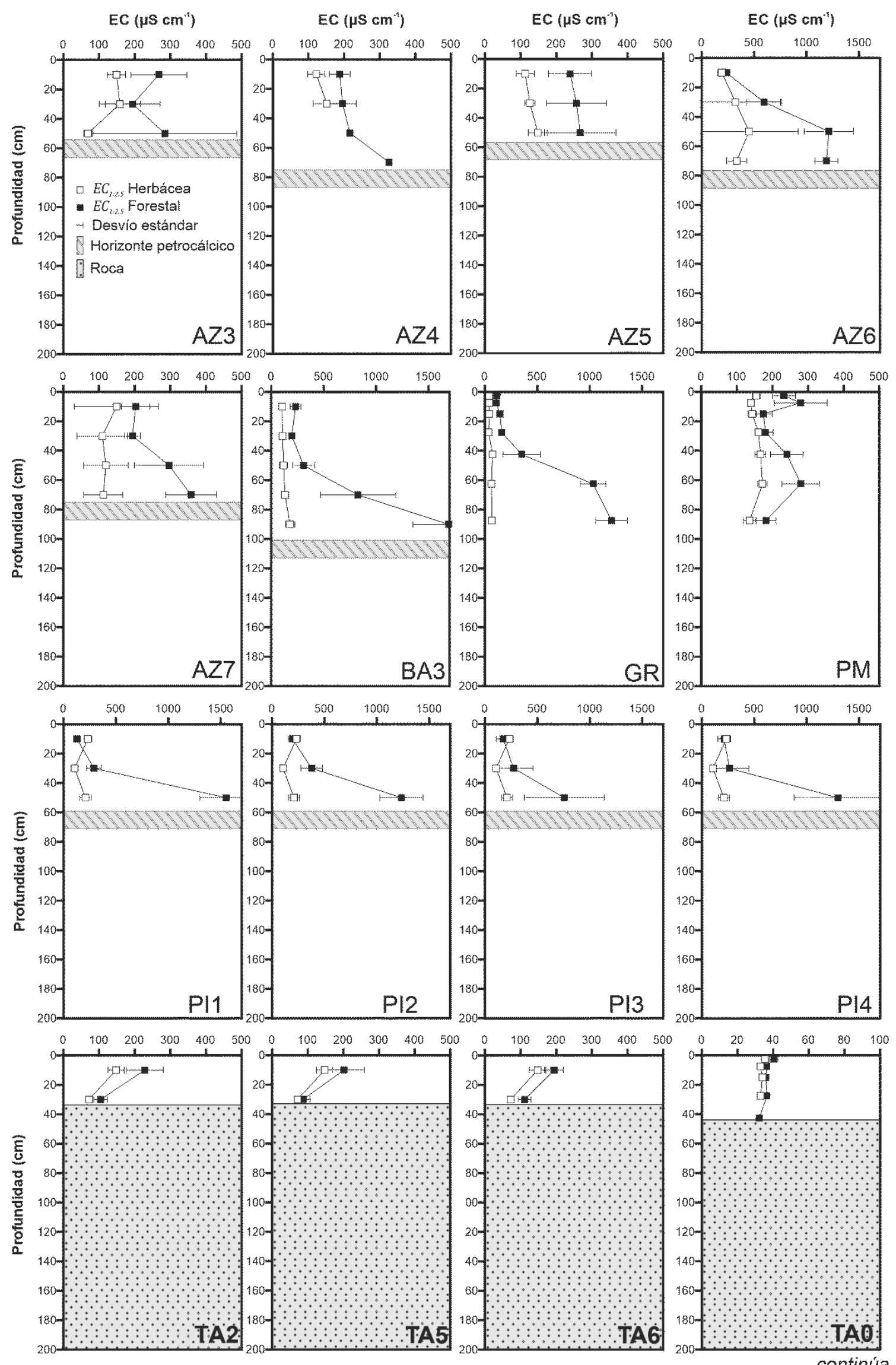


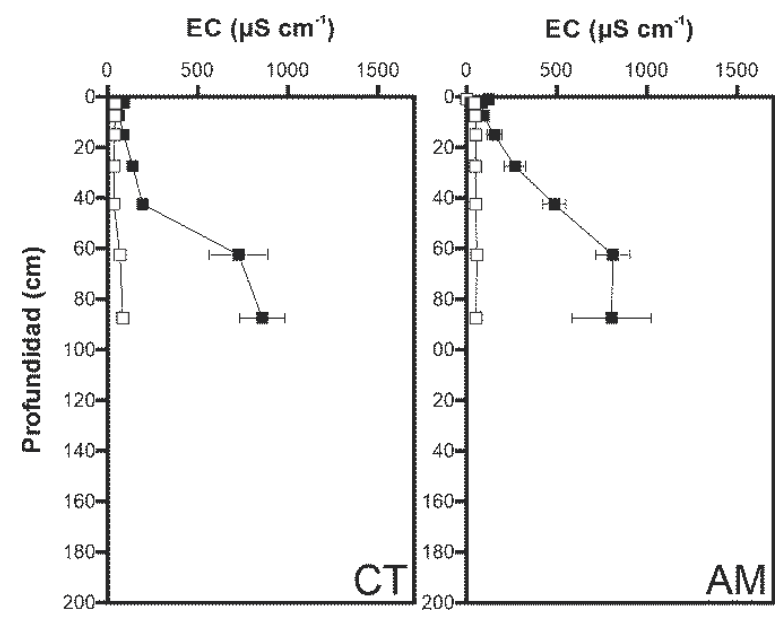

Figura 2-4. Conductividad eléctrica del suelo $\left(E C_{1: 2.5}\right)$ en sitios donde se encontraron diferencias entre la parcela herbácea y forestal a favor de la forestación. Los cuadrados blancos corresponden con la parcela herbácea y los negros con la forestal y las líneas horizontales indican el desvió estándar. Nótese que la escala de $E C_{1: 2.5}$ varía entre los sitios.

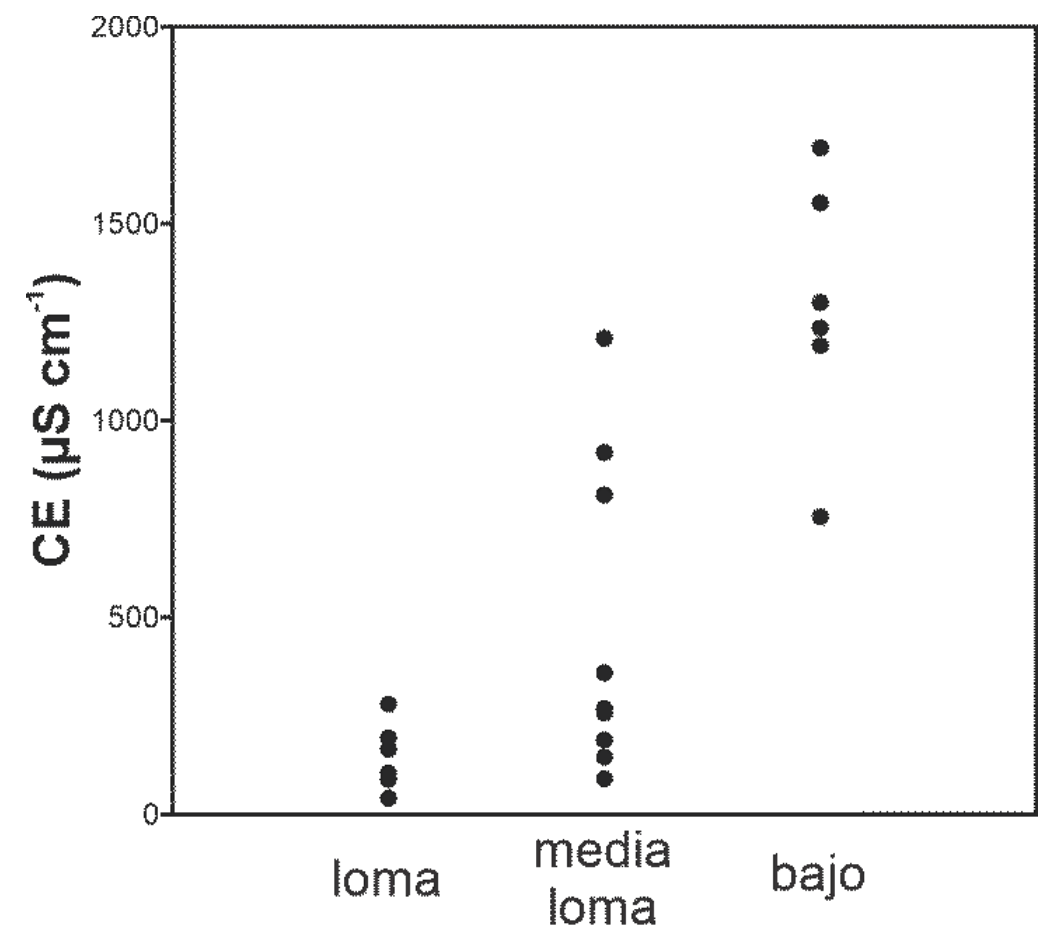

Figura 2-5. Relación entre la conductividad eléctrica acumulada en el suelo de la parcela forestal y la posición en el terreno (la categoría loma incluye todas las posiciones altas, como loma, laderas de cerro y dunas). El coeficiente de correlación $(R)$ entre estas dos variables es de 0.80 .

En la presente tesis, el efecto del $\mathrm{BH}$ regional no pudo ser asociado con los procesos de salinización en suelos, tal como lo sugirió Nosetto et al., 2008 (véase también Jobbágy et al., 2008). Por ejemplo, en la franja con BH de 200 mm se pudieron observar gran cantidad de sitios donde hubo acumulación de 
sales debajo de la forestación (i.e., AZ3, AZ4, AZ5, AZ6, AZ7, BA3, CT, GR, PI1, PI2, PI3, PI4, TA2, TA5 y TA6, Figura 2-2) pero también en los sitios con balances menores (0 mm o menos, i.e., AM, GU3 y GU6, Figura 2-2). Por el contrario, en estas mismas franjas también se pudo verificar la ausencia del proceso de salinización (i.e., AZ1, AZ2, BA1, BA2, CH, TA1, TA3, TA4, Ta7, TA8 y TA9 en la franja de $200 \mathrm{~mm}$ y GU1, GU2 y GU4 en la franja de $0 \mathrm{~mm}$ o menos, Figura 2-2).

Esto podría ser probablemente debido a que en el análisis pudieron existir sitios con presencia de impedimentos para acceder al acuífero freático por parte de las forestaciones, por lo que $\mathrm{BH}$ negativo no necesariamente conllevó a un mayor consumo de agua y a una acumulación de sales (Figura 2-2). Sin embargo, el modelo propuesto por Nosetto et al., (2008) en base al BH podría cumplirse a menor escala espacial o temporal. Es decir, cuando el sistema forestado transpirase cierta proporción de agua proveniente de fuera de sitio ocupado por la misma, aunque esto no se observe en el $\mathrm{BH}$ regional. Como se mencionó anteriormente, esta fuente de agua puede provenir del acuífero freático (generalmente en las áreas más planas como las de la Pampa Deprimida, p. ej. AZ6, PI1, PI2, PI3, PI4, CT y GR) o los excesos hídricos del área circundante (favorecido por la topografía, e.g., AZ5, GU3 y TA6, ver Figura 2-1 y Figura 2-4).

Con respecto a la relación entre la textura del suelo con los procesos de salinización en pastizales forestados (Jobbágy y Jackson, 2004a), no pudo ser comprobado en la presente tesis (Figura 2-6). A diferencia de otros estudios, los sitios que presentaron mayor salinización en el análisis fueron aquellos que 
involucraron suelos con texturas intermedias a finas, sugiriendo un bajo control de este parámetro en el riesgo de salinización.

Los efectos relacionados con la especie forestal de rápido vs. lento crecimiento, no tolerante vs tolerante a la salinidad, capacidad para interceptar más o menos agua y diferentes manejos, tampoco mostraron correlación con la salinización del sitio. En los sitios relevados se pudo comparar alguno de estos aspectos haciendo grupos que correspondieran al mismo predio ya que teniendo en cuenta la gran interacción entre los distintos factores una comparación global sería errónea.

En el predio forestal del partido de Pila (PI1, PI2, PI3 y PI4; 36²8'5,40"S, $58^{\circ} 12^{\prime} 24,60^{\prime \prime}$ ) se pudo comparar entre E. viminalis y E. camaldulensis las cuales se diferencian por tener distinta tolerancia a la salinidad y capacidad de crecimiento (E. viminalis tiene mayor capacidad de crecimiento y es menos tolerante a la salinidad que E. camaldulensis). Si bien este fue uno de los sitios que presentó acumulación de sales respecto del pastizal, no se hallaron diferencias $(p<0.05)$ entre ambas especies (Tabla 2.2).

Por otro lado, en el partido de azul (AZ1, AZ2 y AZ3; $37^{\circ} 07,944 ' S, 60^{\circ}$ 03,769'O) si bien existieron diferencias entre estas especies, solo se observó cerca de la superficie $(0$ a $20 \mathrm{~cm}$ ) y con poca acumulación de sales (un máximo de $343 \mu \mathrm{S} \mathrm{cm} \mathrm{cm}^{-1}$, Tabla 2.2).

Finalmente, en Tandil (TA2, TA3, TA4, TA5, TA6, TA7 y TA8; $37^{\circ} 40^{\prime} 16,92^{\prime \prime S}, 59^{\circ} 4^{\prime} 41,28^{\prime \prime}$ ), si bien no hubo evidencia de salinización causada por la forestación se pudieron encontrar diferencias entre $E$. viminalis y $P$. radiata, y entre distintos tipos de manejo sobre $P$. radiata (Tabla 2.2). Sin 
embargo, en ambos casos estas diferencias no fueron grandes y solo se observaron en una de las profundidades muestreadas (Tabla 2.2).
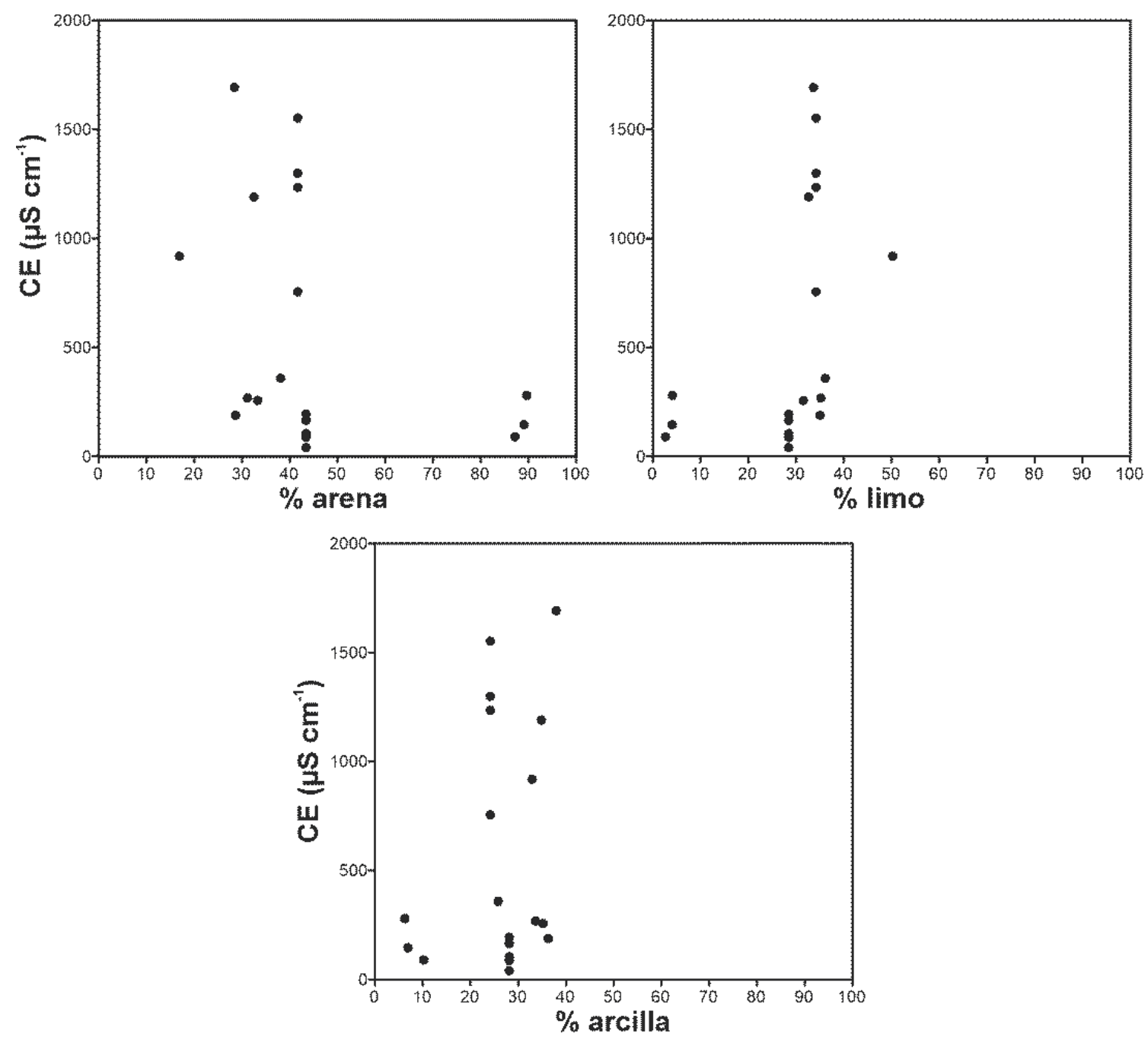

Figura 2-6. Relación entre la $E C_{1: 2.5}$ de la forestación y cada una de las componentes texturales. Los coeficientes de correlación entre $E C_{1: 2.5}$ y arena, limo y arcilla son de $-0.37,0.04$ y 0.26 , respectivamente.

Tabla 2.2. Análisis de varianza entre dos especies en el mismo sitio. Se comparan las $E C_{1: 2.5}$ de dos especies forestales y de tres tipos de manejo ( $P$. radiata).

\begin{tabular}{ccccc} 
& & \multicolumn{3}{c}{$\mathrm{CE}\left(\mu \mathrm{S} \mathrm{cm}{ }^{-1}\right)$} \\
\cline { 3 - 5 } sitios & Especie & $\begin{array}{c}\text { Profundidad } \\
0-20 \mathrm{~cm}\end{array}$ & $\begin{array}{c}\text { Profundidad } \\
20-40 \mathrm{~cm}\end{array}$ & $\begin{array}{c}\text { Profundid } \\
\text { ad } \\
40-60 \mathrm{~cm}\end{array}$ \\
\hline \multirow{2}{*}{ Pila } & E. camaldulensis (PI1 y PI2) & $161 \pm 49.52$ & $334 \pm 94.87$ & $1393 \pm$ \\
& E. viminalis (PI3 y PI4) & $192.8 \pm 76$ & $267.38 \pm 153$ & $1027 \pm 55$ \\
\hline \multirow{2}{*}{ Azul } & E. camaldulensis (AZ3) & $267.84 \pm 79.00 *$ & $194.46 \pm 77.16$ & $284.67 \pm$ \\
& E. viminalis (AZ1 y AZ2) & $158.03 \pm 54.43$ & $204.62 \pm 313.51$ & $281.30 \pm$ \\
& E. viminalis (TA2 y TA3) & $167.92 \pm 74.24$ & $79.34 \pm 29.65$ & -
\end{tabular}




\begin{tabular}{cccc}
\hline P. radiata (TA4, TA5 y TA6) & $186.73 \pm 44.62$ & $110.44 \pm 30.19 *$ & - \\
\hline P. radiata en fajas (TA7 y TA8) & $153.45 \pm 40.66$ a & $101.31 \pm 20.77$ a & - \\
P. radiata en macizo (TA4, TA5 y & $186.73 \pm 44.62$ a & $110.44 \pm 30.19$ a & - \\
TA6) & $150.60 \pm 28.53$ a & $65.08 \pm 11.25 \mathrm{~b}$ & - \\
\hline P. radiata talado (2 años, TA9) & * y las letras (a y b) indican diferencias y grupos de medias ( $\mathrm{p}<0.05)$. & \\
\hline
\end{tabular}

Cabe destacar que si bien el presente análisis discute la acumulación de solutos o aumento de la salinidad, hay sitios donde los valores de $E C_{1: 2.5}$ son extremadamente bajos a medios y no constituyen un impedimento para el crecimiento de la gran mayoría de las especies cultivables (Maas, 1985).

\subsection{Conclusiones}

En general se puede concluir que el problema de la salinización secundaria causada por la forestación de pastizales no es un problema que afecte a todos los ambientes de la provincia de Buenos Aires. Existen sitios donde la producción forestal es factible con bajo riesgo de salinización.

El proceso de salinización tiene un alto grado de complejidad y algunas de las generalidades establecidas en los trabajos previos mencionados no han podido ser constatadas en los sitios bajo observación en la presente tesis. Los factores ambientales que se relacionan a los flujos de agua y nutrientes a nivel de predio resultaron ser los más idóneos para tratar de predecir el riesgo de salinización, sobre todos aquellos relacionados a la posibilidad para la forestación de acceder a fuentes de agua con cierta concentración de solutos, distinta del agua de lluvia y que fue recargada en otro sitio o previamente.

El acceso al acuífero freático es el principal factor que permitiría predecir la acumulación de sales. Sin embargo, en sitios que no tienen la presencia de este factor predominarían factores relacionados con la topografía y los flujos hídricos someros. En este sentido se concluye que, más allá de las 
aproximaciones que se puedan hacer en base a estos resultados y los de los estudios previos, es necesario un análisis más detallado de la hidroquímica estos sistemas.

Los estudios deberán, por un lado, hacer foco en el movimiento del agua a través de los perfiles edáficos (aquellos que presentan discontinuidades tales como roca o horizontes petrocálcicos son los que presentaron más incertidumbre). Por otro lado, también se deberían focalizar en los procesos hidroquímicos de la rizósfera responsables de estos cambios complejos (p. ej. exclusión de solutos, exudación, entre otros). 


\section{Capítulo 3}

Control de las heterogeneidades del suelo sobre los procesos de salinización causados por la forestación de pastizales. (*)

* Este capítulo se basa en:

Mujica, C. R., Milione, G. M., Bea, S. A., \& Gyenge, J. E. 2019a. Impacto en los flujos hídricos por la presencia de horizontes petrocálcicos en parcelas forestadas en ambientes de llanura. Revista de Investigaciones Agropecuarias, 45(3), 426-436.

Mujica, C.R., Milione, G.M., Bea, S.A., Gyenge, J.E., 2019b. A process-based numerical approach to estimate forest groundwater consumption in flatland petrocalcic soils. J. Hydroinformatics 1-36. https://doi.org/10.2166/hydro.2019.093

Mujica, C.R., Bea, S.A., 2020. Estimations of rooting depths and sources of plant-available water (PAW) in flatland petrocalcic soils under different land uses. Geoderma 361, 114019. https://doi.org/10.1016/j.geoderma.2019.114019 


\subsection{Introducción}

En muchos ambientes de llanura alrededor del mundo, incluida la región pampeana, existe la presencia de horizontes petrocálcicos a diferentes profundidades, espesores, y grados de cementación (Figura 3-1 y Figura 3-2; Duniway, Herrick, \& Monger, 2010; Pazos \& Mestelan, 2002). En muchos casos, estos horizontes son considerados una barrera para el desarrollo de las raíces y el flujo de agua (Dietrich et al., 2014; Shreve y Mallery, 1933). Sin embargo, cómo impacta su presencia en la dinámica de los flujos de agua, y aquella almacenada disponible para consumo de las plantas (Plant Available Water, PAW), han sido poco estudiados (Duniway et al., 2007, 2010).

Se ha observado que estos horizontes, conocidos localmente también como 'tosca', tienen la capacidad de retener ciertos volúmenes de agua (entre $\sim 60$ y $\sim 260 \mathrm{~mm}$ de agua expresado en lámina por metro de espesor del horizonte; Duniway et al., 2007). Constituyendo así, un efectivo reservorio natural para abastecer de agua a las plantas en periodos de bajas precipitaciones en ciertos ambientes (Duniway et al., 2007). Por ejemplo, en ambientes áridos donde se ha observado que las comunidades vegetales naturales sobreviven con más frecuencia a las sequías si crecen sobre suelos con la presencia de estos horizontes (Duniway et al., 2010; Georgen et al., 1991; Herbel et al., 1972).

Además, se encontró que ciertas especies de herbáceas perennes, e incluso cultivos como el girasol (Helianthus annuus L.), y el de algodón (Gossypium hirsutum L.) son capaces de penetrar dentro de estos horizontes y acceder al agua almacenada en ellos (Gibbens y Lenz, 2001; Georgen et al., 1991). Sin embargo, esos trabajos se limitan a sitios áridos o semi áridos donde los suelos naturalmente no son tan retentivos $(\sim 70 \mathrm{~mm}$ de agua expresado en 
lámina, en un metro de espesor, Duniway et al., 2010; Georgen et al., 1991;

Mengel, 1994).

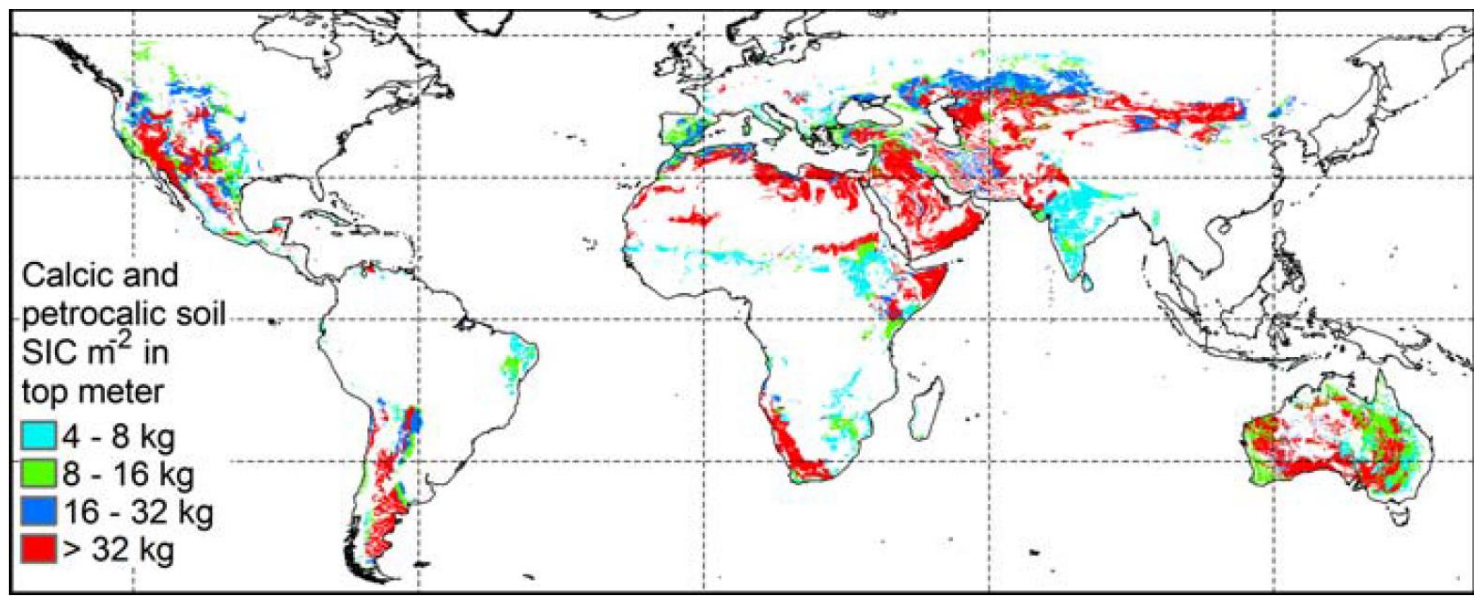

Figura 3-1. Distribución mundial probable de los horizontes cálcicos y petrocálcicos. El mapa fue generado interceptando los mapas de subórdenes de suelos que contienen horizontes cálcicos y petrocálcicos (global maps of soil taxonomy) y de carbono inorgánico del suelo (SIC). Extraído de (Duniway et al., 2010). 


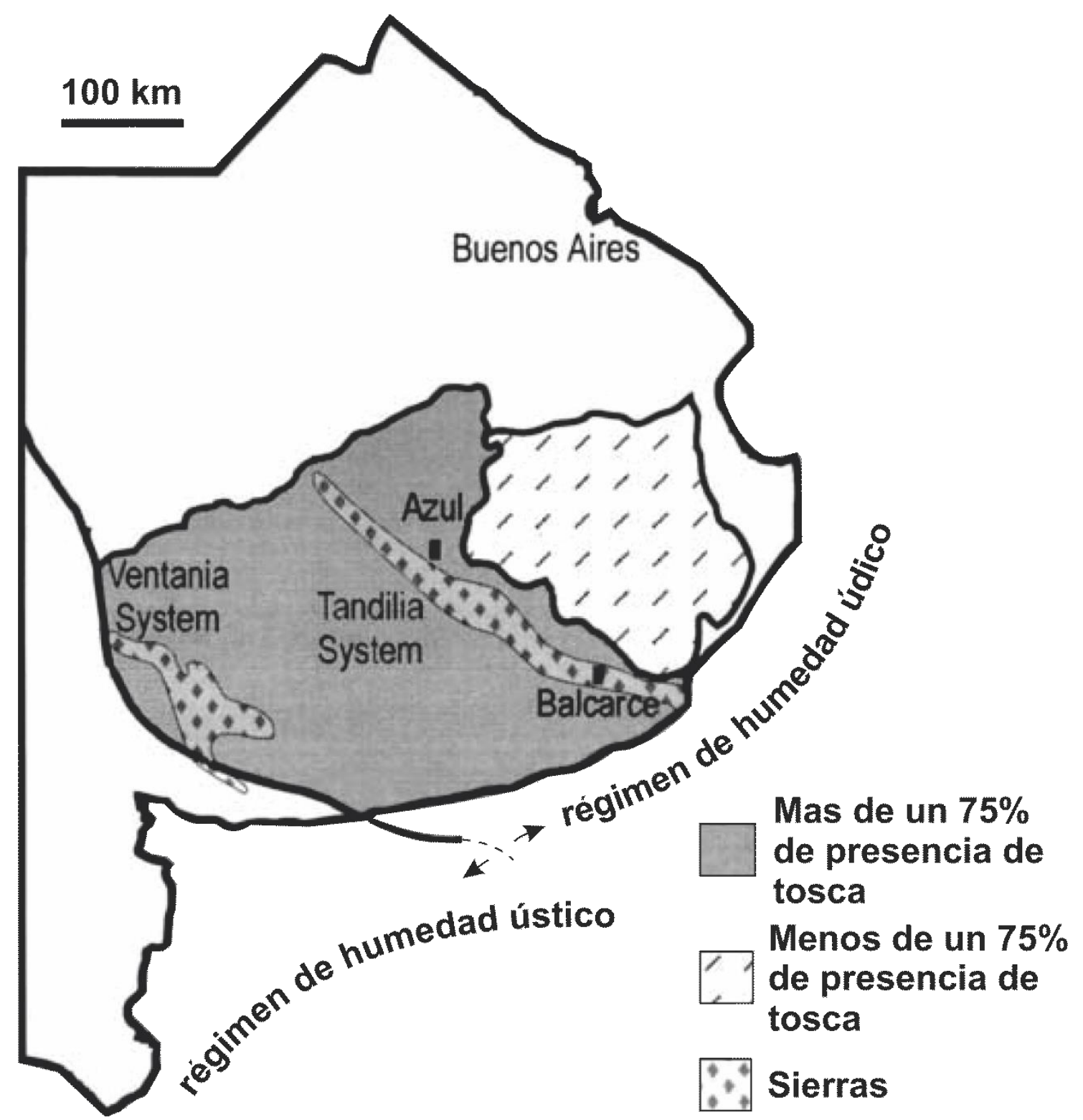

Figura 3-2. Distribución de la capa de tosca en los duelos de la Provincia de Buenos Aires bajo régimen de humedad del suelo údico, extraído de (Pazos y Mestelan, 2002).

Los suelos más fértiles de Argentina se encuentran en Llanura Pampeana y el orden característico de esta región es el de los Molisoles (Liu et al., 2012). En ellos se desarrollan algunas de las principales actividades productivas del país, con un margen bruto anual de aproximadamente 146 U\$D ha año-1 (Carreño et al., 2012). Por ejemplo, en la provincia de Buenos Aires la agricultura y ganadería produjeron 7 mil millones de dólares en el 2015 (DPE, 2016). 
Aunque, después de décadas de agricultura convencional y monocultivos que deterioraron en cierto grado sus propiedades físicas, son aún muy favorables para el crecimiento de los cultivos (Amiotti et al., 2012). Gran parte de esta región presenta horizontes petrocálcicos con una gran variabilidad en profundidad, dureza, contenido de $\mathrm{CaCO}_{3}$, y estructura (Figura 3-2; Rubio et al., 2019; Kuznetsova y Khokhlova, 2015; Blanco y Stoops, 2007; Pazos y Mestelan, 2002).

Dado que la gran mayoría de los cultivos de esta región se realizan en secano, es clave el volumen de agua que pueda ser almacenado en el perfil del suelo. Estos molisoles pueden almacenar hasta $\sim 180 \mathrm{~mm}$ de agua (expresado en lámina) en el primer metro, por lo que se obtienen rendimientos de aceptables a altos en cultivos agrícolas en secano (Monzon et al., 2018; Pazos y Mestelan, 2002). Habitualmente se asume que cuando el perfil del suelo presenta horizontes de tosca cementadas entre 0,5 y $1 \mathrm{~m}$ de profundidad, este podría reducir su capacidad de almacenar agua, afectando así el rendimiento potencial de los cultivos (Pazos y Mestelan, 2002; Moscatelli y Pazos, 2000). Sin embargo, la experiencia ha mostrado que pueden esperarse rendimientos aceptables en pasturas y cultivos de invierno (e.g., trigo [Triticum aestivum ], avena [Avena sativa]) con tosca a esas profundidades (entre 0,5 y $1 \mathrm{~m}$ de profundidad; Damiano y Taboada, 2000; Monzon et al., 2018).

Por el contrario, aquellos suelos que presentan un horizonte de tosca cementada a una profundidad menor a los $25 \mathrm{~cm}$ son descartados para el uso agrícola, o la implantación de pasturas, y generalmente mantienen la cobertura de pastizal natural, y son destinados a la cría de ganado bovino. Cabe aclarar

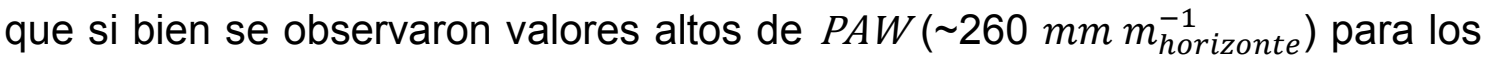
horizontes petrocálcicos, dado que su dureza impide que sean libremente 
ocupados por las raíces, estos reducen el agua que pueden aprovechar las plantas en los suelos de la llanura Pampeana (hasta $180 \mathrm{~mm} \mathrm{morizonte),} \mathrm{cuando}$ están dentro de los primeros 0,5 m de profundidad (Damiano y Taboada, 2000). Por el contrario, en suelos menos retentivos como los del sur de New México, US ( $\left.70 \mathrm{~mm} \mathrm{~m}_{\text {horizonte }}^{-1}\right)$ favorecen el $P A W$ cuando se hallan a menos de 0,5 $\mathrm{m}$ de profundidad (Duniway et al., 2010).

Además de la presencia de tosca, existen áreas con la presencia de basamento cristalino, recurrentes inundaciones, salinidad, sustratos muy arenosos o arcillosos, que impiden o limitan la producción agrícola (Jobbágy et al., 2006a; Damiano y Taboada, 2000). A pesar de que todas estas áreas son marginales a la agricultura, las limitaciones de estos sitios no afectan de forma importante a los sistemas forestales, ofreciendo así una alternativa de mayor rentabilidad con tres a cinco veces la productividad de los pastizales que reemplazan (Pinus radiata $\sim 15 \mathrm{~m}^{3} \mathrm{ha}^{-1}$ año ${ }^{1}$ y Eucalyptus viminalis $\sim 35-40 \mathrm{~m}^{3}$ ha${ }^{1}$ año-1; Ferrere et al., 2008, 2015; Jobbágy et al., 2006b).

Como se mencionó en capítulos anteriores, el proceso de salinización secundaria derivado de la forestación de pastizales depende en gran medida del acceso a acuíferos freáticos relativamente salinos (Nosetto et al., 2008, 2013). Teniendo en cuenta esto, conocer el efecto que tiene la presencia de horizontes petrocálcicos es fundamental, considerando su amplia distribución en la región. Sin embargo, su efecto no ha sido evaluado en las numerosas publicaciones que son referentes en la temática de salinización dentro de la llanura Pampeana Argentina (Nosetto et al., 2013, 2009, 2008; Nosetto, 2007; Jobbágy y Jackson, 2007; Jobbágy et al., 2006a; Jobbágy y Jackson, 2004b). 
El flujo de agua a través de los horizontes petrocálcicos es complejo por su gran heterogeneidad, entre zonas cementadas de baja permeabilidad y zonas no cementadas donde se genera un flujo preferencial (Dietrich et al., 2014). Sumado a esto se ha encontrado evidencia de que especies de arbustos y herbáceas perennes tienen la capacidad de atravesar estos horizontes cálcicos y petrocálcicos, y acceder a capas más profundas para abastecerse de agua (Gibbens y Lenz, 2001), con lo cual existe cierta incertidumbre sobre el impacto global sobre las plantaciones forestales.

La proporción del agua usada por las plantas $(P A W)$ que proviene del acuífero freático es clave para comprender los procesos de salinización causado por las forestaciones (Nosetto et al., 2008, 2012; Jobbágy y Jackson, 2007; Jackson et al., 2001). Sin embargo su estimación es muy compleja y difícil de medir (Feikema et al., 2010). Para estimar PAW en los bosques se han utilizado diferentes técnicas, entre ellas: (1) isótopos estables $\left({ }^{2} \mathrm{H},{ }^{18} \mathrm{O}\right.$, e.g., Farrington et al., 1996; Feikema et al., 2010; Fernández et al., 2008; Jolly y Walker, 1996; Mensforth y Walker, 1996); y 2) fluctuaciones diurnas del nivel freático (Farrington et al., 1990; Freeze y Cherry, 1979; White, 1932), y su variante que incluye un balance de agua (p. ej., Engel et al., 2005; Salama et al., 1994).

Este último enfoque supera el problema de la extrapolación del uso del agua porque los cambios en los niveles debajo de un bosque representan la integración de los componentes del balance hídrico. Este enfoque es adecuado para ser aplicado en: (1) aquellos sitios cercanos a la divisoria de agua subterránea para minimizar el flujo lateral en el acuífero debajo de la forestación y (2) acuíferos con baja conductividad hidráulica (e.g., 0,01-0,1 m día-1), de tal manera que impida la atenuación de las fluctuaciones del nivel freático más allá 
de los límites de la forestación (Salama et al., 1994). Sin embargo, en gran parte de la región, sobre todo en posiciones cercanas a las cabeceras de las cuencas hidrográficas, las conductividades hidráulicas del acuífero rondan los $5 \mathrm{~m}_{\text {día }}^{-1}$ (Varni y Usunoff, 1999).

Por otro lado, los modelos numéricos basados en procesos (i.e., flujo de agua y vapor, y transporte de energía) son una herramienta capaz de capturar los procesos físicos/biológicos en el continuo suelo-planta-atmósfera. El código de transporte reactivo MIN3P tiene la capacidad de calcular los flujos de agua, calor y vapor en la zona no saturada del suelo imponiendo condiciones de contorno atmosféricas. Es decir, puede simular tanto la evaporación directa del suelo, como la condensación (Bea et al., 2012; Mayer et al., 2002). Por otro lado, para el cálculo de la transpiración este modelo tiene en cuenta una función empírica limitada por: (1) la evapotranspiración del cultivo bajo condiciones estándar (Allen et al., 2006), (2) el agua disponible en el perfil (PAW), y (3) la cantidad y distribución de raíces (Mujica et al., 2019a; Mayer et al., 2012; Battaglia y Sands, 1997).

Por lo tanto, conocer la distribución de las raíces en el suelo es crucial para una mejor comprensión de los procesos hidrológicos y biogeoquímicos en los sistemas naturales (Laio et al., 2006); o para evaluar el riesgo de salinización del suelo en pastizales forestados (Jobbágy y Jackson, 2007). Algunos autores han caracterizado la arquitectura de las raíces para un gran número de especies vegetales en todo el mundo (e.g., Schenk y Jackson, 2002a, 2002b). Otros autores han aplicado metodologías de optimización del uso del agua para estimarla (e.g., Kleidon, 2004; van Wijk y Bouten, 2001), o mediante modelación inversa (e.g., Zuo y Zhang, 2002). Otra posibilidad es estimarla en base a una 
comprensión integrada que contempla la dependencia con las propiedades del suelo y las condiciones climáticas (Laio et al., 2006; Schenk y Jackson, 2005). Sin embargo, aún no se ha incorporado a esta comprensión integrada cómo la distribución raíces y $P A W$ varían con respecto a: (1) los distintos usos del suelo (i.e., pastizal o forestación), y (2) la presencia de horizontes cementados (e.g., petrocálcicos).

El objetivo de este capítulo es comprender cómo impacta la forestación de pastizales sobre los flujos hídricos, cómo esto interactúa con la presencia de los horizontes petrocálcicos y sus implicancias en el proceso de salinización secundaria. De esto, a su vez, se deriva la implementación de una herramienta para cuantificar la distribución de raíces, él $P A W$ y el consumo de agua freática de la vegetación en suelos con la presencia de estos horizontes.

\subsection{Métodos}

\subsubsection{Descripción del sitio}

Este estudio fue llevado a cabo en dos parcelas apareadas de pastizal y forestación localizadas en la subcuenca sur del arroyo Azul (102.400 ha), entre $36^{\circ} 49^{\prime} 39^{\prime \prime}$ y $37^{\circ} 21^{\prime} 6 "$ S, y entre $60^{\circ} 9^{\prime} 10^{\prime \prime}$ y 5945'53" W (ver Figura 3-3). Desde el punto de vista topográfico, la cuenca del arroyo Azul muestra promedios de pendientes superficiales de aproximadamente $5 \%, 0.5-0.8 \%$ y $0.2 \%$ en la parte superior (i.e., sur, sitio de estudio), media e inferior (norte) de la cuenca hidrológica, respectivamente (Varni y Usunoff, 1999). El clima de esta región fue clasificado como templado, subhúmedo-húmedo. En contraste con otras regiones ubicadas en latitudes comparables en el hemisferio norte, la Pampa Argentina se caracteriza por un gradiente de humedad de este a oeste y una continentalidad creciente hacia el noroeste (Burgos y Vidal, 1951). Las 
temperaturas medias en la parte noreste de la región son de $24^{\circ} \mathrm{C}$ (enero) y 10 ${ }^{\circ} \mathrm{C}$ (julio) en verano e invierno, respectivamente, mientras que en el suroeste, son $20^{\circ} \mathrm{C}$ y $7{ }^{\circ} \mathrm{C}$, respectivamente (Prieto, 1996).

La cuenca sedimentaria está rellena de loess y arenas del Pleistoceno tardío-Holoceno temprano que forman un manto continuo (Zárate, 2003). Dentro de la cuenca, la región de estudio se subclasificó como una unidad geomorfológica: "Nivel de agradación disectado con costra calcárea" (Zárate y Mehl, 2010). Consiste en crestas aisladas con formas muy suaves y alturas relativas variables que van desde 6 hasta $4 \mathrm{~m}$. Estas elevaciones constituyen una divisoria de agua secundaria de la red de drenaje que da un relieve moderadamente ondulado al sector. Presentan una costra calcárea fuertemente cementada (0,7-1 $\mathrm{m}$ de espesor), estratiforme compuesta por planchas macizas de 5-10 cm de espesor. Los depósitos loésicos constituyen el material parental de una parte considerable de los suelos actuales y por esta razón, exhiben un alto grado de reorganización pedogénica en los 0,7-0,8 m superiores (Zárate y Mehl, 2010). 


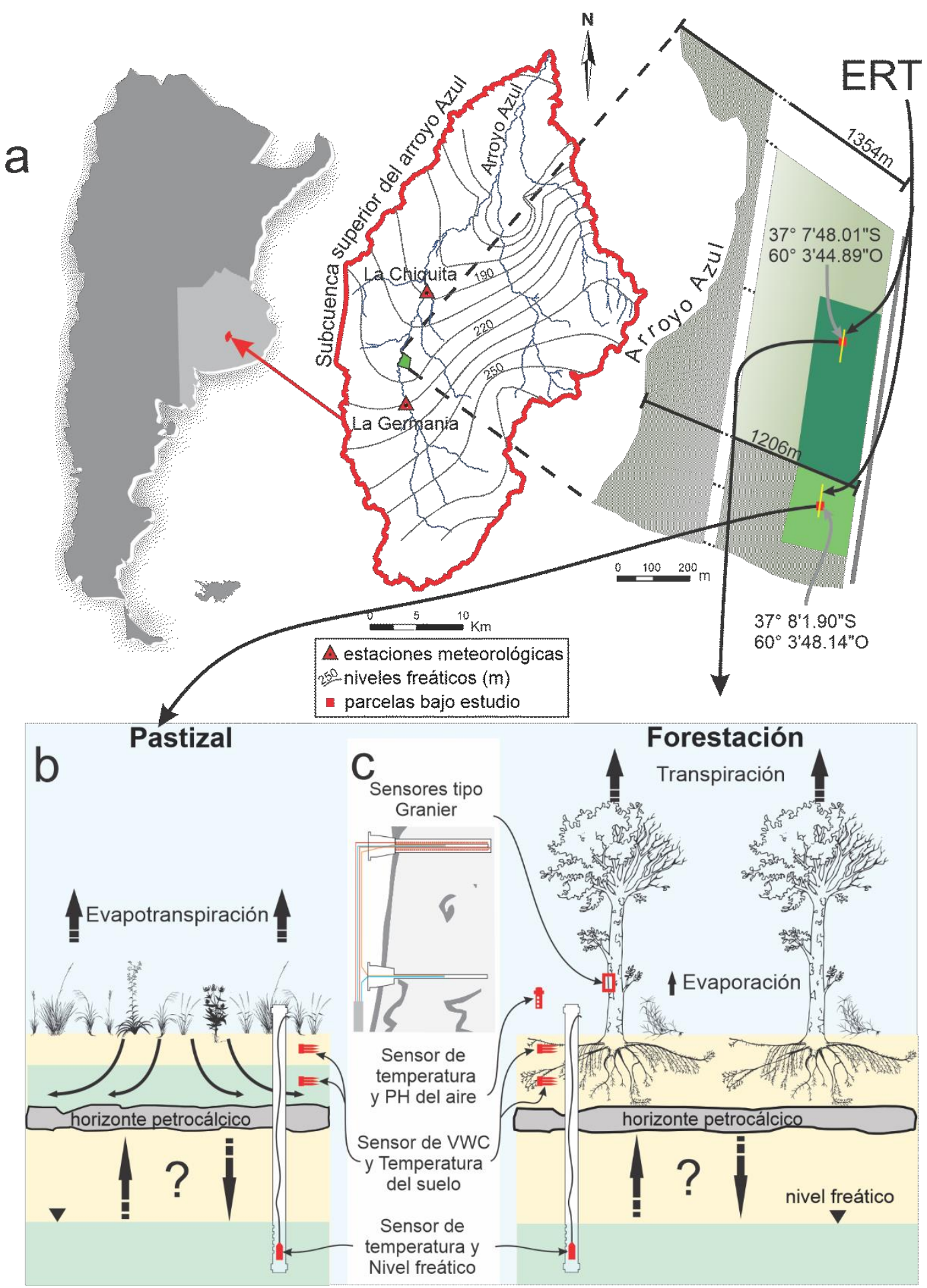

Figura 3-3 (a) Localización del sitio de estudio y (b, c) principales variables medidas. ERT: tomografía de resistividad eléctrica ('electrical resistivity tomography').

El suelo del sitio de estudio fue clasificado como Argiudol petrocálcico (Soil Survey Staff, 2014) a partir de la observación del perfil y se determinó la siguiente secuencia de horizontes (Figura 3-4a): (1) O (0-0,02 m) principalmente compuesta de materia orgánica de hojarasca en descomposición; (2) Ap (0,02- 
$0,27 \mathrm{~m}$ ) es una capa con textura arcillosa, con una estructura granular moderada y fina, muy friable; (3) BA $(0,27-0,47 \mathrm{~m})$ también es arcilloso, con bloques subangulares moderados que se rompen en forma granular, muy friable; (4) Bt1 $(0,47-0,59 \mathrm{~m})$ es arcilloso con prismas compuestos regulares medianos y moderados que se rompen en prismas subangulares medianos, débiles y delgados y abundantes películas de arcilla; (5) Bt2 (0,59-0,76 m) con textura arcillosa, prismas compuestos moderados y regulares que se rompen en bloques angulares y subangulares, películas muy duras y comunes de pieles de arcilla, límite inferior abrupto; (6) 2Ckkm (>0,76 m) es un horizonte continuo y masivo casi totalmente cementado por carbonatos, muy difícil y prácticamente imposible de penetrar con herramientas manuales.

La clase textural de cada horizonte se obtuvo utilizando el método del hidrómetro (Bouyoucos, 1936), mientras que la densidad aparente se obtuvo al pesar muestras de cilindros de suelo sin disturbar de $169,65 \mathrm{~cm}^{3}$, después de secarlos durante 24 horas a $105^{\circ} \mathrm{C}$. Además, se midió $\mathrm{pH}$ y conductividad eléctrica $\left(E C_{1: 2,5}\right)$ en muestras correspondientes a cada uno de los horizontes. Estas mediciones se realizaron en el sobrenadante de diluciones con una relación suelo:agua de 1:2,5, previamente agitadas (6 horas), por medio de un lector OAKTON PC700 con sonda de pH Cole-Palmer 05992-62 y sonda de CEtemperatura 35608-74. Los parámetros para el modelo van Genuchten se calcularon utilizando el software Rosetta Lite v.1.1 (Schaap et al., 2001) basados en la textura y la densidad aparente. 
a

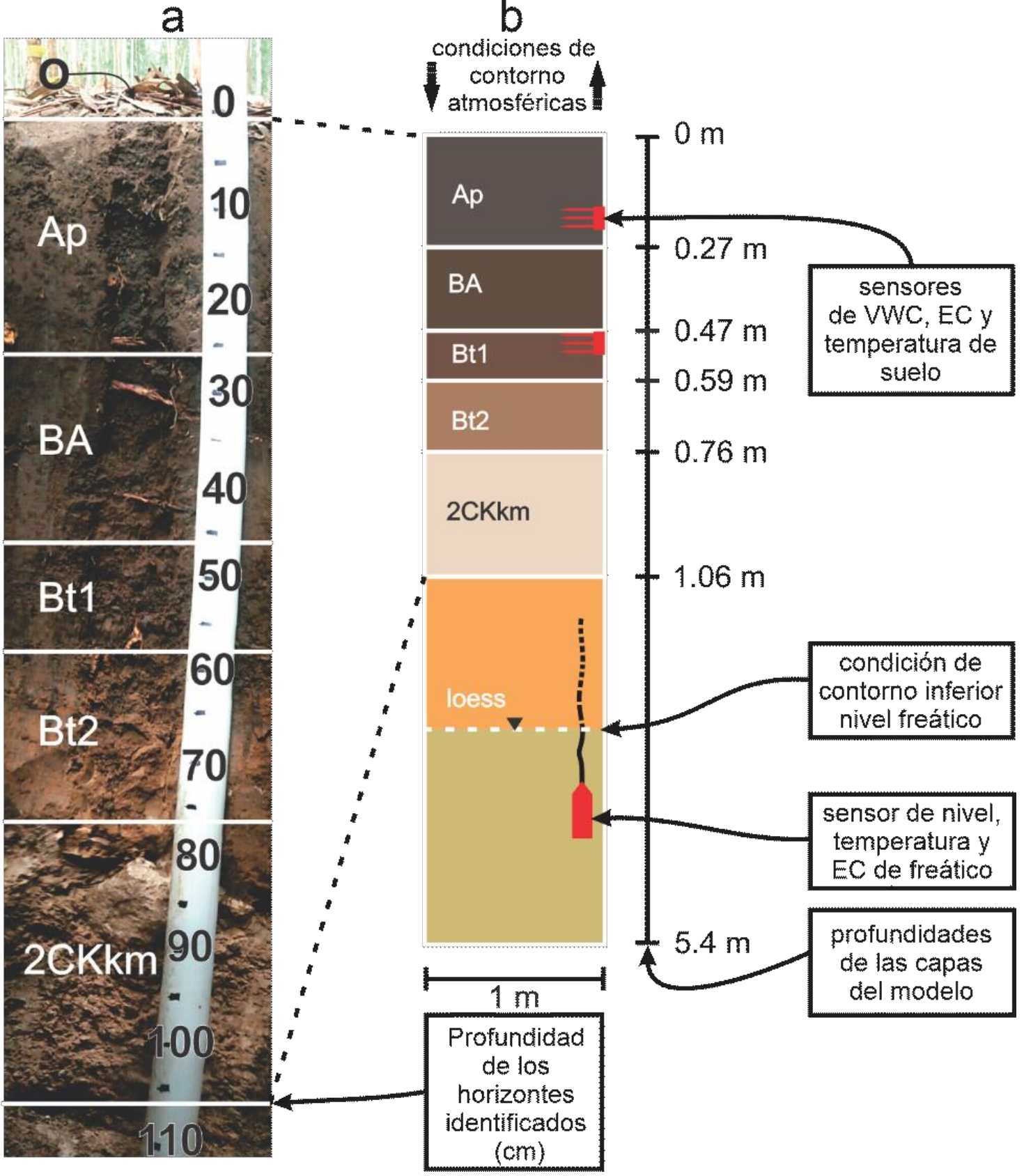

Figura 3-4. (a) Horizontes identificados en el perfil, (b) dominio del modelo y condiciones de contorno.

\subsubsection{Características del pastizal y de la forestación}

La forestación consiste de 7,8 ha plantadas en 1999 con Eucalyptus viminalis (Figura 3-3), en una cuadricula de 2,5 por $3 \mathrm{~m}$.

El género Eucalyptus comprende cerca de 500 especies, desde arbustos hasta árboles, que habitan un vasto rango de hábitats originario de Australia (Rivera y Villegas, 2002). Eucalyptus viminalis se distribuye naturalmente en 
climas con rangos de precipitaciones desde $\sim 500$ a $1700 \mathrm{~mm}^{2} \mathrm{ano}^{-1}$ y entre 32 y $-3{ }^{\circ} \mathrm{C}$ de temperatura. Esta especie se incorpora en Argentina por su gran capacidad de crecimiento (hasta $35 \mathrm{~m}^{3} \mathrm{ha}^{-1} \mathrm{año}^{-1}$ ), la calidad de su madera, buena forma forestal y su tolerancia a las heladas. Principalmente se cultiva en la región Pampeana, en las provincias de Buenos Aires, este de La Pampa y sur de Santa Fe y Córdoba (Cappa et al., 2010).

Actualmente, en la plantación estudiada se observa un 33\% de mortalidad como resultado de la alta densidad inicial para el sitio y por la ausencia de manejo, quedando una densidad remanente de $\sim 893$ árboles ha ${ }^{-1}$. El sotobosque es escaso, casi totalmente compuesto por Cynodon dactylon, excepto en los claros donde es más abundante y además crecen especies de asteráceas como Carduus acanthoides y Dispsacus fullonum. Para la instalación de la parcela en la forestación se delimitó el área ocupada por 4 filas de 10 árboles. Allí, se midió el diámetro a la altura del pecho de todos los individuos vivos y en función del área ocupada se determinó el área basimétrica de la parcela $\left(B_{A}, \mathrm{~m}^{2} \mathrm{ha}^{-1}\right)$.

Adyacente a la forestación se ubica el pastizal que cubre una superficie de 3,6 ha (Figura 3-3 a y b), dominada por matas monoespecíficas de poáceas (Paspalum quadrifarium, Stipa brachychaeta, Pithochaetium spp., Mellica spp., Bothriochloa laguroides), y apiáceas (Eryngium paniculatum). El uso de este sitio es el típico lote de tránsito, donde se encierra ganado vacuno, ovino, equino según las necesidades del establecimiento, alternando entre un pastoreo intenso y periodos de baja o nula carga animal. De acuerdo al manejo, la estacionalidad y a la disponibilidad hídrica, esta dominancia se alterna con la aparición de asteráceas de menor valor forrajero Carduus acanthoides, Dispsacus fullonum, Bellis spp. y Hypochaeris spp. 


\subsubsection{Parámetros monitoreados}

Los parámetros atmosféricos (temperatura, humedad relativa, precipitación, heliofanía y velocidad del viento) se midieron tanto en el pastizal como en la forestación. En la parcela forestada la temperatura del aire $\left(T_{a t m}\right)$ y la humedad relativa $(R H)$ se registraron con una frecuencia horaria con sensores de temperatura y humedad Cavadevices (modelos TC1047A, HIH4000 y 2K14, respectivamente; Cavadevices.com Inc., CABA, Bs.As., AR).

Las precipitaciones $(\mathrm{P})$ y el flujo fustal en el tallo se recolectaron con pluviómetros $(n=9)$ y embudos instalados en el tronco del árbol $(n=4)$, respectivamente. Se midieron con una frecuencia mensual durante todo el período de tiempo estudiado (desde el 10 de diciembre del 2015 al 23 de febrero del 2017). En cuanto a la parcela de pastizal, la precipitación fue medida mensualmente con el mismo procedimiento que en la forestación $(n=2)$.

Los parámetros restantes (es decir, $T_{a t m}$ y $R H$ ) se tomaron de dos estaciones meteorológicas regionales (estaciones "La Chiquita" y "La Germania" en la Figura 3-3 a), situadas a 4,3 y 8,2. km del sitio de estudio, respectivamente (BDH, 2019). Además, estas estaciones cuentan con datos de precipitaciones, heliofanía, velocidad del viento y humedad relativa con una frecuencia horaria, que permitió completar la información necesaria para alimentar el modelo. La información de las estaciones meteorológicas se combinó usando en cada intervalo de tiempo aquella que coincidió mejor con las mediciones obtenidas in situ.

Por otro lado, se midió el contenido de agua $\left(\mathrm{VWC}, \mathrm{m}^{3} \mathrm{~m}^{-3}\right)$, conductividad eléctrica $\left(E C b, \mathrm{dS} \mathrm{m}^{-1}\right)$ y temperatura $\left(T,{ }^{\circ} \mathrm{C}\right)$ del suelo a intervalos de una hora con sondas Decagon 5TE (Decagon Devices, Inc., Pullman, WA, US.), durante 
todo el periodo estudiado. El VWC se midió a 0,2 y 0,5 $\mathrm{m}$ de profundidad por duplicado en ambas parcelas, y se validaron por el método gravimétrico una vez por mes durante todo el período.

La profundidad del nivel freático, la conductividad eléctrica (ECwt, $\mathrm{dS} \mathrm{m}^{-}$ $\left.{ }^{1}\right)$ y la temperatura $\left(T_{w t},{ }^{\circ} \mathrm{C}\right)$ se midieron también con frecuencia horaria utilizando sensores Decagon CTD-10 (Decagon Devices, Inc., Pullman, WA, EE. UU.) instalados en pozos de $6 \mathrm{~m}$ de profundidad encamisados con PVC (piezómetros ranurados entre 5,5 y $6 \mathrm{~m}$ de profundidad) en la parcela herbácea y forestal (Figura 3-3 b). Estos sensores utilizan un transductor de presión diferencial ventilado para medir la presión de la columna de agua por encima del sensor. Y por diferencia entre este valor y la posición a donde está suspendido el sensor se obtiene la profundidad del nivel freático respecto de la superficie del suelo. Estas mediciones se verificaron manualmente, mientras que ECwt se verificó en el laboratorio en muestras de agua.

\subsubsection{Cálculo de la conductividad eléctrica del agua de poro}

La salinidad de una solución acuosa puede ser medida en términos de conductividad eléctrica, la cual está estrictamente correlacionada con la concentración total de sales disueltas (Miller et al., 1988). La conductividad eléctrica es usualmente usada para determinar la salinidad de aguas naturales, así como también en extractos acuosos de suelo en pasta. Sin embargo, estos métodos suelen ser destructivos y no permiten una medición continua.

Las sondas de múltiples sensores utilizadas en este trabajo permitieron una medición continua y no destructiva, sin embargo, evaluar la salinidad del suelo requiere de un procesamiento posterior de los datos. La variable medida 
por el sensor es la conductividad eléctrica aparente $\left(E C b, \mathrm{dS} \mathrm{m}^{-1}\right)$ la cual es una combinación de la contribución de las tres fases presentes en el suelo: las partículas sólidas, el agua y el aire. Para despejar la conductividad eléctrica que corresponde al agua de poro del suelo $\left(E C p, \mathrm{dS} \mathrm{m}^{-1}\right)$, se han desarrollado varios modelos basados en relaciones empíricas, así como en supuestos teóricos (Scudiero et al., 2012; Hilhorst, 2000; Rhoades et al., 1976; Archie, 1942). Ya que todos estos modelos contienen parámetros empíricos obtenidos en otros sitios de estudio, se utilizaron 3 de estos modelos con el fin de obtener la mejor estimación de la $E C p$ para el tipo de suelo bajo estudio y su rango de salinidad.

Uno de los modelos utilizados fue el propuesto por Archie, (1942):

$$
E C p=k \frac{E C b-E C S}{\phi^{m} \times S^{n}}
$$

donde ECs es la conductividad eléctrica de la fase sólida calculada en función del contenido de arcilla; $\phi$ es la porosidad del suelo; $S$ es la saturación $\left(V W C \times \phi^{-1}\right)$ y $k, m$ y $n$ son parámetros de ajuste. ECs se calcula según la relación:

$$
\text { ECs }=c \cdot \% \text { arcilla }-d
$$

Ecuación 2

donde c y d (0.023 y 0.021) son obtenidos empíricamente (Amente et al., 2000; Rhoades et al., 1989). Para obtener $m$ y $n$ se usaron las siguientes relaciones (Scudiero et al., 2012):

$$
\begin{array}{ll}
m=-0.018 \cdot S O C+\frac{4.35 \cdot S O C}{0.966+S O C} & \text { Ecuación 3 } \\
n=-0.699+0.035 \times \% \text { arena } & \text { Ecuación 4 }
\end{array}
$$

donde $S O C$ es el porcentaje de carbono orgánico del suelo. 
Otro de los modelos utilizados fue el de Hilhorst, (2000):

$$
E C p=\frac{\varepsilon_{p} E C b}{\varepsilon_{b}-\varepsilon_{E C b=0}}
$$

Ecuación 5

donde $\varepsilon_{p}$ es la permitividad dieléctrica (ver Hilhorst, 1998) del agua de poro, $\varepsilon_{b}$ es la permitividad del suelo (medida por el sensor) y $\varepsilon_{E C b=0}$ es la permitividad del suelo cuando $E C b$ es despreciable (se toma un valor de 4.1 sugerido por Hilhorst, 2000). Para calcular $\varepsilon_{p}$ se utiliza una relación propuesta por el mismo autor que depende la temperatura $(T)$ medida por el mismo sensor:

$$
\varepsilon_{p}=80.3-0.37(T-20)
$$

Ecuación 6

Finalmente, otra alternativa utilizada fue la de Scudiero et al., (2012), que incluye un cálculo simultáneo (llamado así por el autor) de WWC y ECp:

$$
\begin{array}{cc}
E C p=0.466 \frac{E C b}{\phi^{n^{\prime}}\left(\frac{V W C}{\phi}\right)^{m^{\prime}}} & \text { Ecuación 7 } \\
V W C=\left(a+a^{\prime} E C b\right)\left(1-0.738 \times \ln _{\varepsilon_{b}}\right) & \text { Ecuación 8 } \\
a=-0.427-0.006 \cdot \text { SOC } & \text { Ecuación 9 } \\
a^{\prime}=0.036-0.012 \cdot \frac{\% \text { acilla }}{\% \text { arena }} & \text { Ecuación 10 } \\
m^{\prime}=-2.8 \cdot 10^{-4} S O C+\frac{4.134 \text { SOC }}{\% \text { arena0.719 }+ \text { SOC }} & \text { Ecuación } 11 \\
n^{\prime}=-0.697+0.04 \% \text { arena } & \text { Ecuación } 12
\end{array}
$$

donde $a, a^{\prime}, m^{\prime}$ y $n^{\prime}$ son parámetros de ajuste que dependen de la textura y el SOC según las relaciones halladas por Scudiero et al., (2012). A partir de la Ecuación 7 y Ecuación 8 se puede reescribir como: 


$$
E C p=0.466 \frac{E C b}{\phi^{n^{\prime}}\left(\frac{\left(a+a^{\prime} E C b\right)\left(1-0.738 \times \ln _{\varepsilon_{b}}\right)}{\phi}\right)^{m^{\prime}}}
$$

donde el cálculo de $E C p$ se hace a partir de las dos mediciones directas del sensor de $E C b$ y $\varepsilon_{b}$.

Para seleccionar el modelo más adecuado se evaluó la correlación con los valores medidos $\left(E C_{1: 2,5}\right)$ y de la comparación entre WWC y $E C p$. En esta última comparación se espera una correlación negativa ya que un aumento de VWC implica una disminución en $E C p$ por dilución de sales. El modelo propuesto por Hilhorst, (2000) fue el que mejor se correlacionó con los datos medidos y el que mostró un mejor comportamiento respecto de VWC mostrando la dilución de las sales (Figura 3-5). Cabe destacar que estos modelos solo son válidos cuando el contenido de agua en el suelo permite una corriente continua a través del suelo, por lo que a valores muy bajos de VWC no es posible estimar ECp. 


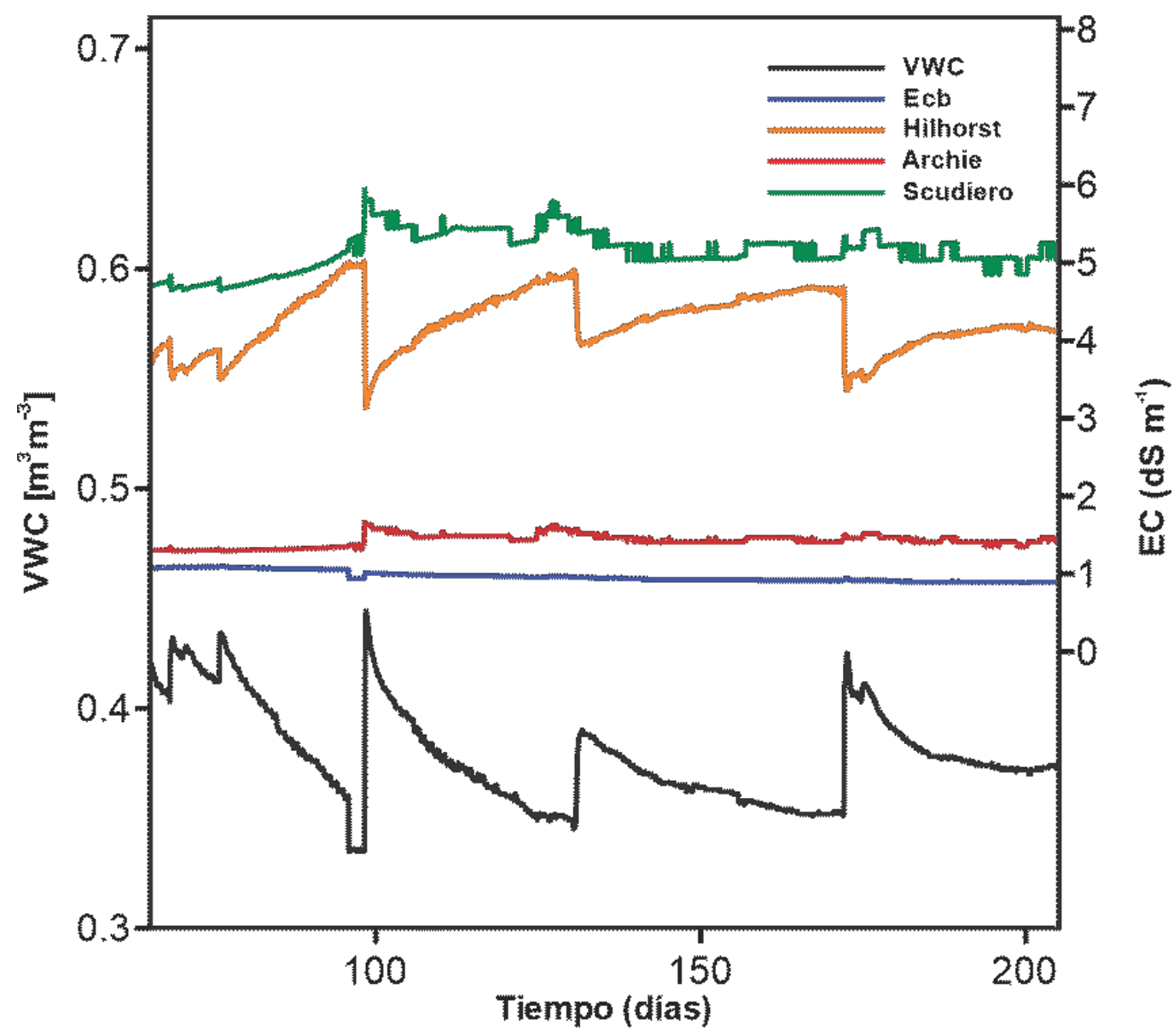

Figura 3-5. Comparación entre los diferentes modelos de cálculo de la ECp. Valores medidos en el pastizal a $0.2 \mathrm{~m}$ de profundidad a modo de ejemplo.

\subsubsection{Transpiración de la forestación}

Se midió el flujo de savia en 9 árboles mediante sensores de disipación de calor tipo Granier (ver Granier, 1985, 1987), los datos medidos se almacenaron en un colector automático de datos cada 30 minutos (Campbell CR10X, Campbell Scientific, Logan, Utah, EE.UU.). El método consiste de dos termocuplas instaladas en contacto con el xilema del árbol, a través de un orificio y separadas a $10 \mathrm{~cm}$ entre sí y a $1 \mathrm{~m}$ de altura en el tronco. Sólo una de ellas se calienta y el flujo de savia se calcula en base a la diferencia de temperaturas entre ellas (Figura 3-3 c). Para evitar el calentamiento externo de la zona intervenida, como de las termocuplas instaladas, se protegió con un aislante de espuma de polietileno aluminizado de $1 \mathrm{~cm}$. 
Así, la velocidad de flujo de savia $\left(v, \mathrm{~mm} \mathrm{~s}^{-1}\right)$ se calculó con la fórmula establecida por Granier (1985, 1987):

$$
v=0.119 k^{1.231}
$$

Ecuación 14

donde $k$ está relacionado con la diferencia de temperatura entre los dos sensores instalados $(\Delta T)$ :

$$
k=\frac{\left(\Delta T_{m}-\Delta T\right)}{\Delta T}
$$

y $\Delta T_{m}$ es la diferencia de temperatura cuando $v=0$, el cual corresponde con la máxima $\Delta T$ registrada por el sensor (i.e., no hay enfriamiento de la termocupla calentada artificialmente por parte del flujo de sabia).

Para medir el área de xilema activo $(X A)$ se barrenaron tarugos con un barreno de Pressleer, de árboles representativos de la parcela medida $(n=15)$ y se midió la sección del tarugo con xilema hidroactivo $\left(S e c_{x a}\right.$, se reconoce por ser húmeda y translúcida). Además, se midió el diámetro de cada uno de estos individuos $\left(S e c_{\text {total }}\right)$, y el espesor de la corteza $\left(S e c_{c o r}\right)$. La termocupla insertada en contacto con el xilema fue de $2 \mathrm{~cm}$ de largo (Granier, 1985), sin embargo el xilema activo puede tener una sección igual, mayor o menor.

La Ecuación 15 es correcta sólo en el primer caso, para el caso de que el $S e c_{x a}$ es mayor al largo de la termocupla se usó una función decreciente lineal en la sección no alcanzada por la termocupla, ya que varios autores han observado una disminución en la conducción desde el exterior hacia el centro del xilema (Zang et al., 1996). Esta corrección se calculó según:

$$
v_{c}=v \frac{S e c_{t e}}{\operatorname{Sec}_{x a}}+v \frac{v}{\operatorname{Sec}_{x a}}
$$


donde $v_{c}$ es la velocidad de flujo de sabia corregida y $S e c_{t e}$ es el largo de la termocupla.

Para el caso en que $S e c_{x a}$ es menor que el largo de la termocupla, se aplicó una corrección en $\Delta T$ según (Lu et al., 2004; Clearwater et al., 1999):

$$
\Delta T=\frac{\Delta T-b \Delta T_{m}}{a}
$$

donde $a$ y $b$ son las proporciones de la termocupla en el $X A$ y en el xilema inactivo, respectivamente. Finalmente, para calcular la lámina transpirada por el rodal $\left(Q_{T, S F}, \mathrm{~mm} \mathrm{~s}^{-1}\right)$ se escaló $B_{A}$ por el área proporcional de $X A$ (Ecuación 18) de un árbol ( $f_{X A}$, Ecuación 19), obteniendo en este punto una representación del área de $X A$ por hectárea, y se multiplicó por $v$ (Ecuación 20).

$$
\begin{array}{cr}
X A=\left(\pi\left(\frac{S e c_{\text {total }}-S e c_{\text {cor }}}{2}\right)^{2}\right)-\left(\pi\left(\frac{\operatorname{Sec}_{\text {total }}-S e c_{\text {cor }}-S e c_{x a}}{2}\right)^{2}\right) & \text { Ecuación } 18 \\
f_{X A}=X A /\left(\pi \cdot\left(\frac{S e c_{\text {total }}-S e c_{\text {cor }}}{2}\right)^{2}\right) & \text { Ecuación } 19 \\
Q_{T, S F}=v \cdot f_{X A} \cdot B_{A} & \text { Ecuación 20 }
\end{array}
$$

\subsubsection{Exploración geoeléctrica}

Para obtener una mejor exploración del perfil vertical, el 17/11/2016, se realizó un relevamiento con tomografía de resistividad eléctrica (ERT de 'electrical resistivity tomography'; Equipo AGI SuperString R1/IP de 56 electrodos), para esto se instalaron los electrodos con una separación de $1 \mathrm{~m}$, por lo cuales se inyecta corriente eléctrica y se mide alternativamente y de modo automático para generar una grilla de puntos de resistividad aparente. Estos valores fueron invertidos con el código Earthlmager 2D (Advanced Geosciences, Inc., 2005), para obtener las resistividades reales (Dietrich et al., 2014). 


\subsubsection{Modelos de transporte reactivo}

Los procesos de salinización conducen a la pérdida de fertilidad del suelo para la mayoría de las actividades agropecuarias. Este proceso disminuye drásticamente el rendimiento de los cultivos agrícolas (o los imposibilita), así como también es restrictivo para el crecimiento de verdeos, pasturas y especies forestales (Maas, 1985). Es por ello, que disponer de herramientas que permita mejorar el conocimiento sobre los procesos que potencialmente generarían la salinización en suelos, permitirá desarrollar prácticas y normas acordes con la sostenibilidad de los sistemas productivos.

La modelación del transporte reactivo (TR) es una de estas herramientas y se basa esencialmente en el balance de masa y energía, y permitiría testear hipótesis, validar modelos conceptuales, y realizar análisis cuantitativos de las complejas interacciones hidrogeoquímicas dentro de estos sistemas (Figura 3-6). Esta herramienta permite estimar la distribución de las concentraciones de solutos y nutrientes dentro del suelo consecuencia del acoplamiento entre los procesos de flujo de agua en la fase líquida y vapor, transporte de calor y solutos, las reacciones químicas, y las interacciones suelo-rizósfera.

En la actualidad existen una gran variedad de modelos de TR aplicados a suelos bajo condiciones saturadas y no saturadas, como por ejemplo para la evaluación de residuos mineros (Bea et al., 2012; Meima et al., 2012), residuos radioactivos (Hyman et al., 2015; Bea et al., 2013; Steefel y Lichtner, 1998), la formación y meteorización química de suelos (Lawrence et al., 2014), procesos de bio-remediación de suelos (Steefel et al., 2015; Yabusaki et al., 2011), evolución de comunidades de microorganismos en sistemas de aguas subterráneas, así como su transporte y fijación/liberación del sustrato (Cho et al., 
2016; Hron et al., 2015), así como también tienen aplicaciones en agricultura y silvicultura (Hopmans y Bristow, 2002), entre muchas otras aplicaciones (Mujica y Bea, 2020; Mujica et al., 2019a).

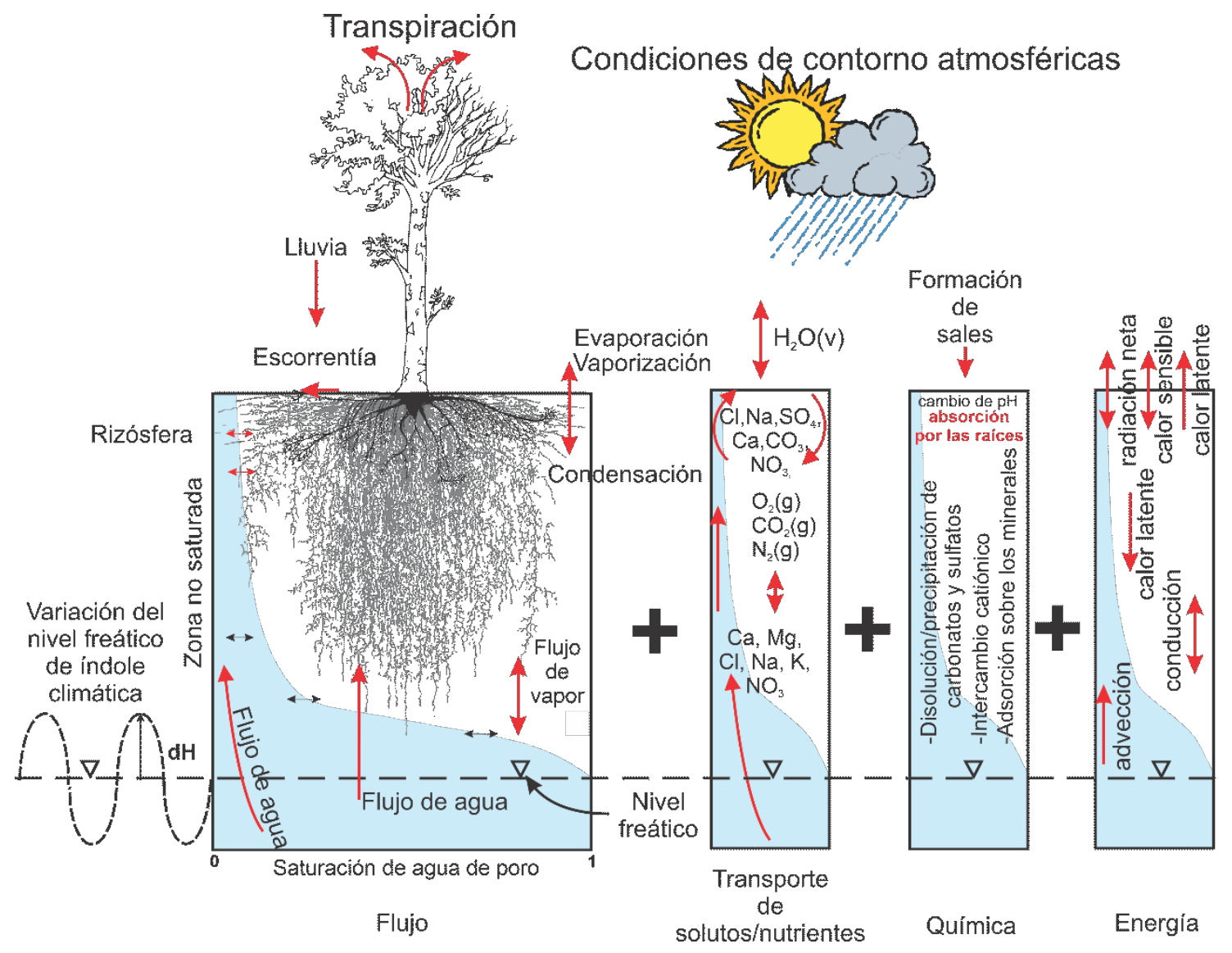

Figura 3-6. Modelo conceptual contemplado por la modelación de transporte reactivo en la presente tesis.

Recientemente se desarrollaron modelos de TR acoplados al crecimiento de las raíces y su interacción con el sustrato, en términos de flujo de agua y solutos (Gérard et al., 2004, 2017; Steefel et al., 2015; Dunbabin et al., 2013; Mayer et al., 2012; Seaman et al., 2012; Nowack et al., 2006; Hinsinger et al., 2005). Durante la presente tesis se usará y desarrollará el modelo de transporte reactivo MIN3P (Bea et al., 2012, 2015; Mayer et al., 2002, 2012).

\subsubsection{Ecuaciones del modelo MIN3P}

El principio básico de TR es la conservación tanto de masa como de energía, y de hecho el flujo de agua en la ZNS se describe por medio de la 
ecuación de Richards modificada de acuerdo a (Bea et al., 2012; Saito et al., 2006):

$$
\frac{\delta \phi S_{l} \rho_{l}}{\delta t}+\frac{\delta \phi S_{v} \rho_{v}}{\delta t}=\nabla \cdot q_{l}+\nabla \cdot q_{v}+f_{w} \zeta
$$

Ecuación 21

donde $\phi$ es la porosidad [-], $S_{l}$ y $S_{v}$ son las saturaciones en líquido y vapor (calculadas con el modelo de van Genuchten, 1980), respectivamente [-], $\rho_{l}$ y $\rho_{v}$ son las densidades en fase líquida y vapor $\left[\mathrm{M} \mathrm{L}^{-3}\right]$, respectivamente, $t$ es el tiempo [T], $q_{l}$ y $q_{v}$ son los flujos en fase liquida $\mathrm{y}$ vapor $\left[\mathrm{M} \mathrm{L}^{-2} \mathrm{~T}^{-1}\right.$, respectivamente, $f_{\mathrm{w}}$ es el término fuente/sumidero $\left[\mathrm{M} \mathrm{L}^{-2} \mathrm{~T}^{-1}\right]$, mientras que $\zeta$ es una constante que relaciona la superficie en el contorno con el volumen del medio poroso $\left[\mathrm{L}^{2} \mathrm{~L}^{-3}\right]$. El modelo de van Genuchten (1980) describe la saturación $(S)$ en medios porosos (Wosten y van Genuchten, 1988; van Genuchten, 1980):

$$
\begin{gathered}
S=S^{r l}+\frac{1-S^{r l}}{\left(1+\alpha_{v g} h^{n}\right)^{m}} \\
k_{r}=S_{e a}^{l}\left[1-\left(1-S_{e a}^{1 / m}\right)^{m}\right]^{2}
\end{gathered}
$$

Ecuación 23

donde $S^{r l}$ es la saturación residual de la fase acuosa del suelo [-], $\alpha_{v g}$ es un coeficiente que relaciona con la inversa de la succión de entrada de aire del suelo $\left[\mathrm{m}^{-1}\right]$ y $n$ medida de la distribución del tamaño de poros [-]; $k_{r}$ es la permeabilidad realtiva expresada como función de la saturación [-]; l es un parámetro empírico específico del suelo y $m$ es igual a:

$$
m=1-\frac{1}{n}
$$

$S_{e a}$ es la saturación efectiva en fase acuosa y está dada por: 


$$
S_{e a}=\frac{S-S^{r l}}{1-S^{r l}}
$$

El flujo de agua líquida $\left(q_{l}\right)$ depende principalmente de las propiedades físicas del suelo, y de los gradientes hidráulicos y térmicos expresados a través de la ley de Darcy:

$$
q_{l}=\rho_{l} v_{l}=-\rho_{l} \frac{K k_{r}}{\mu_{l}}\left[\left(\nabla P_{l}+\rho_{l} g\right)+G_{w t} \frac{P_{l}}{\gamma_{0}} \frac{\partial \gamma}{\partial T} \nabla T\right] \quad \text { Ecuación } 26
$$

donde $v_{l}$ es el flujo de Darcy modificado $\left[\mathrm{L} \mathrm{T}^{-1}\right], K$ es el tensor de permeabilidad [ $\left.\mathrm{L}^{2}\right], k_{r}$ es la permeabilidad relativa [-] que es una función de la saturación de la fase de agua líquida $\left(S_{l}\right), P_{l}$ es la presión del líquido $\left[\mathrm{M} \mathrm{L}^{-1} \mathrm{~T}^{-2}\right], g$ es la contante gravitacional [L T-2$], \mu_{l}$ es la viscosidad dinámica del agua líquida $\left[\mathrm{M} \mathrm{L}^{-1} \mathrm{~T}^{-1}\right], G_{w t}$ es un factor de ganancia que cuantifica la dependencia de la curva de retención con la temperatura. [-], $\gamma$ y $\gamma_{0}$ son la tensión superficial del agua [M T-2], y su valor de referencia a $25^{\circ} \mathrm{C}\left(71.89 \mathrm{~g} \mathrm{~s}^{-2}\right)$, respectivamente.

La estimación de los flujos de agua en el suelo implica conocer el equilibrio entre la fase liquida y vapor, el cual depende fuertemente de la temperatura. Para este propósito, MIN3P resuelve el balance de energía de acuerdo a (Bea et al., 2012; Philip y Vries, 1957):

$$
\frac{\delta \phi c_{l} S_{l} \rho_{l} T}{\delta t}+\frac{\delta \phi c_{v} S_{v} \rho_{v} T}{\delta t}+\frac{\delta(1-\phi) c_{s} \rho_{s} T}{\delta t}+\frac{\delta L_{w} \phi S_{v} \rho_{v}}{\delta t}=\nabla \cdot j_{h}+f_{h} \zeta \quad \text { Ecuación } 27
$$

donde $c_{l}, c_{v}$ y $c_{s}$ son los coeficientes de calor específico para el agua líquida, vapor y sólido, respectivamente. [E M $\left.{ }^{-1}{ }^{\circ} \mathrm{C}^{-1}\right], j_{h}$ es el flujo de energía $\left[E \mathrm{~L}^{-3} \mathrm{~T}^{-1}\right]$, $L_{w}$ es el calor latente de vaporización del agua líquida $\left[\mathrm{E} \mathrm{M}^{-1}\right]$, y $f_{h}$ es un término fuente/sumidero de energía $\left[E \mathrm{~L}^{-2} \mathrm{~T}^{-1}\right]$. El término $\nabla \cdot j_{h}$ en la Ecuación 27 incluye 
los procesos de transporte de calor por advección, conducción y dispersión de acuerdo a:

$$
\nabla \cdot j_{h}=\nabla \cdot c_{l} q_{l} T-\nabla \cdot \lambda \nabla T+\nabla \cdot \phi c_{l} \rho D_{h} \nabla T+\nabla \cdot c_{v} q_{v} T+\nabla \cdot L_{w} q_{v} \quad \text { Ecuación } 28
$$

donde $\lambda$ es el tensor de conductividad térmica $\left[E \mathrm{~L}^{-1} \mathrm{~T}^{-10} \mathrm{C}^{-1}\right]$, y $D_{h}$ es el tensor de dispersión térmica $\left[\mathrm{L}^{2} \mathrm{~T}^{-1}\right]$.

El balance de masa de agua en el suelo depende también de parámetros climáticos como lluvia, la humedad relativa, la radiación solar, etc. La evaporación/condensación $(E)$, la lluvia $(P)$, la escorrentía superficial $\left(J_{s r}\right)$, y la transpiración $\left(Q_{T}\right)\left[\mathrm{M} \mathrm{L}^{-2} \mathrm{~T}^{-1}\right]$, son consideradas en el término fuente/sumidero $f_{w}$ (Ecuación 21), definido como:

$$
f_{w}=P+F_{i} I+E+J_{s r}+Q_{T} \quad \text { Ecuación } 29
$$

donde $I$ es la intercepción por el dosel vegetal $\left[\mathrm{M} \mathrm{L}^{-2} \mathrm{~T}^{-1}\right]$, y $F_{i}[-]$ es un factor de cultivo que representa la velocidad a la que se evapora el agua interceptada.

La evaporación de agua como proceso físico es controlada por el intercambio de calor entre la superficie del suelo y la atmósfera, el flujo de agua dentro del suelo, y la trasferencia de vapor de agua desde la superficie del suelo a la atmósfera. Si alguno de estos procesos se altera, la evaporación también lo hará. La forma integrada de la Ley de Fick de difusión de vapor contempla los procesos antes mencionados. Esta forma de la Ley de Fick implica que la tasa de evaporación es proporcional al déficit de densidad de vapor entre la superficie del suelo y la atmósfera, e inversamente proporcional a la suma de las resistencias al flujo de vapor de la capa límite de la atmósfera $\left(r_{h}\right)$ y de la superficie del suelo $\left(r_{s}\right)\left[\mathrm{T} \mathrm{L}^{-1}\right]$ : 


$$
E=\frac{\left(\rho_{v}^{a t m}-\rho_{v}\right)}{r_{s}+r_{h}}
$$

donde $\rho_{v}^{a t m}$ es la densidad de vapor de la atmósfera $\left[\mathrm{M} \mathrm{L}^{-3}\right]$ que es función de la humedad relativa del aire (Bea et al., 2012; Saito et al., 2006).

Por otro lado, el termino fuente sumidero de energía $\left(f_{h}\right)$ en la Ecuación 27 se calcula de acuerdo al balance en la superficie del suelo como (Bea et al., 2012; Saito et al., 2006):

$$
f_{h}=h_{s}+L_{w} E+c_{l} P T_{a t m}+R_{n}
$$

Ecuación 31

donde $R_{n}$ es la radiación solar neta [E L $\left.\mathrm{L}^{-2} \mathrm{~T}^{-1}\right]$. El flujo de calor sensible $h_{s}$ [E $\mathrm{L}^{-2}$ $\mathrm{T}^{-1}$ ] en la Ecuación 31, de la misma forma que la evaporación, se describe también por una relación de difusión de acuerdo a:

$$
h_{s}=\rho_{g}^{a t m} c_{g} \frac{\left(T_{a t m}-T\right)}{r_{h}}
$$

Ecuación 32

donde $\rho_{g}^{a t m}$ es la densidad del aire $\left[\mathrm{M} \mathrm{L}^{-3}\right]$, y $c_{g}$ es el calor específico del aire [E $\mathrm{M}^{-1}{ }^{\circ} \mathrm{C}^{-1}$ ]. Los términos $c_{l} P T_{\text {atm }}$ y $L_{w} E$ en la Ecuación 31 consideran los flujos internos de energía y flujo de agua.

La transpiración ( $Q_{T}$ en Ecuación 29) depende la de la humedad del suelo, y está limitada por la evapotranspiración del cultivo en condiciones estándar $\left(E T_{c}\right)$. Esta última es calculada con la ecuación de Penman-Monteith actualizada por Allen G. et al. (2006). Así, $Q_{T}$ se calcula como la suma de la transpiración de cada volumen discreto de suelo representando la rizósfera de acuerdo a:

$$
Q_{T}=E T_{c} \sum_{i} \frac{\alpha_{i} V_{i} R_{k(i)} S_{a, i}}{\sum_{j \in l} V_{j} R_{k(j)} S_{a, j}}
$$


donde $\alpha_{i}$ es el factor de estrés (es la relación entre la transpiración real y la potencial), $R_{\mathrm{i}(\mathrm{k})}$ es la densidad longitudinal de raíces [ $\left.\mathrm{L} \mathrm{L}^{-3}\right], V_{i}$ es el volumen discreto de suelo $\left[\mathrm{L}^{3}\right]$. Así, el factor de estrés del $i$-ésimo Ecuación 34 volumen discreto de suelo $\left(\alpha_{i}\right)$ es calculado con la expresión dada por Battaglia \& Sands, (1997):

$$
\begin{gathered}
\alpha_{i}=\frac{w_{i}^{2} \exp \left(a_{w} w_{i}\right)}{w_{0}^{2} \exp \left(a_{w} w_{0}\right)+w_{i j}^{2} \exp \left(a_{w} w_{i}\right)} \\
w_{i}=\frac{S_{a, i}^{a v g}-S_{a}^{l i m}}{S_{a}^{f}-S_{a}^{l i m}}
\end{gathered}
$$

Ecuación 35

donde $w_{i}$ define la reserva de agua extractable, $w_{0}$ es el valor de $w$ para el cual $\alpha=1 / 2, a_{w}$ es la pendiente de la porción lineal de la curva de factor de estrés y agua disponible en el suelo, $S_{a, i}^{a v g}$ es la saturación del suelo en la rizósfera, $S_{a}^{f}$ es la saturación a capacidad de campo, y $S_{a}^{\lim }$ es la saturación en punto de marchitez permanente. ambos $w_{0}$ y $a_{w}$ fueron extraídos de Battaglia \& Sands (1997) para E. globulus (Figura 3-7). Nótese que este método es más riguroso desde la perspectiva del medio poroso, porque tiene en cuenta la variación espacial de los parámetros del suelo. Sin embargo, es menos riguroso desde el punto de vista de la fisiología del árbol, ya que se asume que la apertura estomática está controlada por el valor de $w_{i}$ (Mayer et al., 2012). 


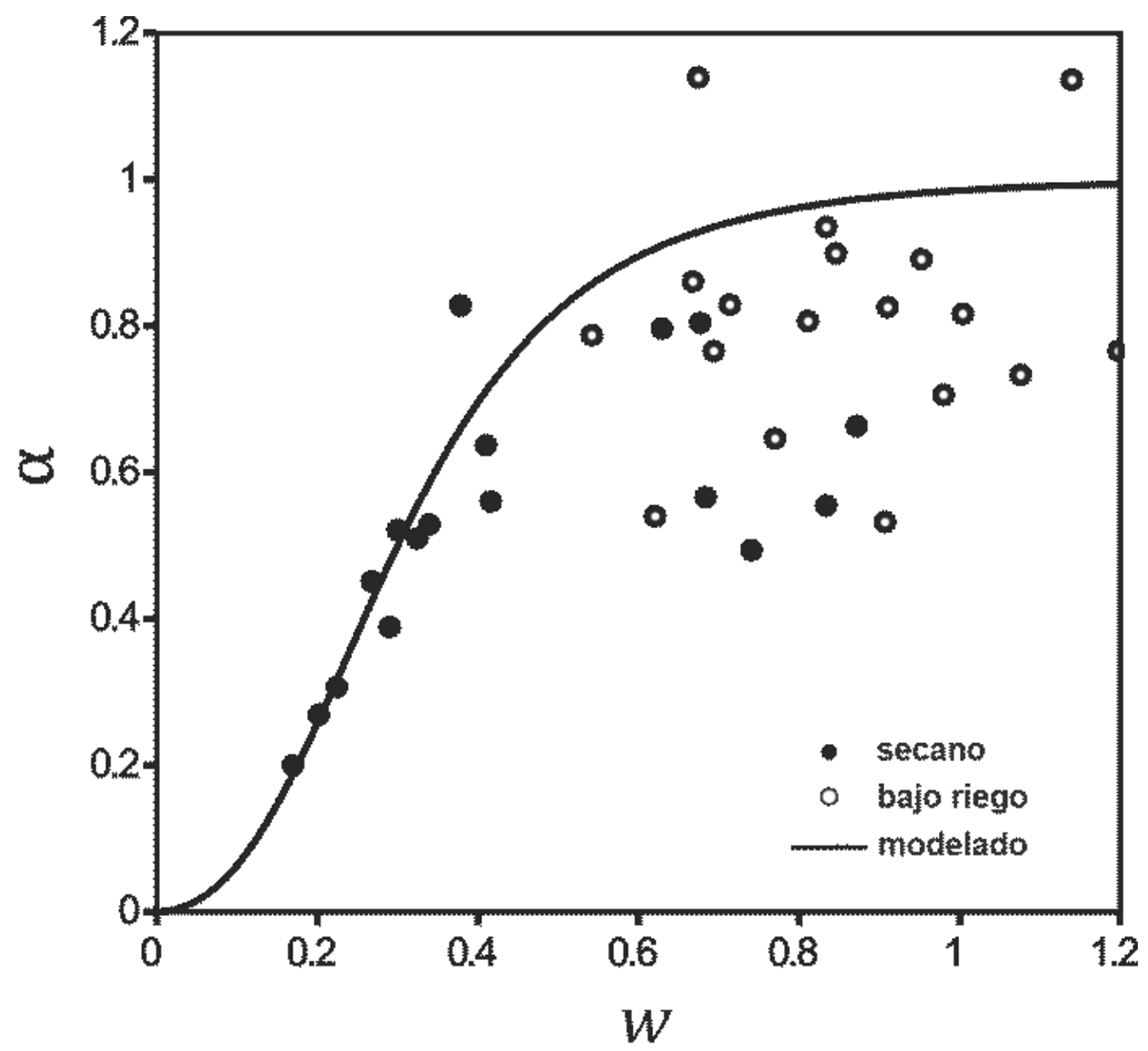

Figura 3-7. Relación observada entre los parámetros $\alpha$ y w (Ecuación 34 y Ecuación 35) Modificadas de Battaglia \& Sands (1997) para E. globulus bajo secano y riego.

Acoplado al flujo, la modelación del TR requiere resolver las ecuaciones de conservación de masa para cada una de las componentes químicas (Mayer et al., 2002) de acuerdo a:

$$
\frac{\delta \phi S_{l} T_{j}^{a}}{\delta t}+\frac{\delta T_{j}^{d}}{\delta t}+\frac{\delta \phi S_{g} T_{j}^{g}}{\delta t}=
$$

Ecuación 36

$$
\begin{gathered}
\nabla \cdot \phi S_{l} D_{w} \nabla T_{j}^{a}+\nabla \cdot \phi S_{g} D_{g} \nabla T_{j}^{g}-\nabla \cdot q_{w} T_{j}^{a}+Q_{j}^{a, m}+Q_{j}^{a, b c}+Q_{j}^{g, b c} \\
T_{j}^{a}=C_{j}^{c}+\sum_{i=1}^{N_{x}} v_{i j}^{x} C_{i}^{x} \\
T_{j}^{d}=\sum_{i=1}^{N_{d}} v_{i j}^{d} C_{i}^{d}
\end{gathered}
$$

Ecuación 38 


$$
T_{j}^{g}=\sum_{i=1}^{N_{g}} v_{i j}^{g} C_{i}^{g}
$$

donde $T_{j}^{a}, T_{j}^{d}$, y $T_{j}^{g}$ son las concentraciones totales de la $j$-ésima componente química en la fase acuosa, intercambiada y gaseosa, respectivamente $\left[\mathrm{M} \mathrm{L}^{-3}\right] ; C_{j}^{c}$ es la concentración acuosa de la $j$-ésima especie primaria $\left[\mathrm{M} \mathrm{L}^{-3}\right] ; v_{i j}^{x}$ es el coeficiente estequiométrico de las especies que participan en la reacción [-]; $C_{i}^{x}$ es la concentración de la $i$-ésima especie acuosa secundaria $\left[\mathrm{M} \mathrm{L}^{-3}\right] ; C_{j}^{d}$ es la concentración de la $i$-ésima especie intercambiada $\left[\mathrm{M} \mathrm{L}^{-3}\right] ; v_{i j}^{d}$ es el coeficiente estequiométrico de la reacción [-]; $C_{i}^{g}$ es la concentración de la $i$-ésima componente gaseosa $\left[\mathrm{M} \mathrm{L}^{-3}\right]$ y $v_{i j}^{g}$ es el coeficiente estequiométrico de la reacción [-], (detalles de cálculos pueden ser obtenidos de Mayer et al., 2002). Mientras que $Q_{j}^{a, m}$ es la generación/consumo de dicha componente química como consecuencias de las reacciones químicas de disolución/precipitación mineral cinéticas, $Q_{j}^{a, b c}, Q_{j}^{g, b c}$ son los términos fuente/sumidero correspondiente a las condiciones de contorno, para la fase líquida y gaseosa, respectivamente $\left[M \mathrm{~L}^{-3}\right.$ $\mathrm{T}^{-1}$, y $D_{w}, D_{g}$ son la dispersión mecánica en la fase acuosa y gaseosa, respectivamente $\left[\mathrm{L}^{2} \mathrm{~T}^{-1}\right]$. El término $Q_{j}^{a, b c}$ en la Ecuación 36 también incluye el flujo másico consecuencia de la toma de nutrientes/solutos por parte de las plantas, y aquél que resulta para equilibrar eléctricamente la solución acuosa en el entorno de la raíz, y se define como (Mujica et al., 2019c):

$$
Q_{j}^{a, b c}=Q_{j}^{a, e}+Q_{j}^{a, u p}+Q_{j}^{a, u a}+Q_{j}^{a, c h}
$$

donde $Q_{j}^{a, e}$ es el flujo de masa que entra por los contornos, mientras que $Q_{j}^{a, u p}$ y $Q_{j}^{a, u a}$ son los flujos másicos por la toma de nutrientes/solutos por un mecanismo 
pasivo y activo, respectivamente $\left[\mathrm{M} \mathrm{L} \mathrm{L}^{-3} \mathrm{~T}^{-1}\right]$. El mecanismo activo $\left(Q_{j}^{a, u a}\right)$ responde a la expresión de Michaelis-Menten (Nowack et al., 2006; Hopmans y Bristow, 2002):

$$
Q_{j}^{a, u a}=\left(1-f_{u}\right) \cdot F_{m, j} \frac{T_{j}^{a}-T_{j}^{a, m i n}}{K m_{j}+\left(T_{j}^{a}-T_{j}^{a, \min }\right)} \rho_{r}
$$

donde $f_{u}$ es un factor que relaciona $Q_{j}^{a, u p}$ y $Q_{j}^{a, u a}, \rho_{r}$ es la densidad de área de raíz por unidad de volumen de medio poroso $\left[\mathrm{L}^{2} \mathrm{~L}^{-3}\right], F_{m, j}$ es el flujo máximo de entrada de la $j$-ésima especie química $\left[\mathrm{M} \mathrm{L} \mathrm{L}^{-2} \mathrm{~T}^{-1}\right], K m_{j}$ es la constante que equivale a la concentración de la j-ésima componente cuando el flujo de entrada es la mitad de $F_{m, j}\left[\mathrm{M} \mathrm{L}^{-3}\right]$. El mecanismo pasivo se describe como:

$$
Q_{j}^{a, u p}=f_{u} \cdot Q_{T} T_{j}^{a} \rho_{r}
$$

Ecuación 42

Sin embargo, y como ha sido expuesto anteriormente, la toma selectiva/exclusión de nutrientes/solutos por parte de las freatófitas puede generar un desbalance eléctrico en la solución acuosa que es compensado por las raíces por medio de la exudación de la $j$-ésima componente química (Dakora y Phillips, 2002), e internamente en MIN3P es calculado en el término $Q_{j}^{a, c h}$ de la Ecuación 40 como (Mujica et al., 2019c):

$$
Q_{j}^{a, c h}=F_{m, j} \cdot\left(1-\frac{\sum_{i}^{N_{a}}\left(Z_{i} C_{i}\right)}{\sum_{i}^{N_{c}}\left(Z_{i} C_{i}\right)}\right) \rho_{r}
$$

donde $Z_{i}$ y $C_{i}$ son la carga eléctrica y concentración de la $i$-ésima especie iónica, y $N_{a}, N_{c}$, son el número total de aniones y cationes, respectivamente.

Por último, el TR también implica resolver las ecuaciones de conservación de la masa de mineral (Mayer et al., 2002): 


$$
\frac{\delta V_{f, i}^{m}}{\delta t}=V_{i}^{m} R_{i}^{m}\left(\Omega_{\mathrm{i}}\right)
$$

donde $V_{f, i}^{m}$ [-] es la fracción volumétrica de la $i$-ésima especie mineral, $V_{i}^{m}$ su volumen molar [ $\left.\mathrm{L}^{3} \mathrm{M}^{-1}\right]$, y $R_{i}^{m}$ es su velocidad de disolución/precipitación [M $\mathrm{L}^{-3}$ $\left.\mathrm{T}^{-1}\right]$ que es función del estado de saturación del mismo $\left(\Omega_{\mathrm{i}}\right)[-]$. Los cambios en la porosidad consecuencia de la disolución/precipitación mineral $\left(\Delta \phi^{m, t+\Delta t}\right)$ son calculados en cada incremento de tiempo $(\Delta t)$ como (e.g., ver Xie et al., 2015):

$$
\Delta \phi^{m, t+\Delta t}=\sum_{i-1}^{N m} V_{f, i}^{m, t+\Delta t}-V_{f, i}^{m, t}
$$

donde $V_{f, i}^{m, t+\Delta t}$ y $V_{f, i}^{m, t}$ son las fracciones volumétricas del $i$-ésimo mineral antes y después de cada incremento de tiempo.

Para calcular la conductividad eléctrica $(E C)$ a partir de las concentraciones, se utilizó la formulación de Miller et al., (1988):

$$
E C=\sum \alpha_{m} \lambda_{i}^{o} C_{i}
$$

Ecuación 46

donde $\alpha_{m}$ es la fracción de la especie $i$ que esta en forma de ion, se considera igual a uno en la mayoría de los casos lo que implica completa disociación; $\lambda_{i}^{o}$ es la conductancia equivalente límite del ion $i$ (Tabla 3.1). 
Tabla 3.1, Conductancias equivalentes limite extraído de (Selvaratnam y Spiro, 2004; Miller et al., 1988)

\begin{tabular}{cccc}
\hline Catión & $\lambda^{0}$ & Anión & $\lambda^{0}$ \\
\hline $\mathrm{Ca}^{+2}$ & 59.50 & $\mathrm{Br}^{-}$ & 78.2 \\
$\mathrm{H}^{+}$ & 349.8 & $\mathrm{Cl}^{-}$ & 76.35 \\
$\mathrm{~K}^{+}$ & 73.52 & $\mathrm{~F}^{-}$ & 55.32 \\
$\mathrm{Li}^{+}$ & 38.66 & $\mathrm{HCO}_{3}^{-}$ & 44.5 \\
$\mathrm{Mg}^{+2}$ & 53.06 & $\mathrm{I}^{-}$ & 76.9 \\
$\mathrm{Na}^{+}$ & 50.11 & $\mathrm{NO}_{3}^{-}$ & 71.44 \\
$\mathrm{NH}_{4}^{+}$ & 73.4 & $\mathrm{OH}^{-}$ & 197.8 \\
$\mathrm{Sr}^{+}$ & 59.46 & $\mathrm{SO}^{-2}$ & 80.0 \\
& & $\mathrm{PO}_{4}^{-}$ & 32.3 \\
\hline
\end{tabular}

\subsubsection{Dominio del modelo de flujo y condiciones de contorno}

El dominio del modelo consistió de un bloque de 5,4 m de profundidad con 6 capas correspondientes a cada uno de los horizontes de suelo observados, sin tener en cuenta el orgánico O (ver Figura 3-4b). En la parte superior del modelo se impuso condiciones de contorno atmosféricas, mientras que los contornos laterales se consideraron impermeables al flujo de calor y agua (Figura 3-4b). Los registros de temperatura de la atmósfera, la humedad relativa, y la radiación solar utilizada en las simulaciones se muestran en la Figura 3-8a y Figura 3-9a, respectivamente. La radiación que se impuso en el modelo se calculó a partir de los datos diarios de heliofanía de la estación meteorológica, escalados por el factor de cobertura forestal del suelo. Esta se obtuvo a través de un análisis de imágenes tomadas desde abajo del dosel con una cámara fotográfica digital y utilizando el software Image J (US Natl Inst. of Health, Bethesda, Maryland, USA, 1997-2012). La velocidad del viento medida de alrededor $\left(\sim 2.75 \mathrm{~m} \mathrm{~s}^{-1}\right)$ se redujo un $50 \%$ de acuerdo a lo hallado por otros autores en rodales similares (Souza et al., 2010; Stigter et al., 2002). Por otro lado, en el borde inferior del dominio se 
impuso una condición de nivel fijo variable en el tiempo, representando la variabilidad del nivel freático (Figura 3-8 d). Las densidades de raíces se calibraron usando el modelo PEST (Doherty, 2016) acoplado al modelo MIN3P en cada uno de los escenarios simulados, y se utilizaron los valores medidos de VWC y transpiración como parámetros de observación.

Tabla 3.2. Parámetros físicos usados en el modelo

\begin{tabular}{|c|c|c|c|c|c|c|}
\hline Parámetro & $\mathrm{Ap}$ & BA & Bt1 & Bt2 & $2 \mathrm{CKkm}$ & loess \\
\hline porosidad [-] & 0.4874 & 0.4512 & 0.4944 & 0.4603 & 0.4980 & 0.6620 \\
\hline $\begin{array}{l}\text { Conductividad hidráulica } \\
\qquad\left[\mathrm{m} \mathrm{s}^{-1}\right]\end{array}$ & 3.1E-6 & $1.05 \mathrm{E}-6$ & $1.89 \mathrm{E}-6$ & 1.03E-6 & $2.89 E-7^{a}$ & $5.78 \mathrm{E}-7^{a}$ \\
\hline \multicolumn{7}{|l|}{ Curva de retención } \\
\hline$\alpha_{V G}\left[\mathrm{~m}^{-1}\right]$ & 1.42 & 1.61 & 1.58 & 1.38 & $0.65^{a}$ & $1.00^{a}$ \\
\hline$n_{V G}[-]$ & 1.41 & 1.34 & 1.38 & 1.39 & $1.50^{a}$ & $1.70^{a}$ \\
\hline$S^{\lim }[-]$ & 0.34 & 0.44 & 0.40 & 0.52 & 0.23 & 0.23 \\
\hline$S^{f}[-]$ & 0.51 & 0.62 & 0.57 & 0.58 & 0.36 & 0.37 \\
\hline$S^{r l}[-]$ & 0.049 & 0.038 & 0.044 & 0.038 & 0.089 & 0.119 \\
\hline Rugosidad aerodinámica, [m] & & & & 1 & & \\
\hline \multicolumn{7}{|l|}{ Caso base forestación } \\
\hline Distribución de raíces [\%] ${ }^{b}$ & 93.23 & 0.31 & 2.96 & 2.96 & 0.02 & 0.51 \\
\hline$a_{w}{ }^{\mathrm{c}}$ & & & & 2.5 & & \\
\hline$w_{0}{ }^{c}$ & & & & 0.3 & & \\
\hline \multicolumn{7}{|l|}{ RSUP } \\
\hline Distribución de raíces [\%] & 100 & 0.00 & 0.00 & 0.00 & 0.00 & 0.00 \\
\hline$a_{w}$ & & & & 2.5 & & \\
\hline$w_{0}$ & & & & 0.3 & & \\
\hline \multicolumn{7}{|l|}{ RPROF } \\
\hline Distribución de raíces [\%] ${ }^{\mathrm{d}}$ & 44.72 & 18.77 & 13.77 & 11.18 & 8.64 & 2.90 \\
\hline$a_{w}$ & & & & 2.5 & & \\
\hline$w_{0}$ & & & & 0.3 & & \\
\hline \multicolumn{7}{|l|}{ REST } \\
\hline Distribución de raíces [\%] & 93.23 & 0.31 & 2.96 & 2.96 & 0.02 & 0.51 \\
\hline$a_{w}$ & \multirow{2}{*}{\multicolumn{6}{|c|}{$\begin{array}{l}2.5(0.6 \text { en periodos LR })^{b} \\
0.3(0.5 \text { en periodos LR })^{b}\end{array}$}} \\
\hline$w_{0}$ & & & & & & \\
\hline \multicolumn{7}{|l|}{ Caso base pastizal } \\
\hline Distribución de raíces [\%] & 99.97 & 0.001 & 0.001 & 0.001 & 0.0 & 0.0 \\
\hline \multicolumn{7}{|l|}{ SIN TOSCA } \\
\hline $\begin{array}{l}\text { Conductividad hidráulica } \\
\qquad\left[\mathrm{m} \mathrm{s}^{-1}\right]\end{array}$ & $3.1 \mathrm{E}-6$ & $1.0 \mathrm{E}-6$ & $1.8 \mathrm{E}-6$ & $1.0 \mathrm{E}-6$ & $2.8 \mathrm{E}-6^{\mathrm{e}}$ & $5.7 \mathrm{E}-6^{\mathrm{e}}$ \\
\hline Distribución de raíces [\%] ${ }^{\mathrm{b}}$ & 99.97 & 0.001 & 0.001 & 0.001 & 0.0 & 0.0 \\
\hline \multicolumn{7}{|c|}{ 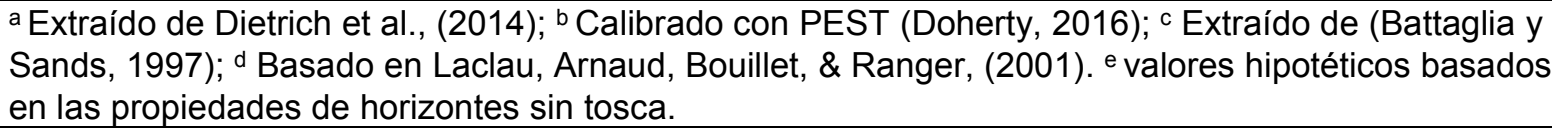 } \\
\hline
\end{tabular}

Se simularon un caso base y tres escenarios alternativos, para representar la parcela forestada, y un escenario base y otro alternativo para la parcela de pastizal. En ambos casos, los escenarios alternativos tienen el 
objetivo de evaluar la sensibilidad del modelo y potenciales modelos conceptuales. Los parámetros usados en el caso base y alternativos se detallan en Tabla 3.2.

Para evaluar la sensibilidad del modelo base a la distribución de la densidad de raíces, se ensayaron dos escenarios alternativos que reflejan situaciones extremas: (1) uno donde las raíces están distribuidas superficialmente (RSUP), y otro (2) donde éstas llegan en profundidad hasta el nivel freático (RPROF, ver Tabla 3.2).

El primero (1) asume que las raíces se distribuyen solo en el horizonte Ap, mientras que el segundo (2) supone una conexión hidráulica entre la forestación y el acuífero freático, con una distribución de raíces consistente con aquellas observadas para eucaliptos sobre suelos arenosos sin impedimentos para el desarrollo de las raíces (Laclau et al., 2001).

Para evaluar los parámetros empíricos que controlan la transpiración de la forestación ( $w_{0}$ y $a_{w}$ en la Ecuación 34; ver Figura 3-16) se montó el escenario REST. En este escenario los parámetros de Battaglia y Sands $\left(w_{0}\right.$ y $\left.a_{w}\right)$ en la Ecuación 34, se modificaron en los intervalos de tiempo inmediatamente después del período de escasos eventos de lluvia (del 10 de diciembre de 2015 al 25 de enero de 2016 y del 5 de septiembre de 2016 al 25 de enero de 2017 , ver sectores sombreados en la Figura 3-17, LR). En estos intervalos, los parámetros $w_{0}$ y $a_{w}$ se calibraron por medio de PEST (ver línea discontinua en la Figura 3-18), mientras que los períodos restantes se mantuvieron los valores utilizados en el caso base. 
Respecto de la parcela de pastizal, el escenario alternativo SIN TOSCA se diseñó para evaluar el impacto de la ausencia del horizonte petrocálcico sobre los flujos de agua dentro de la parcela herbácea (Tabla 3.2).

Por último, para evaluar el riesgo de salinización de una parcela forestada con las características anteriormente mencionadas, se llevó a cabo una simulación con un modelo de transporte conservativo con toma de nutrientes pasivo (Ecuación 42). Así, las mediciones de conductividad eléctrica del suelo, del agua freática y de la lluvia se impusieron como condiciones iniciales y de contorno, respectivamente.

El consumo del agua freática fue calculado en base al balance global de agua de acuerdo a:

$$
\underbrace{\left(G_{w}+P+C_{d}\right)}_{\text {entradas }}-\underbrace{\left(E+Q_{T}\right)}_{\text {salidas }}=\Delta S
$$

donde $G_{w}, P$, y $C_{d}$ son las entradas de agua desde el fondo del dominio del modelo (i.e., desde el acuífero freático), las precipitaciones y la condensación, respectivamente $\left[\mathrm{L} \mathrm{T}^{-1}\right], E$ y $Q_{T}$ son la evaporación física y la transpiración, respectivamente $\left[\mathrm{L} \mathrm{T}^{-1}\right]$, y $\Delta S$ es el cambio en el almacenamiento de agua $\left[\mathrm{L} \mathrm{T}^{-1}\right]$. Así, el porcentaje de agua freática $\left(\% G_{w}\right)$ consumida por la vegetación se calculó aproximadamente como:

$$
\% G_{w}=\frac{G_{w}}{E+Q_{T}} \cdot 100 \approx \frac{G_{w}}{Q_{T}} \cdot 100 \text { si } E<<<Q_{T}
$$

\subsubsection{Evaluación del modelo}

La precisión entre los resultados medidos y de MIN3P se evaluó estadísticamente mediante 4 indicadores. (1) El error cuadrático medio (RMSE), que mide la discrepancia de los valores simulados alrededor de los medidos. (2) 
El error medio absoluto $(M A E)$, que indica el porcentaje de la desviación promedio de los valores predichos de los medidos. (3) El coeficiente de eficiencia $(N S)$ del modelo Nash-Sutcliffe, que determina la magnitud relativa de la varianza residual en comparación con la varianza de los datos medidos. Además, indica qué tan bien se ajustan los datos simulados graficados contra los simulados a la línea 1:1. NS va desde $-\infty$ a 1.0 (1 inclusive), $N S=1$ es el valor óptimo. Valores entre 0.0 y 1 se consideran aceptable, mientras que valores $<0.0$ son cuestionables (Toumi et al., 2016; Moriasi et al., 2007; Nash y Sutcliffe, 1970). (4) Por último, también se evaluó el sesgo entre los resultados del modelo y las mediciones $(B I A S=\bar{m}-\bar{s}$, siendo $\bar{m}$ y $\bar{s}$ las medias de los valores medidos y modelados).

Respecto de RMSE, se calculó según:

$$
R M S E=\sqrt{\frac{\sum_{i=1}^{n}\left(m_{i}-s_{i}\right)^{2}}{n}}
$$

donde $m_{i}$ y $s_{i}$ son el $i$-ésimo valor medido y simulado, respectivamente y $n$ es el número de observaciones.

Respecto de $M A E$, se calculó según:

$$
M A E=\frac{\sum_{i=1}^{n}\left|m_{i}-s_{i}\right|}{n}
$$

Finalmente, el coeficiente $N S$, según:

$$
N S=\frac{\sum_{i=1}^{n}\left(m_{i}-s_{i}\right)^{2}}{\sum_{i=1}^{n}\left(m_{i}-\bar{s}\right)^{2}}
$$




\subsection{Resultados}

\subsubsection{Evolución del contenido de agua del suelo (VWC) y la temperatura del suelo a 0,2 y $0,5 \mathrm{~m}$ de profundidad}

En general, los VWC incrementan en respuesta a los eventos de lluvia en ambas parcelas, sin embargo, los patrones de cambio a lo largo del tiempo fueron diferentes. En el pastizal a 0,2 m, los VWC incrementan progresivamente (i.e., incrementa el almacenamiento de agua), particularmente durante el primer período con mayor frecuencia de lluvias (definido como P1, Figura 3-8b) que cubre los 100 primeros días estudiados (desde el 10 de diciembre de 2015 hasta 19 de marzo de 2016). Después de este periodo, y hasta el 10 de septiembre de 2016, las lluvias son escasas, sin embargo, el VWC mantiene constante sus valores alrededor de los valores máximos alcanzados $\left(\sim 0,3 \mathrm{~m}^{3} \mathrm{~m}^{-3}\right.$, este periodo es definido como P2, Figura 3-8 b). En el siguiente periodo, también lluvioso (P3, Figura 3-8 b), el comportamiento de VWC fue similar al observado en P1. Por otro lado, a 0,5 m el comportamiento general fue similar, excepto que los valores alcanzados fueron mayores $\sim 0,4 \mathrm{~m}^{3} \mathrm{~m}^{-3}(\mathrm{P} 2$, Figura $\mathrm{c})$.

Como se mencionó anteriormente, en la parcela forestal, los VWC se comportaron de manera diferente. A pesar de que también respondió a los eventos de precipitación a $0,2 \mathrm{~m}$, los valores alcanzados rápidamente decrecieron hasta alcanzar el punto de marchitez permanente (WP, Figura 3-8 b). Por otro lado, a 0,5 m, casi no se observaron cambios en los VWC relacionados con las lluvias (Figura $3-8 c$ ).

Respecto de la temperatura del suelo, esta fue $\sim 5{ }^{\circ} \mathrm{C}$ superior en la parcela herbácea respecto de la forestación en las épocas cálidas, mientras que durante el invierno ambas parcelas fueron prácticamente iguales (Figura 3-9). La temperatura del aire no mostró grandes diferencias en ambas parcelas (14.21 
y $14.18{ }^{\circ} \mathrm{C}$ en pastizal y forestación, respectivamente). Por este motivo, las diferencias en la temperatura del suelo se atribuyen a la disminución en la radiación solar incidente en la forestación ya que se midió un 66 \% de cobertura arbórea (Lejeune et al., 2018; Kreidenweis et al., 2016; Figura 3-9). 


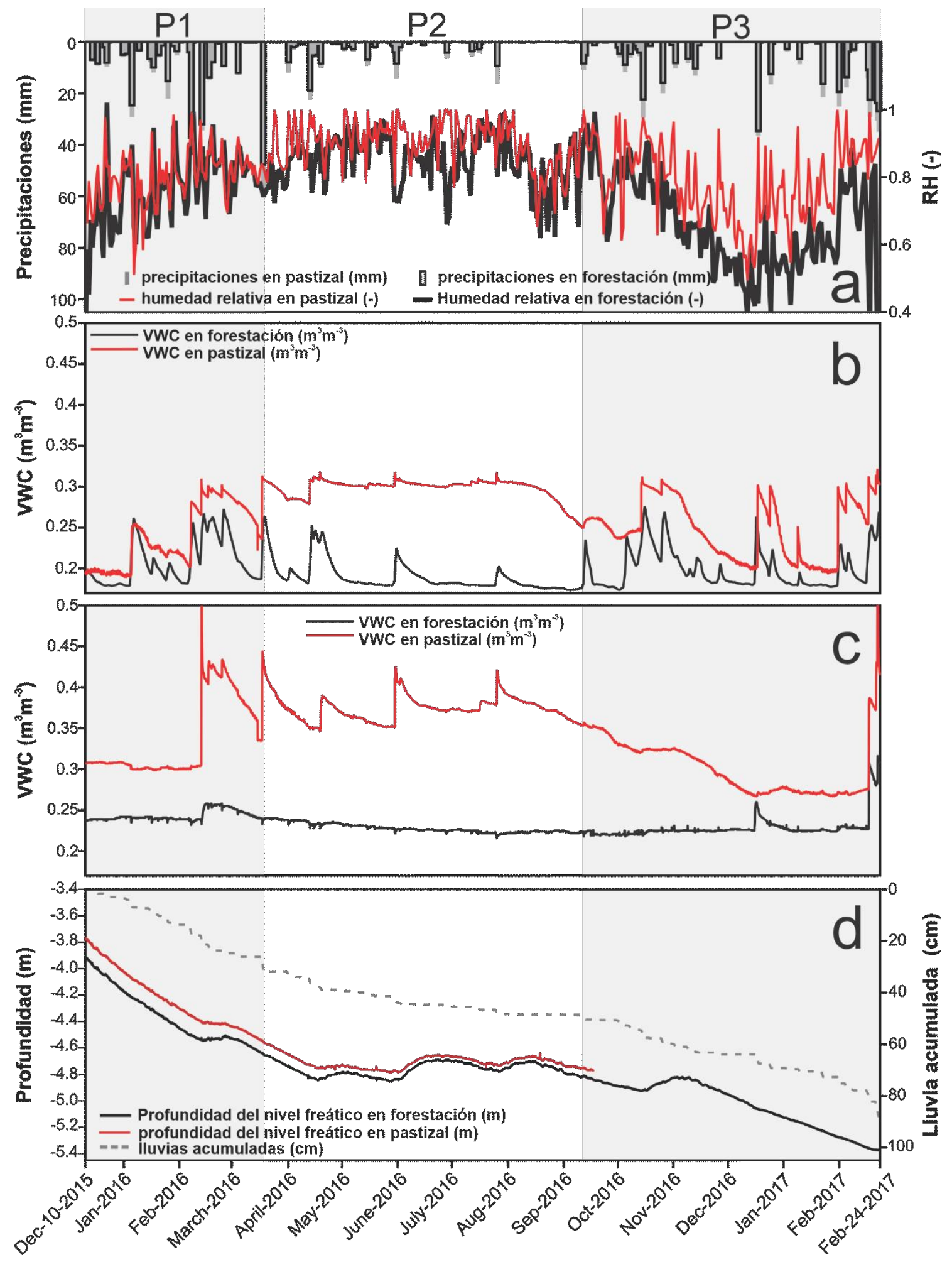

Figura 3-8. Evolución temporal de: (a) las precipitaciones y humedad relativa, contenido volumétrico de agua del suelo (VWC) en la parcela herbácea y forestal a (b) 0,2 y (c) $0,5 \mathrm{~m}$ de profundidad, y de (d) las precipitaciones acumuladas y nivel freático. 

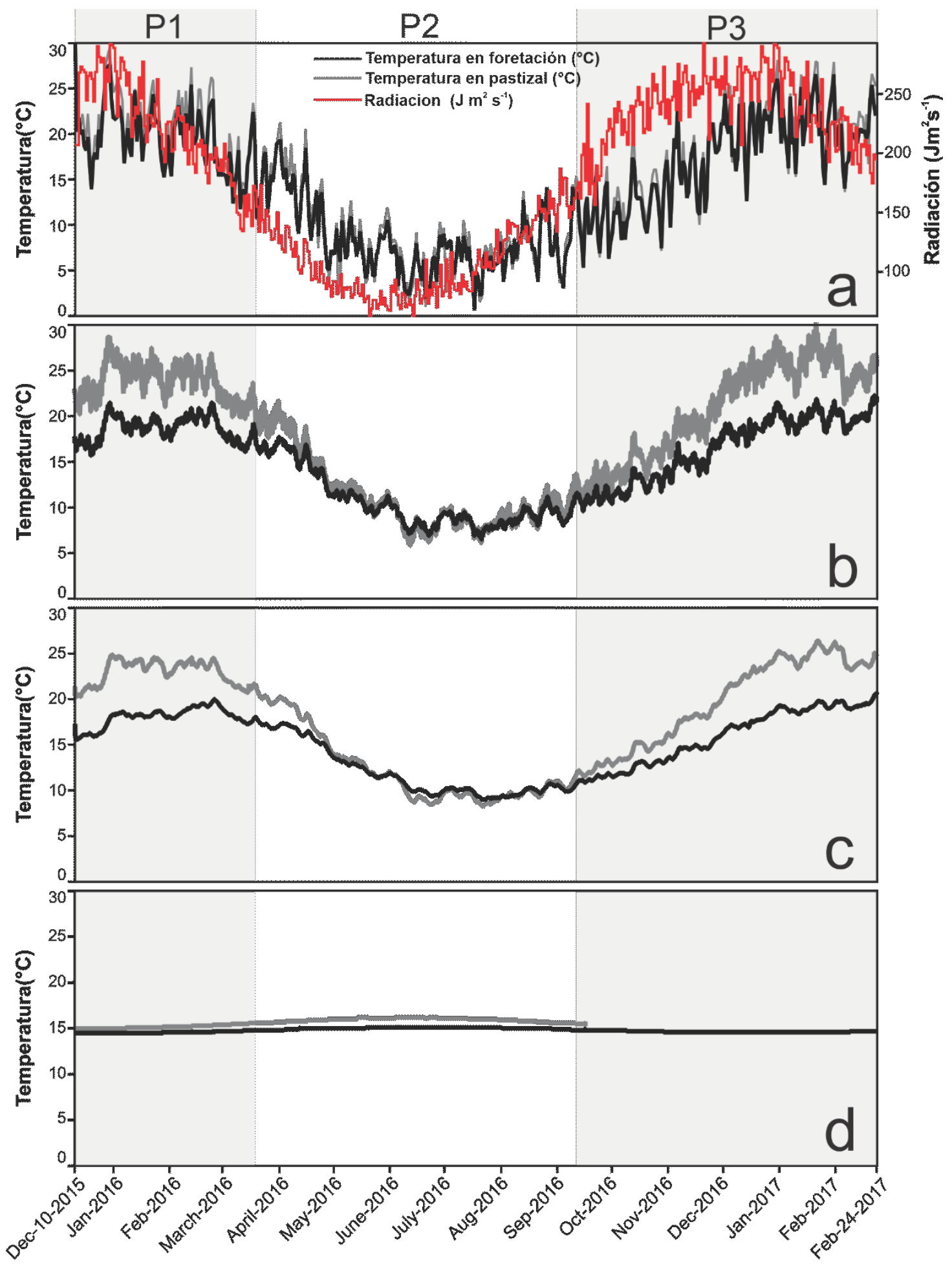

Figura 3-9. Evolución temporal de: (a) temperatura del aire y radiación solar, temperatura del suelo a (b) 0,2 y (c) 0,5 m de profundidad, y (d) temperatura del nivel freático en pastizal y forestación.

\subsubsection{Evolución de la conductividad eléctrica}

A la profundidad de $0,2 \mathrm{~m}$, la $E C p$ varió entre 0.45 y $2.76 \mathrm{dS} \mathrm{m}^{-1}$ (Figura 3-10 b), y en ambas parcelas los promedios para esta variable fueron similares

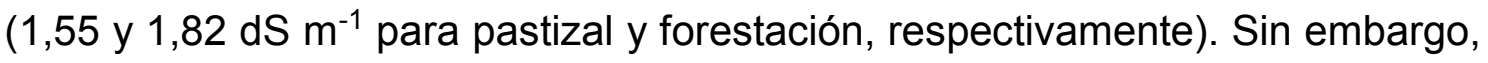


ECp fue levemente mayor a 0,5 m en el pastizal (entre 0,14 y 6,45 dSm ${ }^{-1}$ ), con respecto a aquél medido en la forestación (entre 1,20 y 4,28 dS $\mathrm{m}^{-1}$ ). Los promedios a $0,5 \mathrm{~m}$ fueron 3,69 y $2,92 \mathrm{dS} \mathrm{m}^{-1}$ para el pastizal y forestación, respectivamente (Figura 3-10 c).

Cabe destacar que la formula aplicada para el cálculo de $E C p$ sólo es válida en los intervalos de VWC que permitan una corriente continua a través del suelo, es decir, sin interrupciones causadas por aire atrapado en el suelo (Rhoades et al., 1989). En este sentido es probable que por el menor VWC en el suelo de la forestación, estas diferencias en ECp sean consecuencia de estar fuera del rango de aplicación de la Ecuación 5. Sin embargo, esta misma tendencia se reprodujo en una de las mediciones de conductividad eléctrica sobre muestras de suelo a $0,5 \mathrm{~m}\left(E C_{1: 2,5}\right)$, las cuales en promedio fueron 158,24 y $87,32 \mu \mathrm{S} \mathrm{m} \mathrm{m}^{-1}$ para el pastizal y la forestación, respectivamente.

\subsubsection{Evolución del nivel freático, temperatura y conductividad eléctrica}

Los niveles freáticos evolucionaron de manera similar en ambas parcelas, partiendo de $\sim 3,8 \mathrm{~m}$ de profundidad y al cabo de 125 días (P1), alcanzaron un nivel casi constante en P2 a $\sim 4,7 \mathrm{~m}$ de profundidad. Finalmente, los niveles continuaron bajando durante P3 hasta el final del período estudiado ( $\sim 5,4 \mathrm{~m}$ de profundidad, Figura 3-8d). Previo a este estudio, se registró una profundidad mínima de 1,66 m (BDH, 2019).

Cabe destacar que no se han encontrado variaciones en el nivel freático que puedan ser relacionadas a la presencia de la forestación, como si ha sido observado en otros trabajos en la misma región (Jobbágy y Jackson, 2007; Engel et al., 2005). Con respecto de la temperatura, esta se mantuvo estable a lo largo 
de todo el período estudiado $\left(\sim 15^{\circ} \mathrm{C}\right)$, con variaciones de $\sim 0,5$ a $1{ }^{\circ} \mathrm{C}$ (Figura 3-10d). La conductividad eléctrica ( $E C w t)$ fue estable, similar en ambas parcelas, y coincide con los valores reportados en la zona $\left(\sim 0,66 \mathrm{dS} \mathrm{m}^{-1}, \mathrm{BDH}, 2019\right.$,

Figura 3-10c).
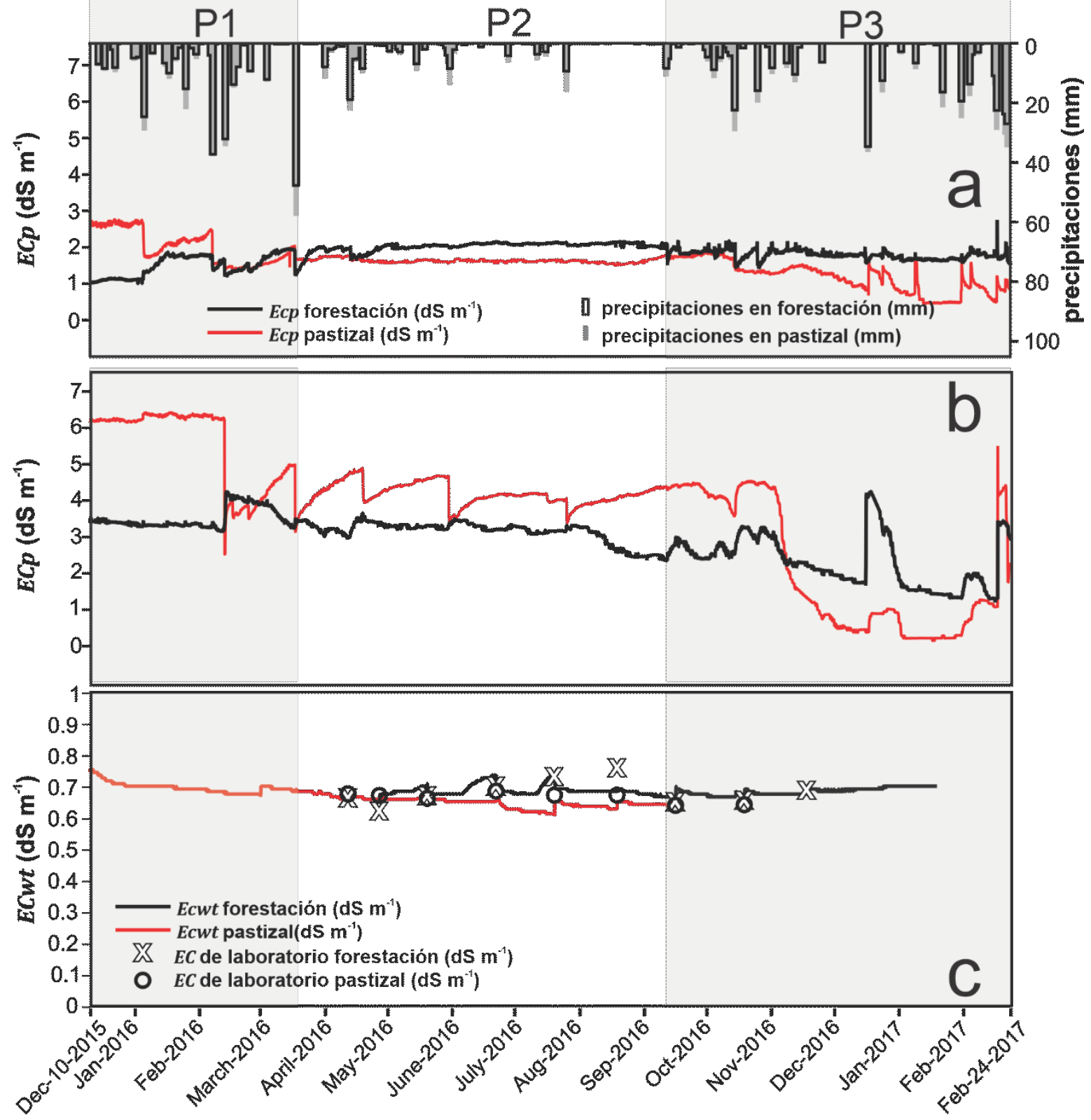

Figura 3-10. Evolución temporal de la conductividad eléctrica del agua de poro a (a) 0.2 y (b) $0.5 \mathrm{~m}$ de profundidad, y (c) del acuífero freático en pastizal y forestación.

\subsubsection{Evolución de la transpiración en la forestación}

Debido al malfuncionamiento del equipo, las mediciones de flujo de savia solamente se pudieron llevar a cabo en dos intervalos de tiempo: (1) desde el 2 
de febrero de 2016 hasta el 30 de marzo de 2016, y (2) desde el 23 de diciembre de 2016 hasta enero de 2017. En el primer intervalo la traspiración de la forestación fluctuó entre 1,95 y $4,87 \mathrm{~mm} \mathrm{día}^{-1}$ (promedios diarios) con un promedio general de $3,38 \mathrm{~mm}$ día ${ }^{-1}$. Durante el segundo intervalo, el promedio fue de $2,69 \mathrm{~mm}$ día $^{-1}$ y varió entre 0,97 y $5,38 \mathrm{~mm} \mathrm{día}^{-1}$. Cabe destacar que no se encontró correlación entre la transpiración y el déficit de presión de vapor (Figura 3-11), tal como ha sido encontrado en otros sitios dentro de la misma región (Engel et al., 2005). La ausencia de estas correlaciones sugiere una desconexión hidráulica entre el acuífero freático y la forestación.

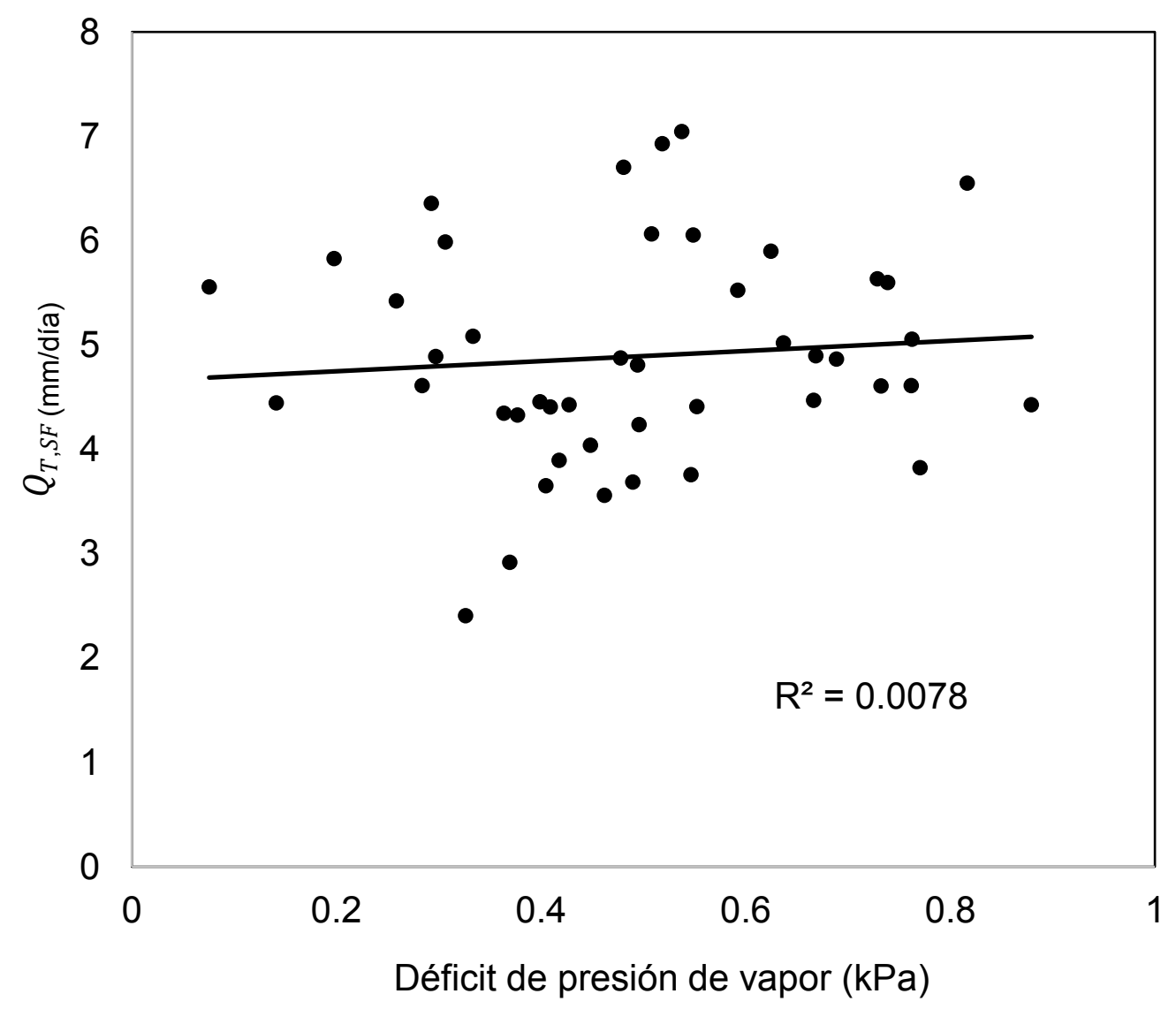

Figura 3-11. Correlación entre déficit de presión de vapor y transpiración medida $\left(Q_{T, S F}\right)$.

\subsubsection{Resultados de la exploración geoeléctrica.}

La tomografía arrojó una sección en 2 dimensiones de la resistividad eléctrica del suelo $\left(\mathrm{ohm} \mathrm{m}^{-1}\right)$, esos valores se convirtieron en conductividad 
eléctrica $\left(E C b_{g e o}, \mathrm{dS} \mathrm{m}^{-1}\right)$ para tener uniformidad en las variables analizadas. Esta medición, al igual que la de los sensores del suelo $(E C b)$, varía en función de un conjunto de características del suelo como el contenido de humedad (VWC), salinidad, temperatura, tamaño composición y arreglo espacial de las partículas.

En este caso con la información disponible no es posible discriminar cual es la componente de salinidad en la $E C b_{g e o}$. Sin embargo, el perfil observado, en conjunto con el resto de la información disponible nos permite inferir que en este caso $E C b_{g e o}$ responde principalmente a la humedad del suelo. Asumiendo que las propiedades y la composición de las partículas es la misma y teniendo en cuenta que la conductividad eléctrica en el suelo y en el acuífero freático también es similar, es posible identificar en la Figura 3-12 el nivel freático (que coincide con las mediciones del sensor, Figura 3-8 d), a $\sim 4.5 \mathrm{~m}$ de profundidad. Además, se puede observar que el suelo debajo de la forestación está mucho más seco que en el pastizal (también coherente con Figura 3-8 a y b). Es interesante destacar que debajo de la forestación el sector con un menor contenido de humedad, respecto del pastizal, excede la profundidad de la tosca (entre $0.76 \mathrm{~m}$ $\mathrm{y}$ al menos hasta $1.1 \mathrm{~m}$, Figura 3-4 a). 

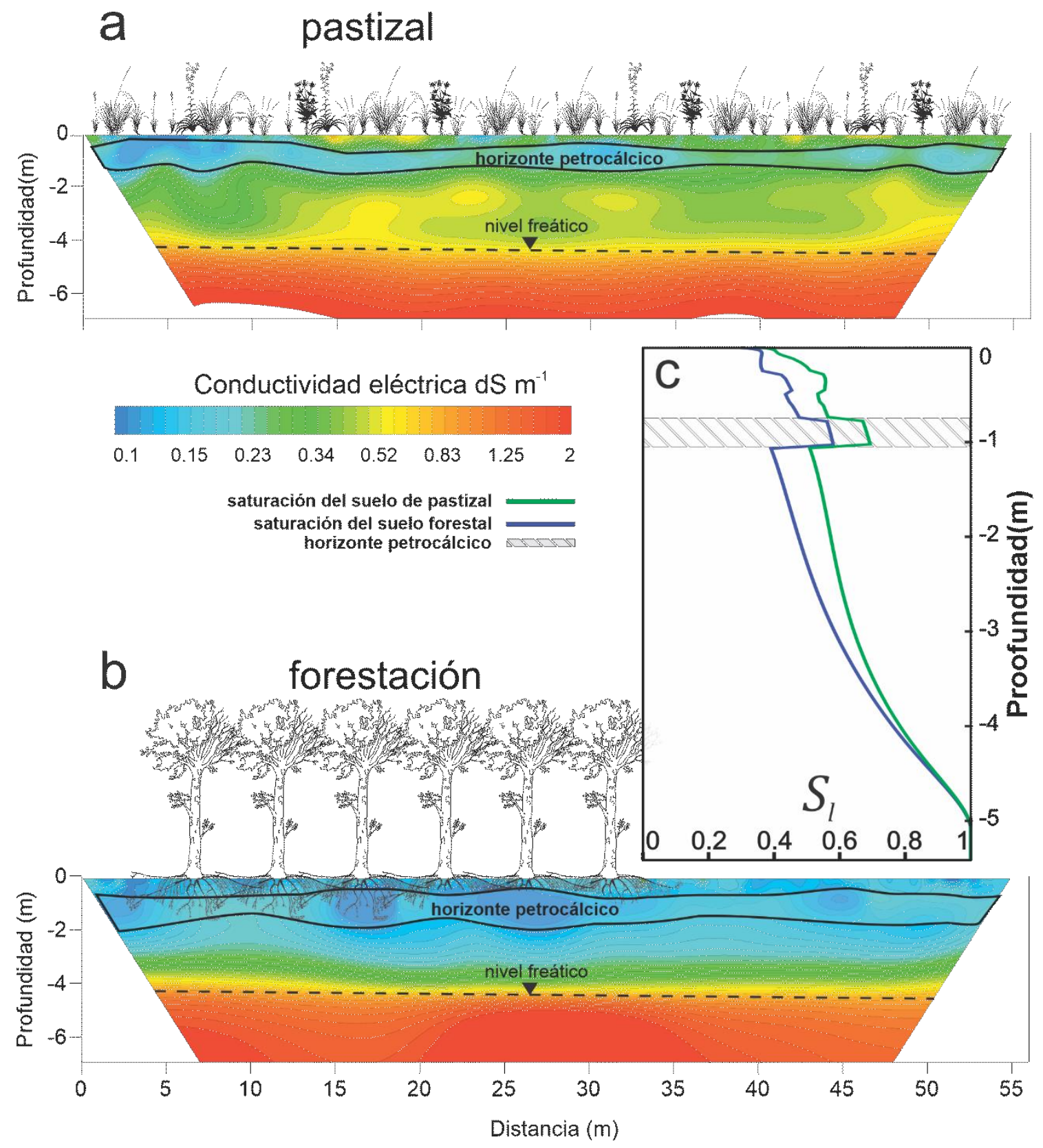

Figura 3-12. Conductividad eléctrica aparente del suelo $\left(E C b_{g e o}\right)$, en pastizal (a) y forestación (b), y $S_{l}$ calculado con el modelo para el mismo momento (c).

\subsubsection{Resultados de la modelación de flujo}

\subsubsection{Caso base de la parcela forestal}

Como resultado de la calibración de la densidad de raíces se obtuvo una mayor distribución en posiciones cercanas a la superficie: 93,23 \% en Ap, 0.31 \% en BA, 2,96 \% en Bt1 y Bt2, 0,02 \% en 2CKkm y 0,51 \% en loess (Tabla 3.2), siendo estos resultados similares a los observados por otros autores (Lambais et al., 2017; Moroni et al., 2003; Bouillet et al., 2002). En general se obtuvo una 
buena correlación entre los valores de VWC y $T$ modelados y observados, por ejemplo, $M A E$ a 0,2 y $0,5 \mathrm{~m}$ fue 0,86 y $0,52{ }^{\circ} \mathrm{C}$ para $T$, respectivamente, y 0,023 y $0,013 \mathrm{~m}^{3} \mathrm{~m}^{-3}$ para VWC, respectivamente (Tabla 3.3).

Tabla 3.3. Evaluación estadística de los resultados del modelo para casos base y escenarios alternativos

\begin{tabular}{|c|c|c|c|c|c|}
\hline & profundidad & $R M S E$ & $M A E$ & $N S$ & BIAS \\
\hline \multicolumn{6}{|c|}{ Caso base forestación } \\
\hline \multirow{2}{*}{$T\left({ }^{\circ} \mathrm{C}\right)$} & $0,2 \mathrm{~m}$ & 1,00186 & 0,86677 & 0,94832 & 0,32907 \\
\hline & $0,5 \mathrm{~m}$ & 0,61520 & 0,52069 & 0,97032 & 0,09273 \\
\hline \multirow{2}{*}{$\operatorname{VWC}\left(\mathrm{m}^{3} \mathrm{~m}^{-3}\right)$} & $0,2 \mathrm{~m}$ & 0,02277 & 0,01636 & 0,09472 & 0,00147 \\
\hline & $0,5 \mathrm{~m}$ & 0,01274 & 0,00915 & $-0,28864$ & $-0,00020$ \\
\hline \multirow{2}{*}{\multicolumn{6}{|c|}{$0,95013-0,02331 \quad-0,21002$}} \\
\hline & & & & & \\
\hline \multirow{2}{*}{$T\left({ }^{\circ} \mathrm{C}\right)$} & $0,2 \mathrm{~m}$ & 1,00446 & 0,87319 & 0,94806 & 0,35026 \\
\hline & $0,5 \mathrm{~m}$ & 0,62368 & 0,53451 & 0,96949 & 0,15397 \\
\hline \multirow{2}{*}{$\operatorname{VWC}\left(\mathrm{m}^{3} \mathrm{~m}^{-3}\right)$} & $0,2 \mathrm{~m}$ & 0,02171 & 0,01525 & 0,17676 & 0,00623 \\
\hline & $0,5 \mathrm{~m}$ & 0,01127 & 0,00812 & $-0,00874$ & $-0,00479$ \\
\hline$Q_{T}(\mathrm{~mm} \mathrm{día-1})$ & & 1,69939 & 1,36738 & $-0,16278$ & $-0,73801$ \\
\hline \multicolumn{6}{|l|}{ RPROF } \\
\hline \multirow[b]{2}{*}{$T\left({ }^{\circ} \mathrm{C}\right)$} & $0,2 \mathrm{~m}$ & 1,06023 & 0,90994 & 0,94213 & 0,32127 \\
\hline & $0,5 \mathrm{~m}$ & 0,69394 & 0,58773 & 0,96223 & $-0,05979$ \\
\hline \multirow{2}{*}{ VWC $\left(m^{3} m^{-3}\right)$} & $0,2 \mathrm{~m}$ & 0,06398 & 0,05052 & $-6,14945$ & $-0,04759$ \\
\hline & $0,5 \mathrm{~m}$ & 0,03250 & 0,02775 & $-7,38576$ & $-0,00817$ \\
\hline$Q_{T}\left(\mathrm{~mm} \mathrm{día}{ }^{-1}\right)$ & & 1,64704 & 1,15982 & $-1,74005$ & 0,88967 \\
\hline \multicolumn{6}{|l|}{ REST } \\
\hline \multirow{2}{*}{$T\left({ }^{\circ} \mathrm{C}\right)$} & $0,2 \mathrm{~m}$ & 0,99775 & 0,86305 & 0,94875 & 0,33298 \\
\hline & $0,5 \mathrm{~m}$ & 0,59791 & 0,50250 & 0,97196 & 0,09107 \\
\hline \multirow{2}{*}{$\operatorname{VWC}\left(\mathrm{m}^{3} \mathrm{~m}^{-3}\right)$} & $0,2 \mathrm{~m}$ & 0,02322 & 0,01569 & 0,05814 & $-0,01119$ \\
\hline & $0,5 \mathrm{~m}$ & 0,01461 & 0,01057 & $-0,69483$ & $-0,00546$ \\
\hline$Q_{T}\left(\mathrm{~mm} \mathrm{día}{ }^{-1}\right)$ & & 1,01788 & 0,81854 & $-0,24599$ & $-0,28686$ \\
\hline \multicolumn{6}{|c|}{ Caso base pastizal } \\
\hline \multirow[t]{2}{*}{$T\left({ }^{\circ} \mathrm{C}\right)$} & $0,2 \mathrm{~m}$ & 2,94748 & 2,56249 & 0,81431 & 1,20899 \\
\hline & $0,5 \mathrm{~m}$ & 2,53796 & 2,18110 & 0,79851 & 1,20389 \\
\hline \multirow[t]{2}{*}{$\operatorname{VWC}\left(\mathrm{m}^{3} \mathrm{~m}^{-3}\right)$} & $0,2 \mathrm{~m}$ & 0,02667 & 0,02161 & 0,52841 & $-0,00503$ \\
\hline & $0,5 \mathrm{~m}$ & 0,02984 & 0,02528 & 0,29100 & $-0,00179$ \\
\hline \multicolumn{2}{|l|}{$Q_{T}\left(\mathrm{~mm} \mathrm{día}{ }^{-1}\right)$} & - & - & - & - \\
\hline \multicolumn{6}{|l|}{ SIN TOSCA } \\
\hline \multirow[t]{2}{*}{$T\left({ }^{\circ} \mathrm{C}\right)$} & $0,2 \mathrm{~m}$ & 2,93077 & 2,54849 & 0,81641 & 1,19473 \\
\hline & $0,5 \mathrm{~m}$ & 2,51095 & 2,16555 & 0,80278 & 1,18924 \\
\hline \multirow[t]{2}{*}{$\operatorname{VWC}\left(\mathrm{m}^{3} \mathrm{~m}^{-3}\right)$} & $0,2 \mathrm{~m}$ & 0,02908 & 0,02374 & 0,43912 & 0,00422 \\
\hline & $0,5 \mathrm{~m}$ & 0,03101 & 0,02496 & 0,23467 & 0,01387 \\
\hline$Q_{T}(\mathrm{~mm} \mathrm{día-1})$ & & - & - & - & - \\
\hline
\end{tabular}

El modelo para el caso base logró capturar los rápidos incrementos observados en el WWC posterior a las lluvias, así como el rápido consumo de agua por parte de las raíces hasta alcanzar el punto de marchitez (WP, Figura 3-13a y b). Sin embargo, ciertas diferencias entre el modelo y las observaciones en P3 fueron obtenidas (ver punto 3 en Figura 3-13a). Además, el modelo predice 
una mayor tasa transpiratoria respecto de los valores medidos, en ese mismo periodo (ver punto 3 en Figura 3-13c). La tasa de traspiración simulada promedio fue de 2,08 $\mathrm{mm}$ día ${ }^{-1}$ durante todo el periodo del estudio (un promedio de 1,97 mm día ${ }^{-1}$ para 2016, Tabla 3.4), alcanzando los valores de $E T_{c}$ en los intervalos de alta disponibilidad de agua (ver punto 1 en Figura 3-13c).

Por otro lado, las menores tasas se predicen durante P2 cuando VWC alcanza los valores de punto de marchitez, $\sim 0.51 \mathrm{~mm} \mathrm{día}^{-1}$ (ver punto 2 en Figura 3-13a y c). El volumen total de agua traspirada fue de $\sim 918 \mathrm{~mm}$ en todo el periodo simulado ( $\sim 723 \mathrm{~mm}$ en 2016$)$, con un $\sim 13 \%$ de agua proveniente del acuífero freático. Estas tasas de transpiración calculadas son consistentes con un rodal con una limitada conexión hidráulica con el acuífero, y una alta densidad de árboles ( 893 árboles ha-1).

En el balance hídrico mensual obtenido (Figura 3-13d), claramente se deduce que las tasas de transpiración de la forestación simuladas dependen exclusivamente de las precipitaciones. Además, las tasas de transpiración calculadas también son consistentes con otras estimadas en la misma región para E. camaldulensis (por ejemplo, 250-500 mm año-1, 500-700 árboles ha-1,

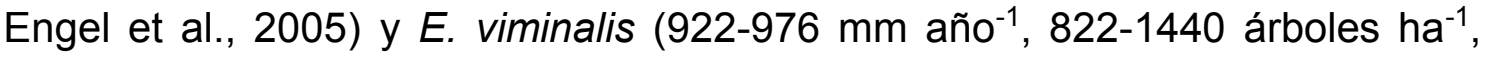
Besteiro, 2014). 
Tabla 3.4. Balance hídrico para los escenarios de forestación

\begin{tabular}{|c|c|c|c|c|c|c|c|c|}
\hline \multirow{2}{*}{ Escenario } & \multicolumn{2}{|c|}{ Caso base } & \multicolumn{2}{|c|}{ RSUP } & \multicolumn{2}{|c|}{ RPROF } & \multicolumn{2}{|c|}{ REST } \\
\hline & total & anual & total & anual & total & anual & total & anual \\
\hline Precipitaciones $(\mathrm{mm})$ & 912,2 & 695 & 912,2 & 695 & 912,2 & 695 & 912,2 & 695 \\
\hline Intercepción (mm) & 141,9 & 133,6 & 141,9 & 133,6 & 141,9 & 133,6 & 141,9 & 133,6 \\
\hline Transpiración total (mm) & 918 & 722,6 & 653,6 & 522,3 & 1567,8 & 1212,2 & 891,7 & 700,5 \\
\hline Tasa transpiratoria (mm/día) & 2,1 & 1,9 & 1,5 & 1,43 & 3,5 & 3,3 & 2,02 & 1,9 \\
\hline Evaporación (mm) & 195,9 & 149,5 & 193,5 & 147,9 & 210,2 & 158,9 & 206 & 155,2 \\
\hline Condensación (mm) & 105,5 & 78,1 & 104,3 & 77,4 & 114,9 & 83,6 & 112,9 & 81,5 \\
\hline Uso del agua freático $(\mathrm{mm})$ & 122,9 & 91,5 & 0,0 & 0,0 & 412,3 & 306,2 & 119,0 & 88,6 \\
\hline $\begin{array}{l}\text { Flujo en el límite inferior } \\
\qquad(\mathrm{mm})\end{array}$ & $-229,5$ & $-139,8$ & $-421,6$ & $-287,9$ & 215,9 & 206,4 & $-209,9$ & $-120,4$ \\
\hline $\begin{array}{l}\text { Cambio en el } \\
\text { almacenamiento del sueloa } \\
(\mathrm{mm})\end{array}$ & $-421,7$ & $-372,6$ & $-348,5$ & $-319,5$ & $-625,7$ & $-519,9$ & $-373,6$ & $-333,2$ \\
\hline
\end{tabular}




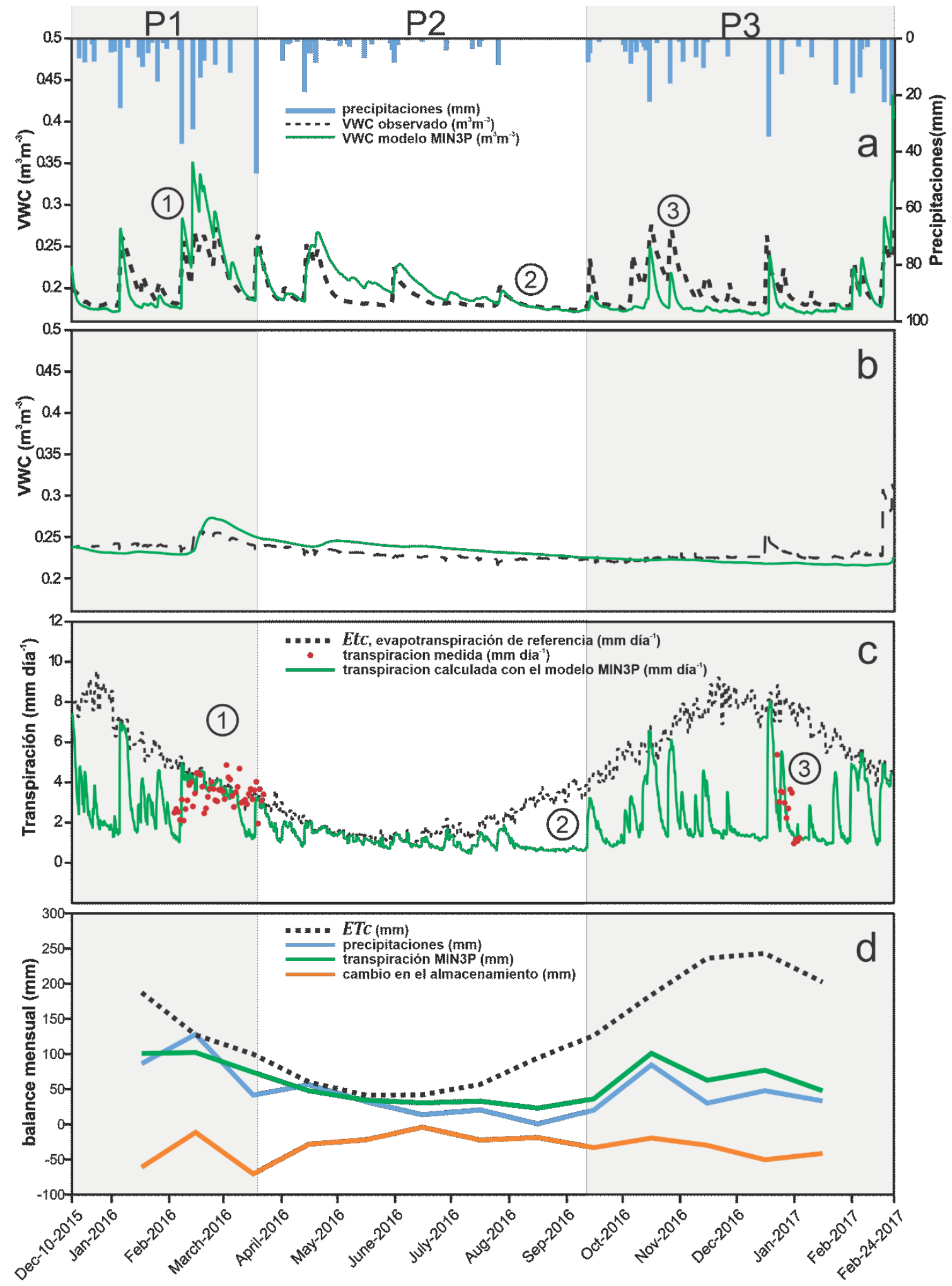

Figura 3-13. Resultados del modelo base para la forestación. Evolución temporal de WWC observados y simulados (a) 0.2 y (b) $0.5 \mathrm{~m}$ de profundidad, (c) $E T_{c}$, transpiraciones observadas y simuladas, y (d) balance hídrico mensual.

La evolución de la temperatura simulada para la forestación se muestra en la Figura 3-14 para 0,2 y 0,5 m de profundidad. Como se espera, estas responden 
principalmente a la radiación solar incidente sobre la superficie del suelo, y a la temperatura del aire. A 0,2 $\mathrm{m}$ de profundidad fue aproximadamente $2-3^{\circ} \mathrm{C}$ más altas que las mediciones durante los períodos P1 y P3, mientras que estas diferencias son mínimas durante P2. Por otro lado, los resultados del modelo muestran un comportamiento similar para la temperatura a 0,5 m. Estos resultados indican que la parte energética, de la cual depende la evaporación, es coherente con los valores medidos y el ajuste es muy bueno (Tabla 3.3).

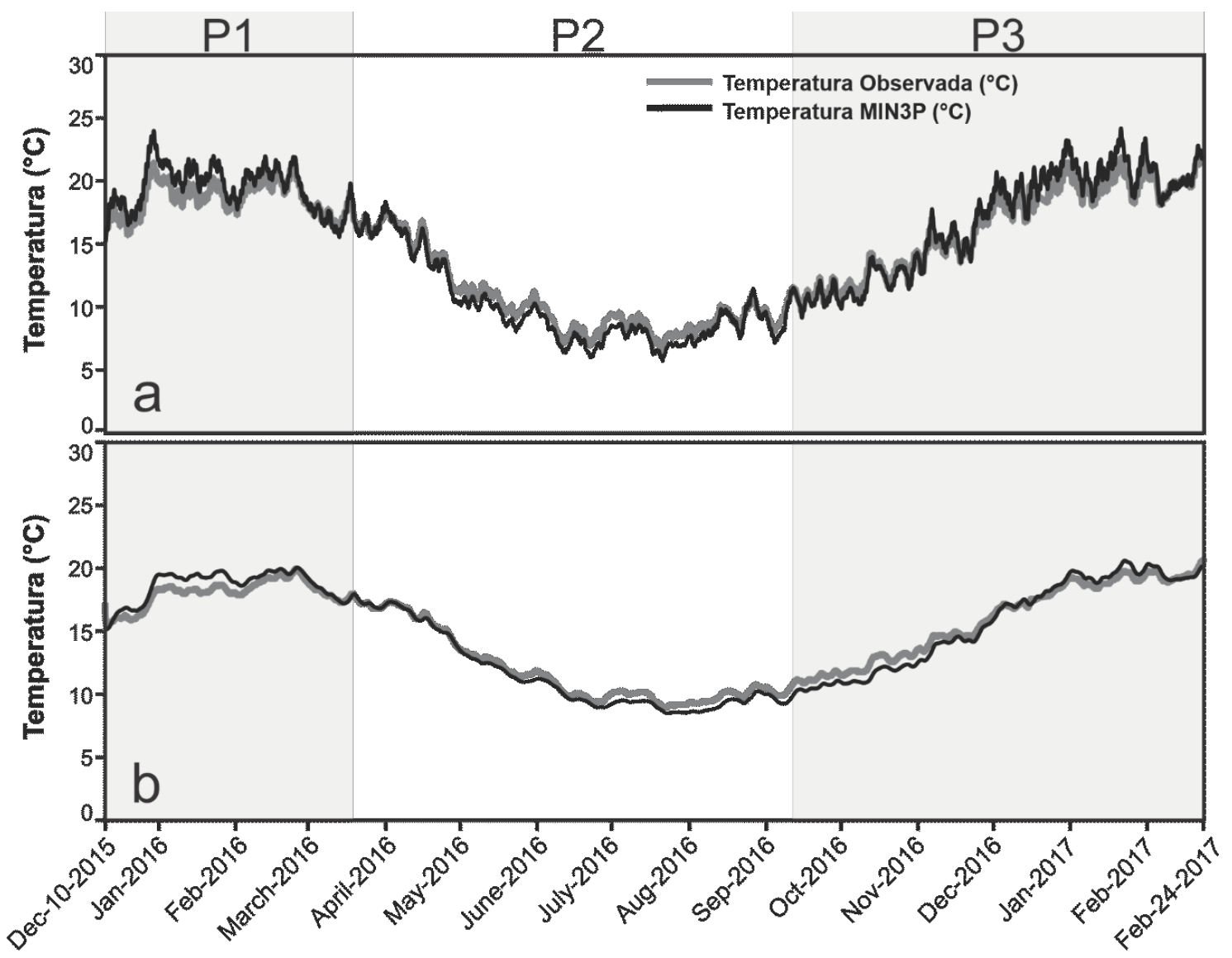

Figura 3-14. Temperatura observada y modelada a (a) 0,2 y (b) 0,5 m de profundidad bajo la forestación.

La distribución vertical de los parámetros hidráulicos utilizados en el modelo base (Figura 3-15), sugiere que la tosca ejercería un efecto de barrera hidráulica a los flujos de agua. Así, el VWC varió por encima del horizonte petrocálcico en respuesta a las precipitaciones, y a la transpiración de la 
forestación, mientras que debajo de este horizonte, las variaciones dependieron de la variabilidad del nivel freático.
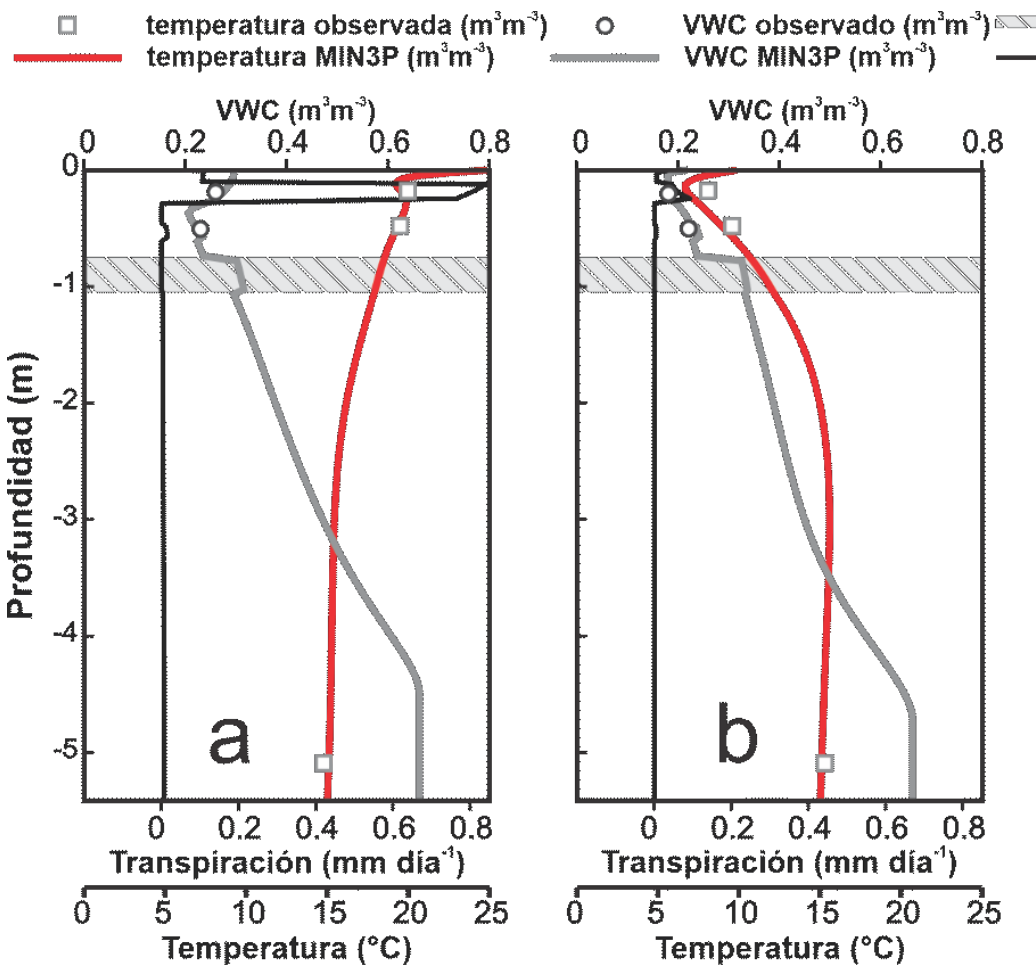

horizonte petrocálcico

Transpiración MIN3P ( $\mathrm{mm}$ día ${ }^{-1}$ )

Figura 3-15. Distribución vertical de VWC y temperatura observada y simulada a (a) 60, (b) 200, y (c) 372 días de simulación.

\subsubsection{Sensibilidad del modelo a los parámetros impuestos en el modelo de forestación}

A pesar de que la simulación del caso base captura el comportamiento global del sistema estudiado, se observaron algunas de diferencias en VWC mencionadas anteriormente (Figura 3-13). Para abordar estas discrepancias, se simularon un conjunto de escenarios alternativos para evaluar la sensibilidad del modelo a los principales parámetros: (1) la distribución de densidad de raíces, y (2) los parámetros empíricos que controlan la transpiración de la forestación $\left(w_{0}\right.$ y $a_{w}$ en la Ecuación 34;Figura 3-16). 


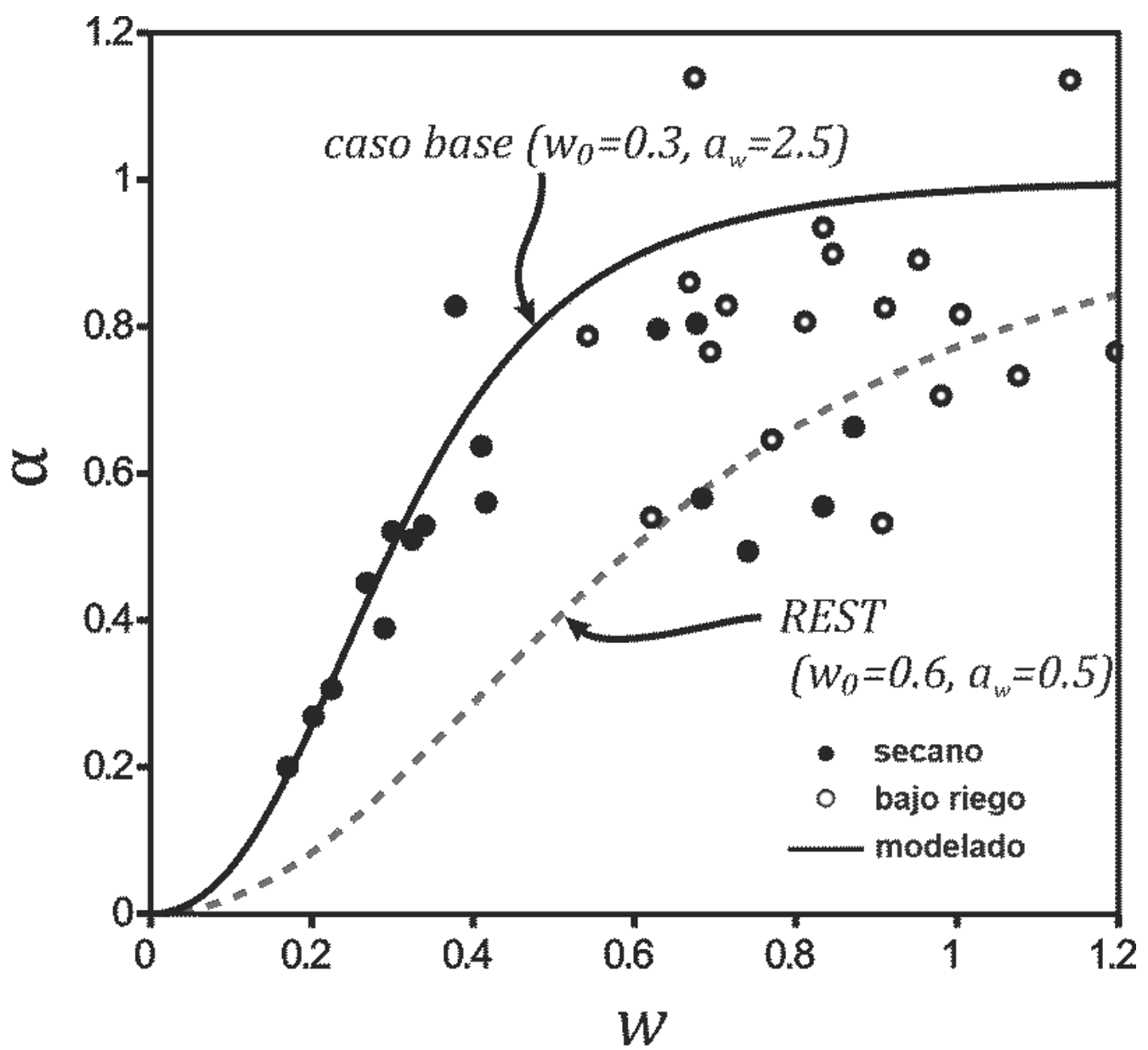

Figura 3-16. Relación observada entre los parámetros $\alpha$ y $w$, Modificado de Battaglia \& Sands, (1997) para $E$. globulus en secano y bajo riego. Las líneas llena e interrumpida fueron calculadas con las Ecuación 34 y Ecuación 35, para la línea punteada $w_{0}$ y $a_{w}$ fueron calibrados con el modelo PEST (Doherty, 2016) acoplado con MIN3P (Mayer et al., 2012).

Como es de esperar, los resultados para el caso del escenario RSUP fueron similares a los obtenidos en la simulación del caso base (Figura 3-13 y Figura 3-17), con una transpiración total de $\sim 654 \mathrm{~mm}$ para todo el período simulado ( $522 \mathrm{~mm}$ para 2016). Al igual que en el escenario base, las tasas de transpiración también estarían controladas principalmente por los eventos de lluvia, prediciendo un fuerte estrés hídrico durante P2 (Figura 3-17).

Por el contrario, el escenario RPROF sobreestima las tasas reales de transpiración de la forestación al estar más cerca de $E T_{c}$ dado que hay acceso de las raíces al acuífero freático (Figura 3-17b). Como resultado de esto, se predice un exceso en el almacenamiento de agua por encima del horizonte 
petrocálcico, en comparación con las mediciones y los resultados de la simulación del caso base (Figura 3-17 a). En este escenario, la transpiración de la forestación calculada fue casi el doble de la obtenida en el caso base $(\sim 1568$ $\mathrm{mm}, 1212 \mathrm{~mm}$ para 2016), y el porcentaje del agua transpirada que provendría del acuífero freático es de $25 \%$ (Figura 3-15c).

Con respecto a la evaluación de la sensibilidad del modelo a los parámetros que intervienen en el cálculo de la transpiración (Ecuación 34), estuvo motivada porque que estos fueron estimados para otra especie de eucalipto (E. globulus) y bajo condiciones de menor estrés (Battaglia y Sands, 1997).

Para evaluar aquellas discrepancias entre los valores de VWC simulados y observados a 0,2 $\mathrm{m}$ de profundidad para algunos intervalos de tiempo (ver puntos 1 y 3 en la Figura 3-13 a), el escenario REST se enfoca en la función de estrés (Ecuación 34) que afecta la transpiración calculada por el modelo. Sólo en estos intervalos es donde el efecto causado por el período previo de estrés se hizo evidente, probablemente porque el sistema radicular bajo estrés hídrico tiene una menor capacidad para tomar el agua disponible con respecto al caso donde la planta nunca sufrió tal nivel de estrés.

Esta respuesta fisiológica diferencial de la forestación reproduce con éxito la evolución de VWC a una profundidad de 0,2 y 0,5 m en los intervalos de tiempo mencionados anteriormente (ver Figura 3-18 a). Las tasas de transpiración calculadas también son consistentes con las mediciones del flujo de savia (ver Figura 3-18 b). La transpiración total de la forestación prevista para este escenario fue de $\sim 891 \mathrm{~mm}$ durante todo el período de tiempo simulado ( 700 
$\mathrm{mm}$ en 2016, ), con un uso de aguas subterráneas de $\sim 13 \%(\sim 119 \mathrm{~mm}, \sim 89$ $\mathrm{mm}$ para 2016, ). 


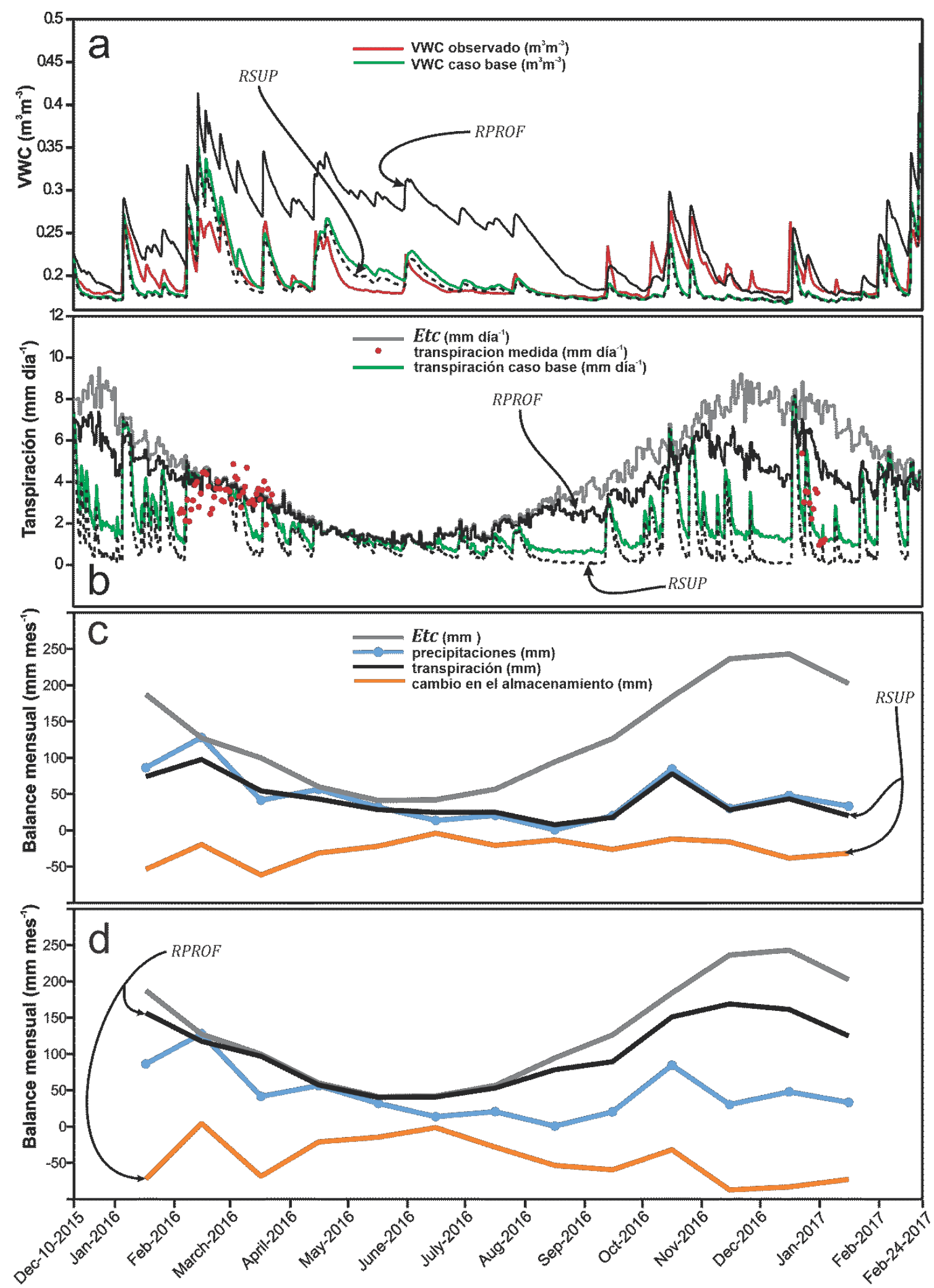

Figura 3-17. Resultados de los modelos alternativos RSUP y RPROF. Evolución temporal de (a) VWC a $0,2 \mathrm{~m}$ de profundidad, (b) $E T_{c}$, (c) y (d) balance hídrico mensual. Los resultados del modelo se comparan con el caso base y las observaciones. 


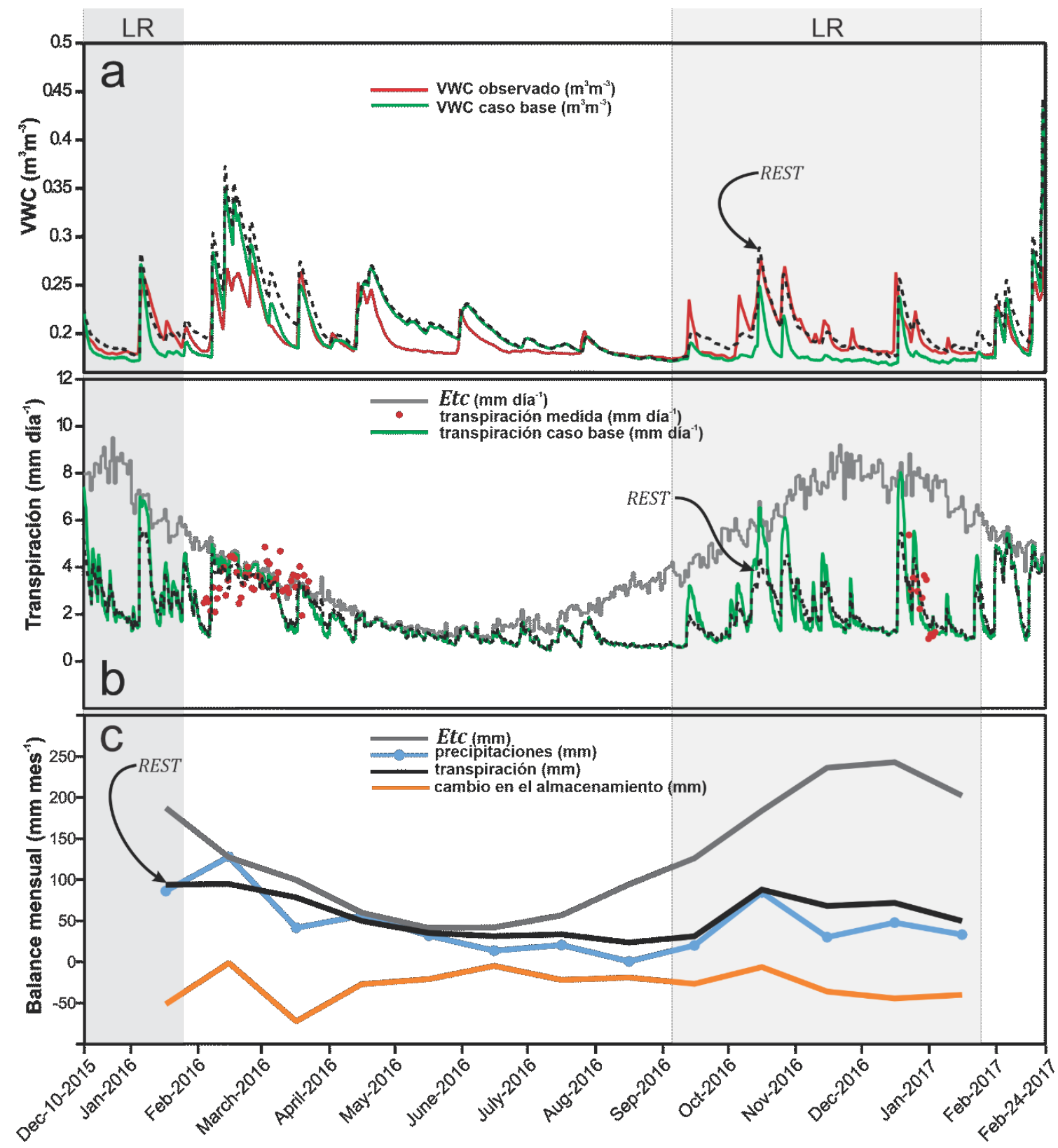

Figura 3-18. Resultados del escenario alternativo REST. Evolución temporal de (a) VWC a 0,2 m de profundidad, (b) $E T_{c}$ y (c) balance hídrico mensual. Las áreas sombreadas indican los intervalos de tiempo en los que se aplicó menores tasas. Se muestran los resultados de estos modelos comparados con los del caso base y las observaciones.

\subsubsection{Caso base de la parcela herbácea}

En el pastizal, el VWC simulado evolucionó de manera similar a los observados, como lo indican los índices de correlación global (Tabla 3.3). La evolución del VWC simulado a diferentes profundidades captura sus incrementos como consecuencia de los eventos de lluvia durante los períodos P1 y P3 (Figura 
3-19), y la posterior absorción de agua del pastizal (ver resultados a profundidades de 0,2 y $0,5 \mathrm{~m}$ en la Figura 3-19a y b, respectivamente).

Sin embargo, durante los períodos con menor demanda atmosférica, el agua de lluvia se almacena sobre el horizonte petrocálcico (ver período P2 en la Figura 3-19), alcanzando un VWC de aproximadamente $0,35 \mathrm{~m}^{3} \mathrm{~m}^{-3}$ a 0,2 y a 0,5 m de profundidad (ver Figura 3-19 a y b, respectivamente). Los resultados de la modelización también sugieren que la transpiración en el pastizal es un proceso activo durante los dos períodos lluviosos cubiertos en este estudio, siempre limitado por la demanda atmosférica a través de $E T_{c}$. La tasa de transpiración media calculada fue de $1,43 \mathrm{~mm} \mathrm{día}^{-1}$ en todo el período de tiempo $(1.37 \mathrm{~mm}$ día $^{-1}$ para 2016, Tabla 3.5). La transpiración simulada total para todo el período de tiempo fue de $\sim 629 \mathrm{~mm}$ ( $\sim 501 \mathrm{~mm}$ para 2016), sin uso de agua subterránea. Tabla 3.5 Balance hídrico para los escenarios de pastizal.

\begin{tabular}{ccccc} 
Escenario & \multicolumn{2}{c}{ Caso base } & \multicolumn{2}{c}{ SIN TOSCA } \\
& total & anual & total & anual \\
\hline Precipitaciones $(\mathrm{mm})$ & 912 & 695 & 912 & 695 \\
Intercepción $(\mathrm{mm})$ & 0,0 & 0,0 & 0,0 & 0,0 \\
Transpiración total $(\mathrm{mm})$ & 629,0 & 501,7 & 612,9 & 487,2 \\
Tasa transpiratoria $(\mathrm{mm} /$ día) & 1,4 & 1,4 & 1,4 & 1,3 \\
Evaporación $(\mathrm{mm})$ & $-219,9$ & $-167,4$ & $-217,6$ & $-165,7$ \\
Condensación $(\mathrm{mm})$ & 141,1 & 104,9 & 139,4 & 103,8 \\
Uso del acuífero freático $(\mathrm{mm})$ & 0 & 0 & 0 & 0 \\
Flujo en el contorno inferior & $-457,0$ & $-308,2$ & $-643,8$ & $-449,3$ \\
$\quad(m m)$ & & & & \\
Cambio en el almacenamiento & $-225,2$ & $-215,0$ & $-395,8$ & $-340,9$ \\
de agua en el suelo ${ }^{\text {a }}(\mathrm{mm})$ & & & & \\
\hline
\end{tabular}




\subsubsection{Sensibilidad del modelo de la parcela herbácea a la presencia de tosca}

Los resultados del escenario SIN TOSCA muestran que la ausencia de un horizonte petrocálcico predice menores VWC, reduciendo ligeramente la transpiración de las plantas ( $3 \%$ menos), y aumentando las pérdidas de agua a través del contorno inferior del modelo ( 46\% más de pérdida, Figura 3-20 y Tabla 3.5).

\subsubsection{Resultados del modelo de transporte}

En cuanto al transporte y acumulación de solutos, el modelo de transporte reproduce en líneas generales el comportamiento del sistema. Las diferencias respecto de las observaciones pueden ser atribuidas a otros procesos biológicoquímicos que no fueron considerados en el presente modelo de transporte (Figura 3-21). Entre estos procesos se destacan la absorción y exclusión de solutos por parte de la vegetación, la respiración de la rizósfera, el intercambio catiónico del suelo, formación y disolución de minerales, entre otros. Algunos de estos procesos serán abordados en mayor detalle en el siguiente capítulo. 


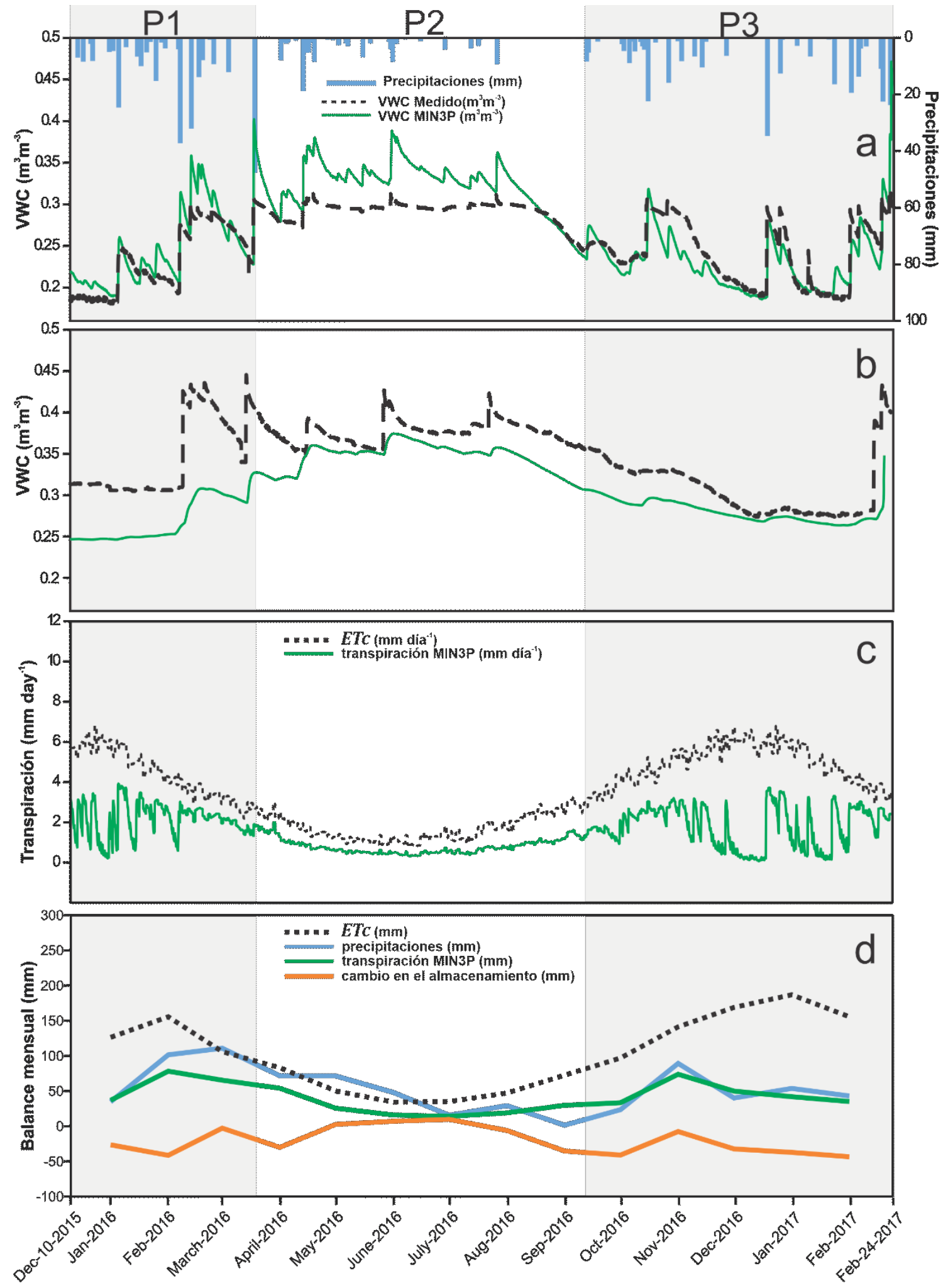

Figura 3-19. Resultado del modelo base para le parcela herbácea. Evolución temporal de VWC observados y simulados (a) 0,2 m (b) 0,5 m de profundidad, (c) $E T_{c}$, transpiraciones observadas y simuladas, y (d) balance hídrico mensual 

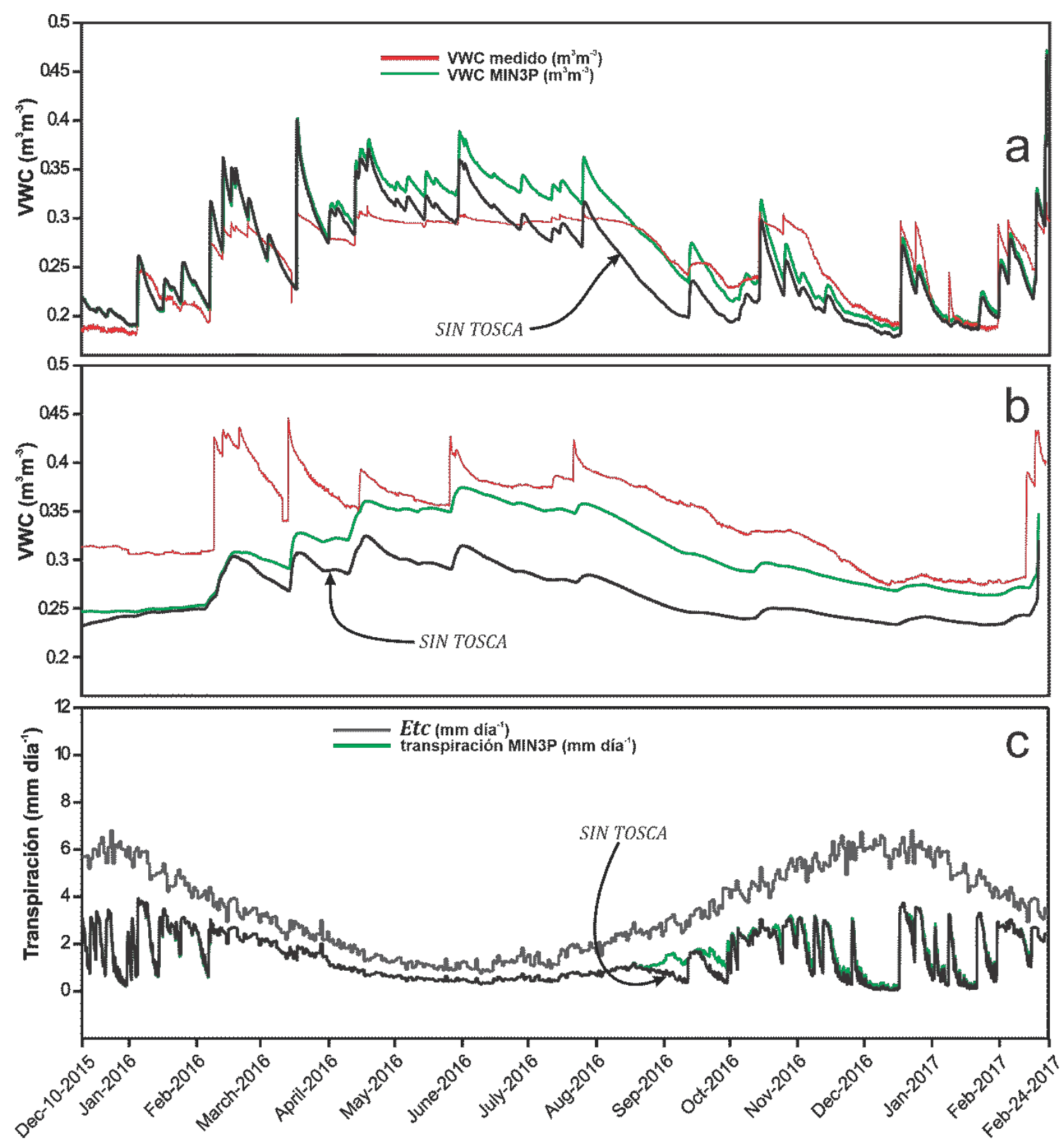

Figura 3-20. Resultados parcela herbácea (escenario SIN TOSCA). Evolución temporal de WWC observados y simulados (a) 0,2 y (b) 0,5 m de profundidad, y (c) $E T_{c}$, transpiraciones observadas y simuladas. 


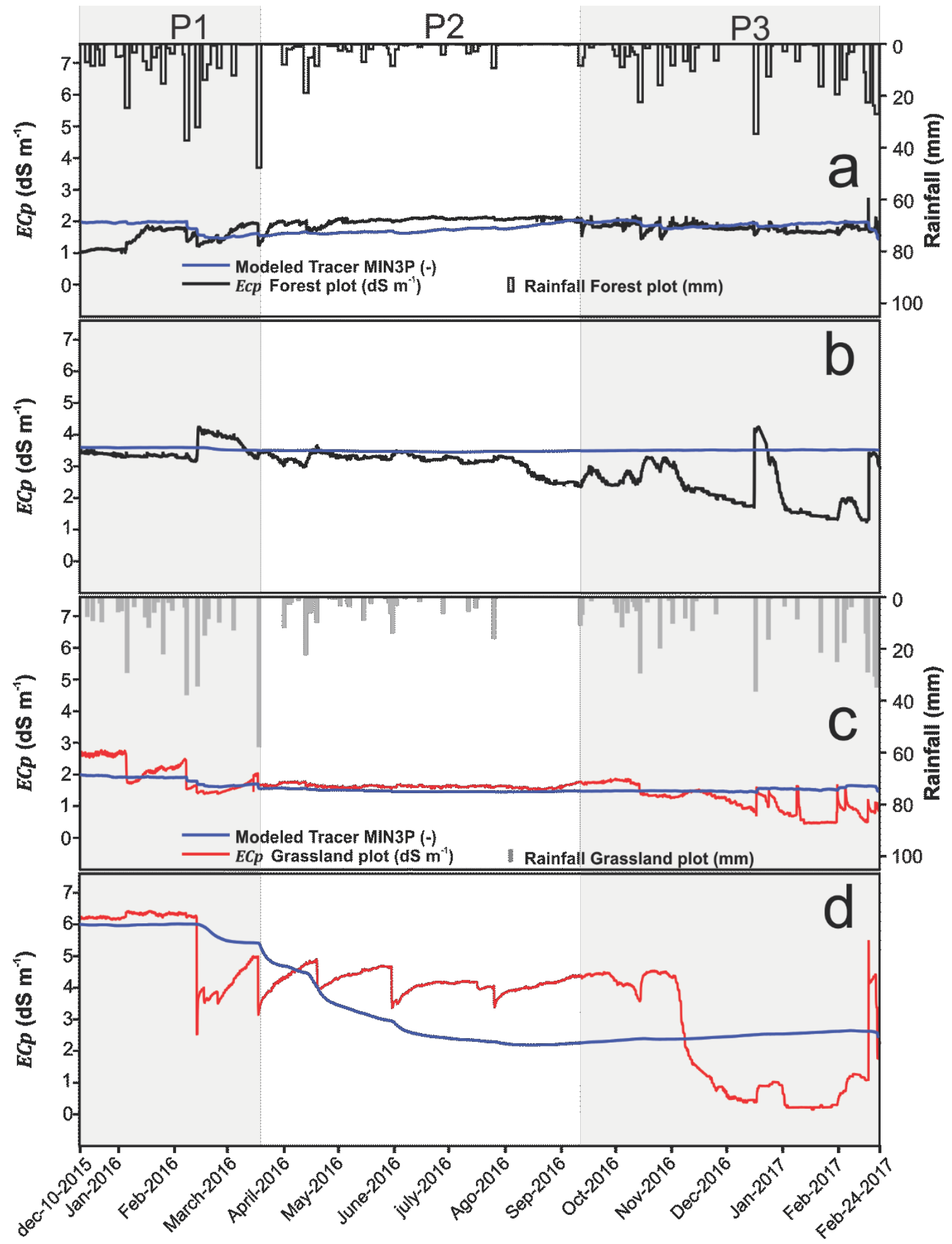

Figura 3-21. Resultados del modelo de transporte de solutos y la correspondiente medición de ECp para forestación ( $a$ y b) y herbácea (c y d) a 0,2 m y 0,5 m de profundidad, respectivamente.

\subsection{Discusión}

El monitoreo intensivo de dos parcelas bajo diferente uso del suelo como es presentado en este capítulo muestra que los flujos de agua son perturbados 
a causa del reemplazo del pastizal por forestación como también se observó en otros sitios en la misma región (Nosetto et al., 2008; Jobbágy y Jackson, 2004a, 2007; Engel et al., 2005). Sin embargo, la presencia de horizontes petrocálcicos altamente cementados en el perfil del suelo introduce una complejidad adicional a la hora de evaluar estos flujos de agua, y el agua consumida por las plantas $(P A W)$. Estos horizontes constituirían una barrera física para el flujo de agua y el propio crecimiento de las raíces, disminuyendo así (e incluso impidiendo) su acceso al acuífero freático.

Los resultados del monitoreo muestran que, en la parcela de pastizal, el almacenamiento de agua incrementa por encima de este horizonte (principalmente durante los períodos de lluvia), reduciendo la infiltración de agua hacia el acuífero (estimado aquí en un $\sim 46 \%$ menos de infiltración). Por otro lado, la transpiración de los árboles en la parcela forestada consume el agua almacenada en los horizontes más someros por encima del horizonte petrocálcico hasta alcanzar el punto de marchitez permanente, reduciendo la humedad del suelo en todo el perfil, e incluso por debajo de este horizonte.

Los resultados de la modelación también sugieren que la humedad en los niveles de suelo más superficiales (es decir, 0,2 y $0,5 \mathrm{~m}$ ) son sensibles a la presencia de raíces en los horizontes más profundos. Esto se puede deducir de los resultados del escenario RPROF donde la presencia de una mínima proporción de raíces ( 3\%, Tabla 3.2) situada por debajo del nivel petrocálcico suministra una proporción de agua tal que se satisface la demanda transpiratoria $\left(E T_{c}\right)$. Esto evita que alcance el punto de marchitez permanente en los horizontes superficiales (ver Figura 3-17). Además, las tasas de transpiración estimadas por ese escenario no son realistas $(\sim 1,200 \mathrm{~mm}$ año-1 $)$. En este sentido, los 
escenarios más realistas sugieren un uso máximo de transpiración total de agua subterránea de $\sim 13 \%$, mientras que en otros trabajos se estimaron en $\sim 50-70 \%$ (Engel et al., 2005; Cramer et al., 1999; Thorburn y Walker, 1994).

Obviamente, aquí estas diferencias podrían atribuirse a la presencia de estos horizontes de suelo altamente cementados. En este sentido es probable que la presencia de estos horizontes tenga también un efecto de disminución del drenaje profundo de agua durante los episodios de lluvias, otorgándole la posibilidad a la forestación de aprovechar una mayor proporción de esta fuente, con respecto a suelos sin restricciones hidráulicas. Sin embargo, la tosca, no impediría el ascenso capilar de agua desde capas más profundas durante los periodos de escasez, tal como lo muestra el perfil de $E C b_{g e o}$ y los resultados de modelación (Figura 3-12).

En el sitio de estudio, a diferencia de los encontrados en otros sitios en la región (ver Engel et al., 2005, y sus referencias), no se ha podido vincular las variaciones del nivel freático con la transpiración de la forestación. Esto podría explicarse de dos maneras, debido: (1) a una limitada conexión hidráulica entre la forestación y el acuífero freático, y (2) a que las conductividades hidráulicas del acuífero son tan altas $\left(\sim 5 \mathrm{~m}^{\text {día }}{ }^{-1}\right)$ que atenúan la perturbación inducida por la transpiración de la forestación. Sin embargo, los resultados de la modelación sugieren la primera opción.

En sitios como el de este estudio, con posiciones topográficas altas y niveles freáticos relativamente profundos, no tendría lugar la ocurrencia de procesos de salinización secundaria, como sí sucede en zonas topográficamente más bajas y con niveles freáticos más someros (Nosetto et al., 2013). Sin embargo Nosetto et al. (2013) encontró una acumulación de sales en el acuífero 
de hasta cuatro veces con niveles freáticos a 5,5 $\mathrm{m}$ de profundidad. En ese caso la salinización se concentró a lo largo de una capa de alrededor de un metro en la zona no saturada (ZNS), lo cual en sí mismo no representaría un riesgo de salinización para la parte más somera del perfil del suelo.

No obstante, en la llanura Pampeana la posibilidad eliminación del exceso de sales acumuladas en las cuencas es muy limitado por sus escasos gradientes topográficos y piezométricos, sumado a una acumulación natural de sales desde las cabeceras hacia las zonas de descarga (Zabala et al., 2016a). En estos casos la presencia de estos niveles de acumulación de sales aumenta el riesgo de una posterior salinización superficial en caso de nuevos cambios en la cobertura (Jayawickreme et al., 2011; George et al., 1997) o de los recurrentes ciclos de inundación de estos ambientes causados por los aumentos de niveles (Kuppel et al., 2015; Viglizzo et al., 2009).

Teniendo en cuenta estos factores, la presencia de tosca impidió el desarrollo de salinización secundaria de la ZNS donde los autores mencionados encontraron una acumulación de sales entre 4 y 7 veces respecto de los pastizales y cultivos herbáceos adyacentes. Nosetto et al., (2013) propone las zonas medias y altas del terreno (con niveles freáticos profundos) como los sitios más apropiados para plantaciones forestales y donde la salinización es menor y más profunda (debajo de los $2 \mathrm{~m}$ ). De acuerdo con los resultados de este estudio la presencia una capa que restrinja el acceso al agua freática, permitiría un menor impacto de la actividad en estas zonas altas y medias del terreno y aun la posibilidad de ocupar terrenos más bajos con impactos presumiblemente menores que en ambientes sin tosca. 
En cuanto a las limitaciones del modelo, como se indicó anteriormente, el enfoque de la toma de agua (Battaglia y Sands, 1997) implementado en MIN3P es más riguroso desde una perspectiva del medio poroso, pero es menos riguroso desde el punto de vista de la fisiología de los árboles. Se podría atribuir las diferencias obtenidas en el modelo base (Figura 3-13) a una respuesta fisiológica de la forestación no contemplada en el enfoque de Battaglia y Sands (1997) implementado en MIN3P. De los resultados obtenidos en el escenario REST se puede deducir que existe esta respuesta a los distintos periodos de disponibilidad hídrica y que no está contemplado por la configuración actual del código MIN3P.

De hecho, las forestaciones han mostrado este tipo de respuestas en condiciones similares (Hendrick y Pregitzer, 1993), y se espera una disminución en la absorción de agua de la forestación después de los períodos de estrés debido a una reducción en la relación crecimiento/envejecimiento de las raíces (Hendrick y Pregitzer, 1993; Bartsch, 1987; Kuhns et al., 1985).

Sin embargo, esta limitación también está presente en otras formulaciones de respuesta al estrés hídrico comúnmente utilizadas en modelos físicos de suelos (Cai et al., 2017; Verma et al., 2014; Šimůnek y Hopmans, 2009; Feddes et al., 1974).

Finalmente, la metodología propuesta aquí (sostenida por modelación basada en procesos en el continuo acuífero-suelo-planta-atmósfera) podría aplicarse para estimar el consumo forestal de agua subterránea donde otras metodologías (habitualmente utilizadas en llanuras) fallarían (por ejemplo, basadas en las fluctuaciones de la capa freática, ver Engel et al., 2005). 


\subsection{Conclusiones}

Se estableció y validó un modelo conceptual de funcionamiento hídrico para pastizales forestados en paisajes de llanura con la presencia de un horizonte petrocálcico.

Los resultados presentados aquí demostraron que, en aquellas áreas de Ilanura con la presencia generalizada de heterogeneidades del suelo, como los horizontes petrocálcicos, el $P A W$ para especies herbáceas (con un sistema de raíces poco profundo) se mejora debido a un menor drenaje profundo de agua. En contraste, estos horizontes petrocálcicos podrían implicar una restricción a la exploración del suelo por las raíces en el caso de especies arbóreas, y en consecuencia restringen también su consumo de agua. Por lo tanto, el riesgo de salinización del suelo causado por la forestación de pastizales se reduciría drásticamente. 


\section{Capítulo 4}

Control hidrogeoquímico del proceso de salinización causado por la forestación de pastizales. (*)

* Este capítulo se basa en el artículo:

Mujica, C.R., Milione, G.M., Bea, S.A., Jobbágy, E.G., 2019c. Modelación de los cambios químicos en suelos inducidos por la forestación de pastizales naturales en ecosistemas de llanura. Ecol. Austral 29, 433-445. https://doi.org/10.25260/EA.19.29.3.0.896 


\subsection{Introducción}

La forestación de pastizales no solo impactaría localmente el balance hídrico del sistema, sino también el de solutos, y las propiedades físico-químicas del suelo (Mujica et al., 2019c; Hong et al., 2018; Nosetto et al., 2007). Existen muchos trabajos que describen las causas y efectos derivados de estos cambios en el uso del suelo (Nosetto et al., 2008; Jobbágy y Jackson, 2007; Heuperman, 1999), pero el acoplamiento entre los procesos implicados no fueron exhaustivamente estudiados desde el punto de vista cuantitativo y de manera comprensiva y acoplada (Hong et al., 2018).

Tal como ha sido mencionado en capítulos anteriores, este mayor uso de agua por parte de las forestaciones generalmente es acompañado por una fuerte redistribución de los solutos presentes en el suelo, y la modificación de las propiedades físico-químicas de este (p. ej., alcalinización, sodificación, etc.). El carbono, y nutrientes como calcio $(\mathrm{Ca})$, magnesio $(\mathrm{Mg})$ y nitrógeno $(\mathrm{N})$ almacenados en el suelo disminuyen, mientras que otros como sodio $(\mathrm{Na})$ y cloro (Cl) se concentran afectando su fertilidad (Hong et al., 2018; Berthrong et al., 2009).

Cabe destacar que la magnitud de estos cambios podría modificar el funcionamiento bioquímico y "estructural" del suelo, generando por ejemplo acidificación que reduce su actividad microbiana (Kunito et al., 2016), e incrementa la pérdida de nutrientes por lixiviación (Bowman et al., 2008). Por otro lado, la acumulación residual (luego de la salinización) de Na causa: (1) la dispersión de coloides disminuyendo la estabilidad estructural del suelo, y su porosidad, con su consecuente disminución en la capacidad de conducción y almacenamiento de agua y gases; y (2) aumenta la movilidad y la pérdida de 
materia orgánica, comprometiendo irreversiblemente su fertilidad (Hong et al., 2018; Jobbágy et al., 2017; van Breemen y Buurman, 2002; Sumner, 1993).

Conocer y cuantificar aquellos procesos que afectan la productividad de los suelos en función de su uso es crucial para una óptima gestión hídrica de las cuencas asociadas en donde se desarrollan estas actividades (Nosetto et al., 2007). Varios trabajos han tratado cualitativamente los potenciales mecanismos que controlan la acidificación y salinización de los suelos en pastizales forestados (Mujica et al., 2019c; Nosetto et al., 2008; Jobbágy y Jackson, 2007; Dakora y Phillips, 2002; Marcar y Termaat, 1990; Nye, 1981). Dentro de estos mecanismos propuestos podemos citar: (1) la intrusión de agua profunda producto de la descarga inducida por la forestación; (2) la toma selectiva de nutrientes; (3) la exudación de solutos por parte de las raíces; (4) el reciclaje de solutos del sistema; y (5) una mayor tasa de respiración en el suelo forestal (Figura 4-1).

Con respecto al ingreso de agua profunda al sistema (1), esta sería consecuencia de una descarga hídrica local generada principalmente por un mayor consumo de agua por parte de la forestación. Previo al establecimiento de ésta, el nivel freático está caracterizado químicamente por agua proveniente de recarga de lluvia local. Pero después del cambio de vegetación, esta agua residente es consumida rápidamente y reemplazada por otra, potencialmente de una fuente más profunda, y con diferente composición química (Jobbágy y Jackson, 2007; Heuperman, 1999). La entrada de este tipo de agua podría alterar el equilibrio químico del agua residente en los poros del suelo, induciendo una serie de reacciones químicas que, sumado a las interacciones con la rizósfera podrían tener lugar cambios físico-químicos más profundos. 
Con respecto a la toma selectiva de nutrientes por parte de la rizósfera (2), esta podría generar la acumulación y/o empobrecimiento de ciertos solutos dentro del suelo (Hong et al., 2018; Ae et al., 2001; Nye, 1981). Ciertos solutos, como $\mathrm{Na}$ y $\mathrm{Cl}$, podrían generar toxicidad en los tejidos vegetales, causando necrosis en hojas, muerte de ramas o incluso del individuo, dependiendo de la especie vegetal que se trate y de las concentraciones a las que se expongan (Bañuls et al., 1997).

Por el contrario, en especies vegetales tolerantes a la salinidad (e.g., Eucalyptus camaldulensis), una exposición a elevadas concentraciones de $\mathrm{NaCl}$ incrementa la selectividad por la toma de $\mathrm{K}$ y Ca como respuesta fisiológica. Tanto el K como el Ca tienen importancia en el potencial osmótico y, afectan la permeabilidad y la capacidad selectiva de la membrana celular (Greenway y Munns, 1980). Así como también cumplen un rol fundamental en el control estomático, en repuestas hormonales y en la estructura de las paredes celulares (Dakora y Phillips, 2002; Raz y Fluhr, 1992). De la misma manera N y Fe son importantes como componente mayoritario de proteínas, ADN y pigmentos (como la clorofila) en las células vegetales (Nelson y Cox, 2018).

Muchos de estos nutrientes son escasos, o están en proporciones menores a las requeridas por las plantas, por lo que las plantas desarrollan distintas estrategias para suplir estas deficiencias. Una de estas estrategias para suplir deficiencias en nutrientes, está relacionada con la exudación de sustancias (3). Estas pueden actuar directamente sobre el suelo (e.g., disolución de minerales, cambios en potenciales osmóticos, etc.), o indirectamente, favoreciendo el desarrollo de microorganismos del suelo implicados en relaciones simbióticas de absorción (Von Wirén et al., 1993; Raven et al., 1990). 
La composición de los exudados radiculares puede ser compleja y comúnmente va desde mucilagos, células de la raíz, enzimas extracelulares, azúcares simples y complejos, fenoles, fitosideróforos, aminoácidos, vitaminas, ácidos orgánicos, macromoléculas nitrogenadas como purinas y nucleósidos, hasta moléculas inorgánicas o gaseosas tales como $\mathrm{HCO}_{3}^{-}, \mathrm{OH}^{-}, \mathrm{H}^{+}, \mathrm{CO}_{2}$ y $\mathrm{H}_{2}$.

Cabe destacar que la exudación de estos iones inorgánicos es importante para la nutrición de las plantas, además de ser un mecanismo para mantener la neutralidad eléctrica. Por ejemplo, ante un exceso de aniones las raíces pueden liberar $\mathrm{H}^{+}$para balancear el medio, lo que a su vez induce un descenso en el pH. Por otro lado la exudación de $\mathrm{HCO}_{3}{ }^{-}$tiende a aumentar la disponibilidad de nutrientes en suelos ácidos y del mismo modo que la exudación de $\mathrm{H}^{+}$en suelos calcáreos (Dakora y Phillips, 2002; Marschner y Römheld, 1994).

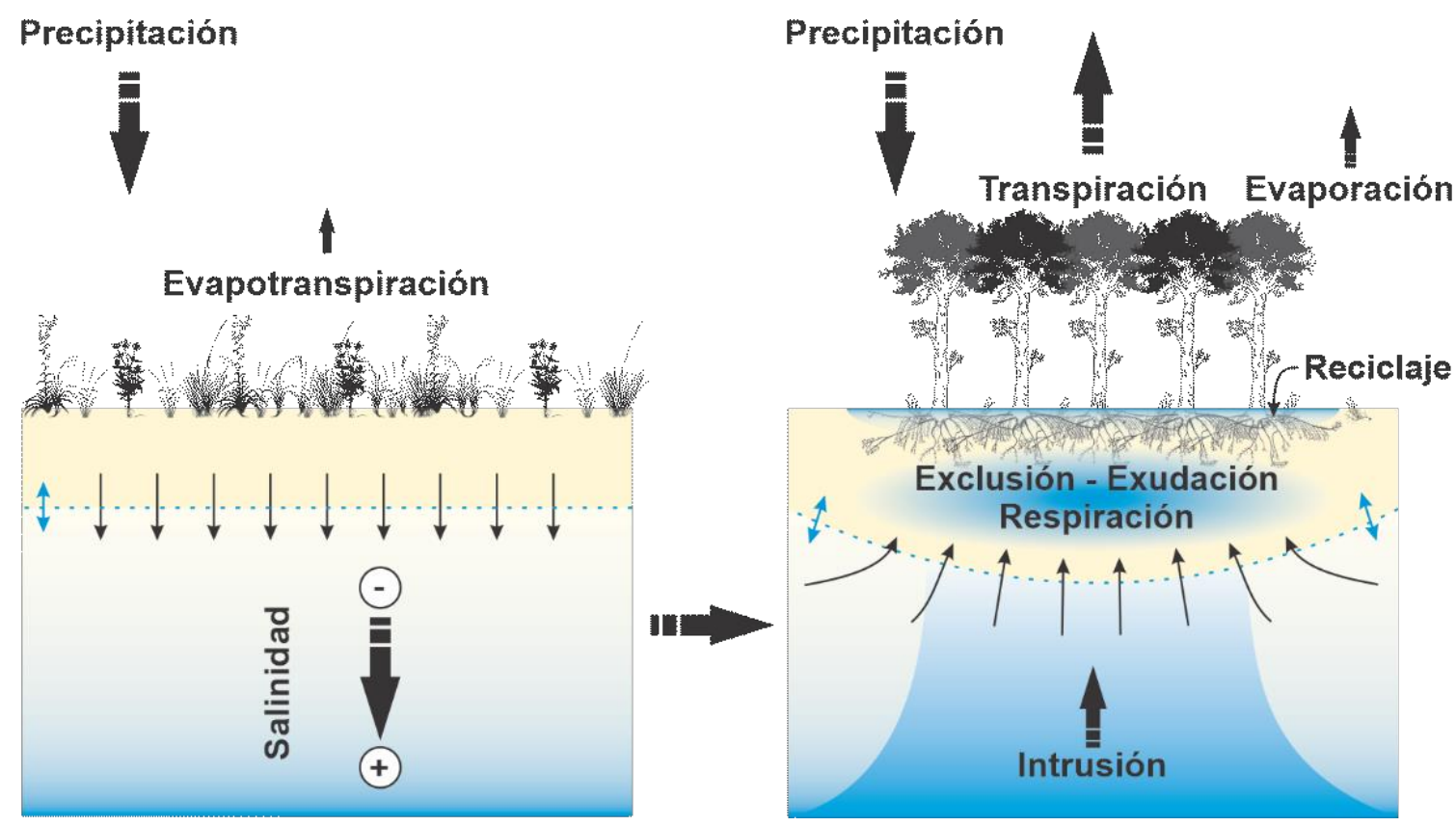

Figura 4-1. Esquema representativo de los mecanismos propuestos desencadenados por la forestación de pastizales sobre los flujos de solutos.

Con respecto al reciclado de nutrientes (4), (Jobbágy y Jackson, 2001, $2003,2004 b)$ resaltan que este sería uno de los mecanismos dominantes en la acidificación y salinización de los suelos forestados. El reciclaje ("cycling") de 
nutrientes por las plantas es el movimiento neto de nutrientes hacia la superficie del suelo transportados dentro de los tejidos de principalmente especies arbóreas, que los libera a través de la hojarasca, descortezado y directamente lavado de la superficie de las hojas por la lluvia que alcanza el suelo (Stone y Gibson, 1975).

El ejemplo más significativo de redistribución de nutrientes por las plantas es la transformación y el movimiento de nutrientes de relativamente bajo peso molecular (e.g, C, H, O, N y S) desde la atmósfera a la superficie del suelo. Sin embargo, la biomasa vegetal está compuesta por un $\sim 5-10 \%$ de nutrientes de mayor peso molecular provenientes de la litósfera. Algunos de estos nutrientes como $\mathrm{Ca}, \mathrm{K}$ y $\mathrm{P}$ se encuentran en concentraciones relativamente altas en las plantas respecto de su abundancia en suelos y rocas (Lambers et al., 2008a; Jobbágy y Jackson, 2004b).

Este reciclado de nutrientes llevaría a los suelos de pastizales forestados a tener acumulación de sales y a un descenso en el pH. La distribución vertical en el perfil de suelo de los solutos acumulados cuando predomina el cycling es opuesta a la situación donde predomina la exclusión (Jobbágy y Jackson, 2007). El proceso de cycling se caracteriza por una acumulación superficial de los solutos (e.g., Ca, Mn, Mg, K y P) y en cambio la exclusión forma una capa de acumulación más profunda en cercanías de la zona saturada ( e.g., $\mathrm{Na} \mathrm{y} \mathrm{Cl}$, Nosetto et al., 2013; Jobbágy y Jackson, 2007).

La mayor tasa de respiración en los suelos forestados (5) estaría dada por el mayor volumen de raíces y por un aumento en la actividad microbiológica del suelo alimentada por la mayor cantidad de residuos vegetales. Esta mayor inyección de $\mathrm{CO}_{2}$ en el suelo puede causar acidificación (Epron et al., 2004; 
O’Connell, 1987) y podría alterar el equilibrio químico de minerales como la calcita u otros carbonatos, generando su disolución (Appelo y Postma, 2005; Andrews y Schlesinger, 2001).

Sin embargo, es posible que el efecto atribuido a la respiración dependa además de otros factores ya que existen autores que indican comportamientos contrarios, con una menor tasa respiratoria en suelos forestados o sin efecto sobre el pH (Saviozzi et al., 2001; Raich y Tufekcioglu, 2000). Se sugiere que factores como la relación $\mathrm{C} / \mathrm{N}$ de los residuos vegetales, temperatura y humedad tienen un mayor efecto sobre la respiración del suelo que la especie vegetal que lo cubre en sí misma (Jobbágy y Jackson, 2003; Saviozzi et al., 2001; Raich y Tufekcioglu, 2000).

Para evaluar y/o predecir el impacto de la actividad forestal en estos ambientes, es necesario tener en cuenta un gran número de procesos físicos, químicos y biológicos que actúan acoplados. Considerando la complejidad y la no linealidad de estos acoplamientos, es necesario aplicar herramientas que permitan capturar y validar estos mecanismos, tales como los modelos de transporte reactivo (Steefel et al., 2005; van Breemen et al., 1983).

En la actualidad se han desarrollado varios modelos de este tipo que incluyen los procesos acoplados mencionados anteriormente (Mujica et al., 2019c; Steefel et al., 2015; Mayer et al., 2012; Bea et al., 2012; Šimůnek y Hopmans, 2009; Nowack et al., 2006). Estos tienen en cuenta: (a) el flujo del agua y el transporte de solutos a través del medio poroso del suelo; (b) procesos químicos tales como la formación de complejos acuosos, el intercambio catiónico, la disolución y precipitación de minerales, reacciones ácido/base, etc.; y (c) procesos de la rizósfera, tales como toma de agua y nutrientes, exudación 
y respiración (Gérard et al., 2017; Nowack et al., 2006; Hinsinger et al., 2005; Hopmans y Bristow, 2002). Sin embargo, a pesar de su relevancia, no han sido utilizados hasta el presente modelos para estudiar los procesos modificadores de la química del suelo asociados a la rizósfera de forestaciones freatófitas (e.g., eucaliptos).

El objetivo de este capítulo es identificar y validar aquellos mecanismos y condiciones que conducen a los cambios químicos del suelo en pastizales forestados haciendo uso de modelos de transporte reactivo. $Y$ de esta manera desarrollar una herramienta que permita predecir el impacto de la actividad forestal sobre ambientes naturalmente cubiertos por especies herbáceas (i.e., pastizales, pasturas y cultivos agrícolas).

El modelo utilizado fue MIN3P (Bea et al., 2012; Mayer et al., 2002, 2012), que ha sido modificado para tener en cuenta los fuertes desbalances eléctricos que tienen lugar en la rizósfera de las forestaciones. Este modelo ha sido aplicado a una típica parcela de pastizal forestada en la llanura Pampeana con evidencias de salinización de suelo (i.e., Castelli, Jobbágy y Jackson, 2004a, 2007; Engel et al., 2005).

\subsection{Materiales y métodos}

\subsubsection{Descripción de la zona de estudio.}

La zona de estudio del presente trabajo involucra una transecta que recorre pastizal/forestación ubicada en la localidad de Castelli $\left(-36^{\circ} 02.0^{\prime}\right.$, $57^{\circ} 50.3^{\prime}$; Figura 4-2). Este sitio, fue forestado con Eucalyptus camaldulensis (50 ha) en 1951 con una cuadricula de plantación de 2 × 3 m, en una matriz de pastizal típico de la Pampa Deprimida (Cabrera, 1976; Burkart et al. 2005). 
Eucalyptus camaldulensis (conocido gomero rojo o eucalipto colorado), es una especie muy distribuida en Argentina por su gran rusticidad y adaptabilidad. Cuenta con una gran variabilidad genética que le permite tolerar temperaturas desde -8 hasta $50{ }^{\circ} \mathrm{C}$ y crecen con precipitaciones de entre 200 y $1100 \mathrm{~mm}$ año${ }^{1}$. Esta especie se adapta bien a suelos arcillosos y tiene tolerancia a la presencia de sales solubles, pero tiene cierta susceptibilidad a la presencia de horizontes calcáreos donde sufre clorosis por falta de hierro (Gutiérrez, 1976) .

La Pampa Deprimida se caracteriza por bajas pendientes topográficas, y por flujos de agua preferencialmente verticales (Varni y Usunoff, 1999). Esta amplia región, de alrededor de 8 millones de hectáreas, está cubierta por depósitos de loess del Pleistoceno-Holoceno tardío, que forman un manto de espesor variable. El tipo de suelo más común en este ambiente de llanura son de tipo salino-sódico (Natracuoles y Natracualfes, US Soil Taxonomy; Solonetzes, según FAO Soil Map) desarrollados a partir de estos sedimentos, adecuados para la ganadería extensiva en pastoreo (Zárate, 2003; Viglizzo et al., 2001; Teruggi, 1957).

El sitio de estudio, sin embargo, se encuentra en una formación eólica típica de la zona con una posición elevada respecto del terreno circundante, con aptitud para la agricultura y ganadería. En el sitio de estudio, el suelo es un Hapludol (del tipo de la serie "Los Naranjos", INTA, 2011) que cubre a un suelo erosionado más antiguo (horizontes II). La secuencia de horizontes en el sitio de estudio es: A (0-15 cm), AC (15-35 cm), IIIB $(35-75 \mathrm{~cm})$ e IIC $(75-300 \mathrm{~cm})$.

Sus escasas pendientes topográficas $(<0,1 \%)$, y la erosión eólica ocurrida durante el Cuaternario crearon una pobre red de drenaje. Esto sumado al clima subhúmedo a húmedo (800-1000 mm año-1), generaron las condiciones para un 
acuífero freático somero, con un tipo químico de agua dominante bicarbonatadasódica o $\mathrm{Na}-\mathrm{HCO}_{3}$ (Zabala et al., 2016a; Carretero et al., 2013). Como se mencionó anteriormente, en estos sistemas las aguas subterráneas incrementan naturalmente su contenido de sales desde las zonas de recarga hacia los puntos de descarga, donde se pueden observar evidencias de salinización y alcalinización y la consecuente pérdida de fertilidad de los suelos (Jobbágy et al., 2017). 


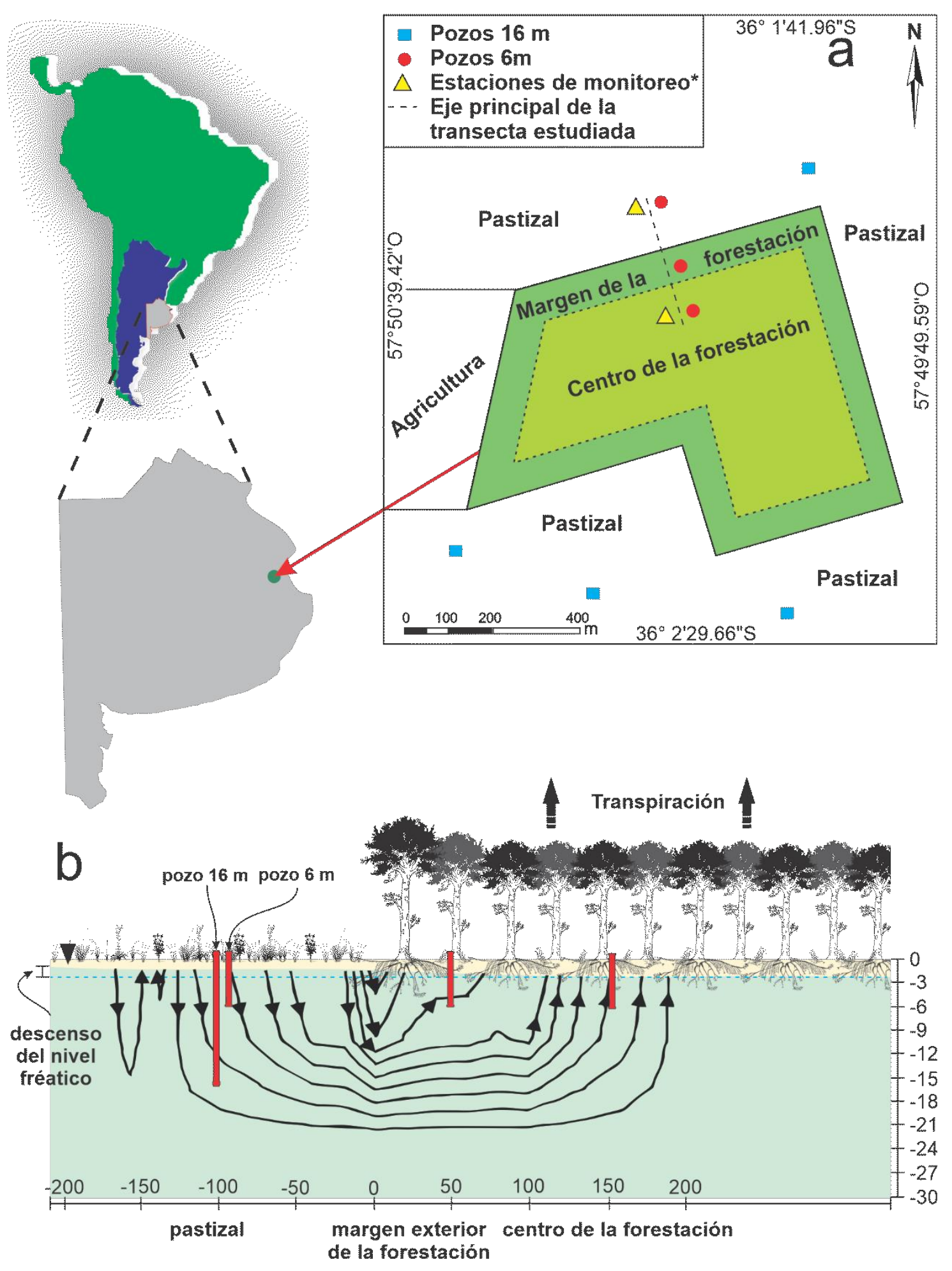

Figura 4-2. Ubicación y características transecta estudiada. *se refiere a las estaciones donde se monitoreó el nivel freático y la traspiración. Las líneas de flujo en (b) fueron extraídas y modificadas a partir de Jobbágy y Jackson 2007.

En el sitio de estudio, el manejo al cual fue sometido coincide con el típico aplicado en la región, el pastizal fue pastoreado, la forestación no tuvo ninguna intervención, y no se realizaron prácticas de riego ni fertilización. Al momento en 
que se realizaron las mediciones, 500 a 700 árboles ha-1 se mantenían en pie con una altura promedio de $\sim 45 \mathrm{~m}$. Mas detalles sobre el sitio de estudio se pueden ver en Jobbágy y Jackson (2004a), y en Engel et al., (2005).

a

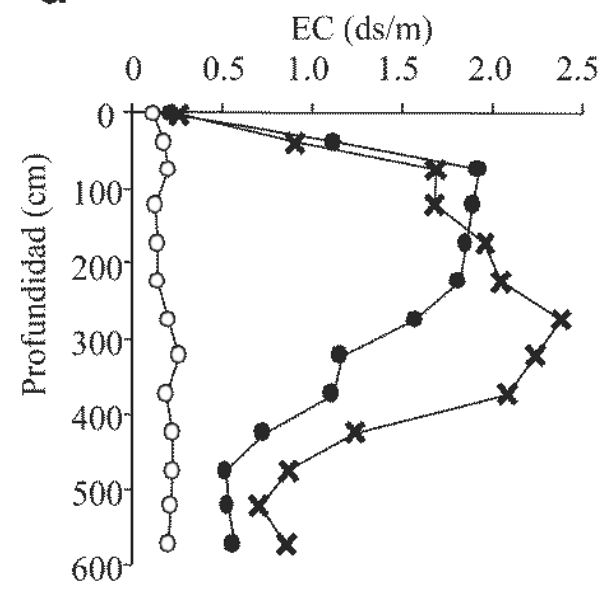

c

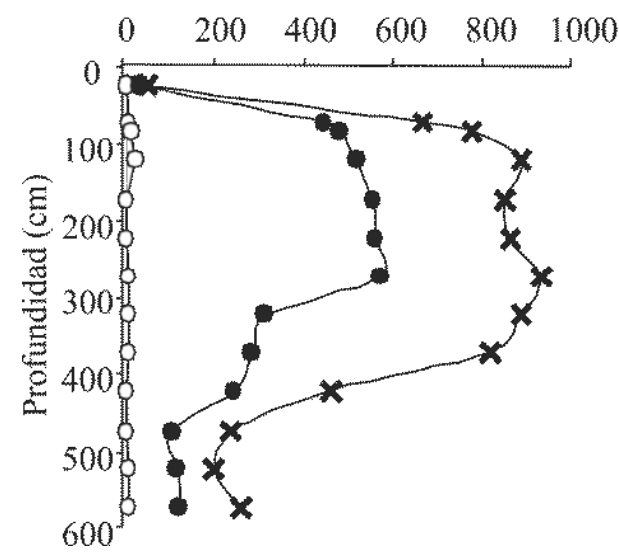

b

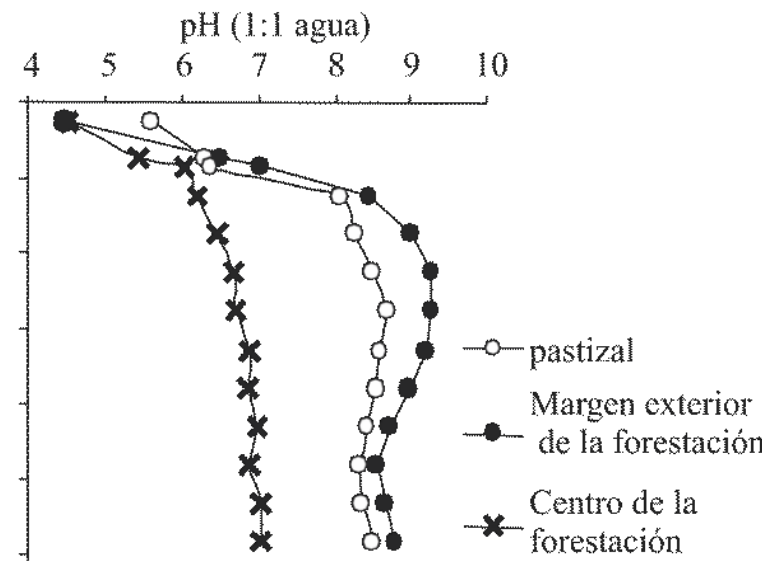

Porcentaje de Na

d intercambiable (PSI, \%)

$\begin{array}{llllll}0 & 5 & 10 & 15 & 20 & 25\end{array}$

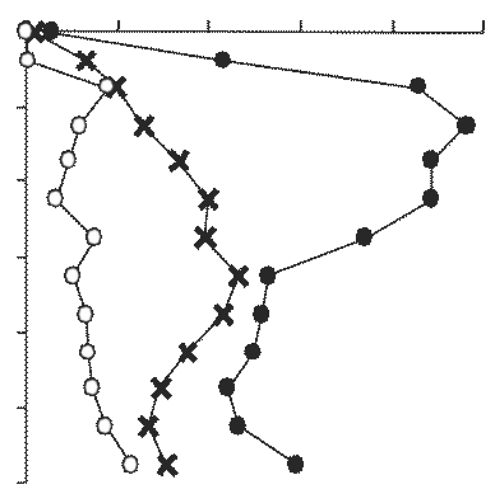

Figura 4-3. Características químicas de la transecta estudiada, extraído de Jobbágy y Jackson (2007). (a) La conductividad eléctrica (EC) corresponde con mediciones sobre una relación suelo:agua de 1:5, (b y c) para $\mathrm{pH}$ y cloruro se usó una relación 1:1. (d) el porcentaje de sodio intercambiable (PSI) indica el porcentaje del complejo de cambio que está saturado por ese elemento. La posición de pastizal se hizo a $100 \mathrm{~m}$ de la forestación, mientras que margen y centro se ubicaron a 50 y $150 \mathrm{~m}$, respectivamente, hacia el interior de la misma.

Las precipitaciones medias en el sitio de estudio son de $\sim 980 \mathrm{~mm}$ año-1 (promedio en los 53 años previos al momento analizado en este estudio, medidas en el mismo establecimiento agropecuario) y los niveles freáticos varían entre $\sim 0,45$ y $\sim 5,5$ m de profundidad, este segundo valor coincide además con el valor de máxima profundidad alcanzada por las raíces (Jobbágy y Jackson, 2004a). 
Cabe destacar que en este sitio la forestación genera un descenso de $\sim 30$ a 70 cm respecto del nivel freático en el pastizal.

La tasa de traspiración de la forestación fue estimada en 2,16 mm día-1, y la misma se sostendría por un consumo de agua freática de $\sim 290$ a $\sim 390$ mm año ${ }^{-1}$ (Engel et al., 2005). Este consumo genera un esquema de flujos laterales (Figura 4-2b, entre $\sim 160$ y $\sim 900 \mathrm{~mm}$ año ${ }^{-1}$ ) que van desde la parcela herbácea hacia la forestación, así como también verticales, provenientes de aguas subterráneas residentes a mayor profundidad (Jobbágy y Jackson, 2004a, 2007; Engel et al., 2005).

El pH de suelo varió a lo largo de la transecta (Figura 4-2), alcanzando valores de $\sim 8$ en el pastizal, $\sim 9$ en el margen exterior y $\sim 6.5$ en el centro de la forestación (Figura 4-3). De la misma manera, la química del suelo y del acuífero freático varió siguiendo este trayecto. El agua de poro debajo de la forestación fue $\sim 5$ veces más salina, con un mayor contenido en $\mathrm{Cl}$ y $\mathrm{Na}$ (Tabla 4.3). La fracción sólida del suelo debajo de la forestación tiene en promedio un 20 \% más de $\mathrm{Na}$ intercambiable, $\sim 800 \mathrm{~g} \mathrm{~m}^{-2}$ más de $\mathrm{Cl}$, y entre $\sim 10 \mathrm{y} \sim 30$ veces más salinidad si se compara con el pastizal (Figura 4-3).

Para obtener el volumen de madera se midió el diámetro a la altura del pecho (DAP) con cinta diamétrica y la altura $(\mathrm{H})$ mediante clinómetro Suunto PM5/360PC (Suunto, Finlandia), en 5 parcelas de 20 árboles vivos y muertos. El volumen real de madera se obtuvo multiplicando esta medición por el coeficiente de forma del rodal (CM). Para obtener $\mathrm{CM}$ se apearon dos árboles de altura y diámetro más representativos (i.e., árbol tipo) y se midió su diámetro cada un metro, seguido de esto se relacionó el volumen calculado con esta medición y el calculado con DAP y $\mathrm{H}$ para obtener $\mathrm{CM}(=0.35)$. 
Sumado a esto se obtuvo la densidad aparente de la madera por medio de 5 tarugos de $0,5 \mathrm{~cm}$ de diámetro con barreno de Pressleer, los cuales se midió su volumen, se secaron en horno y se pesaron. De la misma manera se obtuvo material de ramas y hojas de 5 individuos para obtener la masa en $\mathrm{Mg} \mathrm{ha}^{-1}$. Además, se recolectó la hojarasca y el horizonte orgánico en un volumen conocido $(n=5)$ lo que, sumado a las mediciones de raíces, completa el total de los componentes de la biomasa $\left(\mathrm{Mg} \mathrm{ha}^{-1}\right)$ de la forestación. Muestras de todo este material fue secado a horno $\left(70^{\circ} \mathrm{C}\right)$, pulverizado, tamizado $(0.5 \mathrm{~mm})$ y digerido con una solución de $\mathrm{HNO}_{3} / \mathrm{H}_{2} \mathrm{O}_{2}$ para hacer el análisis de bases con ICP. La biomasa acumulada en la parcela forestal ( 754 $\left.\mathrm{Mg} \mathrm{ha}^{-1}\right)$ tiene una composición química que difiere en sus proporciones respecto a la del suelo y la del agua subterránea, reflejando el efecto de la toma selectiva de nutrientes (Figura 4-4). 


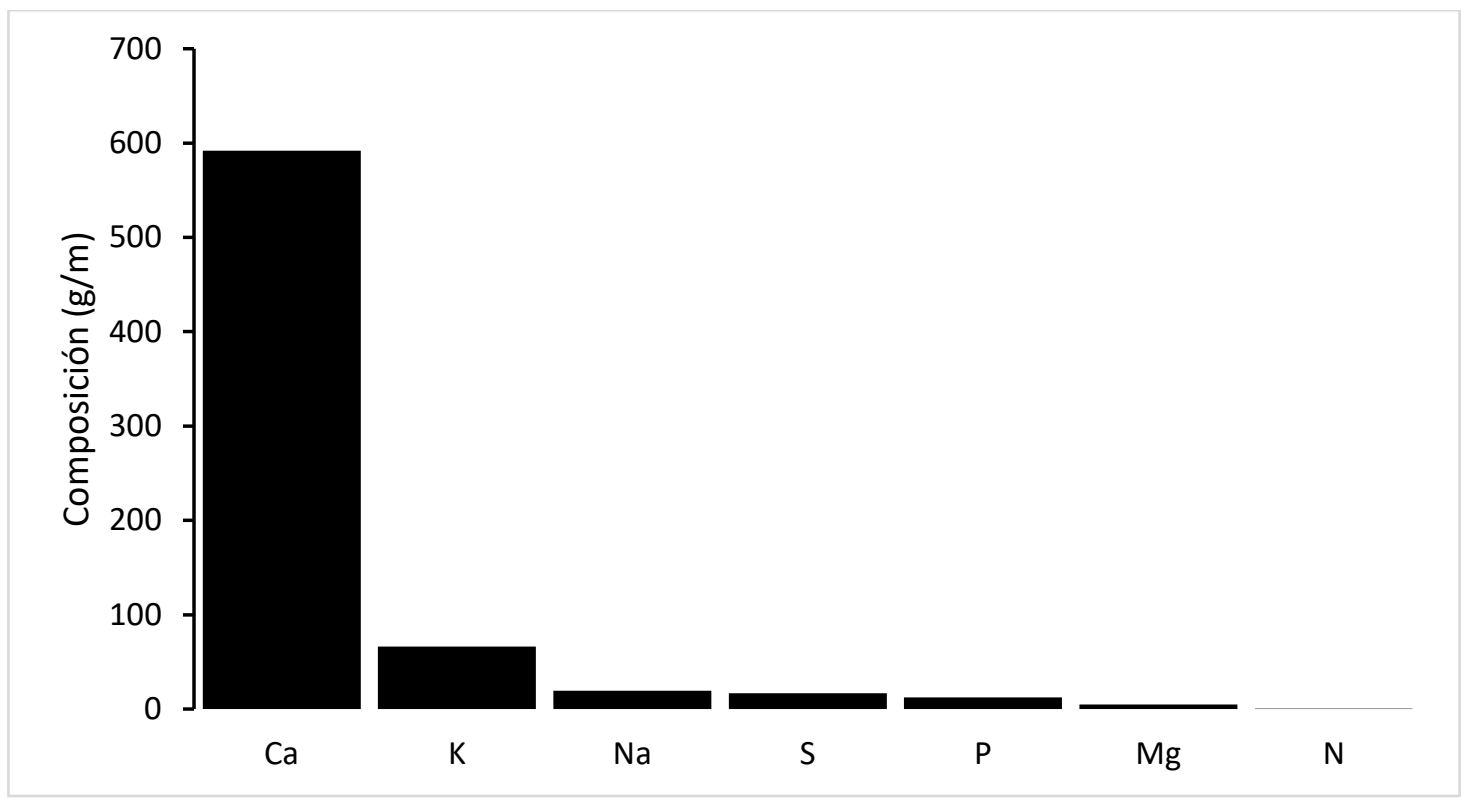

Figura 4-4. Composición de la biomasa de Eucalyptus camaldulensis. Para detalles metodológicos sobre la obtención de estos datos ver Jobbágy y Jackson 2003.

\subsubsection{Dominio y características del modelo}

Basados en los estudios mencionados anteriormente (Figura 4-2) se llevaron a cabo una serie de modelos de transporte reactivo (TR) en un dominio unidimensional y un tiempo total de simulación de 50 años. Los modelos fueron llevados a cabo con el modelo de TR MIN3P (Bea et al., 2012, 2016; Mayer et al., 2002, 2012), en donde se implementó una función que permite mantener la neutralidad eléctrica del agua a pesar de la toma selectiva de iones por parte de las raíces (Ecuación 43). El dominio del modelo consistió en un bloque de 30 m de profundidad de loess y área unitaria $\left(1 \mathrm{~m}^{2}\right)$. El mismo se discretizó en 19 capas, cada una con propiedades físico-químicas diferentes (Figura 4-5 y Tabla 4.1). Como condiciones iniciales se partió de la química observadas en la parcela de pastizal. La parametrización del modelo fue llevada a cabo de acuerdo a propiedades físicas y químicas del suelo recopiladas en trabajos previos cuyos detalles metodológicos pueden obtenerse en Jobbágy \& Jackson, (2003, 2004, 2007) y Engel et al., (2005). 
En la parte superior del dominio (Figura 4-5) se impuso una condición de contorno para el flujo de caudal prescrito representando el volumen promedio de precipitaciones ( $\left.\mathrm{mm} \mathrm{día}^{-1}\right)$, y flujo másico con su respectiva composición química recolectada debajo de superficie del suelo de la forestación como condición de contorno de transporte, considerándose así el aporte de nutrientes/solutos reciclados (Jobbágy y Jackson, 2003, 2007). En la parte inferior del modelo se impone una condición de contorno de flujo de nivel freático prescrito variable en el tiempo (basado en mediciones directas y observación de indicadores edáficos, ver Engel et al., 2005; Jobbágy \& Jackson, 2004). 
Tabla 4.1. Parámetros físicos del modelo

\begin{tabular}{lllllll}
\hline $\begin{array}{l}\text { Intervalo de } \\
\text { profundidad en las } \\
\text { capas del modelo [m] }\end{array}$ & \multicolumn{2}{l}{$\begin{array}{l}\text { Porosidad Conductividad } \\
\left.\text { hidráulica [m s }{ }^{-1}\right]\end{array}$} & $\alpha_{v g}\left[\mathrm{~m}^{-1}\right]^{\mathrm{a}}$ & $n[-]^{\mathrm{a}}$ & $S^{\text {lim }[-]^{\mathrm{a}}}$ & $S^{f}[-]^{\mathrm{a}}$ \\
\hline $0-0,15$ & 0,64 & $3,65 \mathrm{e}-05$ & 1,30 & 1,4340 & 0,18 & 0,45 \\
$0,15-0,35$ & 0,63 & $1,07 \mathrm{e}-05$ & 1,12 & 1,4782 & 0,18 & 0,43 \\
$0,35-0,50$ & 0,58 & $7,67 \mathrm{e}-06$ & 1,29 & 1,4693 & 0,18 & 0,48 \\
$0,50-0,85$ & 0,57 & $5,77 \mathrm{e}-06$ & 0,61 & 1,6091 & 0,18 & 0,57 \\
$0,85-1,20$ & 0,41 & $9,58 \mathrm{e}-07$ & 0,63 & 1,5941 & 0,36 & 0,76 \\
$1,20-1,45$ & 0,40 & $1,06 \mathrm{e}-05$ & 0,63 & 1,5941 & 0,36 & 0,75 \\
$1,45-1,80$ & 0,41 & $7,50 \mathrm{e}-6$ & 0,63 & 1,5941 & 0,36 & 0,75 \\
$1,80-6,0$ & 0,41 & $5,00 \mathrm{e}-6$ & 0,63 & 1,5941 & 0,36 & 0,76 \\
$6,0-30,0$ & 0,41 & $5,00 \mathrm{e}-6$ & 0,63 & 1,5941 & 0,36 & 0,76
\end{tabular}

a Calculado a partir de la densidad aparente y la textura del suelo con el software Rosetta Lite v.1.1 (Schaap et al., 2001; Schaap, 1999). Ver sección '3.2.7. Ecuaciones del modelo MIN3P'

Para construir la serie temporal del nivel freático a 50 años se ensayaron series de niveles combinando las mediciones hechas por Engel et al. (2005) durante 2002 y 2003 (entre 0.45 y 2.93 m de profundidad), con una serie sintética construida en base observación de indicadores edáficos (Jobbágy y Jackson, 2004a), la cual tiene un mínimo de 0.45 m y un máximo en 5,5 m (Figura 4-6).

Con respecto a la tasa de consumo de agua por parte de las raíces se usó el modelo y parámetros propuestos por Battaglia \& Sands, (1997), donde la toma de agua del suelo está restringida por el agua disponible en el perfil y por evapotranspiración del cultivo bajo condiciones estándar. Esta fue calculada según Allen et al. (2006), con los coeficientes de cultivo para Eucalyptus camaldulensis tomados de Besteiro, (2014). Se usó la serie de transpiración medida en el sitio de estudio por Engel et al., (2005) como punto de comparación para validar el modelo. 
La densidad de raíces se distribuyó en los primeros $6 \mathrm{~m}$ del dominio en base a mediciones realizadas en el primer metro y se extrapoló hasta los $6 \mathrm{~m}$ usando una función de densidad decreciente con la profundidad (Jackson et al., 1996). La densidad de raíces se obtuvo por medio de toma de muestras de suelo de volumen conocido, lavado, clasificación y medición de raíces en el primer metro de profundidad a intervalos de espesor crecientes en profundidad de 5 a $25 \mathrm{~cm}$ (i.e., 0-5-10-20-35-50-75-100 cm).

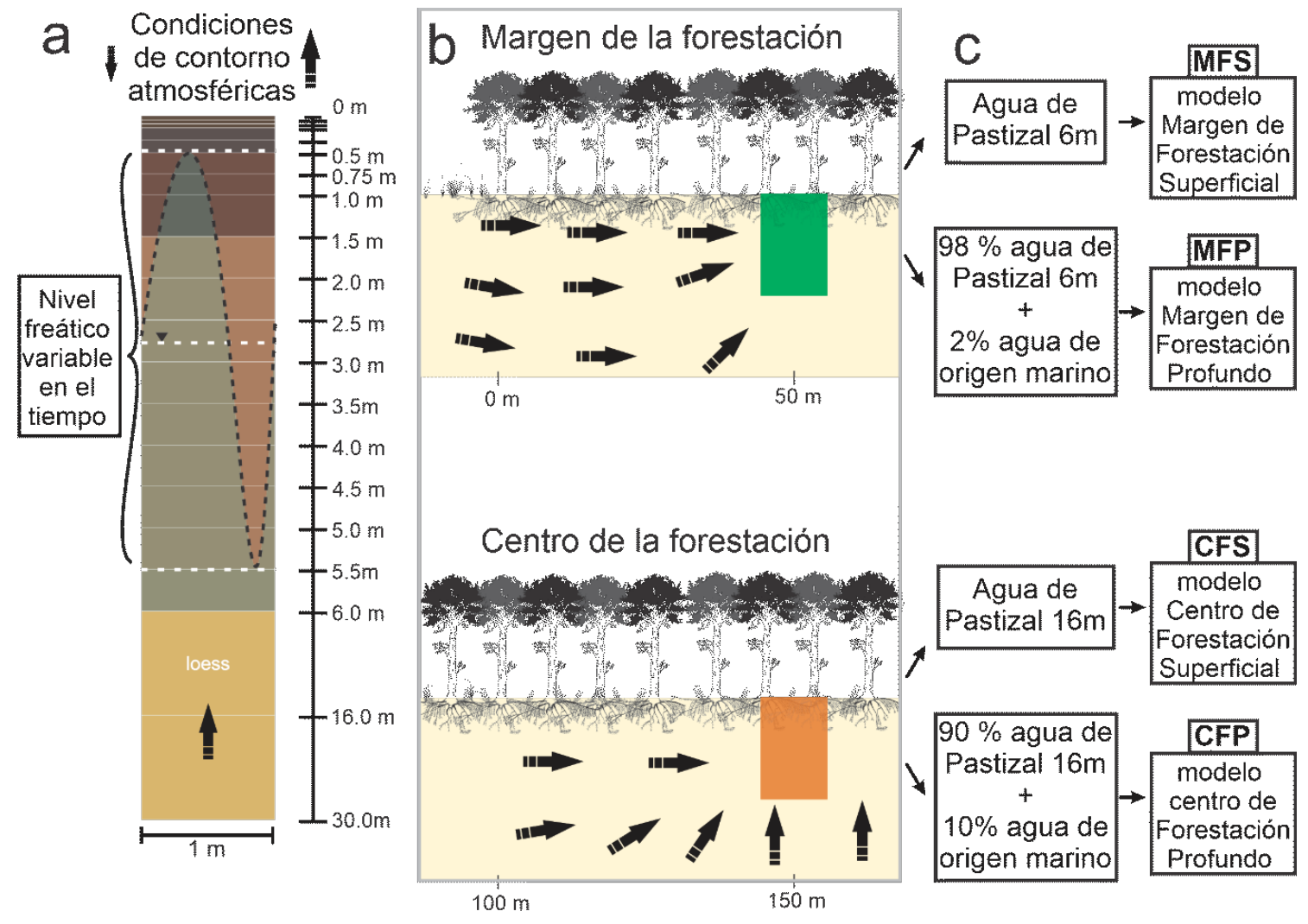

Figura 4-5. Dominio del modelo (a), (b) modelo conceptual de flujo basado en Jobbágy y Jackson, 2007 y (c) modelos implementados.

La toma de nutrientes por parte de la rizósfera fue calibrada con respecto a la biomasa acumulada para el caso de $\mathrm{Na}, \mathrm{Ca}, \mathrm{K}, \mathrm{Mg}, \mathrm{N}, \mathrm{S}$ y P (Figura 4-4). Por otro lado, para el caso de $\mathrm{Cl}$, se asumió que es excluida completamente por las raíces (Teakle y Tyerman, 2010), mientras que la toma de $\mathrm{H}^{+}$y $\mathrm{CO}_{3}{ }^{-2}$ por parte de las raíces es por un mecanismo pasivo (ver Ecuación 21, Ecuación 22 
y Amiro y Ewing, 1992). Para simular la respiración de las raíces sumado a la de la microbiota del suelo se consideró una tasa de liberación constante de $\mathrm{CO}_{2}$ de acuerdo a mediciones realizadas bajo similares condiciones (Epron et al., 2004; Raich y Tufekcioglu, 2000; O'Connell, 1987).

Finalmente, para compensar eléctricamente el agua circundante a las raíces se utilizó en la ecuación de balance de masa un término de consumo/producción de $\mathrm{H}^{+}$(ver Ecuación 43). Con respecto al sistema químico del presente modelo, este tiene en cuenta los procesos de intercambio catiónico $\mathrm{Na} / \mathrm{Ca} / \mathrm{K} / \mathrm{Mg}$, disolución/precipitación de calcita, intercambio gaseoso con la atmósfera, y formación de complejos acuosos (ver Tabla 4.2). 
Tabla 4.2. Reacciones del modelo de trasporte reactivo.

\begin{tabular}{lc}
\hline Reacciones & Log k \\
\hline Intercambio & \\
\hline $\mathrm{Ca} \mathrm{X}_{2}+2 \mathrm{Na}^{+} \leftrightarrow \mathrm{Ca}^{+2}+2 X_{-} \mathrm{Na}$ & $0,8^{\mathrm{a}}$ \\
$\mathrm{Mg} g_{X_{2}}+2 \mathrm{Na}^{+} \leftrightarrow \mathrm{Mg}^{+}+2 X_{-} N a$ & $0,6^{\mathrm{a}}$ \\
$K_{-} \mathrm{X}+\mathrm{Na}^{+} \leftrightarrow \mathrm{K}^{+}+X_{-} \mathrm{Na}$ & $0,6^{\mathrm{a}}$ \\
$H_{-} \mathrm{X}+\mathrm{Na}^{+} \leftrightarrow H^{+}+X_{-} \mathrm{Na}$ & $1,0^{\mathrm{a}}$
\end{tabular}

Precipitación/disolución

$$
\mathrm{Ca}^{+2}+\mathrm{CO}_{3}^{-2} \leftrightarrow \mathrm{CaCO}_{3(s)} \quad 8,5^{\mathrm{b}}
$$

Complejos acuosos

\begin{tabular}{|c|c|}
\hline $\mathrm{OH}^{-}+\mathrm{H}^{+} \leftrightarrow+\mathrm{H}_{2} \mathrm{O}$ & $-13,9^{c}$ \\
\hline $\mathrm{MgOH}^{+}+\mathrm{H}^{+} \leftrightarrow \mathrm{H}_{2} \mathrm{O}+\mathrm{Mg}^{+2}$ & $-11,89$ \\
\hline $\mathrm{MgCO}_{3(a q)} \leftrightarrow \mathrm{CO}_{3}^{-2}+\mathrm{Mg}^{+2}$ & $2,99^{c}$ \\
\hline $\mathrm{MgHCO}_{3}^{+} \leftrightarrow \mathrm{CO}_{3}^{-2}+\mathrm{Mg}^{+2}+\mathrm{H}^{+}$ & $11,4^{c}$ \\
\hline $\mathrm{KOH}+\mathrm{H}^{+} \leftrightarrow \mathrm{K}^{+}+\mathrm{H}_{2} \mathrm{O}$ & $-14,5^{c}$ \\
\hline $\mathrm{NaOH}+\mathrm{H}^{+} \leftrightarrow \mathrm{Na}^{+}+\mathrm{H}_{2} \mathrm{O}$ & $-14,2^{c}$ \\
\hline $\mathrm{CaOH}^{+}+\mathrm{H}^{+} \leftrightarrow \mathrm{Ca}^{+}+\mathrm{H}_{2} \mathrm{O}$ & $-12,8^{c}$ \\
\hline $\mathrm{CaHCO}_{3}^{+} \leftrightarrow \mathrm{CO}_{3}^{-2}+\mathrm{Ca}^{+2}+\mathrm{H}^{+}$ & $11,4^{\mathrm{c}}$ \\
\hline $\mathrm{CaCO}_{3(a q)} \leftrightarrow \mathrm{CO}_{3}^{-2}+\mathrm{Ca}^{+2}$ & $3,1^{\mathrm{c}}$ \\
\hline $\mathrm{CO}_{2(a q)}+\mathrm{H}_{2} \mathrm{O} \leftrightarrow \mathrm{CO}_{3}^{-2}+2 \mathrm{H}^{+}$ & $16,7^{c}$ \\
\hline $\mathrm{NaCO}_{3}^{-} \leftrightarrow \mathrm{CO}_{3}^{-2}+\mathrm{Na}^{+}$ & $1,3^{c}$ \\
\hline $\mathrm{NaHCO}_{3(a q)} \leftrightarrow \mathrm{CO}_{3}^{-2}+\mathrm{Na}^{+}+\mathrm{H}^{+}$ & $10,1^{c}$ \\
\hline $\mathrm{HCO}_{3}^{-} \leftrightarrow \mathrm{CO}_{3}^{-2}+\mathrm{H}^{+}$ & $10,3^{c}$ \\
\hline $\mathrm{H}_{2} \mathrm{CO}_{3(a q)}^{+} \leftrightarrow \mathrm{CO}_{3}^{-2}+2 \mathrm{H}^{+}$ & $16,7^{c}$ \\
\hline $\mathrm{HPO}_{4}^{-2} \leftrightarrow \mathrm{PO}_{4}^{-3}+H^{+}$ & $12,5^{c}$ \\
\hline $\mathrm{H}_{2} \mathrm{PO}_{4}^{-} \leftrightarrow \mathrm{PO}_{4}^{-3}+2 \mathrm{H}^{+}$ & $19,6^{c}$ \\
\hline
\end{tabular}

a Extraído de la base de datos de PHREEQC2 (Parkhurst y Appelo, 1999).

b Extraído de Appelo \& Postma, (2005).

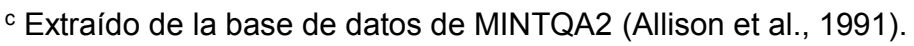


De acuerdo al modelo de patrón de flujo propuesto por Jobbágy \& Jackson, (2007, Figura 4-2b) se plantearon dos escenarios principales: (i) uno en donde el agua que ingresa al modelo por el contorno inferior tendría la química del agua medida en el pastizal a $6 \mathrm{~m}$ de profundidad, y (ii) otro en donde se considera la química del mismo sitio, pero a $16 \mathrm{~m}$ de profundidad. Dichos escenarios intentan reproducir, como una primera aproximación, respectivamente los procesos hidrogeoquímicos observados tanto en el margen exterior como en el centro de la forestación (Figura 4-5). Llamaremos a estos dos modelos "Margen de Forestación" y "Centro de la Forestación" identificados como MFS y CFS, respectivamente, donde la letra final "S" hace referencia a que las aguas que ingresan al sistema son de acuíferos superficiales observados in situ (freatímetros de 6 y 16 m, Tabla 4.3).

Por otro lado, se plantearon otros dos modelos alternativos que intentan evaluar la intrusión en el sistema de agua profunda con mayor salinidad. En estos últimos casos, el agua que ingresa desde el contorno inferior corresponde a una mezcla de agua residente en el acuífero con otra más salina y profunda que descargaría en la forestación (potencialmente identificada aquí como agua de origen marino, ver Carol et al. (2010). Las proporciones de estas mezclas (2\% y $10 \%$ en el modelo del margen y el centro de la forestación, respectivamente) fueron determinadas con el modelo PHREEQC (Parkhurst y Appelo, 1999), a partir de la mezcla con aguas de 6 y 16 m encontradas en el pastizal mezclándolas y un agua de origen marino $(\mathrm{BDH}, 2019)$ para que se aproximen a las proporciones químicas de las aguas encontradas en margen y centro de la forestación a $6 \mathrm{~m}$, respectivamente. Este segundo grupo de escenarios se identificarán, siguiendo la misma lógica que los anteriores como MFP y CFP, 
donde la letra "P" hace referencia a que el agua que ingresa al sistema proviene de una profundidad mayor (Tabla 4.3, Figura 4-5).

Tabla 4.3. Composición química de las aguas medidas y calculadas.

\begin{tabular}{|c|c|c|c|c|c|c|c|c|c|c|c|c|c|}
\hline Muestras & $\begin{array}{l}\text { Posi- } \\
\text { ción } \\
\text { m }\end{array}$ & $\begin{array}{l}\mathrm{EC} \\
\mathrm{dS} / \mathrm{m}\end{array}$ & $\begin{array}{c}\mathrm{pH} \\
- \\
\end{array}$ & $\begin{array}{l}\mathrm{Ca}^{+2} \\
\mathrm{mg} / \mathrm{l}\end{array}$ & $\begin{array}{l}\mathrm{Mg}^{+2} \\
\mathrm{mg} / \mathrm{l}\end{array}$ & $\begin{array}{l}\mathrm{Na}^{+} \\
\mathrm{mg} / \mathrm{l}\end{array}$ & $\begin{array}{l}\mathrm{K}^{+} \\
\mathrm{mg} / \mathrm{l}\end{array}$ & $\begin{array}{l}\mathrm{Cl}^{-} \\
\mathrm{mg} / \mathrm{l}\end{array}$ & $\begin{array}{c}\mathrm{SO}_{4}{ }^{2+} \\
\mathrm{mg} / \mathrm{l}\end{array}$ & $\begin{array}{c}\mathrm{CO}_{3}^{2+} \\
\mathrm{mg} / \mathrm{l}\end{array}$ & $\begin{array}{c}\mathrm{HCO}_{3}{ }^{+} \\
\mathrm{mg} / \mathrm{l}\end{array}$ & $\mathrm{Na}: \mathrm{Cl}$ & $\begin{array}{l}\mathrm{RSC}^{\mathrm{c}} \\
\mathrm{mmol} / \mathrm{l}\end{array}$ \\
\hline $\begin{array}{l}\text { Colectores de } \\
\text { Iluvia }\end{array}$ & 100 & 0,00 & 5,9 & 0,71 & 0,18 & 0,53 & 0,59 & 0,71 & 0,10 & 0 & 0 & 1,15 & - \\
\hline Pastizal (6 m) & 100 & 0,87 & 7,7 & 58 & 28 & 46 & 38 & 15 & 11 & 12 & 537 & 4,73 & 6,4 \\
\hline $\begin{array}{c}\text { Pastizal (16 } \\
\text { m) }\end{array}$ & 100 & 1,24 & 7,7 & 40 & 26 & 161 & 34 & 70 & 36 & 14 & 725 & 3,55 & 10,0 \\
\hline $\begin{array}{c}\text { Margen de } \\
\text { forestación } \\
\qquad(6 \mathrm{~m})\end{array}$ & -50 & 2,02 & 7,9 & 31 & 36 & 250 & 42 & 264 & 104 & 76 & 752 & 1,75 & 11,3 \\
\hline $\begin{array}{l}\text { Centro de } \\
\text { forestación } \\
\qquad(6 \mathrm{~m})\end{array}$ & -150 & 4,21 & 7,2 & 186 & 112 & 478 & 23 & 1165 & 216 & 0 & 387 & 0,63 & $-2,9$ \\
\hline Mezcla MFP b & -50 & $1,74^{\mathrm{a}}$ & 7,6 & 72 & 42 & 239 & 40 & 238 & 71 & 0 & 540 & 1,55 & 5,35 \\
\hline $\begin{array}{c}\text { Mezcla CFP b } \\
\text { Agua de }\end{array}$ & -150 & $9,76^{\mathrm{a}}$ & 7,6 & 219 & 185 & 1646 & 85 & 2315 & 658 & 0 & 719 & 1,10 & $-1,3$ \\
\hline $\begin{array}{l}\text { origen } \\
\text { marino }^{d}\end{array}$ & - & 26,5 & 7,0 & 719 & 678 & 6630 & 118 & 10700 & 2900 & 0 & 659 & 0,96 & $-35,0$ \\
\hline
\end{tabular}

EC=Conductividad eléctrica ${ }^{a}$ Calculadas según Miller et al., 1988. ${ }^{b}$ Calculadas por modelación inversa con PHREEQC para asemejarse a las proporciones encontradas en margen y centro de la forestación. ${ }^{\mathrm{c}} \mathrm{RSC}$ es calculado como RSC $\left.=\left(\left[\mathrm{HCO}_{3}{ }^{+}\right]+\left[\mathrm{CO}_{3}{ }^{2+}\right]\right)-\left(\left[\mathrm{Ca}^{+2}\right]\right)+\left[\mathrm{Mg}^{+2}\right]\right) \cdot{ }^{\text {d }}$ Extraído de $\mathrm{BDH}, 2019$.

Los resultados del modelo se compararon con las mediciones de índole química realizadas en el sitio (Figura 4-3), que fueron descriptas en el presente capítulo, y en Jobbágy y Jackson (2007). Para comparar el aumento de la salinidad en el margen y centro de la forestación se normalizaron las mediciones de conductividad eléctrica ( $E C, \mathrm{dS} \mathrm{m}^{-1}$ ) respecto al valor inicial que corresponde con el medido en el pastizal. Cabe destacar que los resultados del modelo (mol $\left.\mathrm{L}^{-1}\right)$ se transformaron en EC $\left(\mathrm{dS} \mathrm{m}^{-1}\right)$ usando la relación propuesta por Miller et al. (1988) y posteriormente se normalizaron tal como ha sido expuesto anteriormente con las mediciones.

\subsection{Resultados}

Los resultados de los modelos reprodujeron satisfactoriamente los cambios químicos observados en los suelos de parcelas forestadas en el sector de 
estudio. Respecto de las series de niveles freáticos ensayadas, aquella de mayor amplitud (0.5 - 5.5m, Figura 4-6) y menores variaciones temporales fue la que más dispersión vertical generó en los resultados de la simulación. Sin embargo, no se alcanzó la misma dispersión vertical que en los valores observados (véase la Figura 4-3 en comparación con Figura 4-7 y Figura 4-8).

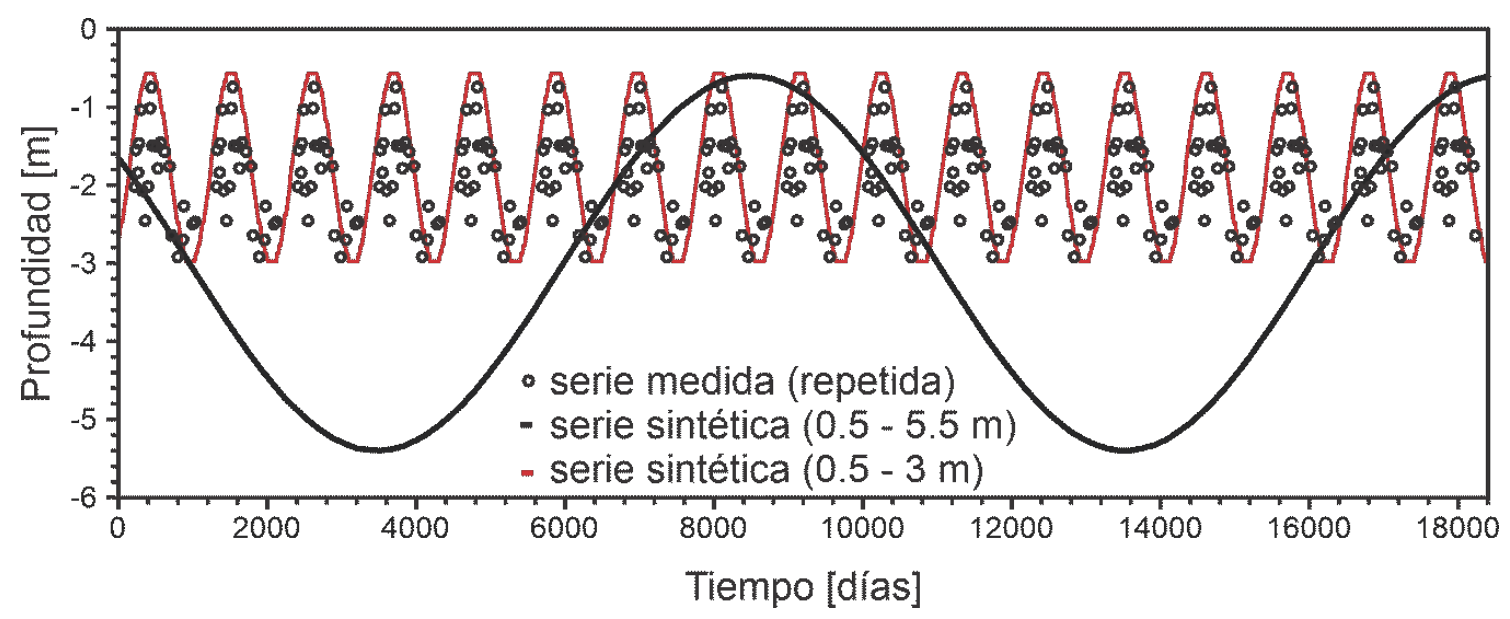

Figura 4-6. Series de niveles freáticos impuestos en el modelo de transporte reactivo

En el modelo MFS, la magnitud de la salinización fue menor ( 1.5 veces, Figura 4-7 a), que aquella observada y descrita por Jobbágy y Jackson (2007) ( 20 veces, Figura 4-3,). Téngase en cuenta que comparar el incremento de la salinidad del suelo medido y simulado implica tener en cuenta que la EC se midió en laboratorio con una relación [suelo (seco):agua destilada] de 1:5 (ver Jobbágy y Jackson, 2007), no siendo esta una medición directa del agua de poro del suelo. Por otro lado, el modelo de Miller et al. (1988) aplicado sobre las concentraciones simuladas implica parámetros empíricos, y no considera la conductividad que tendrían las propias partículas del suelo (Miller et al. 1988, ver Ecuación 45). Es por estos motivos que, aun normalizando la EC con respecto al valor inicial, el aumento en la salinidad se comparará solo en términos aproximados. 
Por otro lado, la acumulación de $\mathrm{Cl}$ en este escenario fue de sólo $\sim 14 \mathrm{~g}$ $\mathrm{m}^{-2}$, similar a aquellos valores máximos observados en el pastizal no forestado, pero inferiores a los $600 \mathrm{~g} \mathrm{~m}^{-2}$ observados en el margen de la forestación ( Figura 4-7 b). Además, la acumulación de Na como complejo de cambio llega a valores de $\sim 5 \%$, mientras que los valores observados llegan a $\sim 25 \%$ (Figura $4-7$ c). Con respecto a la distribución del $\mathrm{pH}$ en el suelo, este modelo reproduce una ligera alcalinización, alcanzando valores de pH máximos de 10 (Figura 4-7 d). Por otro lado, el modelo predice la formación de calcita en todo el perfil, como resultado de la disponibilidad de Ca desplazado del complejo de cambio por el aumento en el porcentaje de sodio intercambiado (PSI; Figura 4-7 e).

Con respecto al escenario MFP, la salinización predicha fue de $\sim 30$ veces, Figura 4-7 f), mientras que la acumulación de $\mathrm{Cl}$ fue de $\sim 600 \mathrm{~g} \mathrm{~m}^{-2}$ (Figura 4-7 g), PSI de $\sim 30 \%$ (Figura $4-7$ h), y un pH promedio de $\sim 8$ (Figura $4-7$ i), y fueron consistentes con las observaciones descritas en el sitio de estudio. Estos resultados (MFS comparado con MFP) sugieren el ingreso de agua salina (probablemente más profunda) para alcanzar los cambios químicos observados en el suelo debajo de la forestación. La mayor liberación de Ca desde el complejo de cambio en este escenario (es decir, desplazado del complejo de cambio por el $\mathrm{Na}$ ), induciría una mayor precipitación de calcita (Figura 4-8h). 

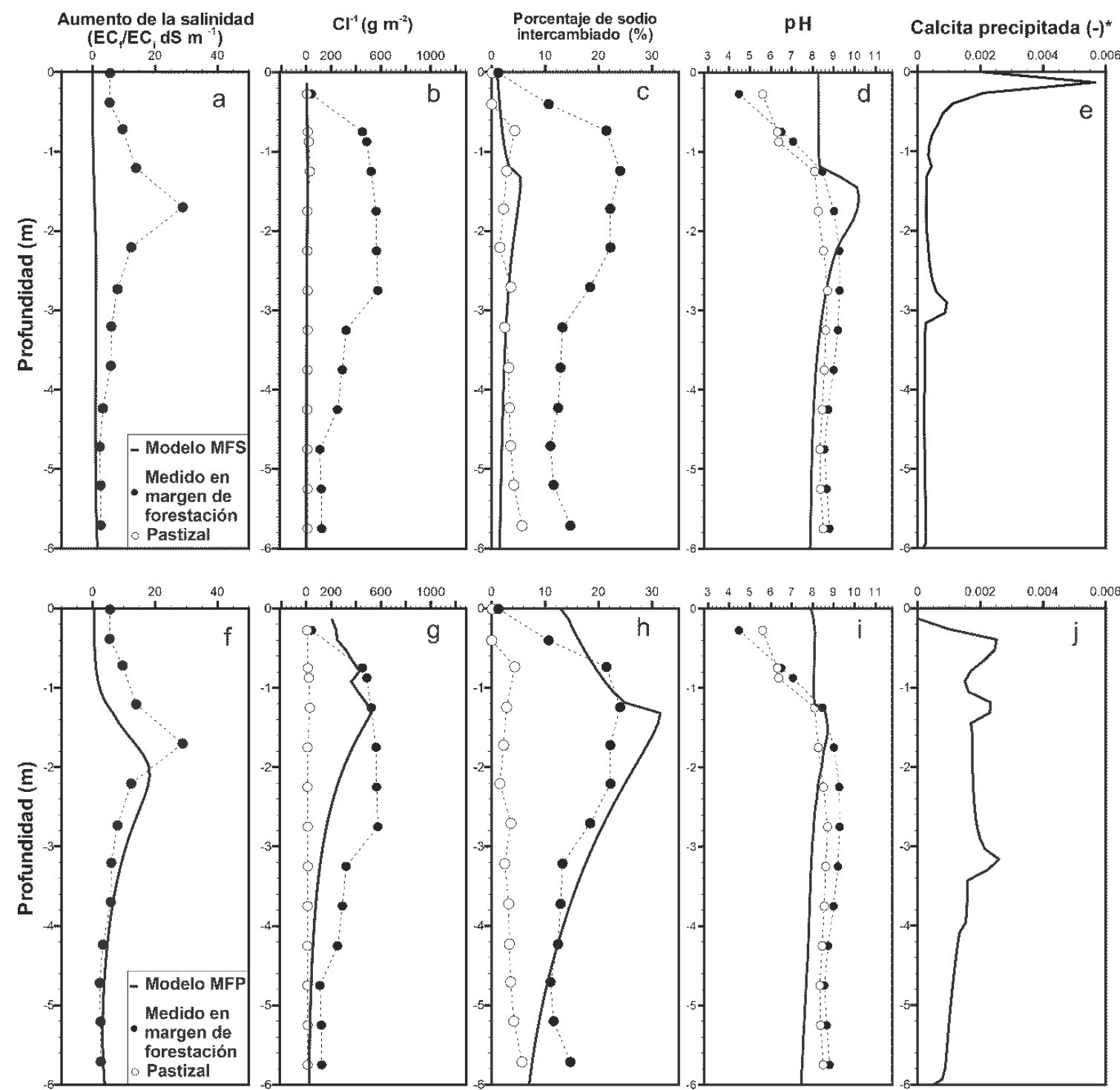

Figura 4-7. Resultados de campo y modelación para el margen de la forestación. En "a", "b", "c" y "d" resultados del modelo "Margen de Forestación Superficial" (MFS) comparados con las observaciones en el pastizal y en el margen de la forestación. De la misma manera, en "f", "g", "h", e "i" se comparan con los resultados del modelo "Margen de Forestación Profundo" (MFP). El aumento de la salinidad fue calculado como ECfinal/ECinicial (dS/m) para los datos medidos y modelados. *El volumen de calcita precipitada en MFS y MFP, respectivamente es calculado como: volumen de mineral/volumen de suelo.

Para el caso del modelo CFS, la salinización predicha en este escenario es de hasta $\sim 40$ veces la observada en el pastizal (Figura 4-8 a), la acumulación de $\mathrm{Cl}$ en el suelo fue de hasta de $600 \mathrm{~g} \mathrm{~m}^{-2}$ (Figura 4-8b), y a pesar de que este escenario reproduce un aumento del PSI, este llega a valores de $\sim 9 \%$, mientras que los máximos observados en el centro de la forestación alcanzan 14\% (Figura 4-8c). Con respecto a la distribución del pH del suelo, este escenario 
reproduce la acidificación observada en el centro de la forestación ( $\mathrm{pH} \sim 6$, Figura 4-8d).

En el escenario CFP, el incremento de la salinidad se mantuvo en $\sim 40$ veces (Figura 4-8 e), el Cl acumulado alcanzó $~ 800 \mathrm{~g} \mathrm{~m}^{-2}$ (Figura 4-8f), el PSI fue de $\sim 10 \%$ (Figura 4-8 g), y el pH del suelo $\sim 6$ (Figura 4-8 h). En este conjunto de escenarios (CFS y CFP) el agua salina más profunda aportaría las concentraciones de $\mathrm{Cl}$ necesaria para reproducir los valores medidos, que de otra forma no se hubieran podido alcanzar considerando las tasas transpiración de la forestación en estudio. Cabe destacar que una menor relación molar $\mathrm{Na:Cl}$ (Tabla 4.3) del agua que ingresa por el contorno inferior del modelo tendría un control directo en el pH ya que habría una compensación eléctrica por parte de la rizósfera por el exceso de aniones. Sin embargo, esta acidez generada por el desbalance eléctrico estaría controlada por la disolución de la calcita presente previamente en el sistema (resultados no mostrados). 

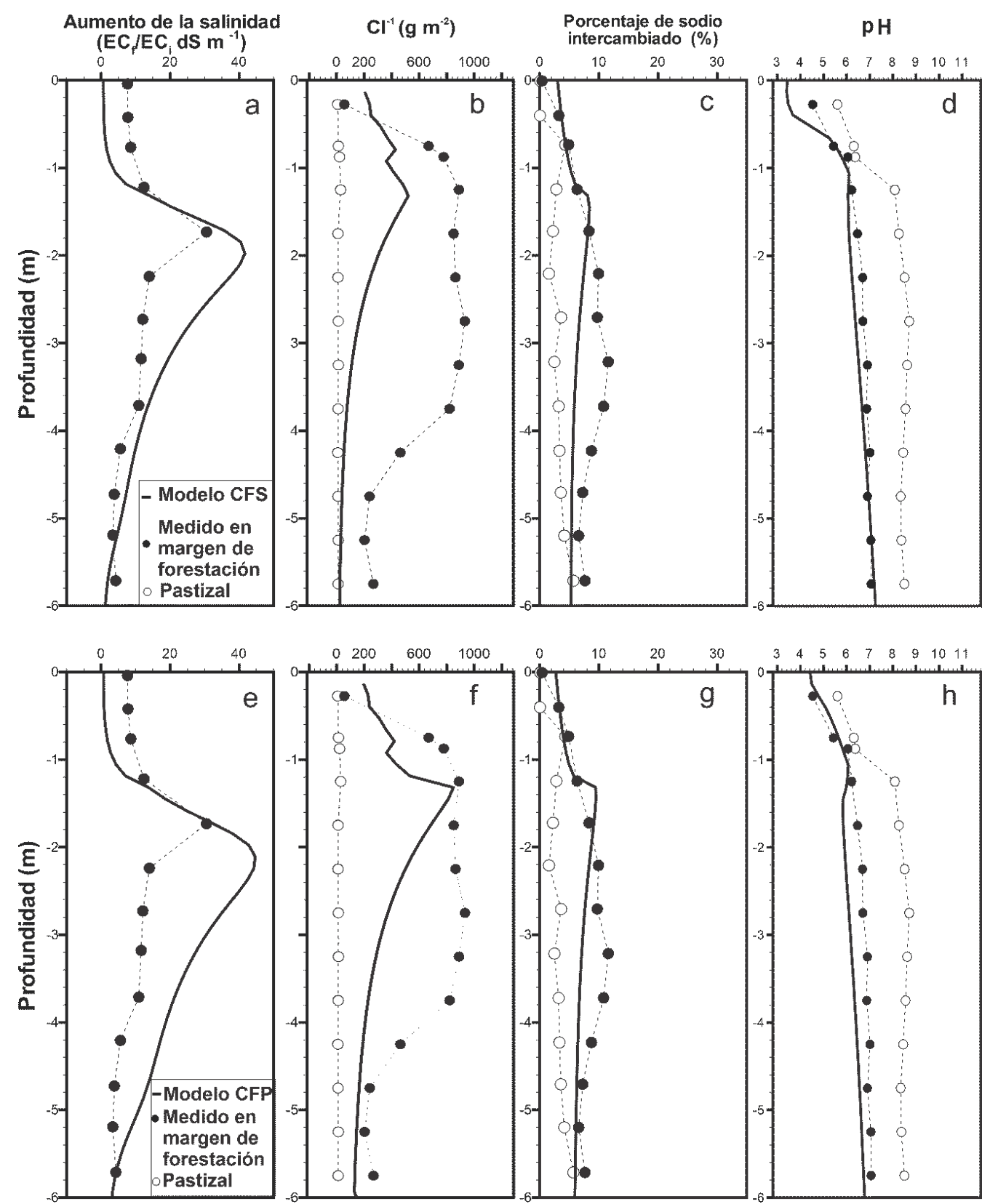

Figura 4-8. Resultados de campo y modelación para el centro de la forestación. En "a", "b", "c" y "d" resultados del modelo "Centro de Forestación Superficial" (CFS) comparados con las observaciones en el pastizal y en el centro de la forestación. De la misma manera, en "f", "g", "h", e "i" se comparan con los resultados del modelo "Centro de Forestación Profundo" (CFP). El aumento de la salinidad fue calculado como ECfinal/ECinicial (dS/m) para los datos medidos y modelados.

\subsection{Discusión}

Los suelos en el pastizal forestado bajo estudio han sido afectados por procesos de salinización, alcalinización/acidificación y sodificación como consecuencia de la actividad freatófita de los árboles. La intensidad y el tipo de cambios químico, tanto en el margen como en el centro de la forestación, 
dependen de la composición hidroquímica de las aguas consumidas por la forestación.

Por otro lado, la distribución vertical de las especies químicas observadas en el perfil (Figura 4-3), con mayores concentraciones distribuidas en una capa de $\sim 2 \mathrm{~m}$ de espesor, sugiere que otros procesos como la variabilidad del nivel freático o variabilidad climática podrían haber controlado esta dispersión. Las series de niveles freáticos ensayados generaron cierta dispersión, sin embargo, las observaciones sugieren otros procesos podrían estar controlando el transporte vertical de los solutos. Como era de esperarse, la serie que consideró una mayor amplitud de niveles (entre 0,5 y 5,5 m, Figura 4-6) fue la que más dispersión generó (resultados no mostrados). No se siguió profundizando en este aspecto porque no está dentro de los objetivos del estudio y por la falta de datos durante tan largo periodo estudiado (50 años).

La modelación de transporte reactivo (TR) aplicado aquí reproduce satisfactoriamente la situación química actual observada en el sitio de estudio. La hidroquímica de las aguas subterráneas sería responsable de la magnitud y dirección de los cambios químicos (alcalinización/acidificación). En este sentido, aquellos escenarios simulados que incluían mezcla con aguas de mayor salinidad (e.g., de potencial origen marino), presentan un mejor ajuste con los cambios químicos observados en estos suelos, y además este hecho es consistente con los bajos contenidos de ${ }^{3} \mathrm{H}$ medidos en el centro de la forestación por Jobbágy y Jackson (2007), típicos de aguas subterráneas con altos tiempos de residencia en el acuífero (Tabla 4.4). 
Tabla 4.4. Concentraciones de tritio en agua subterránea. Extraído de (Jobbágy y Jackson, 2007).

\begin{tabular}{|c|c|c|c|c|}
\hline & \multirow[b]{2}{*}{ posición } & \multicolumn{3}{|c|}{ Tritio (TU) } \\
\hline & & 08-Jan-02 & 02-Feb-02 & 30-May-03 \\
\hline \multicolumn{5}{|c|}{ Pozos de muestreo (sin encamisar) } \\
\hline Pastizal & $-100 m$ & 11,9 & 6,4 & 6 \\
\hline Borde de la forestación & $0 \mathrm{~m}$ & 9,7 & 15,5 & nd \\
\hline Margen de forestación & $50 \mathrm{~m}$ & 10,2 & 16,4 & 2,8 \\
\hline Centro de la forestación & $150 \mathrm{~m}$ & $<1,0$ & $<1,0$ & $<1,0$ \\
\hline \multicolumn{5}{|l|}{ Pozos encamisados } \\
\hline Pastizal (6 m) & $-100 m$ & nd & nd & 6,7 \\
\hline Pastizal (16 m) & $-100 m$ & nd & nd & 3,7 \\
\hline Margen de forestación (6 m) & $50 \mathrm{~m}$ & nd & nd & 1,5 \\
\hline Centro de forestación (6 m) & $150 \mathrm{~m}$ & nd & nd & $<1,0$ \\
\hline \multicolumn{5}{|c|}{$\begin{array}{l}\text { *os pozos encamisados se corresponden con los presentados en la Tabla } 4.3 \text {. } \\
\text { nd: dato faltante; el límite de detección es de } 1 \mathrm{TU} ; 1 \mathrm{TU}={ }^{3} \mathrm{H} / \mathrm{H} \times 10^{18} \text {. Los valores se corresponden } \\
\text { con muestras individuales tomadas en distintas fechas sobre el acuífero freático o en las profundidades } \\
\text { indicadas para los pozos encamisados. La precipitación del área tiene entre } 4 \text { y } 15 \mathrm{TU} \text {, y de acuerdo } \\
\text { con la desintegración radiogénica solamente las aguas recargadas antes de } 1960 \text { podrían tener }<1 \mathrm{TU} \\
\text { (Jobbágy y Jackson, 2007). }\end{array}$} \\
\hline
\end{tabular}

Los resultados de la modelación sugieren que la evolución química de este sistema depende tanto de las relaciones iónicas de los solutos en las aguas subterráneas, como de la exclusión iónica por parte de las raíces. Cuando la solución del suelo es sometida a procesos de transpiración, la exclusión de Na induciría la liberación de Ca del complejo de cambio $\left(C a_{(e x)}\right)$ por $\mathrm{Na}\left(N a_{(e x)}\right)$, sobresaturando la solución con respecto a calcita $\left(\mathrm{CaCO}_{3(s)}\right)$ e induciendo su precipitación:

$$
\mathrm{Ca}_{(e x)}+2 \mathrm{Na}_{(a q)}^{+}+2 \mathrm{HCO}_{3(a q)}^{-} \rightleftharpoons \mathrm{CaCO}_{3(s)}+\mathrm{CO}_{2}+\mathrm{H}_{2} \mathrm{O}+2 \mathrm{Na}_{(e x)}
$$

La precipitación de calcita tiene mayor ocurrencia en el margen de la forestación (ver escenarios MFS y MFP) donde habría una mayor fuente de $\mathrm{Na}$.

En este contexto, ante un exceso de carbonatos en el sistema, se generaría una fuerte alcalinización determinada por el equilibrio: $\mathrm{CO}_{3}^{-2}+\mathrm{H}_{2} \mathrm{O} \rightarrow$ $\mathrm{HCO}_{3}^{-}+\mathrm{OH}^{-}$(Dakora y Phillips, 2002; van Breemen y Buurman, 2002). Una relación $\left[\left(\mathrm{HCO}_{3}^{-}+\mathrm{CO}_{3}^{-2}\right):\left(\mathrm{Ca}^{+2}+\mathrm{Mg}^{+2}\right)\right]$, o carbonato de sodio residual (RSC), mayor a 1 es un indicador de que el sistema evolucionará en esta dirección (Jobbágy et al., 2017). 
No obstante, al considerar estas relaciones es necesario tener en cuenta paralelamente los diferentes procesos involucrados. En primer lugar, la demanda de las raíces competiría por $\mathrm{Ca}^{+2}$ con la precipitación de calcita, lo que podría suponer entonces un efecto aditivo respecto de la alcalinización. Sin embargo, la toma de $\mathrm{Ca}^{+2}$ es acompañada por la liberación de $\mathrm{H}^{+}$desde las raíces para compensar eléctricamente la solución del suelo (Dakora y Phillips, 2002; van Breemen et al., 1983) generando el efecto contrario.

En segundo lugar, es necesario tener en cuenta la relación $\mathrm{Na}: \mathrm{Cl}$ del agua que es transpirada, ya que existe una mayor exclusión de $\mathrm{Cl}$ que de $\mathrm{Na}$ por las raíces (Figura 4-4). Así, en los escenarios CFS y CFP la baja relación $\mathrm{Na:Cl}$ del agua sometida a la exclusión, genera exceso de aniones y descenso del pH a causa de la liberación de $\mathrm{H}^{+}$(Tabla 4.3).

Cabe destacar, que bajo estas condiciones la calcita no precipita y la que se encontraba inicialmente en el sistema se disuelve ejerciendo un control sobre el descenso del pH inducido por la exudación de $\mathrm{H}^{+}$. Así se previene la ocurrencia de valores aún más bajos que los observados entre 1 y $6 \mathrm{~m}$ de profundidad. En este sentido cobra mayor importancia la relación $\mathrm{Na}$ : $\mathrm{Cl}$ ya que, por ser especies químicas mayoritarias las más excluidas por las raíces, serían las componentes químicas que más se acumulan en los suelos debajo de las forestaciones en el sitio de estudio. Por otro lado, en el margen de la forestación el agua que es traspirada presenta una alta relación $\mathrm{Na}: \mathrm{Cl}$ ( $>$ a 1), por lo que el sistema evoluciona a una alcalinización, y con una mayor saturación de Na en el complejo de cambio. Por el contrario, la menor relación $\mathrm{Na}: \mathrm{Cl}(<$ a 1) en el centro de la forestación da como resultado un exceso de aniones que acidificaría el suelo. 


\subsection{Conclusiones}

Los modelos conceptuales presentados en este Capítulo fueron objeto de duda en muchos trabajos a lo largo de varias décadas (Hong et al., 2018, 2019; Jobbágy et al., 2017; Berthrong et al., 2009; Jobbágy y Jackson, 2001, 2003, 2004a, 2007; Nosetto et al., 2007; van Breemen y Buurman, 2002; Ae et al., 2001; Nilsson et al., 1982). Los procesos descritos en ellos sólo pueden ser correctamente interpretados a través de modelos que sean capaces de reproducirlos en conjunto e interactuando entre sí.

A través de la modelación numérica del transporte reactivo se capturaron los complejos procesos acoplados que se desencadenan por el cambio en el uso del suelo y se reprodujo satisfactoriamente la situación actual observada en el sitio de estudio. La hidroquímica de las aguas subterráneas sería responsable de la magnitud y dirección (alcalinización/acidificación) de los cambios químicos. En este sentido, aquellos escenarios simulados que incluían mezcla con aguas de mayor salinidad, presentan un mejor ajuste de los cambios químicos observados en estos suelos, y además este hecho es consistente con los bajos contenidos de ${ }^{3} \mathrm{H}$ medidos en el centro de la forestación por Jobbágy y Jackson (2007), típicos de aguas subterráneas con altos tiempos de residencia en el acuífero.

El impacto ecológico de la forestación de pastizales es un proceso que debe ser evaluado tanto en la magnitud de los cambios que se imponen sobre el ecosistema vegetal, como en las características hidrogeoquímicas del sitio, ya que diferencias en este punto pueden resultar en alteraciones tan diferentes como las observadas en el margen y el centro de la forestación en este capítulo. 
Capítulo 5

Conclusiones finales 
En este capítulo se resumen las principales conclusiones de la presente tesis doctoral y las conclusiones general a los planteamientos presentados en el capítulo introductorio. Por otro lado, se describirán los nuevos interrogantes surgidos durante su desarrollo como potenciales líneas futuras de estudio.

\subsection{Cambio en el uso del suelo y sus implicancias ecohidrológicas}

Al hacer una evaluación extensiva a distintos sitios de la provincia de Buenos Aires (Capítulo 2) se pudo llegar a la conclusión que el acoplamiento entre los distintos factores de cada sitio impide generalizar sobre su mayor o menor riesgo a sufrir procesos de salinización secundaria. El acceso a fuentes de agua externas a la que infiltra sobre la superficie ocupada por la propia forestación (i.e., sectores aledaños y acuífero freático) es el principal factor que determina la ocurrencia de este proceso.

Esto último guarda una estrecha relación con la posición topográfica, ya que sitios en posiciones relativas bajas son más propensos a recibir aportes hídricos (agua y solutos) desde las posiciones más altas, así como también suelen tener niveles freáticos más someros. De la misma manera la dinámica de las cuencas hidrográficas es otro factor importante a tener en cuenta en estas interacciones ya que desde las cabeceras hacia los cierres de cuencas los acuíferos muestran una acumulación de sales y disminución de la profundidad.

Como la presencia de horizontes petrocálcicos, conocidos locamente como "tosca" son entidades conspicuas en la región, una de las principales interrogantes que surgió fue como impactan éstas en el flujo de agua en suelos forestados, y su potencial riesgo de sufrir salinización secundaria. Para resolver 
esta incógnita se planteó una parcela de monitoreo intensiva cuyo análisis se desarrolló en el Capítulo 3.

\subsection{Control de las heterogeneidades del suelo sobre los procesos de salinización secundaria en pastizales forestados}

Dado que la presencia de discontinuidades en el perfil edáfico como los niveles petrocálcicos generó gran incertidumbre en los distintos sitios muestreados en el Capítulo 2, en el Capítulo 3 se procedió a un monitoreo intensivo y modelación numérica de flujo de agua y transporte conservativo a través de un perfil de ese tipo.

Nuestro análisis sugiere que, con un nivel freático que fluctúa entre $\sim 1,7$ m y $\sim 5,4$ m de profundidad, la presencia de un horizonte petrocálcico altamente cementado (a $\sim 0,76 \mathrm{~m}$ de profundidad) impediría el acceso de la forestación a este, reduciendo así el riesgo a sufrir salinización secundaria. Además, los resultados de la modelación sugieren que la presencia del horizonte petrocálcico retrasarían el drenaje profundo, y tendrían la capacidad de almacenar el agua de lluvia disponible para ser consumida por la forestación.

En este sentido, los sitios con características similares permitirían una actividad forestal de moderada productividad $\left(\sim 15,5 \mathrm{~m}^{3} \mathrm{ha}^{-1}\right.$ año-1 medido en la forestación analizada en el Capítulo 3, mejorable con manejo y anticipando el aprovechamiento), sin riesgo de sufrir acumulación de sales en el suelo y acuífero freático.

\subsection{Control hidrogeoquímico del proceso de salinización secundaria en pastizales forestados}

Existen situaciones donde la salinización secundaria de suelos además presenta ciertas particularidades hidroquímicas diferenciables. Estas son 
reflejadas en la ocurrencia de procesos como alcalinización, sodificación y acidificación del suelo, los cuales son de un gran impacto en la fertilidad de los suelos, y potencialmente irreversibles.

Para evaluar dichos procesos se utilizó la modelación del transporte reactivo para evaluar diferentes escenarios teniendo en cuenta los principales procesos hidroquímicos que tendrían lugar dentro de rizósfera de la forestación. Los resultados de la modelación revelaron que el tipo de cambio químico observados en sitios salinizados (i.e., sodificación, alcalinización/acidificación) es controlado principalmente por procesos que ocurren en la rizósfera como: (1) la exclusión y exudación de solutos por parte de las raíces, (2) el tipo de químico y salinidad del agua capturada por la forestación, (3) el reciclado de ciertas sales a través de la acumulación en la biomasa y posterior reincorporación al suelo, y (4) la respiración por parte de las raíces.

Se puede concluir que el origen hidroquímico del agua que es transpirada por la forestación determinará la magnitud y la dirección de los cambios químicos en el suelo/acuífero. Así, una forestación que pueda hacer uso de agua de origen más profundo (con rNa:rCl bajos) provocará un aumento de la salinidad y disminución del pH, mientras que si se utiliza agua de origen más somero (con mayor rNa:rCl) provocara salinización, sodificación y alcalinización.

\subsection{Conclusión final}

Sin dudas el cambio en el uso del suelo ha generado grandes impactos ecohidrológicos en el mundo, y dentro de estos, la forestación de pastizales naturales, ha generado salinización secundaria dentro de la región pampeana. En el continuo acuífero-suelo-planta-atmósfera se dan una serie de procesos acoplados no lineales, y a diferentes tasas, de muy difícil interpretación sin hacer 
uso de herramientas como las numéricas. En este sentido, el complejo acoplamiento entre los procesos que se establecen puede ser abordado desde distintas perspectivas, pero la modelación es la única herramienta que permite dar respuestas cuantitativas y que incluyan esta gran diversidad de procesos. Las características del ambiente que predominan para determinar el riesgo de salinización son la presencia de una fuente hídrica (además de las precipitaciones) accesible para las raíces de la forestación y las características hidroquímicas de esta.

A pesar de los impactos de la forestación de pastizales en el medio ambiente, también es necesario destacar que en muchas situaciones estos fueron mínimos o inexistentes desde el punto de vista del sistema suelo/acuífero. La salinización, acidificación y/o alcalinización de los suelos forestados, sólo se da con una combinación de condiciones específicas, y existirían situaciones donde es posible la producción forestal sin mayores impactos aún en ecosistemas similares a los aquí estudiados, en las Pampas y a lo largo del mundo.

\subsection{Líneas futuras de investigación}

De acuerdo con las conclusiones extraídas de la presente tesis para ampliar el conocimiento respecto del procesos de salinización secundaria causada por la forestación de pastizales, es necesario ampliar el análisis a la consideración de la dinámica química de las cuencas hidrográficas.

Por otro lado, para mejorar la aplicación de la modelación de estos sistemas una línea futura es aplicar los modelos de crecimiento de raíces, para lograr predecir mejor la relación suelo-raíz. Asimismo, ampliar el sistema de 
trasporte reactivo para considerar la absorción de nutrientes aniónicos como el fosfato, y las dinámicas de estos en el suelo.

Con estos dos avances en términos espaciales y de procesos hidroquímicos/biológicos se esperaría incorporar al análisis con modelos aún más capacidades que permitan un análisis integrado que de otra manera sería muy difícil de alcanzar.

Desde un punto de vista del manejo, se podrían proponer líneas para generar manejo sustentable forestal atendiendo tanto la productividad como los cambios inducidos en los flujos de agua y en los procesos biogeoquímicos asociados. Así como también, poniendo en la balanza variables como el impacto en la biodiversidad, la oferta de 'servicios forestales' y la rentabilidad económica. 


\section{Bibliografía}

Advanced Geosciences. (2005). Earthlmager 2D, resistivity and IP inversion software, version 2.2.8. Instruction manual. Advanced Geosciences, Austin, TX. 139 p.

Ae, N., Arihara, J., Okada, K., Srinivasan, A., 2001. Plant Nutrient Acquisition, Springer Science \& Business Media. Springer Japan, Tokyo. https://doi.org/10.1007/978-4-431-66902-9

Allen, G.R., Pereira, L.S., Raes, D., Smith, M., 2006. Evapotranspiración del cultivo: Guias para la determinación de los requerimientos de agua de los cultivos. FAO Estud. FAO Riego y Dren. 56297.

Allison, J.D., Brown, D.S., Novo-gradac, K.J., 1991. MINTEQA2/ PRODEFA2, a geochemical assessment model for environmental systems: version 3.0 user's manual. U.S. Environmental Protection Agency publication no. Epa/ $600 /, 3-91 / 021$.

Alvarez, J.A., 2006. Estabilidad productiva y plasticidad fenotípica de Populus spp . en relación con el contenido de agua y sales en el suelo en el Delta del. Tesis Dr. Esc. para Grad. Ing. Agr. Alberto Soriano la Fac. Agron. UBA.

Amente, G., Baker, J.M., Reece, C.F., 2000. Estimation of Soil Solution Electrical Conductivity from Bulk Soil Electrical Conductivity in Sandy Soils. Soil Sci. Soc. Am. J. 64, 1931. https://doi.org/10.2136/sssaj2000.6461931x

Amiotti, N.M., Villamil, M.B., Darmody, R.G., 2012. Agronomic and Taxonomic Consequences of Agricultural Use of Marginal Soils in Argentina. Soil Sci. Soc. Am. J. 76, 558. https://doi.org/10.2136/sssaj2011.0306

Amiro, B.D., Ewing, L.L., 1992. Physiological conditions and uptake of inorganic carbon-14 by plant roots. Environ. Exp. Bot. 32, 203-211.

https://doi.org/10.1016/0098-8472(92)90003-K

Amodeo, M.R., Zalba, S.M., 2015. Phenology of Prunus mahaleb, a fleshy fruited tree invading natural grasslands in Argentine pampas. Biol. Invasions Patterns, Manag. Econ. Impacts. New York Nov. Sci. Publ. 121141. 121-141.

Andrews, J.A., Schlesinger, W.H., 2001. Soil CO 2 dynamics, acidification, and chemical weathering in a temperate forest with experimental $\mathrm{CO} 2$ enrichment. Global Biogeochem. Cycles 15, 149-162.

https://doi.org/10.1029/2000GB001278

Appelo, C.A.J., Postma, D., 2005. GEOCHEMISTRY, GROUNDWATER AND POLLUTION.

Archie, G.E., 1942. The Electrical Resistivity Log as an Aid in Determining Some Reservoir Characteristics. Pet. Technol. 54-62.

https://doi.org/10.2118/942054-G 
Bañuls, J., Serna, M.D., Legaz, F., Talon, M., Primo-Millo, E., 1997. Growth and gas exchange parameters of Citrus plants stressed with different salts. J. Plant Physiol. 150, 194-199. https://doi.org/10.1016/S01761617(97)80202-7

Barranquero, R.S., Varni, M., Ruiz de Galarreta, A., 2012. Evaluación de las características del agua subterránea en la cuenca del arroyo Langueyú, Tandil, Buenos Aires, Argentina.

Bartsch, N., 1987. Responses of root systems of young Pinus sylvestris and Picea abies plants to water deficits and soil acidity. Can. J. For. Res. 17, 805-812.

Battaglia, M., Sands, P., 1997. Modelling Site Productivity of Eucalyptus globulus in Response to Climatic and Site Factors. Funct. Plant Biol. 24, 831-850. https://doi.org/10.1071/PP97065

Bea, S.A., Mayer, U.K., MacQuarrie, K.T.B., 2016. Reactive transport and thermo-hydro-mechanical coupling in deep sedimentary basins affected by glaciation cycles: Model development, verification, and illustrative example. Geofluids 16, 279-300. https://doi.org/10.1111/gfl.12148

Bea, S.A., Mayer, U.K., MacQuarrie, K.T.B., 2015. Reactive transport and thermo-hydro-mechanical coupling in deep sedimentary basins affected by glaciation cycles: model development, verification and illustrative example. Geofluids n/a-n/a. https://doi.org/10.1111/gfl.12148

Bea, S.A., Wainwright, H., Spycher, N., Faybishenko, B., Hubbard, S.S., Denham, M.E., 2013. Identifying key controls on the behavior of an acidic$\mathrm{U}(\mathrm{VI})$ plume in the Savannah River Site using reactive transport modeling. J. Contam. Hydrol. 151, 34-54.

https://doi.org/10.1016/j.jconhyd.2013.04.005

Bea, S.A., Wilson, S. a., Mayer, K.U., Dipple, G.M., Power, I.M., Gamazo, P., 2012. Reactive Transport Modeling of Natural Carbon Sequestration in Ultramafic Mine Tailings. Vadose Zo. J. 11, 0.

https://doi.org/10.2136/vzj2011.0053

Berthrong, S.T., Jobbágy, E.G., Jackson, R.B., 2009. A global meta-analysis of soil exchangeable cations, $\mathrm{pH}$, carbon, and nitrogen with afforestation. Ecol. Appl. 19, 2228-2241. https://doi.org/10.1890/08-1730.1

Besteiro, S., 2014. Evaluación de la Influencia hidrológica de forestaciones en la llanura Pampeana.

Blanco, M. del C., Stoops, G., 2007. Genesis of pedons with discontinuous argillic horizons in the Holocene loess mantle of the southern Pampean landscape, Argentina. J. South Am. Earth Sci. 23, 30-45. https://doi.org/10.1016/j.jsames.2006.08.007

Bouillet, J.P., Laclau, J.P., Arnaud, M., M’Bou, A.T., Saint-André, L., Jourdan, C., 2002. Changes with age in the spatial distribution of roots of Eucalyptus 
clone in Congo impact on water and nutrient uptake. For. Ecol. Manage. 171, 43-57. https://doi.org/10.1016/S0378-1127(02)00460-7

Bouyoucos, G.J., 1962. Hydrometer Method Improved for Making Particle Size Analyses of Soils1. Agron. J. 54, 464.

https://doi.org/10.2134/agronj1962.00021962005400050028x

Bouyoucos, G.J., 1936. Directions for making mechanical analyses of soils by the hydrometer method. Michigan Agric. Experitmental Stn. 269, 225-229.

Bowman, W.D., Cleveland, C.C., Halada, Ĺ., Hreško, J., Baron, J.S., 2008. Negative impact of nitrogen deposition on soil buffering capacity. Nat. Geosci. 1, 767-770. https://doi.org/10.1038/ngeo339

Burgos, J.J., Vidal, A.L., 1951. The Climates of the Argentine Retublic According to the New Thornthmaite Classification. Ann. Assoc. Am. Geogr. 41, 237-263. https://doi.org/10.1080/00045605109352055

Burkart, S.E., Garbulsky, M.F., Ghersa, C.M., Guerschman, J.P., León, R.J.C., Oesterheld, M., Aguiar, M., Ghersa, C., Paruelo, J., 2005. Las comunidades potenciales del pastizal pampeano bonaerense. La Heterog. la Veg. los agroecosistemas. Un Homen. a Rolando Le\{ó\}n. Ed. Fac. Agron. Buenos Aires, Argentina 379-400.

Burkart, S.E., Leon, R.J., Movia, C.P., 1990. nventario fitosociológico del pastizal de la Depresión del Salado (Prov. Bs. As.) en un área representativa de sus principales ambientes. Darwiniana 1, 27-69.

Cai, G., Vanderborght, J., Couvreur, V., Mboh, C.M., Vereecken, H., 2017. Parameterization of Root Water Uptake Models Considering Dynamic Root Distributions and Water Uptake Compensation. Vadose Zo. J. 17, 0. https://doi.org/10.2136/vzj2016.12.0125

Calder, I.R., 1998. Water use by forests, limits and controls. Tree Physiol. 18, 625-631. https://doi.org/10.1093/treephys/18.8-9.625

Cappa, E.P., Pathauer, P.S., Lopez, G.A., 2010. Provenance variation and genetic parameters of Eucalyptus viminalis in Argentina. Tree Genet. Genomes 6, 981-994. https://doi.org/10.1007/s11295-010-0307-9

Carol, E.S., Kruse, E.E., Pousa, J.L., 2010. Eco-hydrological role of deep aquifers in the Salado sedimentary basin in the Province of Buenos Aires, Argentina. Environ. Earth Sci. 60, 749-756. https://doi.org/10.1007/s12665009-0212-4

Carreño, L., Frank, F.C., Viglizzo, E.F., 2012. Tradeoffs between economic and ecosystem services in Argentina during 50 years of land-use change. Agric. Ecosyst. Environ. 154, 68-77. https://doi.org/10.1016/j.agee.2011.05.019

Carretero, S.C., Dapeña, C., Kruse, E.E., 2013. Hydrogeochemical and isotopic characterisation of groundwater in a sand-dune phreatic aquifer on the northeastern coast of the province of Buenos Aires, Argentina. Isotopes 
Environ. Health Stud. 49, 399-419.

https://doi.org/10.1080/10256016.2013.776557

Cho, K.H., Pachepsky, Y.A., Oliver, D.M., Muirhead, R.W., Park, Y., Quilliam, R.S., Shelton, D.R., 2016. Modeling fate and transport of fecally-derived microorganisms at the watershed scale: State of the science and future opportunities. Water Res. 100, 38-56.

https://doi.org/10.1016/j.watres.2016.04.064

Clearwater, M.J., Meinzer, F.C., Andrade, J.L., Goldstein, G., Holbrook, N.M., 1999. Potential errors in measurement of nonuniform sap flow using heat dissipation probes. Tree Physiol. 19, 681-687. https://doi.org/10.1093/treephys/19.10.681

Cramer, V.A., Thorburn, P.J., Fraser, G.W., 1999. Transpiration and groundwater uptake from farm forest plots of Casuarina glauca and Eucalyptus camaldulensis in saline areas of southeast Queensland, Australia. Agric. Water Manag. 39, 187-204. https://doi.org/10.1016/S03783774(98)00078-X

Dakora, F.D., Phillips, D.A., 2002. Root exudates as mediators of mineral acquisition in low-nutrient environments, en: Food Security in NutrientStressed Environments: Exploiting Plants' Genetic Capabilities. Springer Netherlands, Dordrecht, pp. 201-213. https://doi.org/10.1007/978-94-0171570-6_23

Damiano, F., Taboada, M.A., 2000. Predicción del agua disponible usando funciones de pedo-transferencia en suelos agrícolas de la región pampeana. Cienc. del Suelo 18, 77-88.

De Kauwe, M.G., Medlyn, B.E., Pitman, A.J., Drake, J.E., Ukkola, A., Griebel, A., Pendall, E., Prober, S., Roderick, M., 2019. Examining the evidence for decoupling between photosynthesis and transpiration during heat extremes. Biogeosciences 16, 903-916. https://doi.org/10.5194/bg-16-9032019

Dietrich, S., Weinzettel, P.A., Varni, M., 2014. Infiltration and drainage analysis in a heterogeneous soil by electrical resistivity tomography. Soil Sci. Soc. Am. J. 78, 1153-1167. https://doi.org/10.2136/sssaj2014.02.0062

Doherty, J., 2016. PEST Model-Independent Parameter Estimation User Manual Part I: PEST, SENSAN and Global Optimisers. Watermark Numer. Comput. 279.

Donaldson, D., Hasey, J., Davis, W., 1983. Eucalyptus out-perform other species in salty, flooded soils. Calif. Agric. 37, 20-21.

Dunbabin, V.M., Postma, J.A., Schnepf, A., Pagès, L., Javaux, M., Wu, L., Leitner, D., Chen, Y.L., Rengel, Z., Diggle, A.J., 2013. Modelling root-soil interactions using three-dimensional models of root growth, architecture and function. Plant Soil 372, 93-124. https://doi.org/10.1007/s11104-0131769-y 
Duniway, M.C., Herrick, J.E., Monger, H.C., 2010. Spatial and temporal variability of plant-available water in calcium carbonate-cemented soils and consequences for arid ecosystem resilience. Oecologia 163, 215-226. https://doi.org/10.1007/s00442-009-1530-7

Duniway, M.C., Herrick, J.E., Monger, H.C., 2007. The High Water-Holding Capacity of Petrocalcic Horizons. Soil Sci. Soc. Am. J. 71, 812. https://doi.org/10.2136/sssaj2006.0267

Engel, V., Jobbágy, E.G., Stieglitz, M., Williams, M., Jackson, R.B., 2005. Hydrological consequences of Eucalyptus afforestation in the Argentine Pampas. Water Resour. Res. 41, 1-14. https://doi.org/10.1029/2004WR003761

Epron, D., Nouvellon, Y., Roupsard, O., Mouvondy, W., Mabiala, A., SaintAndré, L., Joffre, R., Jourdan, C., Bonnefond, J.M., Berbigier, P., Hamel, O., 2004. Spatial and temporal variations of soil respiration in a Eucalyptus plantation in Congo. For. Ecol. Manage. 202, 149-160. https://doi.org/10.1016/j.foreco.2004.07.019

FAO, 2015. Global Forest Resources Assessment 2015, Forest Ecology and Management.

Farley, K.A., Jobbágy, E.G., Jackson, R.B., 2005. Effects of afforestation on water yield: A global synthesis with implications for policy. Glob. Chang. Biol. 11, 1565-1576. https://doi.org/10.1111/j.1365-2486.2005.01011.x

Farrington, P., Turner, J. V., Gailitis, V., 1996. Tracing water uptake by jarrah (Eucalyptus marginata) trees using natural abundances of deuterium. Trees - Struct. Funct. 11, 9-15. https://doi.org/10.1007/s004680050052

Farrington, P., Watson, G.D., Bartle, G.A., Greenwood, E.A.N., 1990.

Evaporation from dampland vegetation on a groundwater mound. J. Hydrol. 115, 65-75. https://doi.org/10.1016/0022-1694(90)90198-7

Feddes, R.A., Bresler, E., Neuman, S.P., 1974. Field test of a modified numerical model for water uptake by root systems. Water Resour. Res. 10, 1199-1206. https://doi.org/10.1029/WR010i006p01199

Fehlenberg, V., Baumann, M., Ignacio, N., Piquer-rodriguez, M., Gavier-pizarro, G., Kuemmerle, T., 2017. The role of soybean production as an underlying driver of deforestation in. Glob. Environ. Chang. 45, 24-34. https://doi.org/10.1016/j.gloenvcha.2017.05.001

Feikema, P.M., Morris, J.D., Connell, L.D., 2010. The water balance and water sources of a Eucalyptus plantation over shallow saline groundwater. Plant Soil 332, 429-449. https://doi.org/10.1007/s11104-010-0309-2

Fernández, M.E., Gyenge, J., Licata, J., Schlichter, T., Bond, B.J., 2008. Belowground interactions for water between trees and grasses in a temperate semiarid agroforestry system. Agrofor. Syst. 74, 185-197. https://doi.org/10.1007/s10457-008-9119-4 
Fernández, R.D., Ceballos, S.J., González Achem, A.L., Hidalgo, M. del V., Fernández, H.R., 2016. Quality and Conservation of Riparian Forest in a Mountain Subtropical Basin of Argentina. Int. J. Ecol. 2016, 1-10. https://doi.org/10.1155/2016/4842165

Ferreras, A.E., Funes, G., Galetto, L., 2014. Evaluación interanual de las estrategias regenerativas de la especie exótica invasora Gleditsia triacanthos en relación a la nativa Acacia aroma en el bosque chaqueño serrano de Córdoba (Argentina). Bosque (Valdivia) 35, 155-162. https://doi.org/10.4067/s0717-92002014000200003

Ferrere, P., Lupi, A.M., Boca, R., Nakama, V., Alfieri, A., 2008. Biomasa en plantaciones de Eucalyptus viminalis Labill. de la provincia de Buenos Aires, Argentina. Ciência Florest. 18, 291. https://doi.org/10.5902/19805098440

Ferrere, P., Lupi, A.M., Boca, T., 2015. Crecimiento del Pinus radiata sometido a diferentes tratamientos de raleo y poda en el sudeste de la provincia de Buenos Aires, Argentina. Bosque (Valdivia) 36, 423-434. https://doi.org/10.4067/S0717-92002015000300009

Freeze, R.A., Cherry, J.A., 1979. Groundwater. Prentice- Hall, Upper Saddle River, N. J.

Gasparri, N.I., Grau, H.R., 2009. Deforestation and fragmentation of Chaco dry forest in NW Argentina (1972-2007). For. Ecol. Manage. 258, 913-921. https://doi.org/10.1016/j.foreco.2009.02.024

George, R., McFarlane, D., Nulsen, B., 1997. Salinity Threatens the Viability of Agriculture and Ecosystems in Western Australia. Hydrogeol. J. 5, 6-21. https://doi.org/10.1007/s100400050103

George, R.J., Nulsen, R.A., Ferdowsian, R., Raper, G.P., 1999. Interactions between trees and groundwaters in recharge and discharge areas - A survey of western Australian sites. Agric. Water Manag. 39, 91-113. https://doi.org/10.1016/S0378-3774(98)00073-0

Georgen, P.G., Davis-Carter, J., Taylor, H.M., 1991. Root Growth and Water Extraction Patterns from a Calcic Horizon. Soil Sci. Soc. Am. J. 55, 210. https://doi.org/10.2136/sssaj1991.03615995005500010036x

Gérard, F., Blitz-Frayret, C., Hinsinger, P., Pagès, L., 2017. Modelling the interactions between root system architecture, root functions and reactive transport processes in soil. Plant Soil 413, 161-180. https://doi.org/10.1007/s11104-016-3092-x

Gérard, F., Tinsley, M., Mayer, K.U., 2004. Preferential Flow Revealed by Hydrologic Modeling Based on Predicted Hydraulic Properties. Soil Sci. Soc. Am. J. 68, 1526. https://doi.org/10.2136/sssaj2004.1526

Gibbens, R.P., Lenz, J.M., 2001. Root systems of some Chihuahuan Desert plants. J. Arid Environ. 49, 221-263. https://doi.org/10.1006/jare.2000.0784 
Granier, A., 1987. Evaluation of transpiration in a Douglas-fir stand by means of sap flow measurements. Tree Physiol. 3, 309-320.

https://doi.org/10.1093/treephys/3.4.309

Granier, A., 1985. Une nouvelle methode pour la measure du flux de seve brute dans le tronc des arbres. Ann. des Sci. For. 42(2), 193-200. https://doi.org/org/10.1051/forest:19850204

Granier, A., Hue, R., Barigah, S.T., 1996. Transpiration of natural rain forest and its dependence on climatic factors. Agric. For. Meteorol. 78, 19-29. https://doi.org/10.1016/0168-1923(95)02252-X

Greenway, H., Munns, R., 1980. Mechanisms of Salt Tolerance in Nonhalophytes. Annu. Rev. Plant Physiol. 31, 149-190. https://doi.org/10.1146/annurev.pp.31.060180.001053

Gutiérrez, L., 1976. Atlas del eucalipto. Instituto Nacional para la Conservación de la Naturaleza. Instituto Nacional de Investigaciones Agrarias, Sevilla.

Gyenge, J., Fernández, M.E., Sarasola, M., Schlichter, T., 2008. Testing a hypothesis of the relationship between productivity and water use efficiency in Patagonian forests with native and exotic species. For. Ecol. Manage. 255, 3281-3287. https://doi.org/10.1016/j.foreco.2008.01.078

Gyenge, J.E., Fernández, M.E., Salda, G.D., Schlichter, T.M., 2002. Silvopastoral systems in Northwestern Patagonia II: Water balance and water potential in a stand of Pinus ponderosa and native grassland. Agrofor. Syst. 55, 47-55. https://doi.org/10.1023/A:1020238330817

Hendrick, R.L., Pregitzer, K.S., 1993. The dynamics of fine root length, biomass, and nitrogen content in two northern hardwood ecosystems. Can. J. For. Res. 23, 2507-2520. https://doi.org/10.1139/x93-312

Herbel, C.H.., Ares, F.N., Wright, R.A., 1972. Drought Effects on a Semidesert Grassland Range. Ecology 53, Bloor, J. M. G., Bardgett, R. D. (2012). Stabili. https://doi.org/10.2307/1935420

Heuperman, A., 1999. Hydraulic gradient reversal by trees in shallow water table areas and repercussions for the sustainability of tree-growing systems. Agric. Water Manag. 39, 153-167. https://doi.org/10.1016/S03783774(98)00076-6

Hilhorst, M.A., 2000. A Pore Water Conductivity Sensor. Soil Sci. Soc. Am. J. 64, 1922-1925. https://doi.org/10.2136/sssaj2000.6461922x

Hilhorst, M.A., 1998. Dielectric characterisation of soil.

Hinsinger, P., Gobran, G.R., Gregory, P.J., Wenzel, W.W., 2005. Rhizosphere geometry and heterogeneity arising from root mediated physical and chemical processes. New Phytol. 168, 293-303.

https://doi.org/10.1111/j.1469-8137.2005.01512.x 
Hong, S., Gan, P., Chen, A., 2019. Environmental controls on soil pH in planted forest and its response to nitrogen deposition. Environ. Res. 172, 159-165. https://doi.org/S0013935119300933

Hong, S., Piao, S., Chen, A., Liu, Y., Liu, L., Peng, S., Sardans, J., Sun, Y., Peñuelas, J., Zeng, H., 2018. Afforestation neutralizes soil pH. Nat. Commun. 9, 520. https://doi.org/10.1038/s41467-018-02970-1

Hopmans, J.W., Bristow, K.L., 2002. Current Capabilities and Future Needs of Root Water and Nutrient Uptake Modeling. pp. 103-183. https://doi.org/10.1016/S0065-2113(02)77014-4

Hoyk, E., Gácsi, Z., Buzás, I., 2007. The connection between afforestation and aridification on the sand ridges between river Danube and Tisza. Cereal Res. Commun. 35, 757-760. https://doi.org/10.1556/crc.35.2007.2.148

Hron, P., Jost, D., Bastian, P., Gallert, C., Winter, J., Ippisch, O., 2015. Application of reactive transport modeling to growth and transport of microorganisms in the capillary fringe. Vadose Zo. J. 14, 1-17. https://doi.org/10.2136/vzj2014.07.0092

Hubbard, R.M., Ryan, M.G., Giardina, C.P., Barnard, H., 2004. The effect of fertilization on sap flux and canopy conductance in a Eucalyptus saligna experimental forest. Glob. Chang. Biol. 10, 427-436. https://doi.org/10.1111/j.1529-8817.2003.00741.x

Hubbard, R.M., Stape, J., Ryan, M.G., Almeida, A.C., Rojas, J., 2010. Effects of irrigation on water use and water use efficiency in two fast growing Eucalyptus plantations. For. Ecol. Manage. 259, 1714-1721. https://doi.org/10.1016/j.foreco.2009.10.028

Hyman, J.D., Karra, S., Makedonska, N., Gable, C.W., Painter, S.L., Viswanathan, H.S., 2015. DfnWorks: A discrete fracture network framework for modeling subsurface flow and transport. Comput. Geosci. 84, 10-19. https://doi.org/10.1016/j.cageo.2015.08.001

Jackson, R.B., Banner, J.L., Jobba, E.G., Pockman, W.T., Wall, D.H., 2002. Ecosystem carbon loss with woody plant invasion of grasslands $277,2000-$ 2003. https://doi.org/10.1038/nature00952.

Jackson, R.B., Canadell, J., Ehleringer, J.R., Mooney, H.A., Sala, O.E., Schulze, E.D., 1996. A global analysis of root distributions for terrestrial biomes. Oecologia 108, 389-411. https://doi.org/10.1007/BF00333714

Jackson, R.B., Carpenter, S.R., Dahm, C.N., McKnight, D.M., Naiman, R.J., Postel, S.L., Running, S.W., 2001. WATER IN A CHANGING WORLD. Ecol. Appl. 11, 1027-1045. https://doi.org/10.1890/10510761(2001)011[1027:WIACW]2.0.CO;2

Jayawickreme, D.H., Santoni, C.S., Kim, J.H., Jobbágy, E.G., Jackson, R.B., 2011. Changes in hydrology and salinity accompanying a century of agricultural conversion in Argentina. Ecol. Appl. 21, 2367-2379. 
https://doi.org/10.1890/10-2086.1

Jobbágy, E.G., Jackson, R.B., 2007. Groundwater and soil chemical changes under phreatophytic tree plantations. J. Geophys. Res. 112, G02013. https://doi.org/10.1029/2006JG000246

Jobbágy, E.G., Jackson, R.B., 2004a. Groundwater use and salinization with grassland afforestation. Glob. Chang. Biol. 10, 1299-1312. https://doi.org/10.1111/j.1365-2486.2004.00806.x

Jobbágy, E.G., Jackson, R.B., 2004b. The uplift of soil nutrients by plants: biogeochemical consequences across scales. Ecology 85, 2380-2389. https://doi.org/10.1890/03-0245

Jobbágy, E.G., Jackson, R.B., 2003. Patterns and Mechanisms of Soil Acidification in the Conversion of Grasslands to Forests 64, 205-229.

Jobbágy, E.G., Jackson, R.B., 2001. The distribution of soil nutriments with depth: Global patterns of the imprint of plants. Biogeochemistry 53, 51-77.

Jobbagy, E.G., Nosetto, M.D., Santoni, C.S., Baldi, G., 2008. El desafio ecohidrologico de las transiciones entre sistemas lenosos y herbaceos en la llanura Chaco-Pampeana. Ecol. Austral 18, 305-322.

Jobbágy, E.G., Nosetto, M.D., Santoni, G., Baldi, C.S., 2008. The ecohydrological challenge of woody-herbaceous transitions in the chacopampas plains [El desafío ecohidrológico de las transiciones entre sistemas leñosos y herbáceos en la llanura chaco-pampeana]. Ecol. Austral 18, 305-322.

Jobbágy, E.G., Piñeiro, G., Nosetto, M.D., Paruelo, J.M., 2006a. Las forestaciones rioplatenses y el agua. Cienc. Hoy 16, 12-21.

Jobbágy, E.G., Tóth, T., Nosetto, M.D., Earman, S., 2017. On the Fundamental Causes of High Environmental Alkalinity $(\mathrm{pH} \geq 9)$ : An Assessment of Its Drivers and Global Distribution. L. Degrad. Dev. 28, 1973-1981. https://doi.org/10.1002/ldr.2718

Jobbágy, E.G., Vasallo, M., Farley, K., Piñeiro, G., Garbulsky, M., Nosetto, M., Jackson, R., Paruelo, J., 2006b. Forestación en pastizales: hacia una visión integral de sus oportunidades y costos ecológicos. Agrociencia 109124.

Jolly, I.D., Walker, G.R., 1996. Is the field water use of Eucalyptus largiflorens F. Muell. affected by short-term flooding? Austral Ecol. 21, 173-183. https://doi.org/10.1111/j.1442-9993.1996.tb00598.x

Kleidon, A., 2004. Global datasets and rooting zone depth inferred from inverse methods. J. Clim. 17, 2714-2722. https://doi.org/10.1175/15200442(2004)017<2714:GDORZD>2.0.CO;2

Koul, B., Taak, P., 2018. Soil Pollution: Causes and Consequences, en: 
Biotechnological Strategies for Effective Remediation of Polluted Soils. Springer Singapore, Singapore, pp. 1-37. https://doi.org/10.1007/978-98113-2420-8_1

Kreidenweis, U., Humpenöder, F., Stevanović, M., Bodirsky, B.L., Kriegler, E., Lotze-Campen, H., Popp, A., 2016. Afforestation to mitigate climate change: impacts on food prices under consideration of albedo effects. Environ. Res. Lett. 11, 085001. https://doi.org/10.1088/17489326/11/8/085001

Kuhns, M.R., Garrett, H.E., Teskey, R.O., Hinckley, T.M., 1985. Root Growth of Black Walnut Trees Related to Soil Temperature, Soil Water Potential, and Leaf Water Potential. For. Sci. 31, 617-629.

Kunito, T., Isomura, I., Sumi, H., Park, H.D., Toda, H., Otsuka, S., Nagaoka, K., Saeki, K., Senoo, K., 2016. Aluminum and acidity suppress microbial activity and biomass in acidic forest soils. Soil Biol. Biochem. 97, 23-30. https://doi.org/10.1016/j.soilbio.2016.02.019

Kuppel, S., Houspanossian, J., Nosetto, M.D., Jobbágy, E.G., 2015. What does it take to flood the Pampas?: Lessons from a decade of strong hydrological fluctuations. Water Resour. Res. 51, 2937-2950. https://doi.org/10.1002/2015WR016966

Kuznetsova, A., Khokhlova, O., 2015. Dynamics and genesis of calcic accumulations in soils and sediments of the Argentinean Pampa. Int. J. Sediment Res. 30, 179-189. https://doi.org/10.1016/j.ijsrc.2014.11.002

Laclau, J.P., Arnaud, M., Bouillet, J.P., Ranger, J., 2001. Spatial distribution of Eucalyptus roots in a deep sandy soil in the Congo: relationships with the ability of the stand to take up water and nutrients. Tree Physiol. 21, 129136. https://doi.org/10.1093/treephys/21.2-3.129

Laguë, M.M., Swann, A.L.S., 2016. Progressive midlatitude afforestation: Impacts on clouds, global energy transport, and precipitation. J. Clim. 29, 5561-5573. https://doi.org/10.1175/jcli-d-15-0748.1

Laio, F., Odorico, P.D., Ridolfi, L., 2006. An analytical model to relate the vertical root distribution to climate and soil properties $33,1-5$. https://doi.org/10.1029/2006GL027331

Lambais, G.R., Jourdan, C., de Cássia Piccolo, M., Germon, A., Pinheiro, R.C., Nouvellon, Y., Stape, J.L., Campoe, O.C., Robin, A., Bouillet, J.P., Le Maire, G., Laclau, J.P., 2017. Contrasting phenology of Eucalyptus grandis fine roots in upper and very deep soil layers in Brazil. Plant Soil 1-18. https://doi.org/10.1007/s11104-017-3460-1

Lambers, H., Chapin, F.S., Pons, T.L., 2008a. Plant Physiological Ecology. Springer New York, New York, NY. https://doi.org/10.1007/978-0-38778341-3

Lambers, H., Raven, J.A., Shaver, G.R., Smith, S.E., 2008b. Plant nutrient- 
acquisition strategies change with soil age. Trends Ecol. Evol. 23, 95-103. https://doi.org/10.1016/j.tree.2007.10.008

Lavado, R.S., Taboada, M.A., 1988. Water, salt and sodium dynamics in a Natraquoll in Argentina. Catena 15, 577-594. https://doi.org/10.1016/03418162(88)90008-2

Lawrence, C., Harden, J., Maher, K., 2014. Modeling the influence of organic acids on soil weathering. Geochim. Cosmochim. Acta 139, 487-507. https://doi.org/10.1016/j.gca.2014.05.003

Leblois, A., Damette, O., Wolfersberger, J., 2017. What has Driven Deforestation in Developing Countries Since the 2000s? Evidence from New Remote-Sensing Data. World Dev. 92, 82-102. https://doi.org/10.1016/j.worlddev.2016.11.012

Lejeune, Q., Davin, E.L., Gudmundsson, L., Winckler, J., Seneviratne, S.I., 2018. Historical deforestation locally increased the intensity of hot days in northern mid-latitudes. Nat. Clim. Chang. 8, 386-390.

https://doi.org/10.1038/s41558-018-0131-z

Lewis, J.P., Collantes, M.B., Pire, E.F., Carnevale, N.J., Boccanelli, S.I., Stofella, S.L., Prado, D.E., 1985. Floristic groups and plant communities of southeastern Santa Fe, Argentina. Vegetatio 60, 67-90. https://doi.org/10.1007/BF00040350

Liu, X., Lee Burras, C., Kravchenko, Y.S., Duran, A., Huffman, T., Morras, H., Studdert, G., Zhang, X., Cruse, R.M., Yuan, X., 2012. Overview of Mollisols in the world: Distribution, land use and management. Can. J. Soil Sci. 92, 383-402. https://doi.org/10.4141/cjss2010-058

López-Carr, D., Burgdorfer, J., 2013. Deforestation drivers: Population, migration, and tropical land use. Environment 55, 3-11. https://doi.org/10.1080/00139157.2013.748385

Lu, P., Urban, L., Zhao, P., 2004. Granier's thermal dissipation probe (TDP) method for measuring sap flow in trees: theory and practice.

Maas, E. V., 1985. Crop tolerance to saline sprinkling water. Plant Soil 89, $273-$ 284. https://doi.org/10.1007/BF02182247

MAGyP, 2019. Ministerio de AgricuPItuta Ganaderia y Pesca. Secretaria de Agricultura, Ganadería y Pesca, Subsecretaría de Agricultura, Dirección Nacional de Desarrollo Foresto Industrial, al 3 de diciembre de 2019. https://www.magyp.gob.ar/sitio/areas/ss_desarrollo_foresto_industrial/esta disticas/.

Marcar, N.E., Termaat, A., 1990. Effects of root-zone solutes on Eucalyptus camaldulensis and Eucalyptus bicostata seedlings: Responses to sodium, magnesium and chloride. Plant Soil 125, 245-254.

Marschner, H., Römheld, V., 1994. Strategies of plants for acquisition of iron. 
Plant Soil 165, 261-274. https://doi.org/10.1007/BF00008069

Mayer, K.U., Amos, R.T., Molins, S., Gerard, F., 2012. Reactive Transport Modeling in Variably Saturated Media with MIN3P: Basic Model Formulation and Model Enhancements. Groundw. React. Transp. Model. 186-211. https://doi.org/10.2174/97816080530631120101

Mayer, K.U., Frind, E.O., Blowes, D.W., 2002. Multicomponent reactive transport modeling in variably saturated porous media using a generalized formulation for kinetically controlled reactions. Water Resour. Res. 38, 1174. https://doi.org/10.1029/2001WR000862

Meima, J.A., Graupner, T., Rammlmair, D., 2012. Modeling the effect of stratification on cemented layer formation in sulfide-bearing mine tailings. Appl. Geochemistry 27, 124-137. https://doi.org/10.1016/j.apgeochem.2011.09.024

Mengel, K., 1994. Iron availability in plant tissues-iron chlorosis on calcareous soils. Plant Soil 165, 275-283. https://doi.org/10.1007/BF00008070

Mensforth, L.J., Walker, G.R., 1996. Root dynamics of Melaleuca halmaturorum in response to fluctuating saline groundwater. Plant Soil 184, 75-84. https://doi.org/10.1007/BF00029276

Milione, G.M., 2019. Salinización y otros cambios hidrogeoquímicos asociados a distintos usos del suelo en la Región Centro-Sur bonaerense, Argentina. (Doctoral Diss. Univ. Nac. La Plata).

Miller, R., Wesley, B., Norman, P., 1988. Specific Conductance: Theoretical Considerations and Application to Analytical Quality Control. United States Geol. Surv. Water-Supply 2311, 3-6.

Montico, S., Leo, D., 2007. Cambio de la sostenibilidad biofísica en cuencas hidrográficas: tres décadas de reemplazo de pastizales naturales por agricultura $13,1-8$.

Monzon, J.P., Calviño, P.A., Sadras, V.O., Zubiaurre, J.B., Andrade, F.H., 2018. Precision agriculture based on crop physiological principles improves whole-farm yield and profit: A case study. Eur. J. Agron. 99, 62-71. https://doi.org/10.1016/j.eja.2018.06.011

Moriasi, D.N., Arnold, J.G., Van Liew, M.W., Binger, R.L., Harmel, R.D., Veith, T.L., 2007. Model evaluation guidelines for systematic quantification of accuracy in watershed simulations. Trans. ASABE 50, 885-900. https://doi.org/10.13031/2013.23153

Moroni, M.T., Worledge, D., Beadle, C.L., 2003. Root distribution of Eucalyptus nitens and E . globulus in irrigated and droughted soil 177.

Moscatelli, G., Pazos, M.S., 2000. Soils of Argentina - Nature and Use. Proc. Int. Symp. Soil Sci. Acomplishments Chang. Paradig. 000, 81-92. 
Mujica, C.R., Bea, S.A., 2020. Estimations of rooting depths and sources of plant-available water (PAW) in flatland petrocalcic soils under different land uses. Geoderma 361, 114019.

https://doi.org/10.1016/j.geoderma.2019.114019

Mujica, C.R., Milione, G.M., Bea, S.A., Gyenge, J.E., 2019a. A process-based numerical approach to estimate forest groundwater consumption in flatland petrocalcic soils. J. Hydroinformatics 21, 1130-1146.

https://doi.org/10.2166/hydro.2019.093

Mujica, C.R., Milione, G.M., Bea, S.A., Gyenge, J.E., 2019b. Impacto en los flujos hídricos por la presencia de horizontes petrocálcicos en parcelas forestadas en ambientes de llanura. Rev. Investig. Agropecu. 43, 426-436.

Mujica, Claudio R., Milione, G.M., Bea, S.A., Jobbágy, E.G., 2019c. Modelación de los cambios químicos en suelos inducidos por la forestación de pastizales naturales en ecosistemas de llanura. Ecol. Austral 29, 433-445. https://doi.org/10.25260/EA.19.29.3.0.896

Nash, J.E., Sutcliffe, J. V., 1970. River flow forecasting through conceptual models part I - A discussion of principles. J. Hydrol. 10, 282-290. https://doi.org/10.1016/0022-1694(70)90255-6

Nelson, D.L., Cox, M.M., 2018. Princípios de Bioquímica de Lehninger - 7.ed. Artmed Editora.

Nilsson, S.I., Miller, H.G., Miller, J.D., 1982. Forest Growth as a Possible Cause of Soil and Water Acidification: An Examination of the Concepts. Oikos 39, 40. https://doi.org/10.2307/3544529

Nosetto, M.D., 2007. Conversión de pastizales en forestaciones: impactos sobre la dinámica del agua y las sales 1-131.

Nosetto, M.D., Acosta, A.M., Jayawickreme, D.H., Ballesteros, S.I., Jackson, R.B., Jobbágy, E.G., 2013. Land-use and topography shape soil and groundwater salinity in central Argentina. Agric. Water Manag. 129, 120129. https://doi.org/10.1016/j.agwat.2013.07.017

Nosetto, M.D., Jobbágy, E.G., Brizuela, A.B., Jackson, R.B., 2012. The hydrologic consequences of land cover change in central Argentina. Agric. Ecosyst. Environ. 154, 2-11. https://doi.org/10.1016/j.agee.2011.01.008

Nosetto, M.D., Jobbágy, E.G., Jackson, R.B., Sznaider, G.A., 2009. Reciprocal influence of crops and shallow ground water in sandy landscapes of the Inland Pampas. F. Crop. Res. 113, 138-148.

https://doi.org/10.1016/j.fcr.2009.04.016

Nosetto, M.D., Jobbágy, E.G., Tóth, T., Di Bella, C.M., 2007. The effects of tree establishment on water and salt dynamics in naturally salt-affected grasslands. Oecologia 152, 695-705. https://doi.org/10.1007/s00442-0070694-2 
Nosetto, M.D., Jobbágy, E.G., Tóth, T., Jackson, R.B., 2008. Regional patterns and controls of ecosystem salinization with grassland afforestation along a rainfall gradient. Global Biogeochem. Cycles 22, 1-12.

https://doi.org/10.1029/2007GB003000

Nowack, B., Mayer, K.U., Oswald, S.E., van Beinum, W., Appelo, C.A.J., Jacques, D., Seuntjens, P., Gérard, F., Jaillard, B., Schnepf, A., Roose, T., 2006. Verification and intercomparison of reactive transport codes to describe root-uptake. Plant Soil 285, 305-321.

https://doi.org/10.1007/s11104-006-9017-3

Nye, P.H., 1981. Changes of pH across the rhizosphere induced by roots. Plant Soil 61, 7-26. https://doi.org/10.1007/BF02277359

O'Connell, A.M., 1987. Litter decomposition, soil respiration and soil chemical and biochemical properties at three contrasting sites in karri (Eucalyptus diversicolor F. Muell.) forests of south-western Australia. Austral Ecol. 12, 31-40. https://doi.org/10.1111/j.1442-9993.1987.tb00925.x

Oren, R., Phillips, N., Ewers, B.E., Pataki, D.E., Jp, ..., 1999. ... -Flux-Scaled Transpiration Responses To Light, Vapor Pressure Deficit, and Leaf Area Reduction in a .... Tree Physiol. 19, 337-347.

Oyarzabal, M., Clavijo, J., Oakley, L., Biganzoli, F., Tognetti, P., Barberis, I., Maturo, H.M., Aragón, R., Campanello, P.I., Prado, D., Oesterheld, M., León, R.J.C., 2018. Unidades de vegetación de la Argentina. Ecol. Austral 28, 040-063. https://doi.org/10.25260/ea.18.28.1.0.399

Parkhurst, D.L., Appelo, C.A.J., 1999. Guide To Phreeqc ( Version 2 ).

Parodi, R.L., 1940. La distribución geográfica de: los talares en la Provincia de Buenos Aires. Darwiniana 4, 33-56.

Paruelo, J., Piñeiro, G., 2004. Cambios estructurales y funcionales asociados al pastoreo en los Pastizales del Río de la Plata. Reun. del Grup. técnico Reg. del Cono Sur en Mejor. y Util. los Recur. forrajeros del área Trop. y Subtrop. Grup. Campos 20, 53-60.

Paruelo, J.M., Guerschman, J.P., Piñeiro, G., Jobbágy, E.G., Verón, S.R., Baldi, G., Baeza, S., 2006. Cambios En El Uso De La Tierra En Argentina $Y$ Uruguay: Marcos Conceptuales Para Su Análisis. Agrociencia 10, 47-61. https://doi.org/10.2307/2577037

Pazos, M.S., Mestelan, S.A., 2002. Variability of Depth to Tosca in Udolls and Soil Classification, Buenos Aires Province, Argentina. Soil Sci. Soc. Am. J. 66, 1256. https://doi.org/10.2136/sssaj2002.1256

Pessolano, B., Ruiz de Galarreta, A., Varni, M., Barranquero, R.S., Larsen, A., 2010. Diagnóstico preliminar del recurso hídrico subterráneo y su relación con las actividades agropecuarias en la cuenca del arroyo Chapaleofú Chico,. 
Philip, J., Vries, D. De, 1957. Moisture movement in porous materials under temperature gradients. Trans. Am. Geophys. Union 38, 222-232.

https://doi.org/10.1029/TR038i002p00222

Podestá, G.P., Messina, C.D., Grondona, M.O., Magrin, G.O., 1999.

Associations between Grain Crop Yields in Central-Eastern Argentina and El Niño-Southern Oscillation. J. Appl. Meteorol. 38, 1488-1498. https://doi.org/10.1175/1520-0450(1999)038<1488:ABGCYI>2.0.CO;2

Prieto, A.R., 1996. Late Quaternary Vegetational and Climatic Changes in the Pampa Grassland of Argentina. Quat. Res. 45, 73-88. https://doi.org/10.1006/qres.1996.0007

Ragonese, A.E., Covas, G., 1947. La flora halófila del sur de la provincia de Santa Fe (República Argentina). Darwiniana 7, 401-496.

Raich, J.W., Tufekcioglu, A., 2000. Vegetation and soil respiration.pdf 71-90.

Ramankutty, N., Mehrabi, Z., Waha, K., Jarvis, L., Kremen, C., Herrero, M., Rieseberg, L.H., 2018. Trends in Global Agricultural Land Use: Implications for Environmental Health and Food Security. Annu. Rev. Plant Biol. 69, annurev-arplant-042817-040256. https://doi.org/10.1146/annurev-arplant042817-040256

Raven, J.A., Franco, A.A., De Jesus, E.L., Jacob Neto, J., 1990. Proton extrusion and organic acid synthesis in nitrogen fixing symbioses involving vascular plants. New Phytol. 114, 369-390.

Raz, V., Fluhr, R., 1992. Calcium Requirement for Ethylene-Dependent Responses. PLANT CELL ONLINE 4, 1123-1130. https://doi.org/10.1105/tpc.4.9.1123

Rhoades, J.D., Manteghi, N.A., Shouse, P.J., Alves, W.J., 1989. Estimating Soil Salinity from Saturated Soil-Paste Electrical Conductivity. Soil Sci. Soc. Am. J. 53, 428-433. https://doi.org/10.2136/sssaj1989.03615995005300020067x

Rhoades, J.D., Raats, P.A.C., Prather, R.J., 1976. Effects of Liquid-phase Electrical Conductivity, Water Content, and Surface Conductivity on Bulk Soil Electrical Conductivity. Soil Sci. Soc. Am. J. 40, 651. https://doi.org/10.2136/sssaj1976.03615995004000050017x

Richardson, D.M., 1998. Forestry Trees as Invasive Aliens 12, 18-26.

Rivera, S., Villegas, M., 2002. Revisión xilológica de las principales especies del género Eucalyptus L¿Herit. cultivadas en Argentina. Rev. la Fac. Agron. 105, 8-28.

Rubio, G., Pereyra, F.X., Taboada, M.A., 2019. Soils of the Pampean Region. Springer International Publishing, pp. 81-100. https://doi.org/10.1007/9783-319-76853-3_6 
Ruiz Selmo, F., 2007. Análisis de la heterogeneidad fisonómico-funcional de la vegetación del Parque Nacional El Palmar y su relación con la invasión por leñosas exóticas. Teledetección - Hacia un Mejor entendimiento la dinámica Glob. y Reg. 257-263.

Sacchi, L.V., Gasparri, N.I., 2016. Impacts of the deforestation driven by agribusiness on urban population and economic activity in the Dry Chaco of Argentina. J. Land Use Sci. 11, 523-537.

https://doi.org/10.1080/1747423X.2015.1098739

SAGPyA, 2002. Primer inventario de plantaciones forestales en macizo. Secr. Agric. Ganad. Pesca y Aliment. 2-9.

Saito, H., Simunek, J., Mohanty, B., 2006. Numerical Analysis of Coupled Water, Vapor, and Heat Transport in the Vadose Zone. Vadose Zo. J. 5, 784-800. https://doi.org/10.2136/vzj2006.0007

Sala, J.M., Kruse, E., Aguglino, R., 1987. Investigación hidrológica de la Cuenca del Arroyo Azul, Provincia de Buenos Aires . CIC, Inf. 37, 235 pp.

Salama, R.B., Bartle, G.A., Farrington, P., 1994. Water use of plantation Eucalyptus camaldulensis estimated by groundwater hydrograph separation techniques and heat pulse method. J. Hydrol. 156, 163-180. https://doi.org/10.1016/0022-1694(94)90076-0

Saviozzi, A., Cardelli, R., Ri, R., 2001. A comparison of soil quality in adjacent cultivated, forest and native grassland soils Author ( $s$ ): A. Saviozzi, R . Levi-Minzi , R . Cardelli and R . Riffaldi Published by : Springer Stable URL : http://www.jstor.org/stable/42951921 A comparison of s 233, 251259. https://doi.org/10.1023/a:1010526209076

Schaap, M.G., 1999. Hydraulic functions used by Rosetta. J. Hydrol. 251, 0-3.

Schaap, M.G., Leij, F.J., Van Genuchten, M.T., 2001. Rosetta: A computer program for estimating soil hydraulic parameters with hierarchical pedotransfer functions. J. Hydrol. 251, 163-176. https://doi.org/10.1016/S0022-1694(01)00466-8

Schenk, H.J., Jackson, R.B., 2005. Mapping the global distribution of deep roots in relation to climate and soil characteristics 126, 129-140. https://doi.org/10.1016/j.geoderma.2004.11.018

Schenk, H.J., Jackson, R.B., 2002a. The Global Biogeography of Roots. Ecol. Monogr. 72, 311. https://doi.org/10.2307/3100092

Schenk, H.J., Jackson, R.B., 2002b. Rooting depths, lateral root spreads and below-ground/above-ground allometries of plants in water-limited ecosystems. J. Ecol. 90, 480-494. https://doi.org/10.1046/j.13652745.2002.00682.x

Schofield, N.J., 1992. Tree planting for dryland salinity control in Australia. Agrofor. Syst. 20, 1-23. https://doi.org/10.1007/BF00055303 
Scudiero, E., Berti, A., Teatini, P., Morari, F., 2012. Simultaneous monitoring of soil water content and salinity with a low-cost capacitance-resistance probe. Sensors (Switzerland) 12, 17588-17607.

https://doi.org/10.3390/s121217588

Seaman, J.C., Chang, H., Goldberg, S., Šimůnek, J., 2012. Reactive Transport Modeling, Vadose Zone Journal. https://doi.org/10.2136/vzj2012.0066

Selvaratnam, M., Spiro, M., 2004. Transference numbers of orthophosphoric acid and the limiting equivalent conductance of the $\mathrm{H} 2 \mathrm{PO}-4$ ion in water at $25^{\circ} \mathrm{C}$. Trans. Faraday Soc. $61,360-373$.

https://doi.org/10.1039/tf9656100360

Shreve, F., Mallery, T.D., 1933. The relation of caliche to desert plants. Soil Sci. 35, 99-114. https://doi.org/10.1097/00010694-193302000-00002

Šimůnek, J., Hopmans, J.W., 2009. Modeling compensated root water and nutrient uptake. Ecol. Modell. 220, 505-521.

https://doi.org/10.1016/j.ecolmodel.2008.11.004

Soil Survey Staff, 2014. Keys to soil taxonomy, 12th ed, Natural Resources Conservation Service. United States Department of Agriculture, Washington, DC.

Song, X.P., Hansen, M.C., Stehman, S. V., Potapov, P. V., Tyukavina, A., Vermote, E.F., Townshend, J.R., 2018. Global land change from 1982 to 2016. Nature 560, 639-643. https://doi.org/10.1038/s41586-018-0411-9

Souza, W. De, Barbosa, O.R., Marques, J.D.A., Costa, M.A.T., Gasparino, E., Limberger, E., 2010. Microclimate in silvipastoral systems with eucalyptus in rank with different heights. Rev. Bras. Zootec. 39, 685-694. https://doi.org/10.1590/S1516-35982010000300030

Steefel, C.I., Appelo, C.A.J., Arora, B., Jacques, D., Kalbacher, T., Kolditz, O., Lagneau, V., Lichtner, P.C., Mayer, K.U., Meeussen, J.C.L., Molins, S., Moulton, D., Shao, H., Šimůnek, J., Spycher, N., Yabusaki, S.B., Yeh, G.T., 2015. Reactive transport codes for subsurface environmental simulation. Comput. Geosci. 19, 445-478. https://doi.org/10.1007/s10596-014-9443-x

Steefel, C.I., DePaolo, D.J., Lichtner, P.C., 2005. Reactive transport modeling: An essential tool and a new research approach for the Earth sciences. Earth Planet. Sci. Lett. 240, 539-558. https://doi.org/10.1016/j.epsl.2005.09.017

Steefel, C.I., Lichtner, P.C., 1998. Multicomponent reactive transport in discrete fractures - II: Infiltration of hyperalkaline groundwater at Maqarin, Jordan, a natural analogue site. J. Hydrol. 209, 200.

Stigter, C.J., Mohammed, A.E., Nasr Al-Amin, N.K., Onyewotu, L.O.Z., Oteng i, S.B.B., Kainkwa, R.M.R., 2002. Agroforestry solutions to some African wind problems. J. Wind Eng. Ind. Aerodyn. 90, 1101-1114. https://doi.org/10.1016/S0167-6105(02)00224-6 
Stone, E.L., Gibson, E.J., 1975. Effects of Species on Nutrient Cycles and Soil Change [and Discussion]. Philos. Trans. R. Soc. B Biol. Sci. 271, 149-162. https://doi.org/10.1098/rstb.1975.0041

Sumner, M., 1993. Sodic soils - New perspectives. Soil Res. 31, 683. https://doi.org/10.1071/SR9930683

Sunderland, T.C.H., Rowland, D., 2019. Forests, Land Use, and Challenges to Climate Stability and Food Security, Sustainable Food and Agriculture. Elsevier Inc. https://doi.org/10.1016/b978-0-12-812134-4.00006-6

Swann, A.L.S., Longo, M., Knox, R.G., Lee, E., Moorcroft, P.R., 2015. Future deforestation in the Amazon and consequences for South American climate. Agric. For. Meteorol. 214-215, 12-24.

https://doi.org/10.1016/j.agrformet.2015.07.006

Taboada, M.A., Damiano, F., Lavado, R.S., 2009. Inundaciones en la región pampeana. Consecuencias sobre los suelos. Fac. Agron. Univ. Buenos Aires 103-127.

Teakle, N.L., Tyerman, S.D., 2010. Mechanisms of Cl- transport contributing to salt tolerance. Plant, Cell Environ. 33, 566-589. https://doi.org/10.1111/j.1365-3040.2009.02060.x

Teruggi, M.E., 1957. The Nature and Origin of Argentine Loess. SEPM J. Sediment. Res. Vol. 27, 322-332. https://doi.org/10.1306/74D706DC-2B2111D7-8648000102C1865D

Thorburn, P.J., Walker, G.R., 1994. Variations in Stream Water-Uptake By Eucalyptus-Camaldulensis With Differing Access To Stream Water. Oecologia 100, 293-301.

Timlin, D., Pachepsky, Y., Walthall, C., Loechel, S., 2001. The use of a water budget model and yield maps to characterize water availability in a landscape. Soil Tillage Res. 58, 219-231. https://doi.org/10.1016/S01671987(00)00170-7

Toumi, J., Er-Raki, S., Ezzahar, J., Khabba, S., Jarlan, L., Chehbouni, A., 2016. Performance assessment of AquaCrop model for estimating evapotranspiration, soil water content and grain yield of winter wheat in Tensift Al Haouz (Morocco): Application to irrigation management. Agric. Water Manag. 163, 219-235. https://doi.org/10.1016/j.agwat.2015.09.007

van Breemen, N., Mulder, J., Driscoll, C.T., 1983. Acidification and alkalinization of soils. Plant Soil 75, 283-308. https://doi.org/10.1007/BF02369968

van Breemen, N. Van, Buurman, P., 2002. Soil Formation. Springer Science and Business Media.

van Genuchten, M.T., 1980. Closed-Form Equation for Predicting the Hydraulic Conductivity of Unsaturated Soils. Soil Sci. Soc. Am. J. 44, 892-898. 
van Wijk, M.T., Bouten, W., 2001. Towards understanding tree root profiles: simulating hydrologically optimal strategies for root distribution. Hydrol. Earth Syst. Sci. 5, 629-644. https://doi.org/10.5194/hess-5-629-2001

Varni, M.R., Usunoff, E.J., 1999. Simulation of regional-scale groundwater flow in the Azul River basin, Buenos Aires Province, Argentina. Hydrogeol. J. 7, 180-187. https://doi.org/10.1007/s100400050190

Verma, P., Loheide, S.P., Eamus, D., Daly, E., 2014. Root water compensation sustains transpiration rates in an Australian woodland. Adv. Water Resour. 74, 91-101. https://doi.org/10.1016/j.advwatres.2014.08.013

Viglizzo, E.., Lértora, F., Pordomingo, A.., Bernardos, J.., Roberto, Z.., Del Valle, H., 2001. Ecological lessons and applications from one century of low external-input farming in the pampas of Argentina. Agric. Ecosyst. Environ. 83, 65-81. https://doi.org/10.1016/S0167-8809(00)00155-9

Viglizzo, E.F., Jobbágy, E.G., Carreño, L., Frank, F.C., Aragón, R., De Oro, L., Salvador, V., 2009. The dynamics of cultivation and floods in arable lands of Central Argentina. Hydrol. Earth Syst. Sci. 13, 491-502. https://doi.org/10.5194/hess-13-491-2009

Vitousek, P., Mooney, H.A., Lubchenco, J., Mellilo, J.M., 1997. Human domination of earth. Science (80-. ). 227, 494-499. https://doi.org/10.1126/science.277.5325.494

Von Wirén, N., Römheld, V., Morel, J.L., Guckert, A., Marschner, H., 1993. Influence of microorganisms on iron acquisition in maize. Soil Biol. Biochem. 25, 371-376. https://doi.org/10.1016/0038-0717(93)90136-Y

Wang, C.H., Ko, M.H., Chen, W.J., 2019. Effects of Kyoto Protocol on CO2 emissions: A five-country rolling regression analysis. Sustain. 11, 20082012. https://doi.org/10.3390/su11030744

White, W.N., 1932. A method of estimating ground-water supplies based on discharge by plants and evaporation from soil. USGS Water-Supply Pap. no. 659-A.

Wosten, J.H.M., van Genuchten, M.T., 1988. Using texture and other soil properties to predict the unsaturated soil hydraulic functions. Soil Sci. Soc. Am. J. 52, 1762-1770.

https://doi.org/10.2136/sssaj1988.03615995005200060045x

Wu, L., Guo, X., Hunter, K., Zagory, E., Waters, R., Brown, J., 2001. Studies of Salt Tolerance of Landscape Plant Species and California Native Grasses for Recycled Water Irrigation. Slosson Rep. 2000-2001 1-14.

Xie, M., Mayer, K.U., Claret, F., Alt-Epping, P., Jacques, D., Steefel, C., Chiaberge, C., Simunek, J., 2015. Implementation and evaluation of permeability-porosity and tortuosity-porosity relationships linked to mineral dissolution-precipitation. Comput. Geosci. 19, 655-671. https://doi.org/10.1007/s10596-014-9458-3 
Yabusaki, S.B., Fang, Y., Williams, K.H., Murray, C.J., Ward, A.L., Dayvault, R.D., Waichler, S.R., Newcomer, D.R., Spane, F.A., Long, P.E., 2011. Variably saturated flow and multicomponent biogeochemical reactive transport modeling of a uranium bioremediation field experiment. J. Contam. Hydrol. 126, 271-290.

https://doi.org/10.1016/j.jconhyd.2011.09.002

Zabala, M.E., Manzano, M., Vives, L., 2016a. Assessment of processes controlling the regional distribution of fluoride and arsenic in groundwater of the Pampeano Aquifer in the Del Azul Creek basin (Argentina). J. Hydrol. 541, 1067-1087. https://doi.org/10.1016/j.jhydrol.2016.08.023

Zabala, M.E., Martínez, S., Manzano, M., Vives, L., 2016b. Groundwater chemical baseline values to assess the Recovery Plan in the MatanzaRiachuelo River basin, Argentina. Sci. Total Environ. 541, 1516-1530. https://doi.org/10.1016/j.scitotenv.2015.10.006

Zak, M.R., Cabido, Æ.M., Dı, ÆE.S., 2008. What Drives Accelerated Land Cover Change in Central Argentina ? Synergistic Consequences of Climatic , Socioeconomic, and Technological Factors 181-189. https://doi.org/10.1007/s00267-008-9101-y

Zalba, S.M., Villamil, C.B., 2002. Woody plant invasion in relictual grassland. Biol. Invasions 4, 55-72. https://doi.org/10.1016/S0167-8809(01)00209-2

Zang, D., Beadle, C.L., White, D. a, 1996. Variation of sapflow velocity in Eucalyptus globulus with position in sapwood and use of a correction coefficient. Tree Physiol. 16, 697-703. https://doi.org/10.1093/treephys/16.8.697

Zárate, M.A., 2003. Loess of southern South America. Quat. Sci. Rev. 22, 1987-2006. https://doi.org/10.1016/S0277-3791(03)00165-3

Zárate, M.A., Mehl, A., 2010. Geología y geomorfología de la cuenca del arroyo del Azul, provincia de Buenos Aires, Argentina. I Congr. Int. Hidrol. Llanura-Azul, Buenos Aires, Argentina - 21 al 24/09/2010 81-91.

Zárate, M.A., Tripaldi, A., 2012. The aeolian system of central Argentina. Aeolian Res. 3, 401-417. https://doi.org/10.1016/j.aeolia.2011.08.002

Zuo, Q., Zhang, R., 2002. Estimating root-water-uptake using an inverse method. Soil Sci. 167, 561-571. https://doi.org/10.1097/00010694200209000-00001 